\title{
LEARNING TO NOTICE
}

teachers coaching teachers with video feedback
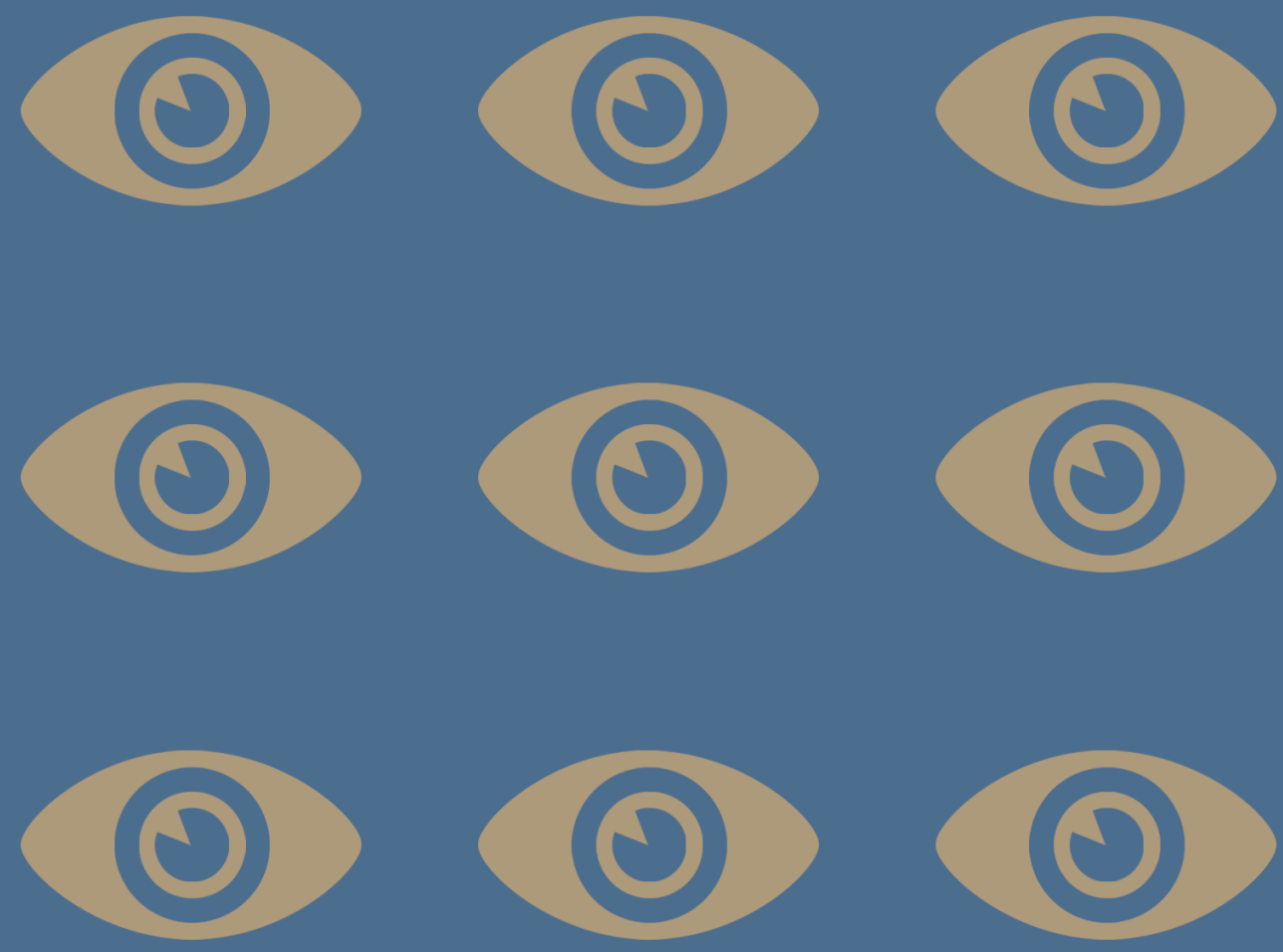

Rita Schildwacht 


\section{LEARNING TO NOTICE}

Teachers coaching teachers with video feedback

Margarita Maria Clasina Schildwacht 
DOCTORAL COMMITTEE

Chairman Prof. Dr. K. I. van Oudenhoven-van der Zee - University of Twente

Promotor Prof. Dr. J. J.H. van den Akker • University of Twente

Assistant promotor Dr. S. Bolhuis • Fontys University of Applied Sciences

Members $\quad$ Prof. dr. J. M. Pieters - University of Twente

Prof. dr. J. W. M. Kessels - University of Twente

Prof. dr. T. C. M. Bergen - Eindhoven University of Technology

Dr. E. van den Berg - University of Twente

Dr. M. van der Klink - Zuyd University of Applied Sciences

This research was supported by Stichting Mobiliteitsfonds $\mathrm{HBO}$ and Fontys University of Applied Sciences.

Schildwacht, M. M. C.

Learning to notice. Teachers coaching teachers with video feedback

Thesis University of Twente, Enschede.

ISBN 978-90-365-3406-2

DOI 10.3990/1.9789036534062

Cover: ebookproduction.nl

Layout: Sandra Schele

Printer: Ipskamp Drukkers B.V. Enschede

(C) Copyright, 2012, M.M.C. Schildwacht 


\section{LEARNING TO NOTICE}

Teachers coaching teachers with video feedback

\section{DISSERTATION}

to obtain

the degree of doctor at the University of Twente, on the authority of the rector magnificus, prof. dr. H. Brinksma,

on account of the decision of the graduation committee to be publicly defended on the $5^{\text {th }}$ of September 2012 at 14.45

$$
\text { by }
$$

Margarita Maria Clasina Schildwacht

born on the 31 $1^{\text {st }}$ of March 1953

in Amsterdam 
Promotor

Assistant promotor
Prof. Dr. J. J. H. van den Akker Dr. S. Bolhuis

This dissertation has been approved by the promotor and assistant promotor. 


\section{TABLE OF CONTENTS}

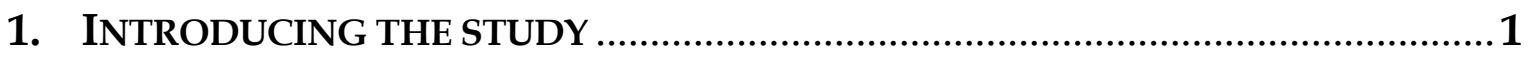



1.1.1 Origin and local setting of the PhD study ............................................. 1

1.1.2 The context of professional development of teachers............................ 3

1.2 Aim of the study and research questions ……………................................... 5



1.3.1 Design research approach ................................................................ 6

1.3.2 Overall research design ...................................................................... 10

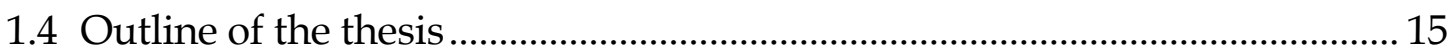

2. Professional DEVELOPMENT, TEACHER LEARNING AND REFLECTIVE PRACTICE; A THEORETICAL FRAMEWORK .................................17

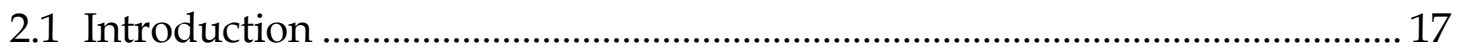

2.1.1 The need for new designs of PD programs.......................................... 17

2.1.2 Multiple views on teacher learning and goals of PD .......................... 20

2.1.3 A knowledge base of teaching ........................................................... 21

2.2 Learning for, in, and from practice …………………………………………. 23

2.2.1 Workplace learning and professional development ........................... 23

2.2.2 Teacher learning: an active, social, construction process .................... 23

2.2.3 Workplace learning ……………………………………………….... 26

2.2.4 The reflective practitioner ................................................................... 32

2.3 Summary and conclusion .............................................................................. 41

3. IN SEARCH OF DESIGN PRINCIPLES FOR PROGRAMS WHICH STIMULATE WORKPLACE LEARNING OF TEACHERS.......................................... 45

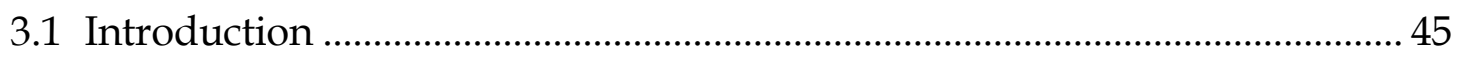

3.2 Review studies of teacher professional development programs ................... 46 
3.3 Five design principles for professional development programs for teachers

3.3.1 Collaborative learning at the workplace in the form of reciprocal peer coaching....................................................................... 58

3.3.2 Focus on own practice with the help of video feedback ...................... 69

3.3.3 Teacher ownership of learning goals ..................................................... 76

3.3.4 Focus on inquiry stance and on outcomes in classroom ...................... 80

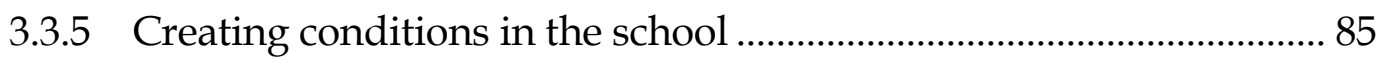

3.4 Summary and recommendations for the design of the program .................. 88

4. PROTOTYPE AND FORMATIVE EVALUATION ................................................... 93

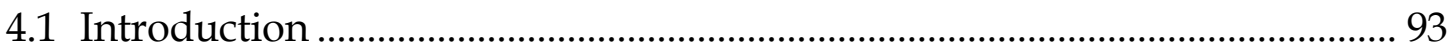

4.2 Background and design of the prototype...................................................... 94

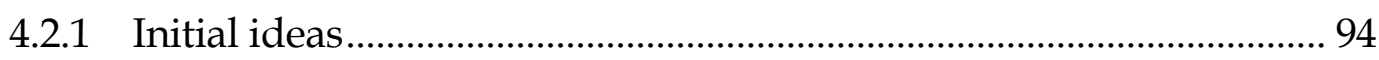

4.2.2 Design of the prototype ........................................................................ 95

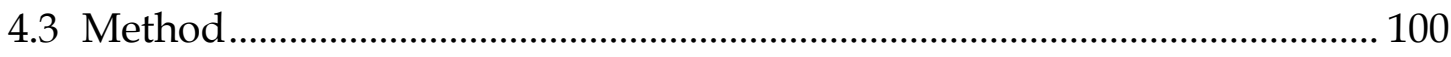

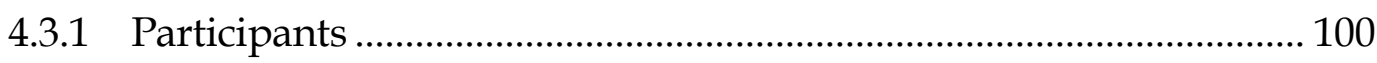

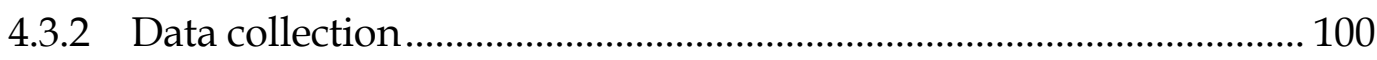

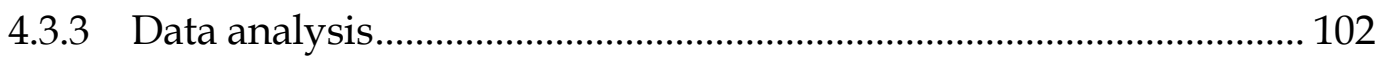

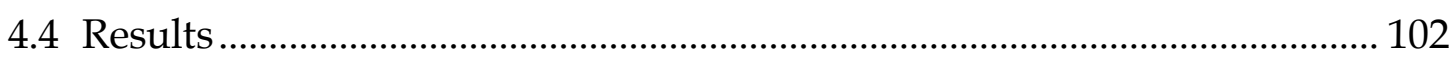

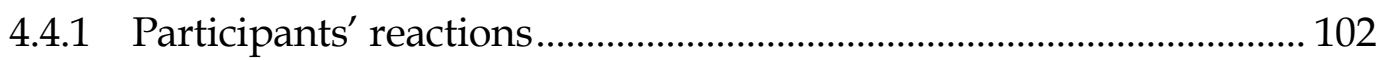

4.4.2 Participants' learning ...................................................................... 105

4.4.3 Participants' use of new knowledge and skills ................................. 111

4.4.4 Organizational support and change ................................................ 112

4.5 Conclusions and recommendations for the redesign..................................... 113

4.5.1 Support of teacher learning in the prototype ...................................... 113

4.5.2 Characteristics of the prototype that stimulated teacher



4.5.3 Conclusions and recommendations for the redesign of the

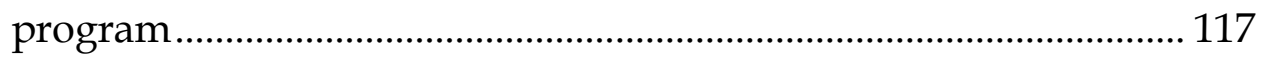

5. EVALUATING A PROFESSIONAL DEVELOPMENT PROGRAM WITH RECIPROCAL PEER COACHING AND VIDEO FEEDBACK ….............................127

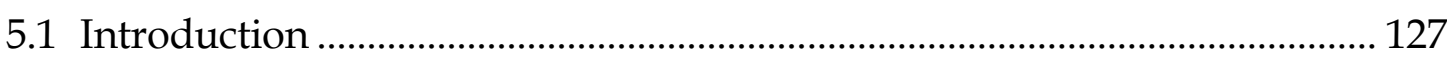

5.2 The professional development program 'Learning to Notice' .................... 129

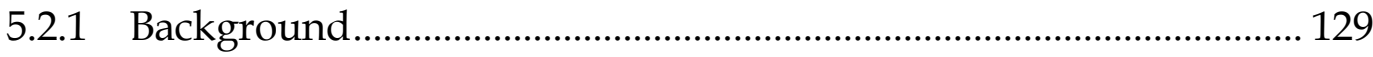

5.2.2 Redesign of the program................................................................... 129 


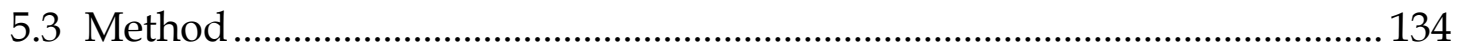

5.3.1 Participants and context of participation ………………………........ 134



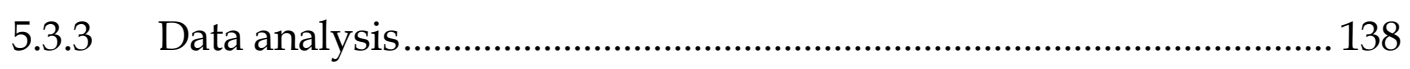

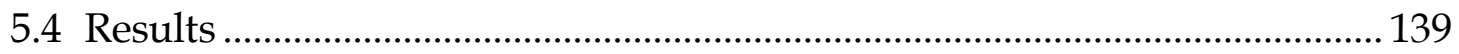

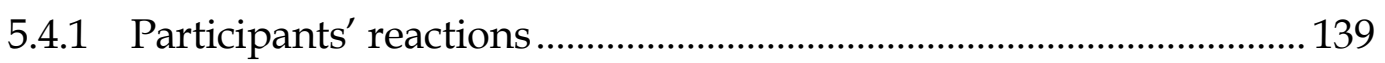

5.4.2 Participants' learning ..................................................................... 147

5.4.3 Participants' use of new knowledge and skills, and



5.4.4 Organizational support and change...................................................... 164

5.4.5 Comparison between the findings of cohort A and B....................... 170



5.5.1 Did the program 'Learning to Notice' support the learning of teachers at the workplace?.............................................................. 171

5.5.2 Which design principles and characteristics of the program supported the learning of teachers at the workplace? ........................................................................................... 171

5.5.3 What was the influence of (in)voluntary participation on teacher learning?

\section{LEARNING FROM EXPERIENCE - A CLOSER EXPLORATION OF}

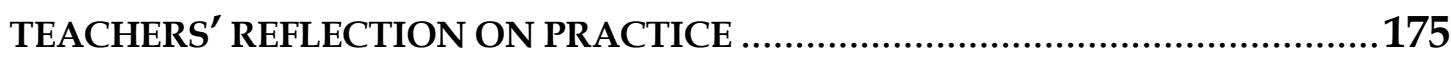



6.2 Teachers' reflection in reciprocal peer coaching dialogues...........................176

6.2.1 Three instruments to study reflection in peer coaching

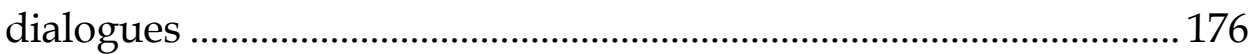



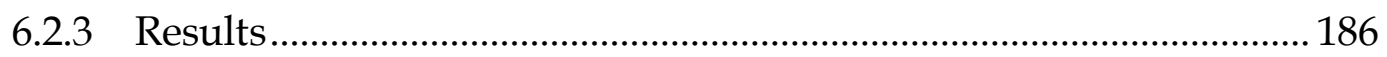

6.2.4 Summary and conclusion sub-study 1 .............................................. 199

6.3 Teachers' inquiries into own practice.................................................................. 201

6.3.1 Inquiry as a professional learning strategy ……………………........... 201

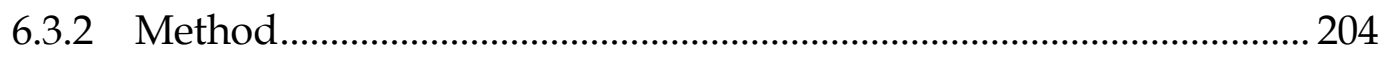

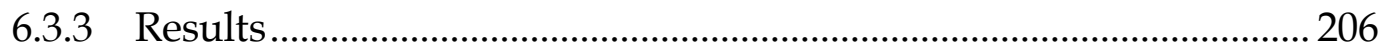

6.3.4 Summary and conclusion sub-study 2 ............................................. 214

6.4 Discussion and conclusion: teachers' reflection on practice ......................... 216 
7. GENERAL DISCUSSION, CONCLUSIONS AND RECOMMENDATIONS

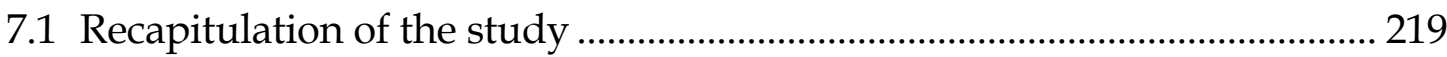

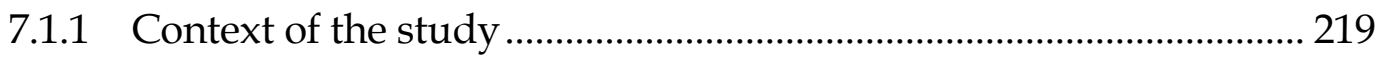

7.1.2 Aims of the study and research questions ......................................... 220

7.1.3 Research approach .......................................................................... 222

7.2 Recapitulation of the main findings ……………………………………...... 223

7.2.1 Which design principles and design characteristics can be derived from literature in order to construct a professional development program that effectively supports teachers' workplace learning?

7.2.2 What is the practicality and effectiveness of the developed professional development program in supporting teachers' workplace learning? ............................................................. 227

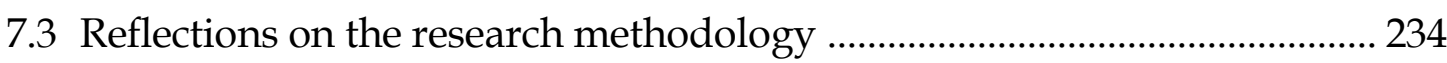

7.4 Discussion and general conclusions .......................................................... 238

7.4.1 Collaborative learning at the workplace ............................................. 238

7.4.2 Focus on own practice with the help of video feedback ................... 241

7.4.3 Teacher ownership of learning goals ................................................. 242

7.4.4 Focus on teacher's inquiry stance and on outcomes in

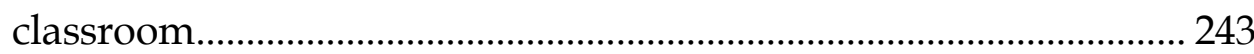

7.4.5 Creating conditions in the school for professional development and the PD program..................................................... 244

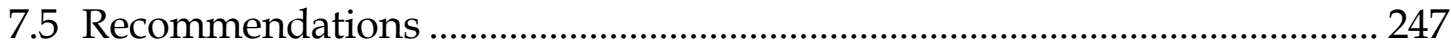

7.5.1 Recommendations for further research ............................................. 247

7.5.2 Implications for practice ................................................................. 249

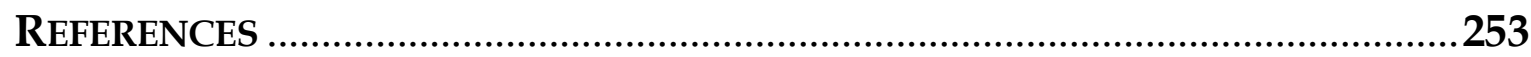

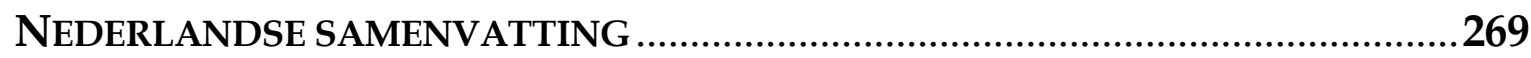

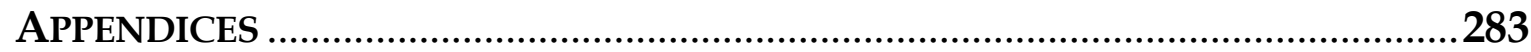

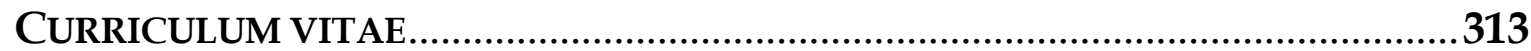

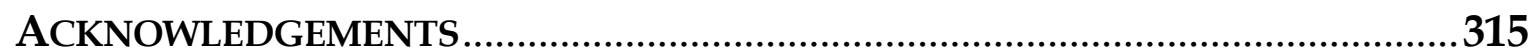




\section{CHAPTER 1 \\ Introducing the study}

In this chapter, to start with, the origin and the local setting of the study are explained. Important concepts such as teacher professional development, teacher learning and workplace learning are described. This is followed by the aim of the study and the main research questions. In the next paragraphs the overall design of the study is described and the chapter ends with a preview of subsequent chapters.

\subsection{INTRODUCTION}

\subsubsection{Origin and local setting of the PhD study}

The subject of this study originated from an urgency, felt in a school for secondary education in the Netherlands, to support teacher learning at the workplace. A vice-principal and a school-based coach observed that especially teachers, who were already experienced and had been working for a number of years, were lacking a new stimulus for their professional learning within the context of the school. However, "to attract contended teachers to consider change, there must be an appealing format that is not overtly change oriented and respects expertise but does raise the critical awareness that the assumptions framing current teaching practice may need to be reexamined" (Qualters, 2009, p. 6).

The researcher of this PhD study a teacher educator who coached studentteachers during their internship in this school) picked up the call and created an opportunity for the school to work together with her teacher education college which was also interested in knowledge building on teacher learning and professional development. A project started to design, implement and evaluate a professional development (PD) program to stimulate teacher learning in the context of the school, which is the focus of this PhD study. 
Reflective peer dialogues on own classroom practice and the use of video taped interactions in own classrooms for study and feedback were chosen as starting point for the design of the PD program. The program focused on experienced teachers; however, beginning teachers who wanted to participate were also invited to join the program. The researcher, in close collaboration with the school-based coach, developed and implemented a PD program suited to the needs of the school. For the design of the PD program the researcher performed a review of literature to identify and describe design principles and design characteristics of effective PD programs. Design principles are validated guidelines or heuristics and design characteristics are the translations of the design principles into the concrete, workable specifications (Plomp \& Nieveen, 2010). Furthermore, the researcher and the school-based coach also applied their own practical knowledge base - gained during many years of experiences with coaching teachers and student-teachers - to the translation of design principles (found in review studies) into concrete characteristics of the program.

The following partners were involved from the start of the study: (a) the management of a school for secondary education (12 to 18 year old students) wishing to stimulate the professional development of their teachers and therefore investing in their human resource management; (b) a teacher education college planning to invest in research with particular relevance for coaching (student-) teachers; and (c), last but not least, teachers willing to participate in the program and to engage in their professional development.

From these backgrounds, a (three year) partnership project started with the following main goals:

1. To design and evaluate a concrete PD program stimulating teacher workplace learning.

2. Studying learning processes and outcomes of participating teachers with the intent to contribute to the development of design principles for PD programs.

3. Strengthening innovation of coaching practices in the participating school and teacher educator institute.

4. Stimulating and supporting professional learning of the participating teachers. 
This study has been developed in the context of a practitioners' research group at a teacher education college of a university of applied sciences. The central goal of the research, as defined in this group, is to gain more insight in and improve own practice and to share results with colleagues and other practitioners. The central focus is the practitioner researchers' design-oriented work as 'reflective professionals' (Schön, 1983) who evaluate their actions, thus building empirical evidence on promising practices (Admiraal, 2009; Bolhuis, 2009a; Veerman \& van Yperen, 2007).

\subsubsection{The context of professional development of teachers}

In the past, teachers' PD often has been organized in formal programs aimed primarily at teaching teachers the necessary knowledge to apply in the classroom. However, that may not be the most fruitful learning environment. PD programs are often perceived by teachers as fragmented, disconnected, and irrelevant to the real problems of classroom practice. In a study of Lieberman and Pointer Mace (2008) less than half of the teachers were satisfied with the quality and quantity of professional learning opportunities available at their school and other studies have shown that teachers hardly implement theories they learned in teacher education in their own practices (Wideen, Mayer-Smith, \& Moon, 1998). Teaching is a highly complex activity in which many things happen simultaneously. To give teachers a 'one size fits all' set of professional development workshops, denies the variability of how teachers teach, how they and their students learn, and the influence of different school contexts on these processes. Professional learning opportunities should adapt to teachers' own workplace (that is teacher's particular context, student population, and own developmental level); a recognition of this implies also that there can be multiple ways to translate strong ideas about teaching into particular classroom contexts.

Literature on learning to teach and on PD of teachers shows multiple views on teacher learning (Borko, 2004; Hoban, 2002; Jordell, 2006; Kazemi \& Hubbard, 2008). Effective teacher learning is often 'situated' and not necessarily confined to planned development activities (Bolhuis, 2009a; Hoekstra, 2007; Lave \& Wenger, 1991); it occurs also implicitly through day-to-day interaction (Bolhuis, 2009; Eraut, 2004, 2007; Marsick \& Watkins, 2001); and can be stimulated by coaching (Joyce \& Showers, 2002; Zwart, 2007). 
Teacher learning has been studied in several different and often unconnected research traditions. There is an extensive literature on teacher development or continuing development, which is paralleled by a long-established literature on workplace learning, but there has been very limited connection between the two (Hodkinson \& Hodkinson, 2005, Hoekstra et al., 2009). Both areas - literature on workplace learning and literature on effective PD strategies - are important to understand teacher learning and to design PD programs that effectively support teacher learning in the context of the school. In this study, in the next Chapters, we will explore both areas: literature on workplace learning (Chapter 2) and literature on teacher PD and effective PD strategies (Chapter 3). The aim is to better understand both concepts; insights leading to the identification of design principles and characteristics that can be built into the PD program.

Definitions of teacher professional development "are almost entirely absent from the literature; even those who are generally considered leading writers in the field do not define precisely what they mean by the term" (Evans, 2008, p. 30). Evans herself (2010) devided the concept in three main constituent elements of professional development. The behavioral component relates to what practitioners physically do at work; the attitudinal component relates to attitudes held; and the intellectual component relates to practitioners' knowledge and understanding, and their knowledge structures. Professional development refers to the process whereby teachers' work-related behavior, and/or attitudes, and/or work-related knowledge, understanding or reflective or comprehensive capacity or competence may be considered to be enhanced (Evans, 2010).

In the last decennium professional development is often used when focusing primarily on the development of competences and skills which are made explicit by representatives of the occupational group, by teacher educators, and school management. The concept of teacher learning as used in this study is a wider notion referring to all learning and development processes which take place and have relevance for the professional behavior of the teacher. It refers to all work-related learning and includes preferred, positive learning processes and outcomes as a result of teachers participating in PD programs and reflecting and experimenting in classroom, however, may also include less positive, non-preferred, or implicit learning processes and outcomes which may take place simultaneously as a result of personal experiences, labeling, and making sense of experiences. 
The present study describes workplace learning as a continuous range of (implicit and explicit) learning processes, embedded in teachers' daily lives, in which every lesson taught and every other professional activity - for better or worse presents a variety of learning opportunities. When talking about PD, "the challenge is to take advantage of these opportunities, to make them available, to make them purposeful, and to use them appropriately" (Guskey, 2000, p. 19).

\subsection{AIM OF THE STUDY AND RESEARCH QUESTIONS}

The general aim of this PhD study is to develop a coherent set of design principles for PD programs stimulating workplace learning of teachers. As we will establish in Chapter 3, collaborative workplace learning is considered a powerful tool in PD programs for teachers. This study investigates such a PD program, which was based on collaborative workplace learning in the form of reciprocal peer coaching with video feedback. Consecutive prototypes of the program were constructed, implemented, evaluated and readjusted to make the design more robust and to identify effective characteristics (van den Akker, 1999; van den Akker, Gravemeijer, McKenney, \& Nieveen, 2006; Plomp \& Nieveen, 2010). By studying implementations of the program, this study aims to identify relations between various characteristics of the design of the program and the learning processes and learning outcomes of the participants.

The central research question is:

Which design principles and characteristics of a professional development program (based on reflective peer dialogues and video feedback) support teachers' workplace learning?

In order to answer this research question, two sub-questions were formulated:

1. Which design principles and design characteristics can be derived from literature in order to construct a professional development program that effectively supports teachers' workplace learning? (Chapter 2 and 3).

2. What is the practicality and effectiveness of the developed professional development program in supporting teachers' workplace learning?

To answer this second research question we evaluated the professional development program with the help of the following questions:

2.1. How did the teachers react to the program? (Chapter 4 and 5). 
2.2. Which learning outcomes did teachers report as a result of their activities in the program? (Chapter 4, 5, and 6).

2.3. Which outcomes in practice in teachers' professional performance and/or learning outcomes in students did the teachers report as a result of their activities in the program? (Chapter 4, 5, and 6)

2.4. Did the school organization meet conditions for the professional development program and did the program have an impact on the organization? (Chapter 4 and 5).

The PD program has been evaluated in two consecutive cycles of design, implementation, evaluation and re-design. The first design cycle (the prototype) is described in Chapter 4. The second design cycle, described in Chapter 5, encompassed the implementation of the PD program in two different settings (voluntary and mandatory participation). A closer examination of teachers' reflection process in peer coaching dialogues and of teachers' inquiries in classroom are described in Chapter 6. With the description of the experiences of the participants involved, this study aims to identify potentially effective design principles and characteristics of professional development programs which stimulate collaborative teacher workplace learning.

\subsection{RESEARCH APPROACH}

\subsubsection{Design research approach}

This study adopted a design-oriented research approach. Educational design research aims to develop research-based solutions for complex problems in educational practice. It refers to:

"the systematic study of designing, developing and evaluating educational interventions (such as programs, teaching-learning strategies and materials, products and systems) as solutions for complex problems in educational practice, which also aims at advancing our knowledge about the characteristics of these interventions and the processes of designing and developing them. [...] Starting point for design research are educational problems for which no or only a few validated principles ('how to do' guidelines or heuristics) are available to structure and support the design and development activities. Informed by prior research and review of relevant literature, researchers in 
collaboration with practitioners design and develop workable and effective interventions by carefully studying successive versions (or prototypes) of interventions in their target contexts, and in doing so they reflect on their research process with the purpose to produce design principles" (Plomp \& Nieveen, 2010, p. 13).

Van den Akker, Gravemeijer, McKenney, \& Nieveen (2006) characterize educational design research as (a) interventionist, aiming at designing an intervention in the real world; (b) iterative, incorporating a cyclic approach of design, evaluation and revision; (c) involvement of practitioners, active participation of practitioners in the various stages and activities of the research; (d) process oriented, with a focus on understanding and improving interventions; (e) utility oriented, by its focus on the practicality for users in real contexts; and (f) theory oriented, the design is (at least partly) based upon a conceptual framework and upon theoretical propositions, and whilst the systematic evaluation of consecutive prototypes of the intervention contributes to theory building.

It is important to note that design research follows a holistic approach, and does not emphasize isolated variables. Design researchers do focus on specific objects and processes (interventions) in specific contexts, but they try to study those as integral and meaningful phenomena (Van den Akker et al., 2006). This context bound nature of much design research also explains why it usually does not strive towards context-free generalizations. If an effort to generalizing is made, then it is an analytical generalization (in contrast to statistical generalization where the researcher may generalize from sample to population). “Where design principles may have been supported by a number of replications, and a new context may be similar to the ones from which design principles have emerged, yet each context has unique characteristics that justifies that the design principles should be used as 'heuristic' statements: they provide guidance and direction, but do not give 'certainties' " (Plomp \& Nieveen, 2010, p. 22). Kelchtermans and Vanassche (2010) criticized the hegemony of effectiveness studies ('what works?') in the educational research agenda. They pleaded for a broader interpretation of research in terms of understanding and insight and argued for sustained collaboration between teachers and trained researchers as the best guarantee for relevant and valuable teacher research. Design research can strengthen this connection between research and school practice through close cooperation between researchers and 
practitioners in different stages of the research process and by studying processes rather than limiting studies to effect measurement.

Educational design research aims at developing theories about both the process of learning and the means designed to support that learning. The goal is not just to find out whether the design 'works', but also to understand the relation between the learning process and the design. More than most other research approaches, design research aims at making both practical and scientific contributions.



Figure 1.1 Predictive and design research approaches in educational technology research

(Reeves, 2006, p. 59)

In search of innovative 'solutions' for educational problems, interaction with practitioners is essential. "The interrelation between theory and practice is complex and dynamic: is it possible to create a practical and effective intervention for an existing problem or intended change in the real world?" (van den Akker, 2006, p. 8). Interaction with practitioners is needed to gradually clarify both the problem at stake and the characteristics of its potential solution. Reeves (2006) considered this conception of design research a viable strategy for socially responsible research in education. As illustrated in Figure 1.1, Reeves noted that even if the results of (what he called) 'business-as-usual predictive research' provided unassailable results demonstrating the efficacy of an educational technology, translating those findings into instructional reform 
would not be given. "Reading research papers and translating the findings into practical solutions is a formidable task for educational practitioners. Also, educational technologists cannot simply install purportedly innovative technologies into the classroom and expect them to work" (Reeves, 2006, p. 5859). One of the primary advantages of design research is that it requires practitioners and researchers to collaborate in the identification of real teaching and learning problems, the creation of prototype solutions based on design principles, and the testing and refinement of both prototype solutions and the design principles in the real world until satisfactory outcomes have been reached by all concerned.

Design research is highly interventionist, simultaneously pursuing the goals of developing effective learning environments and using such environments as natural laboratories to study learning and teaching (de Wolf, 2002). Educational design research is a problem-oriented research methodology aimed at reducing the uncertainty of design decisions; it generates concrete recommendations for quality improvement, it tests general design principles, and it stimulates the professional development of all participants (researchers and other professionals) engaged in the educational intervention development. The premise is that a systematic integration of research and design in cyclic and iterative ways plays an important role in developing and testing the adequacy of interventions for ambitious policies in education where problems and needs are diverse and uncertainty about interventions often exist (van den Akker, 1999; van den Akker et al., 2006).

Walker (2006, p. 11) noted that design researchers must deal simultaneously with many ambiguities and unknowns. He recommended to "concentrate on the most important design problems, understand them thoroughly, identify the most promising features for the design in light of that understanding, build prototypes with these features, and trying them out. This is a much bolder and riskier research strategy than conventional social science research methodologists recommend, but it stands a much better chance of leading to innovative designs." He also emphasized the importance of involving the stakeholders in the process and in judging the overall desirability of a design compared to accepted practices. 


\subsubsection{Overall research design}

\section{Evaluation model}

Guskey and Sparks (1996) proposed a model for PD program evaluation, based on the premise that the quality of PD is influenced by content, context, and process factors. Content factors include the knowledge and skills to be developed, as well as the degree of change required to enact the new knowledge and skills in the classroom. Context factors include the 'who, when, where, and why of professional development'. Process refers to PD delivery format and instructional strategies. Guskey and Sparks claimed that these factors would affect the quality of PD, which in turn would influence outcomes (knowledge and practices) for the teachers, administrators, and others involved. These outcomes will have an impact on student learning. Effective PD affects student achievement through three steps. First, professional development enhances teacher knowledge, skills, and motivation. Second, better knowledge, skills, and motivation improve classroom teaching. Third, improved teaching raises student achievement. If one link is weak or missing, better student learning cannot be expected. If a teacher fails to apply new ideas from PD to classroom instruction, for example, students will not benefit from the teacher's professional development. In other words, the effect of PD on student learning is possible through two mediating outcomes: teachers' learning, and instruction in the classroom. In the first step, for professional development to improve teachers' knowledge, skills, and motivation, it must be of high quality in its theory of action, planning, design, and implementation.

In 2000 Guskey developed this line of thought to an elaborated model for evaluating PD programs included various levels in outcomes. PD evaluation should evolve from the simplest level (reactions of participants), to the most complex level (student learning outcomes), with data from each level building on the previous. Guskey's model consisted of PD evaluation at five levels, each level addressing a certain set of questions and informing the types of evaluation data to be collected.

1. Participants' reactions; at this level evaluators ask the participants whether they liked the PD through questionnaires and interviews.

2. Participants' learning; at this level evaluators ask the participants whether they learned the intended knowledge and skills. Evaluators gather evidence through tests, presentations, and artifacts. 
3. Organization support and change; at this level evaluation is concerned with the impact of PD on the organization (i.e., the school department, school or institution, school district). Questionnaires, interviews, and artifacts can provide such information.

4. Participants' use of new knowledge and skills; at this level evaluation focuses on how participants apply their new knowledge and skills in their classrooms and schools. Evaluators use questionnaires, interviews, written reflections, and observations as evidence.

5. Student learning outcomes; at this level evaluation addresses the impact of PD on student achievement, performance, attitudes, and self-efficacy. Evidence of PD impact on students comes from school records, questionnaires, interviews, and artifacts such as tests.

Desimone (2009) proposed a similar core framework of critical features of teacher learning and recommended its use for studying teachers' professional development. The core theory of action for PD should follow four steps: (a) teachers experience effective PD; (b) PD increases teachers' knowledge and skills and/or changes of attitudes and beliefs; (c) teachers use their new knowledge and skills, attitudes and beliefs to improve the content of their instruction or their approach to pedagogy, or both; (d) the instructional changes foster increased student learning.

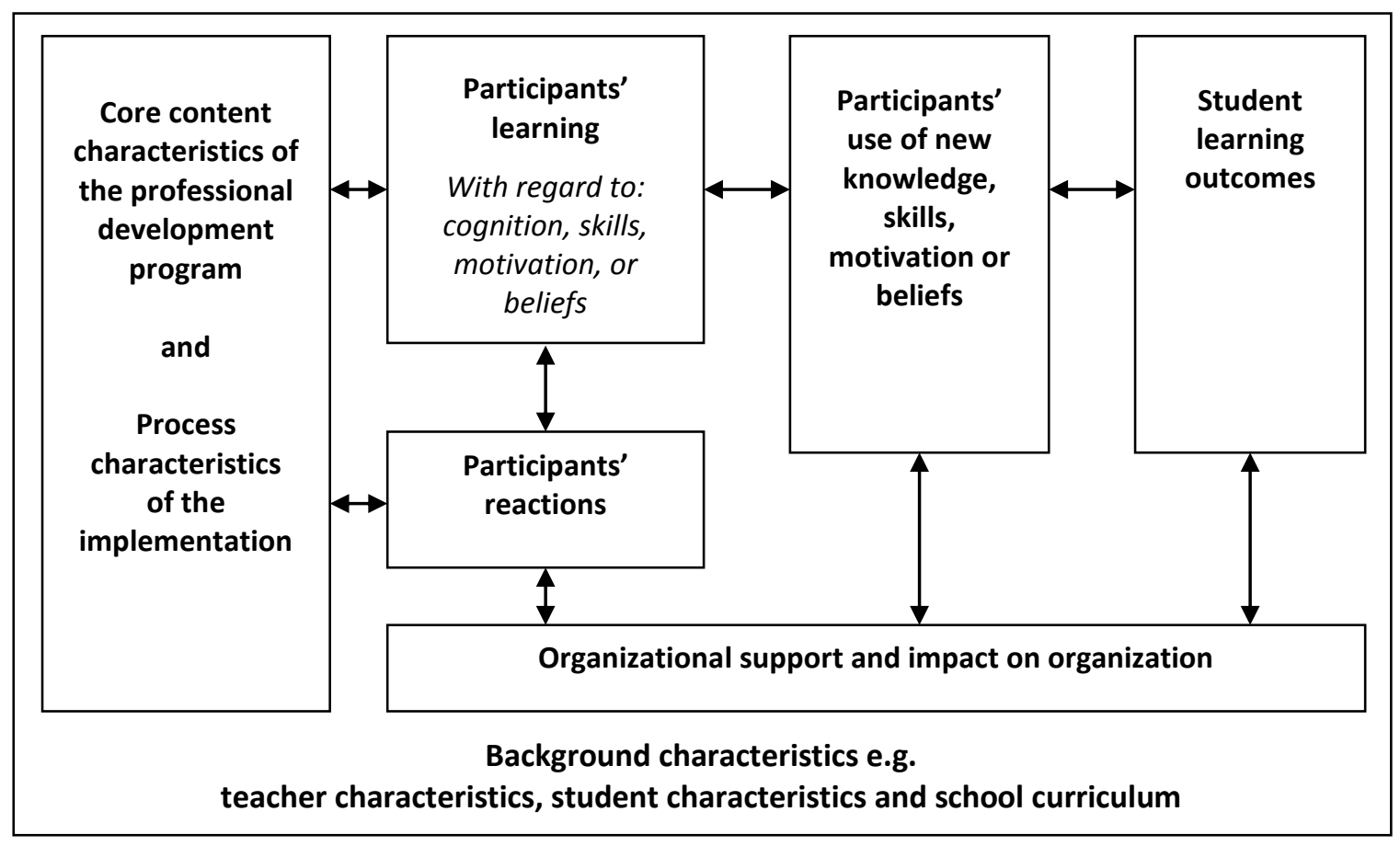

Figure 1.2 Research model for studying the effects of PD 
We defined our research model for PD evaluation based on these models (Figure 1.2). The core content characteristics of the program refer to the design of the professional development program, the process characteristics of the implementation refer to aspects of the realization of the program (e.g. the extent of participation of the teachers and whether the teachers volunteered or not). Participants' reactions refer to the degree in which teachers liked the program, or to the aspects the teachers reacted positively to. Participants' learning can refer to all kinds of learning outcomes such as cognitive, behavioral, motivational outcomes and changes in beliefs and drives. Participants' use of new knowledge, skills, motivation, beliefs focuses on how participants use their new knowledge, skills and motivation in their classrooms and schools (e.g. changes in 'noticing or interpretation or valuing classroom interactions', or changes in 'teachers' selfunderstanding, or task perception, or job motivation', or changes in performance and competence). Student learning outcomes addresses the impact of PD on student achievement, behavior, attitudes, and self-efficacy. Organizational support and impact on organization refers to the support for the program and impact on the organization (i.e., the school department, school or institution, school district), e.g. in relation to commitments and goals or community building. The background characteristics refers to individual characteristics of the teacher (e.g. teaching experience, school subject, stage in professional or personal life, personal goals and learning strategies), or characteristics of the students (e.g. level of or motivation for school or subject, or variations in student group) or characteristics of the school or the school curriculum.

This model implies (1) that PD outcomes, including teacher reactions, knowledge, motivation, and change in practice, as well as organizational change and support, can affect student learning; (2) that outcomes must be interpreted in light of each PD program's content and implementation process, in the context of the school, and in the context of individual characteristics of participants.

The present design study is linked to this model:

1. The study will characterize the process, content, and context variables associated with each implementation of the PD program through participant observation, interviews with participants, and analysis of artifacts such as participants' reports of own inquiries in their practice.

2. The study examines teacher reactions and teacher self reports about knowledge gains and perceived change in practices, as well as possible institutional 
change. We examine teachers' own inquiries and self reports about learning and behavioral outcomes in students in relation to PD activities.

\section{Data collection and participants}

To gain more in-depth knowledge and to stimulate triangulation (Miles \& Huberman, 1994), in each study data was obtained with several instruments and both deductive and inductive analyses were executed. In this study, mainly four of the five scopes of program outcomes have been investigated. In Table 1.1 an overview of evaluation scope and data collection is presented.

Table 1.1 Overview of evaluation scope and data collection methods in this study

\begin{tabular}{|c|c|c|c|c|}
\hline $\begin{array}{l}1 . \\
\text { Participants' } \\
\text { reactions }\end{array}$ & $\begin{array}{l}2 . \\
\text { Participants' } \\
\text { learning }\end{array}$ & $\begin{array}{l}3 . \\
\text { Organizational } \\
\text { support and } \\
\text { impact on } \\
\text { organization }\end{array}$ & $\begin{array}{l}4 . \\
\text { Participants' use } \\
\text { of new } \\
\text { knowledge, } \\
\text { skills, motiva- } \\
\text { tion or beliefs }\end{array}$ & $\begin{array}{l}5 . \\
\text { Student } \\
\text { learning } \\
\text { outcomes }\end{array}$ \\
\hline $\begin{array}{ll}\text { What? } \\
\text { - Program } \\
\text { content } \\
\text { - Program } \\
\text { process } \\
\text { - Program } \\
\text { context }\end{array}$ & $\begin{array}{l}\text { What? } \\
\text { - Knowledge } \\
\text { and under- } \\
\text { standing } \\
\text { - } \quad \text { Skills and } \\
\text { behaviors } \\
\text { - } \quad \text { Attitudes } \\
\text { and beliefs }\end{array}$ & $\begin{array}{l}\text { What? } \\
\text { - School } \\
\text { - policies } \\
\text { - Resources } \\
\text { and time } \\
\text { - Involvement } \\
\text { management }\end{array}$ & $\begin{array}{l}\text { What? } \\
\text { - Stages of } \\
\text { concern: } \\
\text { * Awareness } \\
\text { * Self } \\
\text { * Task } \\
\quad \text { * Impact }\end{array}$ & $\begin{array}{l}\text { What? } \\
\text { - Impact on } \\
\text { students' } \\
\text { performance } \\
\text { or achieve- } \\
\text { ment } \\
\text { - Impact on } \\
\text { students' } \\
\text { physical and } \\
\text { emotional } \\
\text { well-being }\end{array}$ \\
\hline $\begin{array}{l}\text { How? } \\
\text { - Observatio- } \\
\text { nal notes } \\
\text { - } \text { Question- } \\
\text { naire } \\
\text { - Semi- } \\
\text { structured } \\
\text { interview } \\
\text { - Recordings } \\
\text { of coaching } \\
\text { dialogues }\end{array}$ & $\begin{array}{l}\text { How? } \\
\text { - Question- } \\
\text { naire } \\
\text { - Semi- } \\
\text { structured } \\
\text { interview } \\
\text { - } \text { Recordings } \\
\text { of coaching } \\
\text { dialogues }\end{array}$ & $\begin{array}{ll}\text { How? } \\
\text { - } & \text { Observatio- } \\
& \text { nal notes } \\
\text { - } & \text { Question- } \\
& \text { naire } \\
\text { - } & \text { Semi- } \\
& \text { structured } \\
& \text { interviews }\end{array}$ & \begin{tabular}{|l|} 
How? \\
- \\
Question- \\
naire \\
- Semi- \\
$\quad$ structured \\
interview \\
- Teachers' \\
inquiries in \\
own \\
classroom
\end{tabular} & 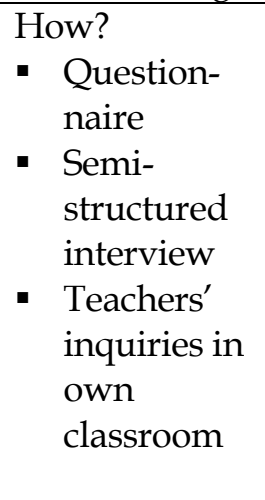 \\
\hline
\end{tabular}

Consecutive cycles of the PD program have been implemented three years in a row and data were gathered from 35 teachers. Each year the program started with a new group of participants and each program was implemented during one school year. In both the first and the second year 9 teachers from various teams in the school participated. In the third year a whole team (consisting of 17 
teachers) joined the program. The researcher co-coached the program during the first two years and participated as an observant during the last year.

\section{Quality assurance}

To increase the internal validity, the study used triangulation of data sources and instruments (Merriam, 1988; Miles \& Huberman, 1994). This approach rests on the premise that the weaknesses of each single data source, method, theory, or data type will be compensated or counterbalanced by the strength of another. By means of triangulation, the researcher gathers evidence from multiple sources to address the questions at hand from different points of view, bringing together different types of evidence in order to test sources of information against each other to determine which explanations are accurate and which should be rejected. Yin (2002) encourages researchers to strive for narratives in a case study and to seek multiple sources of evidence, such as data from questionnaires, interviews, focus groups, documents and other official records. Triangulation brings together quantitative and qualitative data drawn from distinctly different research methods and different sources (Baker, 1999; Creswell \& Miller, 2000). In order to validate our results and conclusions we used triangulation by source (thick descriptions of learning processes of different participants and different participants groups in different contexts) and by method (questionnaire, interview, participant observation, analyses of recorded coaching dialogues and inquiry reports) (see Table 1.1).

Both deductive and inductive data analyses were performed. Analyses of interviews and video-taped peer coaching dialogues were conducted by two researchers analyzing the interviews separately and comparing their results. Furthermore, findings were reported to the school and interpretations were checked and discussed.

Gravemeijer and Cobb (2006, p. 45) noted that "design research aims for ecological validity, that is to say, (the description of) the results should provide a basis for adaptation to other situations. [...] One element that can be helpful in this respect is offering thick description of what happened in the design experiment". This study will give outsiders a basis for deliberating adjustments to other situations, by offering thick descriptions together with an analysis of how these elements may have influenced the whole process and the outcomes (Merriam, 1988; Miles \& Huberman, 1994). In the following chapters, this study 
will discuss in-depth the development of the program and the way the program was used, the experiences of the participants and how the program was readjusted. Traceability will be strengthened by reporting on "failures and successes, on the procedures followed, on the conceptual framework and on the reasons for the choices made [...] The power of this approach is that it creates an experiential basis for discussion" (Gravemeijer \& Cobb, 2006, p.44).

One of the methodological concerns of design research carried out in naturalistic setting is the generalization problem that is the extent to which the findings are transferable from the situation being studied to other situations. Since data collection in design research is usually limited to small (and purposive) samples, efforts to generalize findings cannot be based on statistical techniques, focusing on generalizations from sample to population. Instead one has to invest in 'analytical' forms of generalization: readers need to be supported to make their own attempts to explore the potential transfer of the research findings to theoretical propositions in relation to their own context (van den Akker, 1999). In order to help the readers determine whether the findings of the study are applicable to their own context or situation, and to facilitate the task of analogy reasoning the following aspects are provided (van den Akker, 1999; van den Akker et al. 2006) :

- A clear theoretical articulation of the design principles applied;

- A context-rich description of the research situation, design decisions, and formative as well as summative results;

- A careful description of both the evaluation procedure as well as the implementation context (Miles and Huberman, 1994; Yin, 2002);

- A 'thick' description of the process-in-context to increase the 'ecological' validity of the findings, so that others can estimate in what respects and to what extent transfer from the reported situation to their own is possible.

\subsection{OUTLINE OF THE THESIS}

In Chapter 2 a framework is presented examining the concept of teacher learning, resulting in two basis starting points for the development of the program the notion of workplace learning and the notion of the reflective practitioner. 
In Chapter 3 the outcomes of a literature study are presented, outlining key design principles and characteristics of PD programs that stimulate teacher learning in the context of the school. This Chapter starts with the examination of review studies on effective design principles for PD programs for teachers. Based on this literature study, five design principles were identified. With the help of further literature studies each of these design principles were examined more closely and translated into design characteristics for a PD program.

Chapter 4 presents a study of the design, implementation and evaluation of a PD program (prototype version) based on the design principles and design characteristics identified in Chapter 3.

Chapter 5 presents a study of the design, implementation and evaluation of the PD program 'Learning to Notice' [Bij Nader Inzien]. This PD program is a revised version of the prototype program. The design of the PD is based on the design principles and design characteristics identified in Chapter 3 and on the evaluation outcomes of the prototype program as described in Chapter 4.

Chapter 6 presents a study of teacher learning in the PD program. In this chapter reflection processes in the reciprocal peer coaching dialogues and the teachers' reports of their inquiries into own practice and learning outcomes are analyzed.

Finally, in Chapter 7 the main findings, implications, limitations and further research options are discussed.

All studies are part of an overall study on design principles and design characteristics of a PD program. As a consequence of the iterative character of the overall design study, each study (each Chapter) builds on the results of the previous study. As a result, some recurrence and overlap across Chapters were inevitable. 


\title{
CHAPTER 2 \\ Professional development, teacher learning and reflective practice; a theoretical framework
}

\begin{abstract}
Teacher learning has been studied in several different and often unconnected research traditions. This chapter explores literature on various workplace learning processes and the knowledge base of teaching. Analyzing the way teachers actually learn in their jobs and the variation in learning activities they employ resulted in two basic notions for the design of the PD program: the importance of connecting PD with more non-formal workplace learning activities and the importance of reflective practice for teacher development.
\end{abstract}

\subsection{INTRODUCTION}

\subsubsection{The need for new designs of PD programs}

Today, teachers are being challenged to prepare students for a changing society and to serve increasingly diverse student populations (Lieberman \& Pointer Mace, 2008). We expect teachers to behave as professionals who meet the needs of all their students and perform to the highest standards of their profession. Teaching is a social profession, so schools and teachers are accountable for their results to students, to parents, and to society. Society and schools increasingly emphasize this accountability, and thereby stress the importance of teacher learning and PD to optimize teacher performances. On their part, researchers also underlined the importance of opportunities for teachers' continuous learning and the need for providing sufficient development resources and effective PD programs to support these opportunities (Borko \& Putnam, 1995; Darling-Hammond \& Bransford, 2005; Darling-Hammond \& Richardson, 2009; Desimone, 2009; Hoban, 2002; van Veen, Zwart, Meirink, \& Verloop, 2010; Waslander, 2007). Teacher quality proved to be the factor that matters most for 
student learning, outweighing other factors like standards, funding, and class size (Darling-Hammond \& Berry, 1998; Geringer, 2003; Hattie, 2005, 2009). Therefore, improving teachers' competences is one of the most important investments of time and money that government and school management can make in education.

Continuing to learn is expected of professionals across all professions; undergraduate education is only the beginning of a learning process that continues throughout the professional life. Today organizations question the benefits of standardized training systems and a linear transmission model that extract expertise from the few with the aim of adoption of practices across the many. Interest in informal learning in the workplace is growing (Marsick, 2009). A hallmark of the professional teacher is that he or she is knowledgeable not only about results, content and pedagogy, but also on ways to learn from teaching in an ongoing way, how to pose and address new problems and challenges that do not have existing answers (Darling-Hammond \& Bransford, 2005), and how to integrate and link different kinds of knowledge to the complex problems of schools and classrooms (Hammerness, 2006). This need for continuing PD to maintain high-quality practice as an implicit responsibility of teachers is reinforced today by explicit requirements of professional standards and registration procedures (Beijaard, Meijer, Morine-Dershimer, \& Tillema, 2005; Friedman \& Phillips, 2004). Society asks schools to be accountable for obtained results and centrally managed assessments of students are frequently conducted to gain detailed insight into schools' learning outcomes. Schools and teachers have to explicate how their teaching contributes to achieving the intended student outcomes. The accountability required from schools seems closely connected to the "current 'quest for certainty' from organizations seeking measurable outcomes at lower cost, from professional organizations seeking the certainty of evidence-based practices, and from practitioners themselves acting to minimize the stress of change" (WebsterWright, 2009, p. 717). As a result, there are increasing pressures in education on teachers toward the pursuit of more effective, efficient, and evidence-based practices that deliver improved outcomes for students (Garet, Porter, Desimone, Birman \& Yoon, 2001; Onderwijsraad, 2006; Commissie Dijsselbloem, 2008).

However, with regard to this, a warning is in order. This recent tendency to focus discussions about education almost exclusively on the measurement and 
comparison of learning outcomes needs to reconnect with the fundamental question of purpose in education - the question as to what constitutes good education - for education is also about pedagogical practice and upbringing of children. The focus on 'what works' makes it difficult if not impossible to ask the questions of what it should work for and who should have to say in determining the latter (Biesta, 2010). Moreover, mere outcomes studies do not inform teachers how these outcomes may be obtained. The effectiveness of the pursuit of school improvement is heavily influenced by teachers' ability to adapt to change, teachers' learning abilities, and teachers' capability to design and implement new practices and methods in their classrooms (Hofman \& Dijkstra, 2010; Kwakman, 2003a; Waslander, 2007). If we want to know how to get the best out of teachers, we need to understand teacher development. Essentially, we need to understand the processes involved and what needs to happen in order for teachers to develop (Evans, 2008). Teachers and school leaders need to have a profound knowledge of learning in order to take care of their own learning as professionals and that of their colleagues, staff, and that of their pupils (Huber, 2011). Therefore, in this Chapter, we will further analyze important aspects of teacher learning processes.

Formal educational methods are often inadequate to stimulate continuous professional development (Clarke \& Hollingsworth, 2002). Teacher PD programs have a history of being short-term, individualized and disconnected from practice (van Es, 2006). "Rarely does a one-off workshop promote change, as it does not take into account the existing complexity of a classroom context or have a framework to support teacher learning through the non-linear process of change" (Hoban, 2002, p. 2). To improve PD practice, Tynjälä, Välimaa and Sarja (2003) stated that programs should be based on a form of work-based learning combining the needs of working life and vocational training, and combining theoretical and practical knowledge.

During the last two decades, most research literature about PD advocates improving teaching by providing teachers with opportunities to practice new professional behaviors, and by establishing networks that allow teachers to interact with colleagues (Garet et al., 2001; Lieberman \& Pointer Mace, 2008; Little, 2006; Putnam \& Borko, 2000; Wilson \& Berne, 1999; Zwart, 2007). Empirical research indicated that effective professional learning is best situated within a community that supports learning (Darling-Hammond, 1997; Garet et al., 2001; Little, 2006; Meirink, Meijer, \& Verloop, 2007; Stoll, Bolam, McMahon, 
Wallace, \& Thomas, 2006; Webster-Wright, 2009; Wenger, 1998; Zwart, Wubbels, Bergen, \& Bolhuis, 2007). However, many PD practices still focus on delivering content rather than enhancing learning and although PD programs "are more flexible and learner centered, more engaging and interactive, many remain episodic updates of information delivered in a didactic manner, separated from engagement with authentic work experiences" (WebsterWright, 2009, p. 703). This de-contextualization essentially disregards the value of ongoing and situated learning, thereby reinforcing the perceived divide between theory (what you learn in a course) and practice (what you do at work every day). Such learning may not be integrated into changes in everyday work (Webster-Wright, 2009). This history of failure to improve PD programs signals the need to design of more effective approaches to support teacher learning.

\subsubsection{Multiple views on teacher learning and goals of PD}

Designing a PD program must address how teachers learn and what they have learned before. Understanding teachers' opportunities for learning - including contextual conditions - is important for the construction of programs to stimulate lifelong learning. Although a coherent theoretical framework to guide long-term teacher learning is still lacking (Hoban, 2002; Jordell, 2006; Waslander 2007; Zwart, 2007), a significant body of educational research into professional learning may inform PD practice. Teacher learning is studied from different perspectives focusing on a variation in goals closely related to teachers' tasks, goals varying from very broad terms like professional or vocational identity or competences to suggestions of very long lists of rather small components in the form of specific behavioral and/ or cognitive skills. (Jordell, 2006).

Views on (desired) outcomes seem to be related to conceptions of teaching. Wise, Darling-Hammond, McLaughlin and Bernstein (1984) concluded that teachers usually hold one of four conceptions of teaching; teaching is considered as a craft, labour, profession, or art. These views indicate different approaches to teaching and might also apply to different views on PD of teachers. When considered a craft or a labour, the emphasis is on mastering a repertoire of skills or competences, on a top-down approach of innovation, and on a linear transmission model of PD. However, differences in contexts between schools often present obstacles for teachers attempting to apply new 'generic' learning from conventional PD programs to their own classroom practice (Hattie, 2005; McLaughlin, 1993; Waslander, 2007). A notion of teaching as a 
profession or an art implies that teaching is more than a development of a repertoire of techniques. It also includes personal judgments about when and how these techniques should be applied.

This study adopts the notion of teaching as a profession and regards teachers as genuine professionals who can and should (learn to) make informed decisions about innovations of their own practice, founded on their personal practical knowledge base which is built on theoretical notions as well as on own experiences and inquiries (Groundwater-Smith \& Mockler, 2009). PD programs based on this view of teaching as a profession - implying that teachers as actors themselves are central - seem most promising. Teaching is a highly complex activity and PD needs to be organized in more contextualized ways.

\subsubsection{A knowledge base of teaching}

Teachers teach in the way each situation, each encounter pulls out of their knowing (Clandinin \& Huber, 2005). It is basically 'knowing how things work' that guides action, and it is considered a key factor in a teacher's successes. The failure to develop sufficient practical knowledge will result in rapid frustration and possibly early burnout (Sternberg \& Caruso, 1985). Thus, professionals need a personal practical knowledge base to steer their actions, founded on the knowledge base of the teaching profession.

A professional knowledge base of teaching refers to "all profession-related insights that are potentially relevant to the teacher's activities" (Verloop, van Driel, \& Meijer, 2001, p. 443). Teachers are unable to easily articulate their individual practical knowledge because parts of it are strongly integrated and internalized. In literature, this latter kind of practical knowledge is also called implicit or tacit knowledge.

Teachers generally acquire most of their knowledge during interaction with a variety of systems: during education and training, during work in interaction with students, colleagues and parents, and in participating in society in all kinds of different roles. Learning in all these different contexts contribute to the construction of a personal practical knowledge base. Simply put, the function of a teacher's practical knowledge base is to guide one's actions when encountering the critical question 'what should I do in this particular situation?'. Practical knowledge constitutes of "those beliefs, insights, and habits that enable teachers 
to do their work in schools; it is time bound and situation specific, personally compelling and oriented toward action" (Feiman-Nemser \& Floden, 1986, p. 512). Many researchers have pointed at the 'experiential character' of teachers' practical knowledge. It is developed through an integrative process rooted in teachers' own classroom practices and it guides teacher behavior in the classroom (Meijer, 1999).

Cochran-Smith and Lytle (1999b) made a distinction between knowledge-forpractice, knowledge-in-practice, and knowledge-of-practice. All conceptions imply teacher learning and the construction of a personal knowledge base of teaching. The first conception leads to a definition of teacher learning as mastering the professional knowledge base of teaching and the gathering of all the knowledge that is needed to teach well from sources outside the school such as from experts, courses, or handbooks. The second conception, the knowledge-in-practice approach, leads to the definition of teacher learning as the refinement of a personal practical knowledge base by finding out 'what works' during experiences in day-to-day practice in own school contexts. To this, Cochran-Smith and Lytle added a third conception, the knowledge-of-practice approach, in which teacher learning is defined as the collaborative search of a group of teachers for 'what works' by inquiries into own classroom, learning by collaboratively studying literature, by experimenting and innovating in the classroom, and by collaborative reflecting and building on a shared 'body of knowledge'.

The present study focuses on a design of a PD program integrating the knowledge-in-practice and knowledge-of-practice approaches. It regards teacher learning as an active, complex and continuous process in which during their professional career teachers enlarge their practical knowledge base and acquire and construct new knowledge, skills, attitudes and motives with the purpose of optimizing their performances as a teacher. This study focuses on teacher learning as a social enterprise in which learning can be enhanced by reflective dialogues between teachers within the context of own school practice. This implies a change of emphasis in PD from passive development to active learning and a different conceptualization of knowledge. The importance is not knowledge but 'knowing embedded in practice'. Expertise appears to be context dependent and integrated with the experiences of the teacher in the context of the school (Glazer \& Hannafin, 2006). PD programs should help teachers in connecting their personal practical knowledge with the practical knowledge base of their peers and with the knowledge base of their profession. 


\subsection{LEARNING FOR, IN, AND FROM PRACTICE}

\subsubsection{Workplace learning and professional development}

PD programs need to relate to teacher workplace learning for two reasons. Firstly, as we saw before, PD programs closely related to teachers' own practice appear to be more effective in changing teachers' practice. Workplace learning enhanced by deep and broad reflection and social interaction, and related to own practice, is a powerful way to learn to change teaching practice (VillegarsReimers, 2003). Secondly, teachers do not learn just within PD programs. They mostly have learned and still continue to learn as a side effect of teaching and through all kind of other activities they daily perform; a learning that may be enhanced by reflection and/or interaction with others (Kwakman, 2003b). As a consequence of this, the results of day-to-day teacher workplace learning form the basis for any further teacher learning and therefore need to be treated as a central focus for PD.

Authors on (teachers') workplace learning have made various analyses and used various concepts which show considerable overlap in meaning. This study will discuss some of the most relevant insights and concepts in this paragraph.

\subsubsection{Teacher learning: an active, social, construction process}

As noted before, there is a constant pressure on schools to improve and to innovate. Teacher workplace learning could be characterized as a social interaction process in which the teacher acquires modes of action, practices, procedures and products which fit in with existing practice. Instead of PD programs trying to layer new strategies on top of the old, or instead of teachers simply being socialized into existing practice, what is needed is PD offering active learning opportunities in the workplace which allow teachers to transform their teaching (Snow-Renner \& Lauer, 2005). Learning communities of teachers may be a means to stimulate this (Little, 2007; Sparks-Langer \& Colton, 1991). For example, Englert and Tarrant (1995) established learning communities for literacy teachers to facilitate examination of their own classroom practices and similar PD programs for secondary school teachers were designed and/or studied by other researchers (Borko, Jacobs, Eiteljorg, \& Pittman, 2008; Grossman \& Wineburg, 1997; Horn \& Little, 2010; Meirink, 2007; Sherin \& Han, 2004; Zwart, Wubbels, Bergen, \& Bolhuis, 2007). In such 
communities of teachers teachers discussed their beliefs about teaching and learning and existing practice with one another, investigated their own classrooms, systematically tested new ideas, and shared their findings. Through these efforts, the emphasis shifted to posing questions, not just answering them, and to interrogating one's own practice and the practices of others, making assumptions explicit, and making classrooms sites for inquiry (Cochran-Smith \& Lytle, 1999). Research showed that "this kind of learning can be more than merely additive (grafting new skills onto an existing repertoire); it can be transformative (fostering fundamental changes in deeply held beliefs, knowledge, and habits of practice)" (Thompson \& Zeuli as cited by Windschitl, 2002, p. 161-162). Innovative and transformative learning implies consciousness and the need to change (Freire, 1972; Mezirow, 1981). Transformative (or critical) learning involves reflection on one's own deeply rooted sense making, in which bit by bit parts of that sense making are replaced by new meanings (Bolhuis, 2009a), and implies changes in significant and emotionally based beliefs and behavior. This transformative learning encompasses change as well as unlearning, and refers to a process in which new behavior and knowledge are constructed. Transformative learning may be prevented or hindered, but also stimulated by (part of) the school community (Bolhuis, 2009a).

Teachers need opportunities for conversations among themselves, if for no other reason than to share and discuss their beliefs about teaching and learning. This is not easy because schools maintain a 'dispiriting array of regularities that promote isolation' (Heckman, 1987) and a professional practice characterized by 'public loneliness' (Jordell, 2006). Teachers rarely observe classroom practice of colleagues and rarely discuss productive approaches to classroom problems or even share how they teach. Consequently, the individual and collective beliefs that drive school culture remain unstated and unexamined. Deep and broad reflection (Kelchtermans, 2007) and transformative learning is difficult because changes in sense making go against the existing routine patterns of behavior and thinking. Transformative learning requires effort and opportunities as well as room for experimentation and reflection. Maybe what often holds the status quo in place in education is not so much conscious conservatism, but unexamined institutional habits and widespread cultural beliefs about what constitutes a 'real school' and 'real teaching' (Windschitl, 2002). Creating ways to initiate new kinds of conversations among colleagues and mediate those conversations towards productive ends is one of the main challenges for designs of PD programs. 
A goal of many PD programs and activities is innovation through changing participants' attitudes, beliefs, or dispositions. Researchers have questioned this widely assumed change of behavior as a result of PD practice focusing on new knowledge, beliefs and attitudes (Guskey, 2000; Clarke \& Hollingsworth, 2002; Zwart, Wubbels, Bolhuis, \& Bergen, 2008). They signaled that these procedures seldom change attitudes significantly, nor did they elicit strong commitment from teachers or change their actual practices. The premise of PD efforts that try to change attitudes, beliefs, or dispositions directly is that these affective changes will lead to change in school or classroom practices that will ultimately result in improved learning of students. "Current evidence on teacher change however, indicates that this sequence of change events is inaccurate, especially with regard to professional development endeavours involving experienced educators" (Guskey, 2000, p. 139). Experienced teachers in particular have very strong ideas about which practice will or will not work and whether individual students will learn or change. These strongly held ideas are not likely to change by one-shot workshops or study conferences. In contrast, Guskey's Model of Teacher Change stated that changes in attitudes and beliefs generally follow rather than precede changes in behavior and occur primarily after teachers gained evidence of improvements in student learning. In other words, practice changes attitudes rather than vice-versa. This can be explained by the theory of 'preconceptions' and the influence of the gap between the theory provided and teachers' own preconceptions (Wubbels, 1992), and by the theory of cognitive dissonance (Festinger, 1957). The latter refers to the tension between (new) beliefs and (existing) actual behavior. People will seek balance by changing either their behavior or - if that seems too difficult - changing back their beliefs. In schools, changing behavior may be too difficult because routines have been established long ago and been in place for many years. Existing school culture may impede new behavior and thereby may impede transformative learning. Professional development and innovations of own practice is often accompanied by struggles around mastering new skills and changing habits, individually as well as collectively in the school - the (social) environment. In schools, tensions can result in new insights and beliefs - acquired through PD - being changed back to old beliefs and old routines, which fit in more easily with existing praxis.

A lack of impact of traditional PD programs may also occur due to teachers' limited opportunities for meaningful interaction and lack of follow-up. Teachers may go home with a new idea, but the design of the PD (e.g. lacking thorough links with specific school context or follow-ups) makes it unlikely that 
teachers' practice will change in any significant way (Schwille, Dembélé, \& Schubert, 2007). In this study, the purposes of teacher learning and PD are improving own performances and the collective performances in the school. PD programs working over an extended period of time and adapted to own school context and directly linked to inquiry and experimentation in own school practices, can stimulate transformative teacher learning and is probably the most potent form of professional development.

In the next paragraph, a further specification of the processes of teacher workplace learning will be presented.

\subsubsection{Workplace learning}

\section{Workplace culture affects the learning of teachers}

There is growing acceptance within the research community of the centrality of workplace learning for effective PD (Billett, 2009; Eraut, 2004; Tynjälä, 2008). Also, in pre-service teacher education in the Netherlands, attention for workplace learning has increased during the last decade and is recognized as an important influence on teachers' practice (Bolhuis, 2001; Bolhuis, Buitink, \& Onstenk, 2010; Klarus \& Oosterheert, 2005; Onstenk, 2004). However, workplace learning is not a single unified phenomenon. In the workplace, teachers may be in different positions such as trainee, starter, experienced worker, expert, subordinate, superior, etc. The learner's position will have an effect on the conditions, processes and outcomes of learning (Lave \& Wenger, 1991; Wenger, 1998). Furthermore, not all workplace learning is conducive to the best possible practice. Two aspects emerge from the field of learning at the work place: (a) learning is context dependent and (b) for innovative learning, reflection and critical analysis are necessary.

The workplace culture determines what is learned and the way it is learned (Billett, 2009; Bolhuis, 2009; Webster-Wright, 2009). Workplace culture and workplace learning stimulates socialization and fitting in with existing practice. They can either foster or deter innovative learning and improvements of teacher's classroom practice. For example, established hierarchies in some workplaces impose a view of learning in terms of an apprenticeship where certain skills should be learned, thereby discouraging experienced practitioners from critically evaluating their practice (Billett, Fenwick, \& Somerville, 2006). Furthermore, professionals develop competences in different ways, depending on the context of their practice and their understanding of that practice. 
Change and complexity in the workplace, together with increasing regulation and work intensification, has led to a significant amount of research on the way work interacts with other features of people's lives. For instance, increasing pressure may result in less time and space available to discuss and reflect on work, and may also challenge perceptions of self and people's identities (Webster-Wright, 2009). Time or social constraints at work may limit participation or interactions that support learning, especially within schools, due to the nature of 'the public loneliness' of the teacher's work. Workplace learning (as noted before) does not always result in desirable outcomes, but may also strengthen negative features of the workplace.

\section{Formal, non-formal, and incidental learning in the workplace}

Workplace learning has been studied with key concepts such as non-formal and incidental learning, implicit, unstructured and tacit knowledge - all characterizing these learning processes as mostly unintentional, spontaneous and unplanned - frequently happening more or less unconsciously and not primarily as a result of highly structured PD programs, but as a result of teachers' day to day activities (Eraut, 2004; Bolhuis, 2009; Bolhuis, Buitink, \& Onstenk, 2010; Frietman, Kennis, \& Hövels, 2010; Hoekstra, Beijaard, Brekelmans, \& Korthagen, 2007; Kwakman, 2003; Marsick, 2009; Marsick \& Volpe, 1999; Poell, Yorks, \& Marsick, 2009; Tynjälä, 2008; van Eekelen, Vermunt, \& Boshuizen, 2006). Researchers have described non-formal and incidental learning by their contrast with formal learning (Marsick \& Watkins, 2001). For an overview of different aspects of formal, non-formal and incidental learning see Table 2.1.

This study defines formal learning as typically institutionally sponsored, often classroom-based, and highly structured. Formal learning within PD has a prescribed learning framework in which learning objectives are set by others, the emphasis is mostly on individual and cognitive learning, and outcomes are tested, recognized, and often formally acknowledged by others with an award or certification.

On the other hand, non-formal is strongly related to practice. It refers to more spontaneous learning, and includes characteristics such as more implicit, opportunistic, social-embedded, unstructured learning, and the absence of a trainer or objectives formulated by others (Eraut, 2004). Non-formal learning is hard to standardize, systemize, and assess (Marsick, 2009). Its hallmark is its naturalness of learning often through social interaction and networks. It 
includes socialization processes directed towards continuity (Billett, Fenwick, \& Somerville, 2006). Non-formal learning can be deliberately encouraged by an organization or it can take place despite an environment not highly conducive to learning. The process of non-formal learning stays largely invisible and teachers often lack awareness of their learning. The resultant knowledge is either tacit or regarded as a person's general capability, rather than something that has been learned in the workplace (Eraut, 2004, p. 249).

Incidental learning can result from any daily life activity. It is defined as a form of implicit learning and as a by-product of some other activity, such as task accomplishment, interpersonal interaction, sensing the organizational culture, trial-and-error experimentation, or forms of formal or non-formal learning activities. Incidental learning almost always takes place without much control of the learner or the learning environment and people are mostly unaware of it.

Table 2.1 Overview of aspects of formal, non-formal and incidental learning

\begin{tabular}{|c|c|c|c|}
\hline & Formal learning & $\begin{array}{l}\text { Non-formal learning } \\
\text { related to work }\end{array}$ & $\begin{array}{l}\text { Implicit and incidental } \\
\text { learning }\end{array}$ \\
\hline Examples & $\begin{array}{l}\text { Formal education. } \\
\text { - Formal on-the-job } \\
\text { and off-the-job } \\
\text { training. }\end{array}$ & $\begin{array}{l}\text { - Observing peers. } \\
\text { - Experimenting in } \\
\text { practice. }\end{array}$ & $\begin{array}{l}\text { Incidental learning } \\
\text { occurs always in } \\
\text { every situation } \\
\text { (formal or non- } \\
\text { formal) as a side } \\
\text { effect of activities } \\
\text { and experiences. }\end{array}$ \\
\hline $\begin{array}{l}\text { Nature of the } \\
\text { learning } \\
\text { process }\end{array}$ & $\begin{array}{l}\text { Externally } \\
\text { organized and } \\
\text { structured learning } \\
\text { processes. }\end{array}$ & $\begin{array}{l}\text { - Naturalness of lear- } \\
\text { ning often through } \\
\text { social learning. } \\
\text { - Experiential, oppor- } \\
\text { tunistic learning } \\
\text { process, connected } \\
\text { with own practice } \\
\text { and often strongly } \\
\text { related to daily } \\
\text { routines. }\end{array}$ & $\begin{array}{l}\text { - Implicit and inciden- } \\
\text { tal learning as a by- } \\
\text { product } \\
\text { - Integrated with all } \\
\text { activities. }\end{array}$ \\
\hline
\end{tabular}


Table 2.1 Overview of aspects of formal, non-formal and incidental learning (Continued)

\begin{tabular}{|c|c|c|c|}
\hline & Formal learning & $\begin{array}{l}\text { Non-formal learning } \\
\text { related to work }\end{array}$ & $\begin{array}{l}\text { Implicit and incidental } \\
\text { learning }\end{array}$ \\
\hline $\begin{array}{l}\text { Learning goals } \\
\text { and outcomes }\end{array}$ & 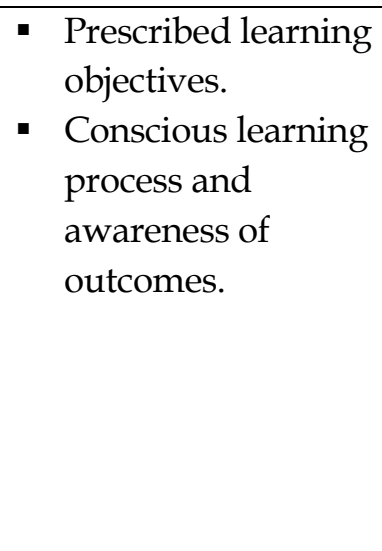 & $\begin{array}{l}\text { Work-based learning } \\
\text { goals. } \\
\text { - Outcomes are less } \\
\text { predictable. } \\
\text { - } \text { More or less } \\
\text { conscious learning } \\
\text { process and } \\
\text { awareness of } \\
\text { outcomes. }\end{array}$ & $\begin{array}{l}\text { - No learning goals. } \\
\text { - Learning is } \\
\text { haphazard and } \\
\text { highly influenced by } \\
\text { chance. } \\
\text { - Activities resulting } \\
\text { in unconsciously } \\
\text { learning } \\
\text { implicit/tacit } \\
\text { knowledge and } \\
\text { beliefs. }\end{array}$ \\
\hline $\begin{array}{l}\text { Ownership of } \\
\text { learning } \\
\text { process }\end{array}$ & $\begin{array}{l}\text { External control } \\
\text { - Learning objectives } \\
\text { and fixed } \\
\text { curriculum set by } \\
\text { other actors } \\
\text { (trainers, institute, } \\
\text { school } \\
\text { management, } \\
\text { government } \\
\text { policy). }\end{array}$ & $\begin{array}{l}\text { More self-directed } \\
\text { learning embedded } \\
\text { in social context of } \\
\text { own practice. }\end{array}$ & $\begin{array}{l}\text { Learning as an } \\
\text { unintended by- } \\
\text { product, taking place } \\
\text { without much } \\
\text { internal or external } \\
\text { control. }\end{array}$ \\
\hline $\begin{array}{l}\text { Consciousness } \\
\text { and } \\
\text { awareness of } \\
\text { learning }\end{array}$ & $\begin{array}{l}\text { Learning activities } \\
\text { are consciously } \\
\text { planned and result } \\
\text { in an explicit } \\
\text { theoretical } \\
\text { knowledge base. } \\
\text { - Learning is often } \\
\text { triggered by } \\
\text { assignments and } \\
\text { assessments. } \\
\text { Visibility of } \\
\text { learning by award } \\
\text { or certification } \\
\text { given by other } \\
\text { actors (educational } \\
\text { institute). }\end{array}$ & $\begin{array}{l}\text { Learning activities } \\
\text { are planned and } \\
\text { unplanned and } \\
\text { results in a practical } \\
\text { knowledge base. } \\
\text { - Learning is triggered } \\
\text { by an activity or } \\
\text { event at the } \\
\text { workplace, or by an } \\
\text { internal jolt. } \\
\text { - Learning is linked to } \\
\text { learning of others and } \\
\text { to working processes } \\
\text { and/or results. }\end{array}$ & $\begin{array}{l}\text { Learning by } \\
\text { unaware trial-and- } \\
\text { error and feedback } \\
\text { processes. } \\
\text { - Learning is taken for } \\
\text { granted or } \\
\text { unconscious. } \\
\text { - Obtained knowledge } \\
\text { remains } \\
\text { implicit/tacit. } \\
\text { - Learning process } \\
\text { stays invisible in } \\
\text { organizations. }\end{array}$ \\
\hline
\end{tabular}

There is a continuum between formal, non-formal and incidental learning. Most learning of experience has some non-formal and implicit aspects, and awareness of formal explicit learning does not mean that non-formal and incidental learning is not also taking place (Eraut, 2004; Bolhuis, 2009). Both types of learning, formal 
and non-formal, may include explicit and implicit learning, taking place on several levels of consciousness. For instance, in a learning context most planned activities may be consciously undertaken by teachers with the intention to learn (e.g. studying classroom management techniques), but teachers might as well at the same time unconsciously develop unintended beliefs (e.g. about a specific student or student groups or about collaboration with colleagues). Non-formal workplace learning is often unplanned but can also result from an intentional and planned activity (e.g. teachers decide for themselves to experiment with a specific strategy in their classrooms).

Many benefits of non-formal learning at work are identified, for example: flexibility, employability, adaptability of learning to context, rapid transfer to practice, and resolution of work-related problems through regular review of work practices and performances (Marsick, 2009). This leads to a plea to combine features of non-formal learning in the workplace with features of more formal learning activities in PD programs (Martens \& de Laat, 2011). Formal education uses and produces explicit knowledge; non-formal and incidental learning uses and produces mostly tacit knowledge. Nonaka and Takeuchi (1995) have described the process of professional knowledge creation as the interaction between explicit knowledge and tacit knowledge; a cyclic process involving four steps: socialization, internalization, externalization and combination. In this context several researchers suggested that, to be successful, teacher PD should adopt certain features of workplace learning and correspondingly, workplace learning should be developed by utilizing strong features of formal professional development (Marsick, 2009; Martens \& de Laat, 2011). These include intentionality, structured learning support and guidance, explication and sharing of personal knowledge, and problem-based approaches linked to own practice (Poell, Yorks, \& Marsick, 2009; Tynjälä, 2008) and reflective dialogues which trigger 'externalization' and thereby the articulation, sharing, and investigation of teacher's (tacit) practical knowledge base.

\section{A classification of workplace learning processes}

Researchers have described and classified formal, informal and incidental workplace learning processes in different ways, focusing on different dimensions (Bakkenes, Vermunt, \& Wubbels, 2010; Bolhuis, 2004, 2009; Bolhuis, Buitink, \& Onstenk, 2010; Bransford, Brown, \& Cocking, 2000; Kwakman, 2003; Tynjälä, 2008). 
Eraut (2004) and Bolhuis (2009) classified workplace learning activities using the dimensions 'consciousness' and 'goal orientation'. Elaborating on the difference between formal intentional learning processes that need attention in the workplace and informal and incidental learning processes that 'just happen' without conscious attention. Bolhuis et al. (2010) described seven work-related learning processes, all differing in degree of consciousness and goal setting:

1. Learning by immediate actions and trial-and-error: participation in a social context in the workplace demands immediate reactions and actions. (Professional) behavior that causes no immediate problems will be repeated the next time. If they do not perceive a change, people tend not to reflect consciously about their habits of thinking and behavior.

2. Learning through conscious ('reflective') actions: for instance, by preparing lessons, by observing and rethinking results aiming at adjustments in the future, or by doing practitioner research (inquiries, action research).

Both of the categories are directly linked to acting and 'doing-the-job'. The next two categories of learning processes in the workplace refer to learning as a result of observations:

3. Model-learning - learning by observing or imitating: people learn primarily through interactions with others and by imitating others. Neuroscience shows us that this process happens mostly unconsciously (Iacoboni, 2008, as cited by Bolhuis et al., 2010). This unconscious imitation process leads to adaptation and socialization without conscious deliberations or efforts. Learning by imitation is strengthened by identification (wanting to be like the other person). As noted, this learning occurs mostly unconsciously but can also be done partly consciously.

4. Learning by (more) conscious ('reflective') observation and imitation: learning by goal orientated and purposeful observations of colleagues, studying their professional performances and drawing conclusions about own performances. Examples of other professionals which fit in with own performances and competences are selected and imitated more easily then models that behave very differently.

The last three categories are linked to learning as a result of verbal interactions between people or through written information:

5. Learning by social interaction; fitting in with the 'discourse': i.e. adapting to and joining the mode of talking (about education, students, parents, own activities, ups and downs) that is standard in the profession, and especially 
in the teacher's actual context, the particular school where s/he works. Joining the discourse usually happens without much conscious attention.

6. Learning through processing information (from education or media) refers to theoretical learning, the traditional type of learning in school settings (for pupils or students). Information processing needs conscious and purposeful attention. It can be no more than 'root learning', but may also be critical and reflective. To connect this learning process with outcomes in professional performances, additional learning in practice will be necessary.

7. Learning by critical reflection and interaction: deliberating conscientiously on own and collective performances, behavior, and discourse as well as information. Critically thinking about and discussing educational goals, methods and results, and designing and experimenting with other ways of teaching is a way to open practice for more transformative learning processes.

Besides, teachers do not only learn about teaching at their work but also in other roles (Bransford et al., 2000). Teachers learn and have learned for years and years what education meant as a side effect of participating in schools as a student or as a parent.

A critical element of professional practice is the capacity to make wise and sound decisions about teaching, based on knowledge of teaching and learning, students and learning context. Teacher's professional judgment is the key and the critical element to teaching. Teachers as professionals need to learn continuously and become reflective practitioners constantly inquiring own practice and striving to improve their performance. In the next paragraph we will explore this strategy.

\subsubsection{The reflective practitioner}

\section{The concept of reflection}

Numerous articles and books on the topic of reflection have appeared in the educational literature widely recommending reflective skills as a means of increasing teacher education, nursing, and PD programs. Several thorough overviews of the literature on reflection have been produced (Fook, White, \& Gardner, 2006; Hatton \& Smith, 1995; Jay \& Johnson, 2002; Korthagen, 2001; Rogers, 2001; Sparks-Langer \& Colton, 1991; Zeichner, 2008). However, the concept is not yet completely understood (Rogers, 2001, p. 37) and different terms and definitions are used to describe reflective processes including 
reflective thinking (Dewey, 1933), reflection-in-action and reflection-on-action (Schön, 1983), and critical reflection (Mezirow, 1990).

Reflection is a form of mental processing that we use purposefully to gain a better understanding of relatively complicated or unstructured ideas (Moon, 2005). It refers to the kind of thinking that consists of turning over a subject in the mind and giving it serious thought; a kind of mulling over a subject (Dewey, 1933). Rogers (2001) distinguished two common antecedents of the reflective process. Firstly, it needs a trigger - e.g. an event or problematic or puzzling situation that creates a state of doubt, hesitation, perplexity or mental difficulty - and secondly, an individual's readiness and willingness to engage in the reflective process, an open-mindedness, wholeheartedness and responsibility on the part of the learner. We take a closer look at the concept of reflection, because all too often, any kind of thinking about one's practice tends to get described as reflective (Thompson, 2010). This study argues that reflection and reflective practice involve:

- a process that is triggered by an unusual or perplexing situation or experience;

- requiring active engagement on the part of the individual;

- a process (cognitive, emotional, and experiential) of examining assumptions and underlying beliefs (of many different types and levels) embedded in actions or experience;

- a linking of these assumptions with many different origins (personal, emotional, social, cultural, historical, political);

- a review and re-evaluation of these according to relevant (depending on context, purpose, etc.) criteria;

- the integration of the new understanding;

- the eventual improvement of professional performance.

Reflection aims to, but is not guaranteed to, improve practice. Reflection processes can lead to more or less permanent cognitive, affective, and behavioral changes; however, not all mental changes will lead automatically to changes in observable behavior (Boud, Keogh \& Walker, 1985). In addition, this study notices that although reflection aims at growth and improvement of professional practice, reflection - like all learning processes - may also lead to unwanted learning outcomes (Bolhuis, 2009). Learning does not necessarily mean an improvement in performance in the eyes of an external observer, but could also involve the development of what an external assessor would 
consider inadequate beliefs about teaching (Hoekstra et al., 2009). Therefore, reflection should also be based on inquiries into own practice and a search for evidence for own assumptions and conclusions.

\section{Broad and deep reflection}

The importance of broad and deep reflections - analyzing how-to questions but also reflecting on feelings, beliefs, drives, and on political and moral issues involved in education - has been underlined by several researchers (Kelchtermans, 2007; Korthagen \& Vasalos, 2005, 2007; Zeichner, 2008). For instance, Zeichner (2008) noted that many of his students, although technically competent in the classroom, were mainly concerned with getting their pupils through lessons in a sloth and orderly fashion. Students did not think much about why they were doing what they were doing, how what they were teaching represented selections from a larger universe of possibilities and how the contexts in which they taught encouraged and discouraged certain practices. He signaled in his own teacher education practice that "our students had no idea of where the curriculum came from and didn't seem to care. Teaching was largely seen as a technical process to be directed by either what people in schools or at the university wanted them to do and for the most part our students did not see teaching as a moral and ethical activity over which they had any control." He warned against a reflection process limited to considerations of teaching skills and strategies and fine-tuning (the means of instruction), and excluding reflection upon the ends of education and the moral and ethical aspects of teaching.

It is important for teachers and student-teachers to talk about their thinking about what they do and would like to do, and to talk about how they adapt their instruction to meet the varied needs of their learners. It is also important for them to gain a level of awareness that helps them: to see own (unproven) assumptions and beliefs, to discover possibilities, and to see that existing practice is not inevitable and that it reflects particular biases (Zeichner, 2008). Likewise, Fook et al. (2006) notified that reflection "may be used to serve many different interests, often simultaneously, some of which may seem contradictory. It may be used, for instance, both for greater or lesser conformity, as a way to increase accountability to existing norms, but also as a way to question the 'taken for granted' which may be explicit in those norms" (Fook et al., 2006, p. 13). This is one of the main differences between what is called reflective practice and critical, transformative practice based on broad and deep reflections. Critical reflection, in this sense, may be seen as the use of 
reflective abilities to achieve some freeing from unproven beliefs and hegemonic assumptions. As Dewey (1933) already stated, it is not our belief in inference that misleads us but our belief in untested inference.

\section{Models of reflection}

Some authors have suggested that models and protocols could help practitioners to focus on outcomes (Ermeling, 2010; Hall, 2009; Nelson, Deuel, Slavit, \& Kennedy, 2010). During the last two decades, various models have been developed to enhance and study the process of reflection by teachers. Such models describe a staged process involving successive steps to structure reflection, and/or describe different levels of depth of reflection processes. Most models recognize at least three steps or levels of reflection: (a) beginning with a more descriptive level, (b) advancing to what might be termed a more reflective, analyzing level, and (c) culminating in a plan of action or a transformational level (Fook, et al., 2006). Several authors critiqued that because of the way practitioners use those models, the focus of reflection is generally on technical aspects of the acquisition of knowledge and skills (Kelchtermans, 2007; Kelchtermans \& Hamilton, 2004; Tigelaar, Dolmans, Meijer, de Grave, \& van der Vleuten, 2008; Zeichner, 2008). This puts 'how' questions, such as 'how can I modify my teaching so as to make it more effective?' at the centre of attention and disregards analyses of own feelings, beliefs, drives, and reflections on political and moral issues involved in education.

Mansvelder-Longayroux, Beiaard and Verloop (2007) studied student-teachers' learning during their internship. They distinguished between action-oriented and meaning-oriented reflection. Action-oriented reflection is aimed at improving teaching practices and involves the mental activities recollection and evaluation. Meaning-oriented reflection is aimed at understanding the teaching and learning processes underlying the situation and includes mental activities such as analyzing, critical processing and diagnosis. What teachers "believe they want is the 'how to' or the next new technique or idea; but in reality what they really need is a way to raise assumptions about teaching and determine the validity of their beliefs before they are given the new pedagogical model, technique, or method" (Qualters, 2009).

Through reflective dialogue, teachers engage in conversations aimed at discussing assumptions about teaching and student learning (Louis, Marks, \& Kruse, 1996). This way reflective dialogue can stimulate teachers to engage in meaning-oriented reflection. Meaning-oriented reflection can also be promoted by input from external resources (Day, 1993). Such input can be generated by 
feedback. For example, teachers may ask each other or their students for feedback about the quality of their work and the impact it has on student learning or they may tape performances in classroom for further study. Finally, discussing and sharing norms and responsibility are considered to be an imperative for teachers to know where they are and to know where they need to go, while the absence of shared norms and responsibility leaves teachers uncertain about how well they are doing.

For this study, we will subsequently describe four different models: Korthagen's ALACT-model, Korthagen and Vasalos' model of Core reflection; Ghaye and Ghaye's Critical Reflective Practice Model; and Kelchtermans' Broad and Deep reflection model. For an overview of these models see Table 2.2.

\section{ALACT-model (Korthagen, 2001)}

Widely used in teacher education is the ALACT-model (Action, Looking-backon-the-action, Awareness-of-essential-aspects, Creating-alternative-methods-ofaction, Trial; Korthagen, 2001). This model has proven to be very useful in guiding and supporting the development of reflective skills of student-teachers during their internship. However, the stages of (student-)teachers' reflection processes are presented in a fixed order and the final focus is on formulating alternatives "which might favour an exclusively technical focus" (Tigelaar et al. 2008 , p. 291). By using this model, learning to teach becomes easily restricted to questions of effectiveness and efficiency. The model "can be applied independently from decisions on what counts as good teaching, but can therefore easily be limited to instrumental interest of effectiveness. This remains true even though the ALACT-model clearly emphasises the importance of taking into account not only the teachers' but also the pupils' perspectives, and not only thoughts but also feelings" (Kelchtermans, 2007, p. 101).

The following three frameworks for reflection deal with this criticism, they focus on teaching 'from within', based on the idea that good teaching cannot be reduced to techniques, since good teaching is based on the identity and integrity of the teacher.

Core reflection ('Onion'-model) (Korthagen E Vasalos, 2005)

Korthagen and Vasalos searched for deepening reflection. They shifted the focus of reflection from a merely technical, rational approach to a focus on more spiritual and intuitive aspects of reflection and teacher learning. Reflection is 
often limited to the surface level of behaviors and competences. The 'model of core reflection' focuses also on more implicit levels of individual teacher functioning, such as beliefs, professional identity and personal mission. The authors distinguished six layers of professional functioning in their model: context (what do I encounter?), behavior (what do I do?), competences (what am I competent at?), beliefs (what do I believe?), own identity (who am I in my work?), and own mission (what inspires me?). Reflections on their self-image and professional identity are of vital significance in PD. Korthagen and Vasalos described this as 'the six layeredness of professional functioning'.

Korthagen and Vasalos searched for deepening reflection, however their focus is more spiritual and on the identity of the individual teacher. The next two models also focus on more political and moral issues and critical reflection practice.

\section{Critical Reflective Practice Model (Ghaye E Ghaye, 1998)}

Ghaye and Ghaye (1998) operated in two professional fields (nurse and teacher education). Their model has four foci of reflection: values, practice, improvement and context. The model wants to broaden the technicalinstrumental dimension mainly focusing on the 'how question', and places an emphasis on the teacher-learners themselves and the values they bring to the reflection practice. In their view, each teacher and student-teacher enters the teacher training environment with attitudes and value-laden opinions that can either support or impede improvement and the ability to reflect. Ghaye and Ghaye introduced the concept of different perspectives as a way to reflect on experiences and distinguished five types (or scopes) of reflection-on-practice, with each type representing a dominant way in which teachers might reflect upon their work:

a. Descriptive reflection-on-practice, which mainly consists of description of own experiences as a teacher.

b. Perceptive reflection-on-practice, in which teachers makes a demonstrable link between descriptions of own teaching and their personal feelings about it.

c. Receptive reflection-on-practice, in which teachers are receptive to and make connections between their view of the world and their construction of classroom reality to the views and practices of others. Teachers bring forward evidence in order to align personal knowledge in relation to some wider and more complex picture. This could be the perspectives of other teachers, the professional knowledge base or inquiries into own practice. The teacher is looking for evidence, synthesis, solutions or new insights. 
d. Interactive reflection-on-practice, in which the focus of reflection shifts to the future and to the design of an articulated action plan.

e. Critical reflection-on-practice, in which the teacher begins to question accepted routines, classroom practices and school rituals and confronts big and complex issues of power and politics in schools.

The first two perspectives are retrospective, personal accounts. They are essentially descriptive in nature and associated with feelings about how well the teaching went according to the teacher. These are egocentric in the sense that they are teacher's own view of things. In the last three types, teachers connect 'their view of the world and their construction of classroom reality' to that of others and to 'evidence'.

The five perspectives are not steps presented to be completed in a fixed order. One perspective is not presented as 'better' than another perspective, but reflection becomes more valuable when more perspectives are included in the reflection process.

\section{Model of Broad and Deep Reflection (Kelchtermans, 2007)}

The model of Kelchtermans (2007) shares similarities with the previous model. It is a framework consisting of four integrated dimensions of teaching: the technical-instrumental, moral, political, and emotional dimension. Kelchtermans stressed the importance of such a broad and deep reflection scope beyond the instrumental and technical dimension (the 'how questions') as a necessary skill for teacher development. The moral dimension refers to questions about normative beliefs about good teaching, justice and responsibility. The political dimension addresses issues of power and interest ('who determines what is to be taught and how?' and 'who benefits?'). Finally, the emotional dimension to teaching plays a central role, since personal commitment and involvement are crucial for teaching. It refers to stress and frustration, passion and satisfaction, but also to the professional identity of the teachers themselves.

Kelchtermans argued that teachers' PD always entails both development of sense of self and development of knowledge, skills, and attitudes. Teachers develop a personal interpretative framework, their personal practical knowledge base. Interwoven with their subjective practical knowledge base are teachers' 
conceptions of themselves as teachers: their self-image, self-esteem, job motivation, task perception and future perspective. Teachers' self understanding only appears in the act of telling to themselves during reflection or during telling to others during dialogues. "Teachers' narrative accounts of their experiences are not just informative about how they think about themselves. Rather they construct that self-understanding in the interactive act, at the same time (implicitly or explicitly) inviting the 'audience' to acknowledge, confirm or question and contradict the statement." (Kelchtermans, 2007, p. 99). Narrative accounts that reveal self-understanding are moments of interactive sense-making and reflection should be broad and deep and include the moral and the political and the emotional aspects of their efforts as a teacher.

To conclude: all models incorporate reflection on the technical-instrumental dimension with the 'how' questions focusing on behavior and competences. However, most models also underline the importance of deepening instrumental and more descriptive reflection; getting to the heart of the matter and not being easily satisfied. The described models (see overview in Table 2.2) distinguish between a number of scopes of reflection important for teacher learning and PD. The two models described at the right side of the overview put their prime focus on reflective practice in relation to different scopes of reflection. There is no fixed sequence to guide reflection, only the notion to broaden and deepen reflection by including more perspectives or scopes. In practice, the two reflection models described at the left side have a tendency to be used as a guide with fixed steps for the reflection process, from experiencing of a problem to finding of the solution (ALACT), from peeling layer after layer to find the core of own mission as a teacher (CORE reflection). 
Table 2.2 Reflection models

\begin{tabular}{|c|c|c|c|}
\hline $\begin{array}{l}\text { ALACT-model } \\
\text { (Korthagen, 2001) }\end{array}$ & $\begin{array}{l}\text { Core Reflection } \\
\text { ('Onion-model' of } \\
\text { six layeredness of } \\
\text { professsionnal } \\
\text { functioning) } \\
\text { (Korthagen } \mathcal{E} \\
\text { Vasalos, 2005) }\end{array}$ & $\begin{array}{l}\text { Critical Reflective } \\
\text { Practice } \\
\text { (Ghaye \& Ghaye, } \\
\text { 1998) }\end{array}$ & $\begin{array}{l}\text { Model of Broad } \\
\text { and Deep } \\
\text { reflection } \\
\text { (Kelchtermans, } \\
2007 \text { ) }\end{array}$ \\
\hline $\begin{array}{l}\text { A cyclical reflection } \\
\text { process of: } \\
\text { - Action } \\
\text { - Looking back on } \\
\text { the action } \\
\text { - Awareness of } \\
\text { essential aspects } \\
\text { - Creating } \\
\text { alternative } \\
\text { - } \text { methods of action } \\
\text { With a balanced focus } \\
\text { on: } \\
\text { - thinking } \\
\text { - feeling } \\
\text { - wanting } \\
\text { - acting } \\
\text { Reflecting on two } \\
\text { perspectives: } \\
\text { - perspective of the } \\
\text { teacher } \\
\text { - perspective(s) of } \\
\text { the student(s) }\end{array}$ & $\begin{array}{l}\text { Reflection on six layers: } \\
\text { - Context: } \\
\text { what do I } \\
\text { encounter? } \\
\text { - Behavior: } \\
\text { what do I do? } \\
\text { - Competences: } \\
\text { what am I } \\
\text { competent at? } \\
\text { - Beliefs: } \\
\text { what do I believe? } \\
\text { - Own identity: } \\
\text { who am I (in my } \\
\text { work)? } \\
\text { - Own mission: } \\
\text { what inspires me? }\end{array}$ & $\begin{array}{l}\text { Reflecting with four } \\
\text { foci: } \\
\text { on values, on } \\
\text { practice, on } \\
\text { improvement, on } \\
\text { context } \\
\text { Five types of reflection: } \\
\text { - Descriptive } \\
\text { reflection: } \\
\text { describing own } \\
\text { experiences } \\
\text { Perceptive } \\
\text { reflection: } \\
\text { connecting } \\
\text { descriptions to } \\
\text { personal feelings } \\
\text { Receptive reflection: } \\
\text { connecting own } \\
\text { views and } \\
\text { knowledge to that } \\
\text { of others } \\
\text { Interactive } \\
\text { reflection: } \\
\text { connecting } \\
\text { learning to future } \\
\text { and action } \\
\text { planning } \\
\text { Critical reflection: } \\
\text { questioning } \\
\text { complex issues of } \\
\text { power and politics } \\
\text { in schools }\end{array}$ & $\begin{array}{l}\text { Reflection to develop } \\
\text { teacher's sense of self } \\
\text { and of teacher's } \\
\text { knowledge, skills, } \\
\text { attitudes. } \\
\text { Reflecting on four } \\
\text { levels: } \\
\text { - Technical- } \\
\text { instrumental } \\
\text { What is the most } \\
\text { effective use of } \\
\text { instruction and } \\
\text { interventions? } \\
\text { - Emotional } \\
\text { Reflecting on } \\
\text { own emotional } \\
\text { experiences and } \\
\text { commitment } \\
\text { - Moral } \\
\text { What is } \\
\text { educationally in } \\
\text { the best interest } \\
\text { of the students? } \\
\text { Political } \\
\text { Who benefits } \\
\text { from what I do? } \\
\text { Reflecting on } \\
\text { 'power and } \\
\text { interest' }\end{array}$ \\
\hline
\end{tabular}


For this study, the reflection models provide tools to stimulate and study reflective dialogues of teachers in PD programs. The models provide also support to teachers to learn how they can question existing practice and stimulate own reflection and the reflections of their peers in dialogues.

\subsection{SUMMARY AND CONCLUSION}

A design for a PD program must be based on the notion of professional learning as continuing, active, social, constructive and related to practice. Teacher learning refers to a non-linear process; learning to do something differently involves adjustments to many elements of classroom practice and implies learning something new, but also unlearning something else. Transformative teacher learning needs PD programs working over an extended period of time and adapted to own school context and directly linked to inquiry and experimenting in own school practices.

Analyzing the way teachers actually learn in their jobs and the variation in learning activities they employ resulted in two basic notions for the design of the PD program: the importance of connecting PD with more non-formal workplace learning and the importance of reflective practice for teacher development.

Teacher learning occurs, much more implicitly than we realize, through nonformal learning by concrete and specific acting and experiencing in day-to-day practices. Teacher workplace learning is intertwined with work in ways that are tacit and not typically proactively engaged. Workplace learning can result in improvement of professional behavior, but it can also result in the learning of wrong things and bad habits. This study places teacher learning and PD in the service of improving own professional performances and the collective performances within the school. PD activities could fit in with workplace learning by enhancing individual's intentionality and consciousness as well as the supportiveness of the environment for learning. The distinction between formal and non-formal learning is not absolute, these are the two extremes of a continuum instead. To be successful, PD programs should adopt certain features of formal and of non-formal learning. These include intentionality, structured learning support and guidance, explication and sharing of personal knowledge, socially embedded, highly contextualized and problem-based approaches linked to own practice. 
Although non-formal learning is very powerful, PD activities that combine characteristics of formal and non-formal learning processes are most promising for several reasons. Non-formal learning is not always adequate, because: (a) teaching and schools need to change in a rapid pace, implicit and reactive nonformal learning cannot ensure that knowledge and skills will keep up with this rapid pace; and (b) implicit and reactive non-formal learning takes place without conscious planning and effort and yields mainly tacit knowledge; this kind of knowledge is hard to change in cases where this might be desirable, e.g. when earlier learning have resulted in bad habits and dysfunctional practices. To add (c) more intentional deliberative learning and formal PD activities may structure non-formal learning and turn tacit knowledge into explicit knowledge which can be shared with others and may lead to integration of conceptual knowledge with practical experience and critical reflection, thus generating expertise.

Teachers are professionals who use judgment in complex, ambiguous circumstances and who are often highly motivated to learn and improve their work. To make informed decisions, PD programs supporting knowledge sharing and engaging teachers in collaborative reflection examining taken-forgranted understandings, assumptions, and intended and unintended consequences in classrooms, may be most promising. Even though there may be some opportunities for isolated work and reflection, most effective PD is expected to happen when there are meaningful interactions among community members. Teacher learning is a highly social activity which (a) requires interaction and dialogue with a focus on co-constructing professional knowledge, (b) requires the kinds of challenges that make learning necessary, and (c) involves reflection on past experiences and the planning of future activities with a focus on critical reflection and analysis of own and collective practice, person, beliefs and assumptions, aiming for better individual and collective practice. In short: focus on reflective practice.

This study defines the concept of reflection as a purposeful cognitive and affective process of examining experiences and assumptions (of many different types and levels) embedded in actions or experience. The process requires active engagement on the part of the individual and involves both exploring the negative and positive emotions triggered by experiences, and examining responses and underlying beliefs and premises in light of the specific situations at hand. It is linked to inquiry into own practice and beliefs and a search for evidence. It is applied to improve practice by gaining a better understanding of relatively complicated or puzzling 
experiences or ideas, and is largely based on the reprocessing of knowledge, understanding and emotions. Reflection implies a conscious awareness and deliberate choice. Teachers as reflective practitioners need to reflect 'broad and deep' and may not restrict themselves to mere technical reflection. Furthermore, it is inherent in the nature of teaching that the person matters as much as the professional knowledge, skills or attitudes. The teacher as a person is at the center of the classroom and the educational process. By implication, it matters to teachers themselves, as well as to their pupils, who and what they are. Supported by various reflection models this study argues that PD programs should stimulate teacher's dialogues to reflect on different perspectives and study problem solving, student perspectives, own perspective, theoretical and moral notions.

The research studied in this Chapter is related to theories concerning workplace learning and does not specifically pay attention to the relation between the described learning activities and the learning outcomes in classroom resulting from PD programs aiming at these activities. So, to design a PD program, we did a second literature study (Chapter 3), related to theories of professional development, in search of effective characteristics of PD programs leading to teacher learning and outcomes in classroom. 


\title{
CHAPTER 3 \\ In search of design principles for programs which stimulate workplace learning of teachers
}

\begin{abstract}
This chapter describes a literature study in search of design principles and characteristics of professional development programs that effectively support teachers learning in the context of the school. The first part of this chapter gives an overview of review studies to establish what is internationally known about design principles and design characteristics of professional development programs at the start of the design process in this study. Five design principles for PD programs were identified. The second part of this chapter takes a closer look at each of the five identified design principles in order to better understand and translate each principle into concrete design characteristics of a professional development program.
\end{abstract}

\subsection{INTRODUCTION}

The previous Chapter focused on analyzing the way teachers actually learn in their jobs and the variation in learning activities they employ. This resulted in two basic notions for the design of the PD program: the importance of connecting PD with more non-formal workplace learning processes and the importance of reflective practice for teacher development. The next question we want to answer is: how to build a highly effective PD program, based on these two notions, which scaffolds and stimulates teacher learning? This Chapter describes the outcomes of a literature study with the following research question:

Which design principles and design characteristics can be derived from literature in order to construct a professional development program that adequately supports teacher learning at the workplace? 
Part 1 of the literature study gathered review studies of effective PD programs to identify design principles for PD programs for teachers. Based on the outcomes of the located review studies five basic design principles for effective PD programs were defined. The identified basic principles generated the first input for the design of the prototype.

Part 2 of the literature study investigated each of the five basic design principles in more depth. The focus was on understanding why and in which way each principle could work and on the translation of these design principles in effective characteristics of the PD program. This part of the literature search started at the beginning of the design of the prototype and - to enlarge our understanding of the design principles - continued during the research process.

Literature was searched with the help of electronic databases such as ScienceDirect, Scopus, Ebsco, ERIC, Google Scholar and Google; references found in the selected literature were used as starting point for further searches (snowball method). The most important search terms we used were: teacher learning, teacher professional development, workplace learning, reflection, collaborative learning, peer coaching, video study groups, video feedback, ownership of learning goals, teacher inquiry.

\subsection{REVIEW STUDIES OF TEACHER PROFESSIONAL DEVELOPMENT PROGRAMS}

In the last decade, several review studies have been published on the subject of teacher professional development programs and their impact on teacher and student learning (Cordingley, Bell, Rundell \& Evans, 2003; Cordingley, Bell, Evans \& Firth, 2005a; Cordingley, Bell, Thomason, \& Firth 2005b; Resnick, 2005; Schwille, Dembélé \& Schubert, 2007; Timperley, 2005; Timperley, Wilson, Barrar, \& Fung, 2007; Villegas-Reimers, 2003; Waslander, 2007). We will describe the main findings in this paragraph.

Villegas-Reimers (2003) studied PD programs for UNESCO and provided a comprehensive literature review of professional development in both industrialized and developing countries. According to Villegas-Reimers, the most traditional form of professional development is the typical 'in-service staff training' that includes the use of workshops, short seminars and courses. Other 
types of professional development she found are case-based professional development, self-directed professional development, collegial development (professional dialogues, peer-supervising), observations of excellent practice, increasing teacher participation in new roles, skills development model, reflective model (teacher as reflective practitioner), project-based model, portfolios, action research, teacher narratives, the cascade-model or training-oftrainers model, and coaching-mentoring. Villegas-Reimers pointed at the following overall characteristics for effective PD strategies:

- PD strategies are based on constructivism rather than on a transmissionoriented model'. Teachers are treated as active learners who are engaged in certain tasks of teaching, assessment, observation and reflection.

- $\mathrm{PD}$ is perceived as a long-term process, teachers are expected to learn over time.

- Pd is perceived as a process that takes place within a particular context. The most effective form of PD is based in schools and is related to the daily activities of teachers. The most successful teacher development opportunities are on-the-job learning activities such as study-groups, action research and eportfolios.

- PD should be intimately linked to school reform as it is a process of culture building and not just skill training.

- A teacher is conceived of as a reflective practitioner, someone who enters the profession with a certain knowledge base and who will acquire new knowledge and experience based on prior knowledge.

- PD is conceived of as a collaborative process.

- PD must be systematically planned, supported, funded and researched. Teachers must be given time and financial support to be active designers, implementers and participants of PD opportunities.

- PD may be very different in diverse settings. It should be in alignment with teacher's personal and professional needs and interest, the stage of their professional development and their school context and the curriculum of the school.

- External agencies can and must support PD programs.

Cordingley was involved in three review studies on the impact of continuing professional development (CPD) on classroom teaching and student learning. The first (Cordingley et al., 2003) and second (Cordingley et al., 2005a) review synthesized the results of 31 studies which looked at teacher and student 
outcomes of collaborative CPD activities. The third review (Cordingley et al., 2005b) synthesized the results of a further 11 studies which described teacheronly CPD program outcomes. They found that:

- Individually-oriented CPD offers only weak evidence of its capacity to influence teacher or pupil change. In contrast, studies of collaborative CPD do offer evidence of changes in teachers' practice, attitudes or beliefs and of improved pupils' learning and behavior.

- A positive impact of collaborative type of PD programs was found on teachers' repertoire of teaching and learning strategies, their ability to match these to their students' needs, their self-esteem and confidence, and their commitment to continuing learning and development.

- Key factors in collaborative CPD were:

- classroom observation;

- reflection and experimentation;

- an emphasis on peer support;

- a scope for teacher participants to identify their own CPD focus;

- processes to encourage, extend and structure professional dialogues;

- processes for sustaining the CPD over time to enable teachers to embed the practices in their own classroom settings;

- recognition of individual teacher's starting points;

- and the use of external expertise linked to school-based activity.

On the basis of their reviews the authors recommend PD programs which include sustained collaboration, grounded in classroom observation and support, and involve external expertise and peer support.

Resnick (2005) reviewed 16 publications on the relation between PD methods and student achievement, many linked with teaching mathematics. She found professional development programs more likely to be effective if sustained over time, and on the condition that:

- there is coherence between these activities and teachers' personal contexts;

- the activities encourage communication among (reform-motivated) teachers; and

- the activities focus on specific subject matter content, standards and assessments that teachers use in the classroom. 
Extended opportunities for teachers to better understand student learning, curriculum materials and instruction, and subject matter content can boost the performance of both teacher and students. PD programs should provide teachers with a way to directly apply learning outcomes to their teaching, to provide adequate time for professional development, and to ensure that the extended opportunities to learn emphasize observing and analyzing students' understanding of the subject matter.

In two syntheses of literature Timperley (2005) and Timperley, Wilson, Barrar and Fung (2007) focused on evidence of improved student learning as a result of PD of teachers. In 2005, Timperley located 17 articles that related effects of PD to student learning. This study recommended developing a culture in PD of using data to support learning and how this 'needs a mind shift that will rock the foundations of what we do and how we do it'. She proposed five elements for teacher learning in professional learning communities:

- The development of shared values and expectations about children, learning, teaching and teachers' roles and the relationship of these to the environment;

- The collective focus on student learning that then becomes part of the normative control of the professional community;

- Collaboration, whereby professional communities foster the sharing of expertise and faculty members call on each other to discuss the development of skills and create shared understandings of effective practice;

- De-privatized practice, and much time and opportunity to talk to each other about teaching;

- Reflective dialogue, which imply self-awareness about one's work as a teacher through engaging in in-depth conversations about teaching and learning.

All of these require a serious commitment to evidence, debates about the contested nature and value of evidence, and actions based on evidence. This implies a major cultural shift for many schools, in which discussions are more about curriculum and students and less about teaching, and evidence of growth in learning is rarely shared across the school.

In 2007 Timperley et al. published a further study "to open the black box between professional learning opportunities provided for teachers, how they impacted on teaching practice and subsequent outcomes for students" (p. 3). They selected almost 80 studies and identified nine elements in the professional learning context as important for promoting professional learning in ways that 
impacted positively and substantively on a range of student outcomes. These elements included:

- providing sufficient time and extended opportunities to learn while using the time effectively;

- engaging external expertise;

- focusing on engaging teachers in the learning process rather than being concerned about whether they volunteered or not;

- challenging problematic discourses;

- providing opportunities to interact in a community of practice;

- sustained PD focused on pedagogical content knowledge, combined with inquiry skills: ensuring the content of the professional development is consistent with wider policy trends; and

- in school-based initiatives, leaders actively leading the professional learning opportunities.

Waslander (2007) reviewed literature on innovation strategies in schools. In her study she distinguished five major indicators of success for innovation strategies which also have implications for PD:

- a school has developed a clear concept;

- the innovation fits in with the zone of proximal development;

- the teachers have ownership of the innovation;

- participants experience moments of success; and

- there is continuity, consistency, and embedding in the school context.

Waslander underlines that teachers need to experience influence on their own practice and accordingly on their own professional development. She refers to the construct of teacher ownership necessary for creating real commitment with the innovation and for translating innovations to the teachers' own situation, since not every teacher, school or class is the same. Hence, every teacher has to translate innovations to local circumstances and to specific student groups and thus to own learning goals.

In their review study, Schwille et al. (2007) summarized the main findings by proposing two key dimensions of effective PD: core features and structural features, which they labeled the 'consensus view' in the USA. The core features included:

- Focus on content: The degree to which the activity focuses on improving and deepening teachers' content knowledge; 
- Active learning: opportunities for teachers to engage in a meaningful analysis of teaching (e.g. observe and be observed); and

- Coherence: continued professional communication among teachers, incorporating experiences consistent with teachers' goals and aligned with system-level curriculum standards and assessments.

The structural features included:

- Duration: the number of hours participants spend in the activity and over what span of time the activity takes place. Longer duration activities typically provide the desired content-specific focus, active learning, and more connection to teachers' other experiences;

- Form: the use of activities structured to support reform (special interventions such as mentoring, networking, study group, resource centre) are more effective compared to more traditional workshops or conferences; and

- Participation: groups of teachers from the same professional culture (e.g. school or grade level) participating as a group as opposed to teachers from other locations participating individually. A common worksite provides a closer link with teachers' experiences and facilitates collegial discussion.

However, they signaled tensions and contradictions in this consensus view between (a) the content and/or pedagogy to be learnt and the processes needed to learn it; (b) between involving targeted educators in decisions about their PD and keeping all professional development targeted on system-wide improvement; and (c) confusion between educators learning for professional growth and learning that contributes to organizational performance.

\section{Conclusion}

Based on the findings of the review studies we defined five basic design principles for devising effective professional development programs for teachers. In Table 3.1 an overview is presented of these five principles and their connection with the main findings of the review studies described in this paragraph. The basic principles may be quite broad and can be put into practice in a variety of ways. We have chosen to specify the first two principles in order to be able to make the next step. The five basic design principles for the PD program are:

1. Collaborative learning at the workplace, specification: in the form of reciprocal peer coaching. We focused on reciprocal peer coaching as a promising principle, because there is growing evidence that peer coaching can be valuable for professional learning (Brouwer, 2009; Bruce \& Ross, 2008; Engelen, 2002; 
General Teaching Counsel for England [GTC], 2005; Murray, Ma, \& Mazur, 2009; Showers \& Joyce, 1996; Zwart, 2007).

2. Focus on own practice, specification: with the help of video feedback. In this study video feedback was added because of our own positive experiences as a teacher educator and as a school internal coach with the power of video recordings of teacher's own classroom to strengthen focus and reflection on own practice.

3. Teacher ownership of learning goals.

4. Focus on teacher's inquiry stance and on outcomes in classroom;

5. Creating conditions in the school for professional development and the PD program. 
Table 3.1 Overview of five design principles and their relation to major findings of the review studies on impact of PD programs for teachers

\begin{tabular}{|c|c|c|c|c|c|}
\hline & $\begin{array}{l}\text { 1. Collaborative } \\
\text { learning at the work- } \\
\text { place (in the form of } \\
\text { reciprocal peer } \\
\text { coaching) }\end{array}$ & $\begin{array}{l}\text { 2. Focus on own practice } \\
\text { (with the help of video } \\
\text { feedback) }\end{array}$ & $\begin{array}{l}\text { 3. Teacher ownership of } \\
\text { learning goals }\end{array}$ & $\begin{array}{l}\text { 4.Focus on teacher's } \\
\text { inquiry stance and on } \\
\text { outcomes in classroom }\end{array}$ & $\begin{array}{l}\text { 5. Creating conditions } \\
\text { in the school for PD and } \\
\text { the PD program }\end{array}$ \\
\hline \multirow[t]{2}{*}{$\begin{array}{l}\text { Villegas-Reimers } \\
\text { (Villegas-Reimers, } \\
\text { 2003) }\end{array}$} & $\begin{array}{l}\text { PD is conceived as a } \\
\text { collaborative process. }\end{array}$ & $\begin{array}{l}\text { PD should be school- } \\
\text { based and related to the } \\
\text { daily activities of } \\
\text { teachers and learners. }\end{array}$ & $\begin{array}{l}\text { PD should be based on a } \\
\text { constructivism rather } \\
\text { than on a 'transmission- } \\
\text { model'. } \\
\text { Teachers are treated as } \\
\text { active learners. } \\
\text { PD in alignment with: } \\
\text { - teacher's personal and } \\
\text { professional needs } \\
\text { and interest, } \\
\text { - the stage of his } \\
\text { professional } \\
\text { development, } \\
\text { - the school context and } \\
\text { the curriculum of the } \\
\text { school. }\end{array}$ & $\begin{array}{l}\text { The teacher is seen as a } \\
\text { reflective practitioner. } \\
\text { The most successful } \\
\text { teacher development } \\
\text { opportunities are on-the- } \\
\text { job learning activities } \\
\text { e.g. study-groups and } \\
\text { action research. }\end{array}$ & $\begin{array}{l}\text { PD is a long-term } \\
\text { process. } \\
\text { PD should be intimately } \\
\text { linked to school reform. } \\
\text { PD must be } \\
\text { systematically planned, } \\
\text { supported, funded, and } \\
\text { researched. } \\
\text { Teachers must be given } \\
\text { time and financial } \\
\text { support to be active } \\
\text { designers, } \\
\text { implementers, and } \\
\text { participants of PD } \\
\text { opportunities. }\end{array}$ \\
\hline & & & & & $\begin{array}{l}\text { External agencies can } \\
\text { and must support PD. }\end{array}$ \\
\hline
\end{tabular}


Table 3.1 Overview of five design principles and their relation to major findings of the review studies on impact of PD programs for teachers (Continued)

\begin{tabular}{|c|c|c|c|c|c|}
\hline & $\begin{array}{l}\text { 1. Collaborative } \\
\text { learning at the work- } \\
\text { place (in the form of } \\
\text { reciprocal peer } \\
\text { coaching) }\end{array}$ & $\begin{array}{l}\text { 2. Focus on own practice } \\
\text { (with the help of video } \\
\text { feedback) }\end{array}$ & $\begin{array}{l}\text { 3. Teacher ownership of } \\
\text { learning goals }\end{array}$ & $\begin{array}{l}\text { 4.Focus on teacher's } \\
\text { inquiry stance and on } \\
\text { outcomes in classroom }\end{array}$ & $\begin{array}{l}\text { 5. Creating conditions } \\
\text { in the school for PD and } \\
\text { the PD program }\end{array}$ \\
\hline $\begin{array}{l}\text { Cordingley et al. } \\
\text { (Cordingley, Bell, } \\
\text { Rundell, E Evans } \\
\text { 2003; } \\
\text { Cordingley, Bell, } \\
\text { Evans, } \\
\text { E Firth, 2005a; } \\
\text { Cordingley, Bell, } \\
\text { Thomason, E Firth, } \\
\text { 2005b) }\end{array}$ & $\begin{array}{l}\text { Collaborative continuing } \\
\text { professional } \\
\text { development (CPD) is } \\
\text { more effective than } \\
\text { individually-oriented } \\
\text { CPD. } \\
\text { Collaborative CPD has a } \\
\text { positive impact upon } \\
\text { repertoire of teaching } \\
\text { and learning strategies, } \\
\text { ability to match these to } \\
\text { students' needs, self- } \\
\text { esteem and confidence, } \\
\text { and commitment to } \\
\text { CPD. } \\
\text { Emphasis on peer } \\
\text { support. } \\
\text { Processes to encourage, } \\
\text { extend, and structure } \\
\text { professional dialogues. }\end{array}$ & $\begin{array}{l}\text { Observation, reflection } \\
\text { and experimentation are } \\
\text { three of the key factors } \\
\text { of success. }\end{array}$ & $\begin{array}{l}\text { Scope for teacher } \\
\text { participants to identify } \\
\text { own CPD focus. } \\
\text { Recognition of } \\
\text { individual teacher's } \\
\text { starting point. }\end{array}$ & & $\begin{array}{l}\text { Sustaining collaborative } \\
\text { CPD over time to enable } \\
\text { teachers to embed the } \\
\text { practices in their own } \\
\text { classroom settings. } \\
\text { External expertise linked } \\
\text { to school-based activity. }\end{array}$ \\
\hline
\end{tabular}


Table 3.1 Overview of five design principles and their relation to major findings of the review studies on impact of PD programs for teachers (Continued)

\begin{tabular}{|c|c|c|c|c|c|}
\hline & $\begin{array}{l}\text { 1. Collaborative } \\
\text { learning at the work- } \\
\text { place (in the form of } \\
\text { reciprocal peer } \\
\text { coaching) }\end{array}$ & $\begin{array}{l}\text { 2. Focus on own practice } \\
\text { (with the help of video } \\
\text { feedback) }\end{array}$ & $\begin{array}{l}\text { 3. Teacher ownership of } \\
\text { learning goals }\end{array}$ & $\begin{array}{l}\text { 4.Focus on teacher's } \\
\text { inquiry stance and on } \\
\text { outcomes in classroom }\end{array}$ & $\begin{array}{l}\text { 5. Creating conditions } \\
\text { in the school for PD and } \\
\text { the PD program }\end{array}$ \\
\hline $\begin{array}{l}\text { Resnick } \\
\text { (Resnick, 2005) }\end{array}$ & $\begin{array}{l}\text { PD activities encourage } \\
\text { communication among } \\
\text { (reform-motivated) } \\
\text { teachers. }\end{array}$ & $\begin{array}{l}\text { PD activities need } \\
\text { coherence with teachers' } \\
\text { personal contexts. } \\
\text { Emphasis on observing } \\
\text { and analyzing students' } \\
\text { understanding of the } \\
\text { subject matter. } \\
\text { Focus on specific subject } \\
\text { matter content, stan- } \\
\text { dards and assessments } \\
\text { that teachers use in } \\
\text { classroom. }\end{array}$ & & $\begin{array}{l}\text { Extended opportunities } \\
\text { to better understand } \\
\text { student-learning, } \\
\text { curriculum materials } \\
\text { and instruction and } \\
\text { subject matter content. } \\
\text { PD provides teachers } \\
\text { with a way to directly } \\
\text { apply learning outcomes } \\
\text { to their teaching. }\end{array}$ & $\begin{array}{l}\text { PD sustained over time. } \\
\text { Provision of adequate } \\
\text { time for professional } \\
\text { development. }\end{array}$ \\
\hline $\begin{array}{l}\text { Timperley et al. } \\
\text { (Timperley, 2005; } \\
\text { Timperley, Wilson, } \\
\text { Barrar, E Fung, } \\
\text { 2007) }\end{array}$ & $\begin{array}{l}\text { PD should focus on } \\
\text { developing a } \\
\text { community, with shared } \\
\text { values and expectations } \\
\text { about children, learning, } \\
\text { teaching, teachers' roles } \\
\text { and the relationship of } \\
\text { these to the } \\
\text { environment. }\end{array}$ & $\begin{array}{l}\text { Self-awareness about } \\
\text { one's work as a teacher. } \\
\text { De-privatized practice. } \\
\text { Provide opportunities to } \\
\text { interact in a community } \\
\text { of practice. }\end{array}$ & & $\begin{array}{l}\text { Develop a culture of } \\
\text { using data to support } \\
\text { teacher learning. } \\
\text { A commitment to } \\
\text { evidence-based practice. } \\
\text { Focus of discussion on } \\
\text { teaching and learning } \\
\text { results and less on } \\
\text { curriculum and } \\
\text { students. }\end{array}$ & $\begin{array}{l}\text { Sustained PD } \\
\text { Providing extended } \\
\text { opportunities to talk to } \\
\text { each other about } \\
\text { teaching and to learn. } \\
\text { Providing sufficient time } \\
\text { and using time } \\
\text { effectively. } \\
\text { Engaging external } \\
\text { expertise. }\end{array}$ \\
\hline
\end{tabular}


Table 3.1 Overview of five design principles and their relation to major findings of the review studies on impact of PD programs for teachers (Continued)




Table 3.1 Overview of five design principles and their relation to major findings of the review studies on impact of PD programs for teachers

\begin{tabular}{|c|c|c|c|c|c|}
\hline & $\begin{array}{l}\text { 1. Collabora-tive } \\
\text { learning at the work- } \\
\text { place (in the form of } \\
\text { reciprocal peer } \\
\text { coaching) }\end{array}$ & $\begin{array}{l}\text { 2. Focus on own practice } \\
\text { (with the help of video } \\
\text { feedback) }\end{array}$ & $\begin{array}{l}\text { 3. Teacher ownership of } \\
\text { learning goals }\end{array}$ & $\begin{array}{l}\text { 4.Focus on teacher's } \\
\text { inquiry stance and on } \\
\text { outcomes in classroom }\end{array}$ & $\begin{array}{l}\text { 5. Creating conditions } \\
\text { in the school for PD and } \\
\text { the PD program }\end{array}$ \\
\hline $\begin{array}{l}\text { Waslander } \\
\text { (Waslander, 2007) }\end{array}$ & & & $\begin{array}{l}\text { Ownership; teachers } \\
\text { need to experience } \\
\text { influence on their } \\
\text { practice and the } \\
\text { innovation, and } \\
\text { accordingly on their PD. } \\
\text { The innovation needs to } \\
\text { fit in with the zone of } \\
\text { proximal development. }\end{array}$ & & $\begin{array}{l}\text { The school has } \\
\text { developed a clear } \\
\text { concept of the } \\
\text { innovation. } \\
\text { There is continuity and } \\
\text { consistency and } \\
\text { embedding in the school } \\
\text { context. } \\
\text { Participants need to } \\
\text { experience moments of } \\
\text { success. }\end{array}$ \\
\hline $\begin{array}{l}\text { Schwille et al. } \\
\text { (Schwille, Dembélé, \& } \\
\text { Schubert, 2007) }\end{array}$ & $\begin{array}{l}\text { Form: the use of } \\
\text { activities which are } \\
\text { structured to support } \\
\text { reform, e.g. special } \\
\text { interventions such as } \\
\text { mentoring, networking, } \\
\text { study group. } \\
\text { Groups of teachers from } \\
\text { the same professional } \\
\text { culture, e.g. school or } \\
\text { grade level, participating } \\
\text { as a group. }\end{array}$ & $\begin{array}{l}\text { Active learning: } \\
\text { opportunities for } \\
\text { teachers to engage in a } \\
\text { meaningful analysis of } \\
\text { teaching (e.g. observe } \\
\text { and be observed) }\end{array}$ & $\begin{array}{l}\text { Continued professional } \\
\text { communication among } \\
\text { teachers, incorporating } \\
\text { experiences consistent } \\
\text { with teachers' goals and } \\
\text { aligned with system- } \\
\text { level curriculum } \\
\text { standards and } \\
\text { assessments. }\end{array}$ & $\begin{array}{l}\text { Focus on content and } \\
\text { improving and } \\
\text { deepening teachers' } \\
\text { content knowledge. } \\
\text { A common worksite } \\
\text { provides a closer link } \\
\text { with teachers' } \\
\text { experiences and } \\
\text { facilitates collegial } \\
\text { discussion. }\end{array}$ & $\begin{array}{l}\text { Duration: the number of } \\
\text { hours participants spend } \\
\text { in the activity and over } \\
\text { what span of time the } \\
\text { activity takes place. } \\
\text { Longer duration } \\
\text { activities typically pro- } \\
\text { vide the desired content- } \\
\text { specific focus, active } \\
\text { learning, and more } \\
\text { connection to teachers' } \\
\text { other experiences. }\end{array}$ \\
\hline
\end{tabular}




\subsection{FIVE DESIGN PRINCIPLES FOR PROFESSIONAL DEVELOPMENT PROGRAMS FOR TEACHERS}

During the years of conducting this study, a continuous literature search into design principles and design characteristics for PD programs was carried out. In addition to the outcomes of the literature search for review studies on effective PD characteristics, more in-depth literature searches were carried out for each of the five different design principles found in the review studies. Further information was gathered to better understand each design principle and to help translate each principle in effective characteristics for the design of the PD program. In each of the following paragraphs studies relating to one of the five design principles will be discussed.

\subsubsection{Collaborative learning at the workplace in the form of reciprocal peer coaching}

\section{Teacher learning in collaborative PD programs}

The quantity and quality of learning and development of teachers at the workplace can be enhanced by frequent (informal) interaction with colleagues and managers (van Eekelen, 2005) and by increasing opportunities for consulting and working with others in teams or temporary groups (Eraut, 2007). A body of research spanning more than 25 years demonstrates this significance of teachers' collegial relationships as a factor in school change and improvement (Hord, 1997; Horn \& Little, 2010; Little, 1982, 2006; Louis, Marks, \& Kruse, 1996). Teachers meet in all kinds of situations, for instance during small talk in staff room or in hallways, during team activities and team conferences, during peer-to-peer support or mentoring. The earliest research in informal learning processes in these situations employed the term collegiality to characterize a set of workplace norms and practices that included frequent, specific talk about teaching and its improvement (Little, 1982). By the late 1980s, the terms professional community, teacher community, teacher learning community, and professional learning community had become a common way of characterizing collegial relations considered conducive to teacher PD and to instructional improvement and school reform. In teacher communities teachers serve as a critical friend in a non-competitive environment. The focus is on teacher-identified problems of practice and on working 'to their passion' rather than to a pre-identified agenda (Hargreaves, 1997). By sharing experiences and 
reflections about professional practice, a community of practice can develop (Lave \& Wenger, 1991).

Programs organized in the working context of teachers - often collaborative settings such as study groups or peer coaching - are nowadays preferred PD and innovation strategies (Grossman, Wineburg, \& Woolworth, 2001; Meirink, 2007; Onderwijsraad, 2003; Zwart, 2007). An important aspect for a collaborative setting for teacher learning is that it stimulates teachers to engage in long-term collaboration with their colleagues, focusing on issues that relate to the day-today practice of teaching (Darling-Hammond, 1997; Little, 1993b). In collaborative settings, teachers exchange ideas or experiences, develop and discuss new materials, and receive feedback from colleagues (Kwakman, 1999; Putnam \& Borko, 2000). Important is to include school leaders as participants in PD programs. "Teachers and school managers do not operate in parallel universes" (Seashore Louis, 2001 p. 21-22), but are both part of the school community.

As we noticed in Chapter 2, recent research on teachers tends to acknowledge expertise gained at the workplace as 'practical knowledge' or 'practical wisdom'. However, there are also reasons for raising critical awareness of the mostly implicit character of experiential knowledge and skills. Bolhuis (2001) summed up five arguments for making knowledge and beliefs explicit by discussing with colleagues what is happening and what is assumed:

a. To discover the restrictedness or faults in individual or shared understandings and practice;

b. To share experiences and build on mutual understanding, exchange and reconstruction;

c. To let newcomers profit from the expertise of others;

d. To share assumptions about goals and activities in the team in order to build team expertise and be productive as a team; and finally;

e. Tacit knowledge and habits need critical appraisal and change in response to changing situations.

PD programs structuring dialogues between practitioners in collaborative settings could be an effective strategy to reflect on implicit practical knowledge and beliefs. Educators at all levels value opportunities to work together, reflect on their practices, exchange ideas, and share strategies. Promoting and structuring collegiality and collaborative exchange is one of the basic characteristics that make PD more effective, however, "for collaboration to bring its intended 
benefits it, too, needs to be structured and purposeful, with efforts guided by clear goals for improving student learning" (Guskey, 2003, p. 749).

\section{Sharing of practice and reflective dialogues}

Collegial dialogues become more valuable when teachers' communications stimulate the sharing of experiences, sense-making and understanding of the phenomena of learning and shared decisions (Bransford, Brown, \& Cocking, 2000; Teurlings \& Uerz, 2009).

The notion of sharing ideas and discussing own practice between colleagues has been used in various PD programs (Bergen, Engelen, \& Derksen, 2006; Glazer \& Hannafin, 2006; GTCE, 2007; Hoban, 2002; Little, 1993a). School-based teacher collaboration provides new possibilities for PD based on shared reflection in the workplace (Lieberman, 1996), by listening to and observing of colleagues (Meirink, 2007), and is claimed to stimulate greater improvements in teaching and learning and to facilitate implementation of effective change (Little, 2006; Talbert \& McLaughlin, 1994; Zwart, 2007). It is seen as a factor of school effectiveness, and is linked in a positive way to teachers' sense of selfefficacy (Lavié, 2006).

Teachers themselves perceive communication with colleagues in collaborative settings as relevant and valuable for the improvement of their own teaching practice (Bakkenes, Vermunt \& Wubbels, 2010; Kwakman, 1999). Among teachers, the most popular long-term PD activities are the observation of colleagues and the sharing of practice (Boyle, Lamprianou, \& Boyle, 2005). Collaborative PD programs appear to function in strengthening social ties among teachers and in turn, these strong social ties seem to encourage further collaboration and professional development. As conditions for outcomes of effective collaborative learning Snoek (2007) signaled the overall importance of trust and a professional attitude, incorporating commitment to school organization, and a collective responsibility.

To summarize, PD programs need to stimulate collaborative learning and knowledge building in school context, preferably with strategies that stimulate observation of colleagues and sharing of practice, and preferably in a context that stimulates trust and commitment. A strategy for this could possibly be peer coaching. In the next sections the following aspects will be discussed: 
mentoring and peer coaching, study groups and video study clubs as special forms of peer coaching, and the role of the peer coach.

\section{Peer mentoring and peer coaching}

Peer coworkers are one of the most mentioned sources for work-related developmental support i.e. that which has helped you learn, grow and develop on the job (Allen \& Finkelstein, 2003). McDougall and Beattie (1997) reported the main organizational benefit identified across various models of peer mentoring and coaching was that of "synergy and cross-fertilization of ideas and experience" (p. 433) and that they all demonstrated the power of informal learning and demonstrated significant learning yields for the organization and individuals. According to these researchers types of learning behaviors during peer mentoring and coaching may include:

a. communication behaviors, such as discussion, listening, and questioning;

b. affective behaviors, such as helping, supporting, encouraging, reaffirming, understanding and calming;

c. cognitive behaviors, such as explaining, advising, accessing and sharing of information, exchanging, and trying ideas with partner;

d. learning behaviors, such as reflecting, taking on different perspectives, and modeling;

e. challenging behaviors, such as criticizing constructively, disagreeing, and providing discipline for progress.

In the literature many models of coaching can be found that represent a range of staff development practices. They differ from each other in: the relationship between observer and observed (manager or peer), the differences in expertise (expert or peer), the primary objective of the observation (evaluation or development), the focus of the teaching and learning process (pedagogical or subject oriented, teacher or student) and in who controls the focus of the dialogue (the observer or the observed) (Becta, 2009; Showers \& Joyce, 1996).

Relationships at work with a focus on development and collaborative workplace learning can be put into two main categories: peer mentoring and peer coaching (Conley, Bas-Isaac \& Scull, 1995). According to these researchers, the difference between both is the relationship between coach and coachee. Peer mentoring involves a hierarchical relationship between senior teachers and junior teachers; in contrast, peer coaching involves a mutual consultation 
between teachers of equal status. It is often assumed that all coaching relationships are hierarchical and that the observer is the coach. This is not necessarily the case. The Becta report (2009) refers to the National Framework for Mentoring and Coaching, which distinguishes between mentoring (a structured, sustained process for supporting professional learners through significant career transitions), coaching (a structured, sustained process for enabling the development of a specific aspect of a professional learner's practice) and collaborative coaching (a structured, sustained process between two or more professional learners to enable them to embed new knowledge and skills from specialist sources in day-to-day practice). These models differ on aspects as relation and goal of collaboration.

Mentoring seems to restrict teacher learning to a novitiate activity where the experts have a role of teacher, facilitator or coach. However, not only novices in the workplace learn and have to learn. People teach each other in their daily work across the traditional workplace boundaries of age, experience and status (Fuller \& Unwin, 2002). Old-timers guide beginners in some activities (for instance classroom management), while new-comers may guide experts in other activities (for instance using ICT in classrooms).

According to Fuller and Unwin, forms of collaborative learning are relevant to all types of employees and workplaces, and organizations need to find ways of encouraging people to share their expertise. The model of collaborative coaching offers ample opportunities to this and may stimulate teachers to participate due to its non-hierarchical, more democratic nature, and the character of reciprocal learning. The collaborative coaching approach - or 'peer coaching' as it is called in this study - makes it possible for both the teacher and the observer to regard themselves as learners. The explicit and primary purpose of the relationship is to service both parties' learning. The power of peer influence of peer coaching has long been noted and advocated in literature and have increasingly highlighted the vital horizontal communication link. In contrast to mentoring, peer coaching is a mutual and reciprocal developmental and learning relationship in the workplace of two or more people of equal or similar status or who perceive themselves as equals (Parker, Hall \& Kram, 2008).

There is growing evidence that peer coaching can be valuable for professional learning (Brouwer, 2009; Bruce \& Ross, 2008; Engelen, 2002; General Teaching Counsel for England [GTCE], 2005; Murray, Ma, \& Mazur, 2009; Showers \& 
Joyce, 1996; Zwart, 2007). Peer coaching had effects on participating teachers in changing and improving teacher performances, student results, and appreciation of coaching (Kohler et al., 1997). Having studied peer coaching of experienced teachers in higher education, Huston and Weaver (2008) reported that peer coaching has the potential to meet the needs of mid-career and senior faculty members. They recommend the creation of peer coaching programs:

"...to engage experienced faculty members in problem-based, contextualized opportunities to reflect on teaching and learning. When faculty members have an opportunity to voluntarily participate in confidential, trusting partnerships with equally experienced colleagues, conversation is focused on problems faced by the participants in the here-and-now. Experienced faculty members know that generalized solutions do not fit specialized problems; thus the ability to investigate solutions to selected problems cooperatively increases the probability that teaching will improve. Furthermore, these conversations provide a safe opportunity for experienced faculty to question assumptions, share problems, and address emerging issues generated by a changing classroom landscape." (Huston \& Weaver, 2008, p. 17).

\section{Study groups}

Different researchers refer to Japan and China as countries that seem to have done most to put effective principles for PD into widespread practice over a long period (Chung Wei, Andrée, \& Darling-Hammond, 2009; Lu, 2010; Schwille, Dembélé, \& Schubert, 2007). They refer to the so-called 'lesson-studygroups' or 'the research lesson', in which groups of 4 to 6 teachers observe one another's classrooms and work together to refine individual lessons, expediting the spread of best practices throughout the school. Every teacher periodically prepares a 'best' lesson that demonstrates strategies to achieve a specific goal, for example, students becoming active problem solvers. A group of teachers observes while the lesson is taught, usually documenting the lesson in a number of ways, including videotapes, audiotapes, and narrative or checklist observations that focus on areas of interest to the instructing teacher (for example, how many students volunteered their own ideas). Afterwards, the teachers - sometimes with outside educators - discuss the lesson's strengths and limitations, ask questions, and make suggestions for improvement. Sometimes, the revised lesson is given by another teacher a few days later and observed again. The lesson studies enable teachers to refine individual lessons, consult with other teachers and receive feedback based on colleagues' observations of their classroom practice, reflect on their own practice, learn new 
content and approaches, and build a culture that emphasizes continual improvement and collaboration (Chung Wei et al., 2009). The most important features of this form of peer coaching are:

- The importance of teachers working together. Lesson study is teamwork, mostly school-based.

- The use of the participants' own classrooms as laboratories for PD. Teachers learn most from working and studying their own classrooms.

- The 'multi-focal' nature of lesson study. On the surface, lesson study appears to be a very limited curriculum development activity, focusing on a narrow slice of target lessons. In fact, in these lesson studies teachers often discuss and investigate long-term, central goals of schooling.

- Inquiry as a means of professional development. Lesson study encompasses also curriculum development, lesson planning and practitioner research. One of the main foci of lesson study is the discussion by teams of teachers on what they have learned or are likely to learn about student learning.

- Cumulative impact through writing and dissemination of reports. Practicing teachers write (good) project reports, and this seems to be one of the main reasons for its presumed cumulative impact. At the start of a new lesson study project, teams consult the reports of other teams who have already done closely related projects. These reports are even published and sold at bookstores.

- Balance between teacher initiative and advice and guidance of an external expert. While the process of lesson study is bottom-up in relying primarily on teachers' initiative and leadership, external experts do provide advice. Teacher educators and other experts are invited to participate in lesson study deliberations at certain points in order to contribute this outsider perspective.

- The public nature of teaching. Peer observations give opportunities for external experts to discuss strengths and weaknesses of what they have observed.

According to these researchers, a lesson study group approach seems one of the most promising strategies for PD programs based on collaborative learning of teachers.

Darling-Hammond and Richardson (2009) identified a related effective study group strategy, which has similarities with the Japanese study group approach sketched above, namely the Integrated Mathematics Assessment (IMA) approach. Teachers in this program had external input through a five-day summer course, after which they met once every two weeks throughout the year to discuss their 
practices and to solve problems. They looked at samples of student work or videotapes of students involved in problem solving; they learned to assess student motivation, and to develop specific pedagogies that included how to lead whole-class discussions, to assess student work with rubrics, and to create assessment tools of their own which they shared with one another.

Teacher study groups are as diverse as the teachers who participate in them. Study groups may or may not use different types of video material: recordings of teachers' own teaching and/or of other teachers' teaching. It can contain more informal conversations about teaching or it can be highly structured inquiry groups, with detailed expectations for participants. Most study groups likely fall somewhere between these two extremes, with colleagues getting together regularly to discuss practice, view videos, and support each other as they test out new strategies in their classrooms.

\section{A video study club}

A video study group, using video recordings to study classroom practice, is a particular kind of study group. From the 1990s onwards, video recordings began to be used by researchers and teacher educators in the context of video clubs (Brouwer, 2007, 2009; Sherin, 2004; Sherin \& van Es, 2009; Thomas, Wineburg, Grossman, Oddmund, \& Woolworth, 1998; Tochon, 1999). “What is surprising, however, is that despite extensiveness, the use of video in teacher education does not always reflect an understanding of precisely what it is about video that might provide support for teacher learning" (Sherin, 2004, p. 10). While most reported cases of video clubs involved a teacher educator or researcher who served as facilitator, there are also cases in which a teacher serves this function for the group or in which teachers take turn performing the role of peer coach (Zwart, 2007). Recent research suggested that video clubs are contributing to effective PD (Borko, Jacobs, Eiteljorg, \& Pittman, 2008; Brouwer 2009; Sherin \& Han, 2004; Sherin \& van Es, 2009; Tochon, 1999; van Es \& Sherin, 2005; van Es, 2006). In paragraph 3.3.2 we will discuss the use of video recordings and video clubs for PD in more detail.

\section{The role of the peer coach}

In the discourse between teachers in schools the overt recognition and naming of teaching assumptions is mostly missing, often assumptions are raised but never identified and examined for validity. Instead the discussion can easily 
become a dialectic pull masked as polite conversations between those with opposing beliefs. To create a different intellectual dynamic there needs to be an intervention that is bold enough to explicitly identify AND challenge unrecognized beliefs yet sets a comfortable climate that is different from the usual professional discourse (Qualters, 2009). Peer coaching aims to create an environment to explicitly identify, state, and explore unexamined assumptions in a non-judgmental, non-threatening manner while allowing participants to share techniques and ideas in a communal setting. It can be a meta-cognitive approach that forces participants to explore practice from an internal perspective, not merely assess if there is a superior practice. Peer coaching can help teachers pay attention to why they are doing and thinking the way the way they are doing and thinking, and help them uncover factors that influence actions, feelings, and believes.

Showers and Joyce (1980), in the field of education, first proposed the concept of peer coaching as an on-site method of staff development. Later, based on years of experience, Showers and Joyce (1996) presented a number of principles for effective teacher peer coaching:

a. There must be collective and supportive agreement to the PD process. If possible, all teachers in the school must agree to be members of peer coaching study teams.

b. Secondly, the essence of the coaching transaction is not to offer advice to their peer. Rather, the collaborative learning is gained through observation, sharing, and reflection.

c. Thirdly, the coaching relation is reciprocal.

d. Lastly, the planning process is collaborative and the feedback is nonevaluative. They signaled problems correlating with vocal feedback and giving evaluations as coaching components. To become a real study group, vocal feedback should be omitted:

"When teachers try to give one another feedback, collaborative activity tends to disintegrate. Peer coaches told us they found themselves slipping into 'supervisory, evaluative comments' despite their intentions to avoid them. Teachers shared with us that they expected 'first the good news, then the bad' because of their past experiences with clinical supervision and admitted they often pressured their coaches to go beyond technical feedback and give them 'the real scoop' to the extent that feedback was evaluative" (Showers \& Joyce, 1996, p. 15). 
Similarly, a classical learner centred approach emphasizes empathy (understanding), unconditional positive regard (warmth), genuineness (selfawareness), non-directivity (learner-initiated and learner-regulated activities) and the encouragement of critical thinking (Cornelius-White, 2007, p. 113). These are all competences also needed for reciprocal peer coaching. However, it is important to realize these are also competences which are not easy to apply.

Siegers (2002) described different roles in which coaches can stimulate reflection with their peers. He made a distinction between peer coaching aimed at advising and peer coaching aimed at reflection. The coach' role as adviser is in line with the traditional expert role of the teacher. The coach provides feedback on the performances of the teacher, gives advice and hints, and seeks in collaboration with the coachee for possible solutions. The criticism on these coach strategies is that their function is limited, the teacher as a person easily remains invisible, and only observable professional performances are being discussed. However, the personality of teachers and their ideas and views on the world, on the schools, on their role as teachers and on learning, strongly determine the way in which they perform their professional role. Peer coaching aimed at advising will create a limited learning process, because teachers are not stimulated to become reflective practitioners who inquire and reflect critically on their own performances, attitudes, and values. Peer coaching aimed at reflection aims at self-directed learning, analyzing relevant aspects both in the professional practice and in own identity as a teacher, and how to deal with these. The peer coach acts predominantly as interviewer, who stimulates the teacher into in-depth reflections.

Similarly, Cochran-Smith and Lytle (2001) promoted an inquiry as stance on teaching that is critical and transformative. The metaphor stance is used "to capture the ways we stand, the ways we see, and the lenses we see through as educators" (Cochran-Smith $\mathcal{E}$ Lytle, 2001. p. 51). In the process of knowledge production and systematic inquiry described by these authors, teachers use questions as lenses or tools with which to see and interrogate practice. Examples of such questions might be: Who am I as a teacher? What am I trying to achieve and what assumptions am I making? What sense are my students making of my teaching/their learning activities? How do my efforts as an individual relate to those of others and to wider concerns and agendas for change? 
It can be concluded that effective peer coaching is based on competencies which may have to be trained in teachers. Teachers are well educated in being experts and giving advice, the traditional role of teachers. With reciprocal peer coaching teachers need other competencies to help their colleagues to reflect on their own practice. Training could prepare them for this new role. Designing effective collaborative learning environments involves the development of norms that encourage cooperation and learning and a sense of trust between participants. Important elements for all peer coaching programs are long-term collaboration; a strong focus on learning and improvement of own practice; an emphasis on interaction and collegiality among participants; a non-hierarchical peer coach relation; mutual support during the phase of analysis and adaptation; and feedback which is objective and non-evaluative; an inquiry-oriented approach; and a combination between teacher initiative and ownership of learning goals and outsider advice and guidance.

Conclusions for the design of the PD program:

- Collaborative learning in the form of study groups and reciprocal peer coaching can stimulate the development of teachers at the workplace. By observation in each other's classroom, by sharing video recordings of own practice, and by structuring professional dialogues, teachers are stimulated to share experiences, build a common vocabulary and a shared knowledge base.

- This study defines peer coaching as a non-hierarchical, collaborative, nonevaluative and reciprocal process among colleagues in the workplace where two or more teachers talk and reflect on their classroom practice together with the intention of supporting each other to investigate, improve and/or expand their professional performances and approaches to teaching. This activity is detached from staff appraisal. Teachers share practice and study self-selected aspects of practice, in which the learning goals are primarily set by themselves. Teachers reflect together on the impact of their teaching on student outcomes (in learning results and/or behavior).

- The configuration of activities can differ from peer group to peer group and from situation to situation, but it must contain the following basic activities in order to qualify as reciprocal peer coaching:

- regular dialogues on own performances and basic assumptions as a teacher;

- study of own practice and use of video feedback or classroom observations as a starting point for reflection and inquiries on student learning;

- reciprocal peer coaching in subgroups is based on equality and trust; 
- the teacher in the role of learner/coachee selects his/her individual learning goals and thus determines the focus of the coaching. The coach focuses on support and in-depth questioning, and not on giving evaluative feedback and own assessments.

- Effective peer coaching is based on competences necessary to stimulate indepth reflection on own practice of colleagues. These competences may have to be trained.

- Important is a collective and supportive agreement in the school for the PD program. To stimulate a community of practice, teachers collaborate in heterogeneous groups. Thus, participants may differ in years of experience, subject taught, team, position in the school. The PD program should also encompass (where possible) collaboration of (middle) managers.

- The PD design may include forms of external input, but these should serve teacher needs and initiatives in the school.

\subsubsection{Focus on own practice with the help of video feedback}

\section{Video as an artefact of practice stimulating reflective practice}

Professional development should start and end with the needs and the performance of the participants in their own school practice. Reflecting on, and studying and experimenting in own practice are the pivot of effective PD activities (see Chapter 2). In this paragraph, we discuss the importance of feedback and how video recording may be helpful in providing feedback for teacher learning.

Video recordings have a unique capability to capture the richness and complexity of elusive classroom practice (Borko, Jacobs, Eiteljorg \& Pittman, 2008). Video allows teachers a form of 'replay' of own experience or a vivid 'second-handexperience' while observing the video of a colleague. Reflection with video is attributed the potential to provide teachers with enough information to be 'inside' an event and offers unique opportunities for activating prior knowledge and experience. It helps learners to reflect on complex connections between video of colleagues and their own teaching, and video appeared to be motivating teachers (Sherin, 2004; Borko et al., 2008). Video is thought to facilitate learner "experiences of immersion, resonance, authenticity, and motivation." (Seidel et al., 2011, p. 260). Video of own practice can function as feedback medium and as artefacts of practice to share with colleagues and to study own practice. Video excerpts can be stopped and replayed to focus conversations on important features. Video can support collaborative learning focused on reflection, analysis, 
and consideration of alternative pedagogical strategies in the context of a shared common experience (Brophy, 2004; Borko et al.; 2008, Sherin \& Han, 2004; Sherin \& van Es, 2009). There are both empirical and theoretical arguments for using video recordings from participants' own classroom to stimulate teacher learning in the program. Video makes teachers' own classroom accessible in a way that other mediums simply cannot, and therefore has the potential to be a powerful catalyst for productive reflection, change and improvement. Researchers found that over time in PD programs using video, important changes occurred in both what the teachers discussed and how the topics were addressed. For example, individual viewing and analysing resulted in specific reflection on own teaching and shifted the focus from classroom management to instruction (Rosaen, Lundeberg, Cooper, Fritzen, \& Terpstra, 2008), participants of video clubs became engaged in increasingly reflective and productive full-group conversations (Borko et al., 2008), and participants' reflections shifted from a primary focus on the teachers' decisions and actions to increased attention on students and their mathematical thinking (Sherin, 2004; Sherin \& Han, 2004; Sherin \& van Es, 2009).

\section{Feedback and learning}

Feedback loops are essential for every learning process. In school practice teachers receive all kind of feedback, for example, through student reactions, (informal) comments of colleagues, and formal assessment procedures. Experiences and especially students' reactions are an influential form of feedback. This form of feedback feeds the spontaneous and implicit learning of teachers at the workplace in particular.

On their part, school managers have introduced assessments as forms of feedback for intentional professional learning. Too often, these assessment procedures are restricted to accountability and accordingly do not provide rich formative feedback to scaffold development. In this study, we focus on formative feedback, defined as information communicated to the learner that is intended to modify teacher's thinking or behavior to "enhance learning, performance of both, engendering the formation of accurate, targeted conceptualizations and skills" (Shute, 2008, p. 175). According to Shute, formative feedback should be nonevaluative, supportive, timely, and specific. Useful feedback depends on three things: motive (the learner needs it), opportunity (the learner receives it in time), and means (the learner is able and willing to use it). 
Feedback is one of the most powerful influences on learning and achievement, but its impact can be either positive or negative. In a review study Hattie and Timperley (2007) distinguished between four levels of feedback, with a differential effect on learning. These levels are feedback on the task, feedback about the processing of the task, about self-regulation, and about the 'self'. They showed that in student learning, feedback on tasks is most effective when it aids in building cues and information regarding erroneous hypothesis and ideas, and then leads to the development of more effective and efficient strategies for processing and understanding the material. In contrast, feedback at the self or personal level - especially simple non-specific forms of praise like 'well done' or 'good girl' - is rarely effective (Hattie \& Timperley, 2007; Shute 2008). The lack of specificity can be one reason for the sometimes decreasing learning effect of praise that these researchers noticed in their review studies.

Both positive feedback (showing support, encouragement or appreciation, and success) and negative feedback (showing disapproval and failure) can enhance learning. However, frequent use of negative feedback can be ineffective and even damaging because of the threat to the learner's self esteem and self efficacy. Interesting is that Hattie and Timperley described that when learners are committed to a goal, they are likely to learn as a function of positive feedback. When learners are forced to do tasks, they are more likely to learn as a result of well-balanced negative feedback. Both positive and negative feedback can have a learning enhancing effect, as long as they provide specific information about the accuracy of particular responses or behaviors (Shute, 2008). "Feedback is information with which a learner can confirm, add to, overwrite, tune, or restructure information in memory, whether that information is domain knowledge, metacognitive knowledge, beliefs about self and tasks, or cognitive tactics and strategies" (Butler \& Winne, 1995, p. 275).

Hattie $(2005,2009)$ performed meta-analyses in search of the most effective influences on learning outcomes in students. Hattie found that providing teachers with formative evaluations was one of the most effective strategies to enhance not only the learning of the teachers themselves, but also to enhance the learning of their students. Neither initial teacher training, nor teacher's profound subject knowledge were most crucial for student outcomes. Feedback loops which stimulate teachers to reflect on their own practice were the most important instead. Effective feedback loops to teachers should not merely provide 
information on learning results of students (How are my students performing?), but should also help teachers to relate student performance to their own actions and competences (How does my performance influence students?).

Video recordings may offer an ideal opportunity for that kind of classroombased feedback. Teachers can study videotapes and reflect on student learning and classroom interactions. By using video feedback, PD strategies build on bridging the gap between more implicit learning processes through direct personal participation and more intentional learning processes through reflection. Video feedback provides possibilities for self-observation and study of own practice. It creates opportunities for collaborative reflection with colleagues, and for viewing and analyzing again and again specific classroom interactions. Furthermore, with the help of recordings the teacher can analyze classroom interactions from different perspectives and thus become a student in his own classroom.

\section{Video feedback and video study groups}

In a review study on video feedback, Fukkink, Trienekens and Kramer (2010) concluded that video feedback is applied in different training programs in order to improve the interaction skills of a broad group of professionals. Their meta-analysis showed that video feedback is effective for improving professionals' key interaction skills. What makes the video feedback method unique is that it allows course participants to look at themselves 'from a distance' and 'with space for reflection', thereby giving them a realistic picture of their own behavior and skills. It offers possibilities for focusing on verbal aspects (i.e., the content of what is being said), paralingual aspects (i.e., intonation, speaking pace, and volume) and non-verbal aspects (e.g., body posture, eye contact, use of gestures). Attention to each of these aspects is important because they all play a significant role in the various communication skills required in professional practice, including receptive skills (e.g., asking open questions, looking at the other person, use of silences), informative skills (e.g., explaining things in a comprehensible way, speaking calmly) and relational skills (e.g., asking about the other's experiences and displaying empathy).

Another use of video feedback is the 'video self-confrontation' approach, its function was to view oneself, with other instructional elements playing only a minor role. According to Fukkink et al. (2010) the emphasis in today's training 
programs is no longer on confronting participants with images of themselves. Instead, 'positive self-modeling' approaches focus solely or primarily on successful interactions by the participant in order to reinforce effective behavior and to support a positive self-image of the participant. This kind of positive empowerment is pedagogically preferable because focusing on successful performances boosts self-efficacy and leads to more frequent display of identified successful behavior. In contrast, educational studies into the effects of feedback in general show that feedback that could erode someone's sense of self-worth is not very effective (Hattie \& Timperley, 2007).

It is equally important that feedback should be specific, because the specificity of the feedback helps professionals to discover the key elements of their behavior and to evaluate their performance. This implies, that video feedback becomes richer with in-depth analysis in collaborative settings in which peers help each other to notice key elements and 'to see what there is to see' (van Es \& Sherin, 2002).

Video recordings of own practice give ample opportunities for different forms of feedback. It gives information and creates opportunities for analysis by the practitioners themselves (self feedback), for studying student behavior (broadening the student feedback), for peer feedback in the form of collaborative inquiry into recorded classroom practices, and for input of external expertise by studying and discussing recordings with experts on the studied issue (expert feedback).

In the last decennium, with significant improvements in video technology, there is a surge of interest in using video technology to scaffold (student) teacher learning. In initial training programs, for example, video is used for applications such as microteaching and new approaches such as online instructional video or video supported instruction (Blijleven, 2005; Brophy, 2004; Brouwer, 2007; van den Berg, 2001). Video recordings are used for portfolio and assessment (Frederiksen, Sipusic, Sherin, \& Wolfe, 1998), as a tool to extend and augment (student) teacher self-reflection and to analyze own teaching individually or in video study groups (Borko, Jacobs, Eiteljorg, \& Pittman, 2008; Brouwer, 2007, 2009; Dicks, 2005; Sherin \& Han, 2004; Sherin \& van Es, 2009; Tochon, 1999; van Es, 2006; van Es \& Sherin, 2002, 2005; Yusko, 2008). 
Video clubs refer to meetings in which groups of teachers watch and discuss excerpts of videotapes from their own classrooms. Advocates and organizers of video clubs suggest that video clubs offer teachers the opportunity to examine teaching and learning in new ways and have the potential to foster the learning called for by reform. Video study clubs are designed to engage teachers as a community and in collaborative reflection. In addition, video clubs redefine practice by engaging teachers in an activity that is very different from their usual classroom practices. During video clubs, teachers do not have to respond immediately to the situation that they view. Thus, unlike teaching, video clubs offer time for reflection rather than immediate action. Feedback and reflection takes place in the form of repeated viewings of an excerpt of classroom interaction and through extensive analysis of this interaction.

Video clubs differ in the choice of the issue to be studied. Sometimes, a facilitator selected relevant fragments to study specific pedagogical problems (Borko et al., 2008), or the group of participating teachers selected a specific issue that it wanted to examine (Tochon, 1999), or the individual teacher whose video was being viewed chose the topic for the dialogue (Sipusic, 1994). In most designs, the focus was on analysis and the selected video excerpts were not intended to illustrate exemplary teaching or a particular model that participants were expected to emulate.

In a video club, teachers watch video clips from the classroom of one of the participants and discuss the contents of the clips in a variety of ways. Research showed that teachers shifted their primary focus away from the performance of the teacher and toward the performances of their students (Sherin, \& Han, 2004). Teachers developed increasingly complex ways to examine student ideas (Sherin, 2004). Teachers moved from an evaluative to an interpretive approach in their analysis of video clip content (Thomas et al., 1998). Viewing footage from their own classrooms allowed the teachers to see what they were doing well and to identify areas for improvement. Observing their colleagues in action, also helped the participants learn new pedagogical strategies, better appreciate their students' capacities for mathematical reasoning, and realize that they all struggle with similar issues (Borko et al., 2008). Sherin and Han (2004) referred to studies showing that those outcomes also extend to the classroom as teachers subsequently used pedagogical strategies that they had viewed initially in the video club. 
Teachers used video not as a resource for evaluating each other's practices, but rather as a resource for trying to better understand the process of teaching and learning. They began to focus on different aspects of classroom interactions and developed new approaches to analyzing both pedagogy and student conceptions. Sherin and Han (2004), however, also reported a number of research studies showing that teachers tend to view video with a focus on the teacher in the video and with an evaluative stance towards what the teacher in the video is doing. They concluded: "we suspect that in any video club teachers would be likely to begin, as in this case, with a focus on pedagogy and on alternative pedagogical strategies that the teacher in the video might have used. However, the question remains as to whether other groups of teachers would begin to focus on student conceptions and to connect their analyses of pedagogy and student thinking as the teachers in this study came to do." (Sherin \& Han, 2004, p. 179).

Video feedback offers opportunities to share and study experiences with others. With the help of video recordings, professional dialogues are less troubled by personally biased memories and subjective interpretations of what has happened. The cooperating teachers can check their interpretations with the 'objective' recorded reality on video. Through dialogue with the help of video feedback they can share each other's practices, build a mutual language and understanding, and thus build a learning community. The use of video provides opportunities for collaboration in assessing own practice. This may be critical because individuals tend to regard themselves as proficient, and honest/objective self-evaluation is difficult. Allowing teachers to view and discuss their teaching together provides a fruitful way to discover what influenced teachers' actions. Although video provides observable evidence of a teacher's instructional decisions, it is necessary to connect 'captured practice' to teacher's intents, feelings and beliefs. While video feedback can help to study verbal and non-verbal behavior, peer coaching focusing on in-depth questioning could provide input for reflections on underlying tacit assumptions and values. This also opens opportunities for professionals to break out of their 'public loneliness', in which teachers are always in contact with others (students), but are functioning alone as a professional.

The use of video to record specific teaching practices followed by review for critical analysis is not new in itself. However, the use of this tool to allow educational practitioners to construct new knowledge is uncommon. "With a view to 
harmonize theory and practice, meetings of a video study group take practice rather than theory as their point of departure" (Tochon, 1999, p. 64). Additional research to explore the way different aspects of the video club environment influence and support teacher learning is needed (Sherin \& Han, 2004).

Conclusions for the design of the PD program:

- PD programs can use video recordings of own practice to provide rich feedback to teachers. With the help of video feedback, teachers can monitor the results of their teaching. Video is a powerful reflective tool; a mirror with a memory. It allows the participants to look at themselves. PD programs can enhance this experience by structuring discussions with peers. Video feedback offers in PD programs possibilities to share practice with colleagues and to learn from practices of others.

- A crucial feature of collaborative learning is a sense of security and trust between participants. This may be enhanced by asking the teacher whose video recordings are going to be watched to choose the topic for reflection and dialogue, and by taking turns in coaching and being coached.

- To stimulate positive empowerment, a PD program should help participants to create awareness of their successful classroom interactions. Positive feedback boosts self-efficacy and leads to the behavior being displayed more frequently.

- Video recordings should be analyzed precisely to provide specific video feedback. The specificity of the feedback helps professionals to notice the key elements of their behavior and their interaction with students, and to evaluate the impact on students of their performance.

\subsubsection{Teacher ownership of learning goals}

PD currently exists in a two-tiered system (Sparks, 2004). The first tier focuses on creating a professional community, while the second depends on scripts and mandates for teachers. Sparks observed that low-performing schools typically implemented tier-two type professional development programs that required teachers to use teaching strategies in a tightly structured and regimented format, while high-performing schools offered teachers some input regarding their PD experiences and allowed flexibility in the classroom. Keay and Lloyd (2009) noted similar differences between views on ownership of PD goals. They pointed out disagreements on the meaning of the terms 'profession', 'professionalism' and 'professionalization'. They recognized that in the differing definitions references to struggles over control, knowledge and 
ownership are embedded. The basic vision on PD is still often a top-down focus, in which goals for PD are mainly determined by school management.

A more promising starting point for a PD program seems to be PD programs in which teachers focus on own concerns in professional practice. Learning from real-life experiences at work is ideally driven by the learner's motivation and preference (Poell, Yorks, \& Marsick, 2009). In a PD program, the ownership of learning goals should be with the teachers themselves for reasons of effectiveness as well as for reasons of emancipation. A number of studies underlined this importance of such an approach in which teachers themselves determine 'what' and 'how' they want to learn (Black, 2005; Cordingley et al., 2003, 2005a; Frietman, Kennis, \& Hövels, 2010; Runhaar \& Loeffen, 2009; Waslander, 2007).

As the General Teaching Counsel for England (GTCE, 2007) put it: "The more influence teachers have over their professional development - and especially in tailoring CPD to meet their needs - the more likely they are to find it effective. More generally, the research lends support to the importance of designing PD that holds teachers' professionalism and individual expertise as a central value." (p. 5). In over half the studies about PD that the GTCE reviewed (GTCE, 2005) it appeared that teachers took local ownership by taking on themselves at least some aspects of the PD. However, the Council (2005) concluded that most PD programs still only partially recognized the ownership of teachers of PD. They advised the following characteristics of PD programs to help teachers to more ownership (GTCE, 2005). Firstly, in PD programs collaborative teachers themselves need to identify their starting points for the PD and need to plan their own pace and scope, giving teachers the opportunity for local leadership. Secondly, a majority of collaborative PD programs need to be carefully constructed to give teachers choice within a broad area of curriculum pedagogy. Thirdly, ownership will be stimulated by making every effort in the program to make teachers feel at home with the PD program, e.g. introducing new strategies in stages, asking the teachers which change strategies they would feel most comfortable with and which areas they feel they need support in as the PD program unfolds.

Encouraging teachers to take responsibility for their professional learning will empower them to make changes that they deem necessary in their practice, rather than imposing changes from above (Black, 2005). Providing teachers with the autonomy to exercise professional judgment about their professional needs 
may be a more efficient means to an end, as autonomy can provide teachers with the ability to choose topics fitting in with their concerns and to identify the best solution to the problem in their context (Bonner, 2006). When teachers are empowered to create their own professional growth plan, their passion for teaching and for improving the lives of their students is greatly enhanced (Colbert, Brown, Choi, \& Thomas, 2008; Sparks, 2004).

Timperley et al. (2007) reported a study in which dissonance was created by exposing the tensions between the current research literature on science teaching and learning, and the teachers' existing beliefs. This led most of the teachers to rethink their beliefs about teaching science and to make substantive changes to their practice. The process described in this study illustrated several features of dissonance as an incentive for learning. The learning process involved active engagement and ownership of change because the teachers did not simply implement an approach to science teaching, they designed a curriculum that was consistent with their changed beliefs. Creating dissonance, however, as we saw in Chapter 2, is a risky business, because for other teachers "the ideas from research conflicted with their personal views to such an extent that they were unable to incorporate them into their belief system" (Timperley et al., 2007, p. 120). A high level of input of teachers in shaping the new practice makes PD programs successful. Exploring and challenging teachers' theories of action can deepen their understanding of new practices, promote greater 'buy-in', and help to build their own new skills on the basis of ownership rooted in understanding.

A challenge for peers is to respect the ownership of learning goals and inquiry of their colleague. Peers should support the teacher's self-evaluation with indepth questioning without imposing own insights and beliefs. Ownership in the PD program of this study includes responsibility for ownership in both roles in peer coaching: in the 'role of learner' whose classroom practice is being studied and in the 'role of peer coach' who facilitates the learning of his colleague. Teachers who both take ownership of their professional growth and support the development of their peers contribute uniquely to the professional community (Grossman, Wineburg, \& Woolworth, 2001).

The National Research Council in the U.S. (Bransford, et al., 2000) described four learning environments for teacher learning, namely learner-centered, knowledge-centered, assessment-centered and community-centered. A PD program fitted for a learner-centered and a community-centered professional 
learning environment seemed most promising. This kind of program provides opportunities for collaborative learning and incorporates teacher ownership of learning goals. Such programs are based on the assumption that individuals can best judge their own learning needs, are substantially capable of self-direction and self-initiated learning, and are motivated to learn when they initiate and plan their own learning activities (Seashore Louis, 2001).

Conclusions for the design of the PD program:

This study focuses on teachers as owners of their professional development. In this study professional development is understood as a process in which professionals develop themselves (actively), and are not being developed by others (passively). As responsible professionals, teachers steer their own development in dialogue with each other and with the environment (students, parents, school context, and school government).

- In this study, the term 'ownership' refers to 'owning' and to 'taking agency' by the teachers of own PD goals and activities. Ownership in a peer coaching program includes responsibility for ownership in both roles, in the role of 'learner' whose classroom practice is studied, and in the role of 'peer coach' that facilitates the learning of colleagues.

- A PD program needs to acknowledge the differences between teachers in concerns, learning goals, starting points, and learning pace, and the program should provide ample learning opportunities for all participants accordingly.

- A PD program needs to challenge teachers to reflect on their own practice and to explore their own learning needs and define individual learning goals within the context of the school.

- As we already noticed in Chapter 2, a PD program should provide opportunities and structures for deep professional dialogues focusing not only on performance but also on underlying assumptions and values. Sharing practice (e.g. classroom observation and video feedback) enables colleagues to understand each other's practice, and to connect with the needs and concerns of each other.

- Peer coaches need to respect the prerequisite of ownership and to behave accordingly. To keep individual teachers in control of their own learning goals, professional dialogues in reciprocal peer coach programs may need structuring and defining of roles. 


\subsubsection{Focus on inquiry stance and on outcomes in classroom}

In the last decades many researchers pointed to the importance of reflection and inquiry in helping to make sense of the complexities of teaching. Researchers have argued that these should be a standard professional disposition for all teachers (Bolhuis, 2009b; Feiman-Nemser, 1990; Schön, 1983, 1987). Zeichner and Liston (1996) stated that reflection is an essential component for bringing understanding to the complex nature of classrooms. Guskey (2000) noted the importance of the ability of individual teachers to develop skills in rigorous self-analysis focusing on gains for students. In line with this research, increase in autonomy for own professional development and reflection and inquiries in own practice became more important in teacher education and professional development. This movement towards stimulating reflective practice has led to a body of research which focused on the teacher as an inquirer into own practice (Bolhuis, 2009b; Boud et al., 1985; Cochran-Smith \& Lytle, 1999a, 2001, 2009; Korthagen, Kessels, Koster, Lagerwerf, \& Wubbels, 2001; Ponte, 2002; Schön, 1983, 1987; Van Manen, 1991; Zeichner, 2008).

PD programs should nurture an inquiry stance towards teaching as a key to ongoing professional development (Cochran-Smith \& Lytle, 1999a). Teachers, as professionals, need to study the everyday realities of classroom life and the complex processes of working with a diversity of students. Teachers should employ inquiry as a way of knowing about teaching, learning and schooling over the course of their professional lifespan. Inquiry as a stance refers to a long-term and consistent positioning (way of seeing), rather than an activity at a single point in time. "Developing and sustaining an inquiry stance is intended to be a life-long and constant pursuit for new teachers, experienced teachers, and teacher educators alike" (Cochran-Smith, Barnatt, Friedman, \& Pine, 2009, p. 22).

Classroom inquiries make it possible for teachers to produce richly detailed and insightful analyses of own teaching and of outcomes in student learning. It can boost professional development and can make the work of teaching and learning public and open to the critique of a larger community (Cochran-Smith et al., 2009). In classroom inquiries teachers use intentional and systematic ways of gathering and recording information and of documenting experiences, such that inquiry is planned and deliberate, rather than spontaneous (Stenhouse, 1985). In a PD program, teachers may be asked to do inquiries and pay close attention to the data of practice, to study the data in ways that will improve their own 
practice and students' learning, both in the short and the long term. The systematic examination and analysis of students' learning is often interwoven with examination of teacher's own intentions, reactions, decisions and interpretations. Inquiry aligns reflection on own practice with a focus on students and on student outcomes (behavioral or learning outcomes). Classroom inquiry is an effective way to relate student outcomes to own actions as a teacher.

\section{Different forms of practitioner research}

In this study, the teacher as reflective practitioner forms a basic principle for PD (see Chapter 2). Through reflection, teachers participate consciously and creatively in their own professional growth and development (Schön, 1987). Through reflective practice, teachers reinterpret and reframe their experiences from a different perspective (Munby \& Russell, 1990). Reflection is an essential component for understanding the complex nature of classrooms. The focus on reflective practice has led to a body of research which focuses on the teacher as researcher, making classroom into sites for inquiry (Bolhuis, 2009b; CochranSmith \& Lytle, 1999, 2009; Ponte, 2002).

The conceptual umbrella of practitioner research refers to a variety of educational research modes, forms, genres and purposes (Anderson, Herr, \& Nihlen, 2007; Cochran-Smith \& Lytle, 2009; Zeichner \& Noffke, 2001), such as action research, teacher research, practitioner research and practitioner inquiry. Although these stem from different historical and epistemological traditions, they share several common features that distinguish practitioner inquiry from more traditional forms and paradigms of education research (Cochran-Smith \& Lytle, 1999, 2009). These forms aim at improving practice rather than proving as an approach to research. All those forms imply also that practitioners will learn from their research into practice, which is not always the case in other forms of research.

In the field of practice-based research, those involved in practitioner inquiry are bound to engage with both theoretical and practical knowledge, moving easily between the two. What connects all the approaches called 'practitioner research' is the fact that they begin with one problematic situation in practice and an emerging need of a practitioner inquirer to not only better understand but also solve the problem or at least find a better way to cope with it. In all approaches, practitioner research allows the inquirers to reflect deeply on their own actions and results (Groundwater-Smith \& Mockler, 2006). Common features are a 
small distance to the subject studied and a large involvement of the researcher (Kools \& Bolhuis, 2008). The practitioner (e.g., teacher, teacher educator, school administrator) simultaneously takes on the role of researcher, which contrasts with conventional research on teaching and teacher education. Collaboration in the form of joint discussions of methods, data analysis, and writing is a prominent feature of many versions of practitioner inquiry. A key assumption is that those who work in particular contexts have significant knowledge about both what the problems and the questions are, and - through systematic data collection and analysis - how to solve those problems within that particular context (Cochran-Smith \& Lytle, 2009).

However, different terms also refer to different conceptions of practitioner research. There is a long tradition of tension between two contrasting aspirations for practitioner research. One is that teachers should inquire own practice to improve own practice. The other is that teacher researchers are doing practitioner research to contribute to public knowledge about teaching and learning (McLaughlin, McIntyre, \& Black-Hawkins, 2004). The focus of this study joins in with the first view in which the teacher improves own practice by inquiring into it. The goal of this study is to develop and study a PD program that stimulates teachers to study and improve own practice.

In this study, the term 'inquiry' is used for activities in the PD program in which teachers engage in a systematic study of their practice. It includes a range of different forms of study and data sampling. The data collecting methods may include, among others, case studies, empirical, ethnographic, biographical and narrative studies, and the use of various instruments e.g. questionnaires, journals, essays, classroom studies, and oral inquiry processes (Cochran-Smith \& Lytle, 2001).

Inquiry contributes to teachers' better understanding of own professional practice and to their identity as professionals. Reflection and inquiry are done for the purpose of optimizing own practice. Encouraging teachers to investigate their practice will have a positive impact on PD and on innovations of school practice (Black, 2005) and yields teachers both practical knowledge (concerning answers to practical questions and the learning of a systematic approach) and a critical view on their work (Kools \& Bolhuis, 2008). 


\section{Inquiry focused on student learning and outcomes in classroom}

Various researchers have pointed at the importance of focusing on student outcomes in PD (GTCE, 2007; Guskey, 2000; Hattie, 2005, 2009; Wasley \& Hampel, 1997). As a major reason for lack of success of PD programs, Hattie $(2005,2009)$ pointed to the fact that too many PD programs for teachers do not have enhancement of student learning as the contingency of success. Important is the ability of individual teachers to develop skills in rigorous self-analysis focusing on gains for students (Guskey, 2000; Guskey \& Yoon, 2009). In schools that experienced significant gains in student outcomes, teachers and administrators alike were in the habit of asking themselves tough questions that focused specifically on gains for students. They carefully scrutinized their results, took personal responsibility for learning outcomes and constantly searched for new ways to make improvements in their policies and practices. (Wasley \& Hampel, 1997).

All these researchers stressed the importance of an emphasis on student outcomes to guide PD activities. These outcomes should be defined broadly to include a variety of indicators of student achievement, such as assessment results, portfolio evaluations, marks or grades or scores from standardized examinations, and may further include affective and behavioral outcomes, such as student attitudes, attendance rates, dropout statistics, and participation in school activities.

Based on content analyses of purposefully selected inquiries, Cochran-Smith, Barnatt, Friedman and Pine (2009) demonstrated that the quality of inquiries of student-teachers also generally depended on the questions posed, and furthermore on the ways they conceptualized and assessed learning and on their understanding of the recursive nature of the inquiry process.

\section{Inquiry supports teacher learning and school improvement}

In the last decade, several authors have claimed benefits of practitioners' research performed by teachers (Bolhuis, 2009b; Cochran-Smith \& Lytle, 1999, 2009; Kools \& Bolhuis, 2008; Lunenberg, Ponte, \& van de Ven, 2006; McLaughlin, McIntyre, \& Black-Hawkins, 2004; Onstenk, Kallenberg, \& Koster, 2007; Ponte, 2002). Doing practitioner research increases the teachers' professionalism (Kools \& Bolhuis, 2008). Teachers obtain insights and solutions for problems arising from practice, in order to learn how to deal with them in the future (Lunenberg, Ponte, \& van de Ven, 2006). Teacher inquiries have a range of influences on staff, including changes to curriculum and pedagogy as 
well as improved confidence, job satisfaction and professional development (Michalak, 2010). When teachers, individually or collectively, inquire into their own practices, teachers' professional growth and pedagogical activity benefit.

McLaughlin, McIntyre and Black-Hawkins (2004) noted the following positive effects of practitioners engaging in inquiry:

- Through engaging in research, teachers gain a better understanding of their practice and ways to improve it;

- Practitioner research can contribute to the knowledge base of teaching;

- Engaging teachers in inquiry gives teachers an enhanced sense of the students' perspective in the classroom;

- It can give teachers a renewed feeling of pride and excitement about teaching and a revitalized sense of themselves as a teacher by stretching their own intellectual capability, by realizing the importance of their work as a teacher, by reconnecting teachers to their colleagues, by restoring an awareness of professionalism and power in the sense of having a voice and an expanded sense of what teachers can and ought to do.

A number of characteristics of collaborative PD programs have been identified that demonstrated effective teacher learning as an outcome of creating a culture of inquiry. In a PD program, a culture of inquiry supports the use of data to evidence success, to identify strengths and weaknesses, and to measure progress towards goals. A culture of inquiry in PD programs provides teachers with opportunities to discuss learning related to lesson planning, student achievement, and student work. A culture of inquiry is characteristic of effective PD because it implies opportunities to give and receive feedback about teaching practice and student learning (Colbert et al., 2008).

This chapter reflected on the nature and creation of teachers' professional knowledge, which need not only be formal and academic, but can also be the result of experience and reflection of the practitioners themselves. Practitioner inquiries can be seen as knowledge construction in and through praxis in which teachers explore and improve practical situations and interpret their findings and improvements in the light of their educational goals. This conception of professional expertise and professional development leads to recommendations to involve teachers in forms of practitioner inquiries (Loughran, Hamilton, LaBoskey, \& Russell, 2004). In this view, teacher inquiry constitutes a framework for professional learning, which functions as a catalyst for both the 
development and the dissemination of professional knowledge (GroundwaterSmith \& Mockler, 2006; Cochran-Smith \& Lytle, 2009).

Conclusions for the design of the PD program:

- PD needs to help teachers to be reflective practitioners and inquirers of their own practice.

- Inquiry is seen as a spiraling process of purposeful engagement with school practice in a systematic, planned and collaborative way, directed to move to informed actions.

- Inquiry may include a range of different forms of study and data sampling.

- PD programs need to stimulate teachers to focus on outcomes in classroom and on results in students.

\subsubsection{Creating conditions in the school}

Individuals seem to be more self-motivated, self-reliant, and self-directed in setting and reaching goals, and in finding opportunities for learning that aids performance, and their own personal agendas. But the context of organizations culture, structure, processes, practices - plays a key role in enabling or inhibiting the motivation, time, resources, expectations, and rewards for learning (Marsick, 2009). The review studies in PD programs, as described in paragraph 3.2, signaled this importance of favorable conditions in the school. Favorable conditions refer to all kinds of support in the school context, e.g. time to invest in the program, timeslots for meetings, continuing attention and support from managers, a non-threatening and mostly formative structure of the program, and the availability of external expertise. Almost every study on PD underlines this overall importance for the success of the program. For instance, Buczynski and Hansen (2010) noticed that some teachers in their study were transferring knowledge/skills gained in PD to their classrooms, whereas others encountered barriers to implementing PD. These obstacles included limited resources, time constraints, mandated curriculum pacing, language learning, and classroom management issues. Strategies to mitigate these barriers in order to maximize the impact of professional development need to be a priority in PD reform. McLaughlin, McIntyre and Black-Hawkins (2004) recapitulated important conditions for PD programs including practitioner research and inquiry:

- Access to relevant information and resources;

- The support of a group;

- A supportive and critical dialogue;

- Support from school managers; 
- External and internal agents to support PD;

- Necessary time, space and appropriate resources.

Most lists of characteristics of effective professional development mention provision of sufficient time as essential to effective $\mathrm{PD}$, a provision of time that is "well organised, carefully structured, and purposefully directed" (Guskey, 2003 , p. 149). There is coherence between the duration of a specific PD activity and its outcome, duration referring in this case to the total number of hours that participants spend in the activity, as well as the span of time over which the activity takes place. Isolated PD experiences short in duration will not lead to growth in teachers' knowledge and skills or to change in teaching practice (Garet, Porter, Desimone, Birman, \& Yoon, 2001). Ponte (2002) concluded in her study on action research of teachers that teachers need time to learn how to do practitioner research, and that this requires a more intense and more time consuming form of support than is normally spent on professional training. School managers should choose for 'duration' as this leads to PD outcomes and to improvement in school practice (Garet et al., 2001; Ponte, 2002).

Managers can stimulate teachers by creating space for teachers to determine what and how they want to learn and by creating opportunities for meetings and professional dialogues between teachers. Time spent in lengthy conversation and reflection may be deemed too costly. In contrast, Borko (2004) warned that without dialogues that support critical examination of teaching in the teacher's own classroom, the norms that sustain and enhance teacher learning are absent in many PD programs. Showers and Joyce (1996) summed up the following three recommendations for creating beneficial conditions for $P D$ programs based on peer coaching:

- Redesign work. Rather than simply advocating that schools provide time for collaborative planning and problem-solving related to specific plans for change, school management and teachers can address the 'time-issue' collaboratively in team meetings.

- Create timeslots in school schedules for mutual activities.

- Start forming peer coaching teams on the first day of training.

- Provide examples of formats or structures for collaborative planning. They are necessary because many teachers have difficulty in jointly performing an activity they have traditionally done alone. Strategies and 'structured walkthroughs of a planning activity' can allow groups to respond to questions within specific time frames. 
Frietman, Kennis and Hövels (2010) signaled a gap between the readiness of teachers to participate in PD activities and the actual participation and effort teachers put into the activity. Managers who stimulate participation can make the difference and help teachers commit to PD learning. Eraut (2007) also underlined the major influence of managers on workplace learning and culture that extends far beyond their job descriptions. Eraut defined as the role for managers to develop a culture of mutual support and learning, not to provide all the support themselves. Managers need to share this role with experienced workers, and this implies some form of distributed leadership. Elliott (1990) studied the important function of external facilitators in his study on action research. "Internal facilitators, occupying senior management positions but committed and competent actionresearchers, ensured in most schools a measure of institutional support during the project, but this was not maintained after the project terminated. It was as if the internal facilitators required their strategies within schools to be validated by a strong external support team possessing influential sponsorship. They had begun to feel isolated and alienated from other managers in the school. Retrospectively we realised that as with teachers, so we need to work with managers collectively." (Elliott, 1990, p. 25).

Finally, the research by Black (2005) also underlines the necessity of mutual trust between all participants, continuing support, and to celebrate finished project with (interactive) presentations.

\section{To conclude}

For favorable results in PD programs for all participants, the following school context conditions are indispensible:

- Continuing support and attention of the school management for the program.

- Provision of necessary time for participants to participate in the program and of timeslots for meetings.

- Ample duration of the PD program referring to the number of hours as well as the span of time.

- To stimulate a learning environment based on mutual trust between all participants.

- Provision of necessary resources, e.g. ample supply of video cameras.

- Combination of internal and external experts for guidance, counseling and support. 


\subsection{SUMMARY AND RECOMMENDATIONS FOR THE DESIGN OF THE PROGRAM}

In this chapter we studied literature on professional development of teachers. In paragraph 3.2 we surveyed review studies in effective design principles for PD programs. On basis of this study we identified five major principles:

1. Collaborative learning at the workplace, in the form of reciprocal peer coaching.

2. Focus on own practice, with the help of video feedback.

3. Teacher ownership of learning goals.

4. Focus on teacher's inquiry stance and on outcomes in classroom.

5. Creating conditions in the school for PD and the PD program.

In paragraph 3.3 we took a closer look at each of these design principles. Every subparagraph of 3.3 examined in more detail one of the five principles, each subparagraph ending with a summary of design characteristics for the development of the program. In Table 3.2 an overview of our literature study in Chapter 3 is presented. In the overview each design principle is followed by the summary of design characteristics which need to be built into the design of the PD program. Based on these guidelines a PD program was designed and implemented in a school for secondary education and the outcomes were evaluated (Chapter 4, 5 and 6). 
Table 3.2 Five design principles for professional development programs for teachers

\begin{tabular}{|c|c|}
\hline Design principle & Characteristics of the PD program \\
\hline $\begin{array}{l}\text { Collaborative learning at } \\
\text { the workplace } \\
\text { (in the form of reciprocal } \\
\text { peer coaching) }\end{array}$ & $\begin{array}{l}\text { - Collaborative learning in the form of study groups and reciprocal peer coaching. } \\
\text { - By observation in each other's classroom or by sharing video recordings of own practice and by structuring professional } \\
\text { - } \text { Pialogues, teachers are stimulated to share experiences, build a common vocabulary and a shared knowledge base. } \\
\text { underlying assumptions and values. } \\
\text { - Structures for peer coaching as a non-hierarchical, collaborative process in the workplace where two or more teachers } \\
\text { work together with the intention of supporting each other in investigating, improving and/or expanding their } \\
\text { professional performances and approaches to teaching. Teachers share practice (through observation or video } \\
\text { recordings) and study self-selected aspects of practice, in which the learning goals are primarily set by themselves. } \\
\text { Together, teachers think about the impact of their teaching on student outcomes (in learning results and/or behavior). } \\
\text { - The configuration of activities can differ from peer group to peer group and from situation to situation, but it must } \\
\text { contain the following basic activities in order to qualify as reciprocal peer coaching: } \\
\text { - regular dialogues on own performances and basic assumptions as a teacher; } \\
\text { - study of own practice and use of video feedback or classroom observations as starting point for reflection and } \\
\text { inquiries on student learning; } \\
\text { - reciprocal peer coaching in subgroups is based on equality and trust; } \\
\text { - the teacher in the role of learner/coachee selects his/her individual learning goals and thus determines the focus of } \\
\text { the coaching. The coach role focuses on support and in-depth questioning and not on giving evaluative feedback and } \\
\text { assessments. } \\
\text { - Effective peer coaching requires the competence to stimulate colleagues to in-depth reflection on own practice and to } \\
\text { respect their ownership. These competences are hard to do and might need to be trained. } \\
\text { - To stimulate a community of practice, teachers should collaborate in heterogeneous groups. Thus, participants may } \\
\text { differ in years of experience, subject taught, team, position in the school. The PD program should also encompass } \\
\text { (where possible) collaboration of (middle) managers. } \\
\text { - The PD design may include forms of external input, but these should serve teacher needs and initiatives in the school. }\end{array}$ \\
\hline
\end{tabular}


Table 3.2 Five design principles for professional development programs for teachers (Continued)

\begin{tabular}{|c|c|}
\hline Design principle & Characteristics of the PD program \\
\hline $\begin{array}{l}\text { Focus on own practice } \\
\text { (with the help of video } \\
\text { feedback) }\end{array}$ & $\begin{array}{l}\text { - The use of video recordings of own practice to provide rich feedback to teachers. With the help of video feedback, } \\
\text { teachers can monitor the results of their teaching. Video is a powerful reflective tool, a mirror with a memory. It allows } \\
\text { the participants to look at themselves and their students. } \\
\text { - In the PD program video feedback offers possibilities to share practice with colleagues and to learn from practices of } \\
\text { others. The PD program can enhance this experience by structuring dialogues which enhance reflection and study of } \\
\text { video recordings with peers. } \\
\text { - A crucial feature of collaborative learning is a sense of security and trust between participants. This can be enhanced by } \\
\text { structures such as asking the teachers whose video recording are going to be observed to choose themselves the topic } \\
\text { for reflection and dialogue, and by taking turns in coaching and being coached. } \\
\text { - To stimulate positive empowerment, the PD program should help participants to create awareness of their successful } \\
\text { classroom interactions. Positive feedback boosts self-efficacy and leads to the behavior being displayed more frequently. } \\
\text { - The PD program should provide structures to analyze video recordings. The specificity of the feedback helps } \\
\text { professionals to notice key elements of their behavior and their interaction with students and to evaluate the impact on } \\
\text { students of their performance. }\end{array}$ \\
\hline $\begin{array}{l}\text { Teacher ownership of } \\
\text { learning goals }\end{array}$ & $\begin{array}{l}\text { - The program regards participants as owners of own professional development. Teachers steer their own development in } \\
\text { dialogue with each other and with the environment (students, parents, school context, and school government). The } \\
\text { structure of the program helps individual teachers to maintain control of own learning goals. } \\
\text { - Ownership in a peer coaching program includes responsibility for ownership in both roles, in the role of 'learner' whose } \\
\text { classroom practice is studied, and in the role of 'peer coach' who facilitates the learning of colleagues. } \\
\text { - The program needs to acknowledge differences between teachers in concerns, learning goals, starting points, and } \\
\text { learning pace, and the program should provide ample learning opportunities for all participants accordingly. } \\
\text { - The program needs to challenge teachers to reflect on their own practice and to explore their own learning needs and } \\
\text { define individual learning goals within the context of the school. }\end{array}$ \\
\hline
\end{tabular}


Table 3.2 Five design principles for professional development programs for teachers (Continued)

\begin{tabular}{|c|c|}
\hline Design principle & Characteristics of the PD program \\
\hline & $\begin{array}{l}\text { The program should provide opportunities and structures for deep professional dialogues focusing not only on } \\
\text { performance, but also on underlying assumptions and values. Sharing practice (e.g. classroom observation and video } \\
\text { feedback) enables colleagues to understand each other's practice, and to connect with the needs and concerns of each } \\
\text { other. Peer coaches need to respect the prerequisite of ownership and to behave accordingly. To keep individual } \\
\text { teachers in control of their own learning goals, professional dialogues in reciprocal peer coaching programs may need } \\
\text { structuring and definitions of roles. }\end{array}$ \\
\hline $\begin{array}{l}\text { Focus on teacher's } \\
\text { inquiry stance and on } \\
\text { outcomes in classroom }\end{array}$ & $\begin{array}{l}\text { - PD needs to help teachers to be reflective practitioners and inquirers of their own practice. } \\
\text { - Inquiry is seen as a spiral process of purposeful engagement with school practice in a systematic, planned and } \\
\text { collaborative way, aiming at informed actions. } \\
\text { - Inquiry includes a range of different forms of study and data sampling, e.g. teachers may use questionnaires or } \\
\text { interviews, create journals or essays, do classroom studies, and engage in oral inquiry processes } \\
\text { - PD programs need to stimulate teachers to focus on outcomes in classroom and on results in students. }\end{array}$ \\
\hline $\begin{array}{l}\text { Creating conditions in } \\
\text { the school for PD and } \\
\text { the PD program }\end{array}$ & $\begin{array}{l}\text { - Continuing support and attention of the school management for the program. } \\
\text { - Provision of necessary time for participants to participate in the program and of timeslots for meetings. } \\
\text { - Ample duration of the PD program referring to the number of hours as well as the span of time. } \\
\text { - A learning environment based on mutual trust between all participants. } \\
\text { - Provision of necessary resources, e.g. ample supply of video cameras. } \\
\text { - Combination of internal and external experts for guidance, counseling and support. }\end{array}$ \\
\hline
\end{tabular}




\title{
CHAPTER 4 \\ Prototype and formative evaluation
}

\begin{abstract}
Based on the outcomes of the literature search and in close cooperation with a school of secondary education a prototype of the professional development program was designed. In this chapter the prototype is described followed by a description of the formative evaluation study. Based on the outcomes of this formative evaluation a number of recommendations for the re-design are formulated.
\end{abstract}

\subsection{INTRODUCTION}

In Chapter 3 review studies of PD programs were examined and the following five principles for a design of a PD program were identified: (a) collaborative learning at the workplace in the form of reciprocal peer coaching; (b) focus on own practice with the help of video feedback; (c) teacher ownership of learning goals; (d) focus on teacher's inquiry stance and on outcomes in classroom; (e) creating conditions in the school for PD and the PD program. The aim of the present study (Chapter 4) is to design a prototype of a PD program based on these principles and to explore the effects of the developed program on the professional development of teachers.

The research questions for the evaluation of the prototype of the PD program are:

1. To what extent does the prototype support the learning of teachers at the workplace?

2. Which characteristics of the prototype stimulated teacher learning?

3. Which recommendations can be derived from the try-out and evaluation of the prototype for the redesign of the professional development program? 
The effects of prototype are described with the help of the research model presented in Chapter 1. This model is based on the PD evaluation model by Guskey (2000) and a similar model for studying effects of PD by Desimone (2009). In this study, effects of the PD program are examined on the level of participants' reactions, participants' learning, participants' use of new knowledge and skills, and the effects on the school organization. Outcomes of the PD program in student learning were not assessed in this evaluation.

In the following paragraphs, first a description of the design process will be given, followed by the description of the developed PD program based on the five design principles. Next, an outline of the method of the study will be provided, followed by a description of the results. In the concluding paragraph the results will be summarized by means of characteristics of the program linked to the five design principles, and recommendations for the redesign of the program will be discussed.

\subsection{BACKGROUND AND DESIGN OF THE PROTOTYPE}

\subsubsection{Initial ideas}

The impetus to the development of this PD program originated from a need felt in a school for secondary education to support teacher learning at the workplace. The vice-principal and a school-based coach observed that especially teachers, who were already experienced and had been working for a number of years, were lacking a new stimulus for their professional learning within the context of the school. The author of this study, as a teacher educator who coached student teachers at the school, responded to this call and created an opportunity for the school to work together with a teacher training college and with an expertise center (het Ruud de Moor Centrum = RdMC) of the Open University of the Netherlands. Both institutes were interested in working with teachers on their professional development. The teacher training college was willing to invest in research on teacher learning. The expertise center (RdMC) wanted to map teacher competences in specific professional worksituations. The school and the teacher training college started a project to work together for three consecutive years on the development and implementation of a program to stimulate teacher learning at the workplace. The expertise center joined in for 
one year and provided a method for the first part of the program. During the pilot program, the center also provided funds to the school with which the school could reward teachers who joined into the program.

The school and the teacher training college jointly developed and implemented a PD program based on shared views on teacher learning as active learners, constructing and reconstructing ideas, and taking responsibility for their own learning. The emphasis was on design principles also found in research: collaborative and reflective dialogues on own practice; the teacher as active learner; teacher as owner of learning goals; and the creation of a favorable conditions in the school.

Experienced teachers were considered the primary target group, however, beginning teachers who wanted to participate were also invited to join the program. The program was designed in close cooperation between the researcher and a school-based coach/teacher educator (who coached teachers and student-teachers in the school). The program was implemented over a period of one school year, starting in November and with the last meeting taking place in June. During this year, the researcher and the school-based coach met frequently to discuss the implementation and to adjust the program based on participants' feedback and also on ongoing literature search.

\subsubsection{Design of the prototype}

In the PD program, teachers had to work together in varying group settings during one school year. To stimulate collaborative learning throughout the school, the developers opted for collaboration in heterogeneous groups (participants differing in subject taught, years of experience, school team). Traditionally, most teachers only work together with colleagues from the same department (van Wessum, 1997; Witziers, Sleegers, \& Imants, 1999). However, in this study it is assumed that interdisciplinary collaboration can foster teachers' acquaintance with a broader variety of ideas and teaching methods, because teachers from different subject matter departments may use diverse teaching methods, and interdisciplinary collaboration stimulates the growth of a larger learning community in the school.

The program consisted of two parts, each with a different design to structure reflective dialogues between peers (see the descriptions of part A and B below). 
The parts were not necessarily successive, but at times alternated each other. Because teaching is still often a lonely profession in which it is not customary to observe other professionals performing in classrooms, it was expected that the part of the program in which teachers would videotape in each other's classrooms and share and observe each other's taped performances (part B of the program), was possibly perceived as threatening. To build on mutual trust and gradually opening up of own practice, the program started with a different form of sharing (part A of the program). In this part of the program teachers discussed own case stories, which were made anonymous by the trainers. In this way each teacher could open up own practice to the level he/she felt comfortable with. For a complete overview of the planning of the program see Figure 4.1.

Part A of the program consisted of four plenary meetings in which the participants discussed relevant teacher topics, using a method, called 'Expert Meeting' (Goes, Dresen, \& van der Klink, 2005). This method was developed at an expertise center (RdMC) of the Open University of the Netherlands. The basic idea behind this method is to structure collaborative dialogues on teachers' professional experiences, and, in doing so, to create opportunities for researchers to investigate implicit professional knowledge. As a group, the teachers had to choose topics they wanted to study. The topics were directly related to work-specific situations of teachers, for instance 'Functioning in a team' or 'Creating a pedagogical safe learning environment'. As input for a plenary meeting, the teachers were requested to do an assignment on the chosen topic and to describe individually what they thought about the chosen topic concerning: (a) desired output with these kinds of tasks, (b) case stories of own experiences with these tasks, (c) factors that affect the complexity of these kinds of tasks and (d) descriptions of effective teacher behavior concerning these tasks. The completed homework was emailed to the trainers. They chose excerpts which formed anonymous input for dialogues during the plenary Expert Meeting. During such three hour long meetings, discussions on excerpts of homework in small groups alternated with plenary moments in which teachers drew shared conclusions.

Part B of the program consisted of reciprocal peer coaching with video feedback. There were four plenary meetings with reciprocal peer coaching meetings in subgroups in between, during which video recordings of own 
classroom practices were studied. In the first two plenary meetings the teachers were familiarized with the goals of reciprocal peer coaching, and with the techniques of videotaping and guiding coaching dialogues in peer groups. The coach training fitted in with the ALACT model of reflection developed by Korthagen (2001) (for a further elaboration on the ALACT model, see the description of this model in Chapter 2). In between meetings, teachers coached each other in triads. Recordings were made in own classrooms around a jointly chosen topic (e.g. 'How do we stimulate interest and curiosity in learning?' or 'What is quality feedback?') and observed and discussed in their triads. Interesting excerpts were also brought in and collectively studied during plenary meetings.

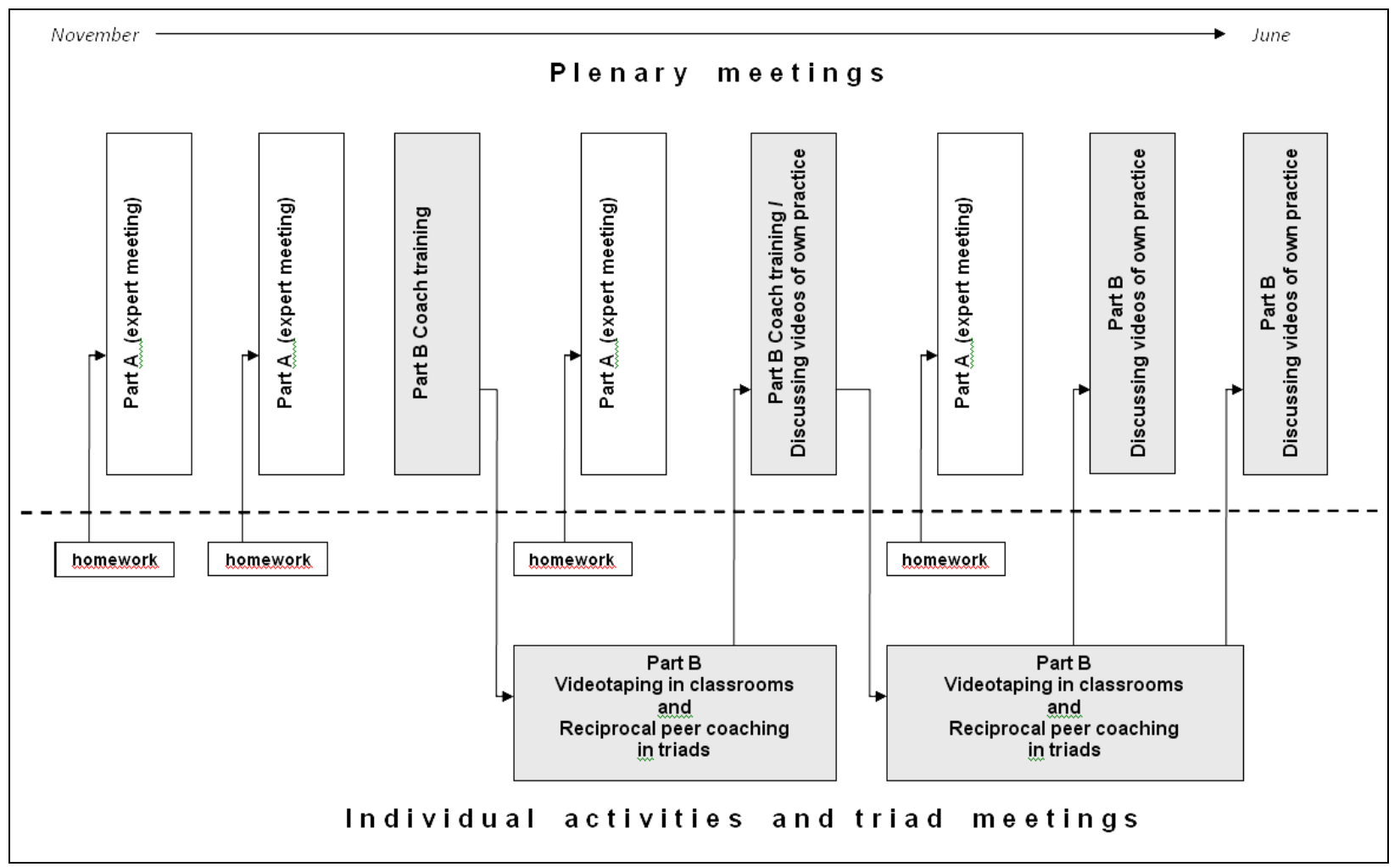

Figure 4.1 Overview of the program (prototype)

A pitfall in peer coaching can be to jump to evaluation ('that went well' or 'that was not effective') followed by tips ('next time try...'). Teachers, in particular, tend to this type of 'expert coaching', because it reflects their traditional role. The problem with this kind of coaching is that it does not adequately stimulate reflective thinking in the trainee. Therefore, the program trained the teachers for their coach role and defined three well-described roles for the triad 
meetings. Teachers coached each other in groups of three, taking turns in roles as trainee, as coach and as observer of the coaching dialogue. They used video recordings of own classroom as a source of feedback. The main focus was to study the performance of the teacher who served as trainee during that session. The function of the peer coach was to stimulate his/her colleague towards reflection. The input of their peer in the role of observer was intended to help optimize the coaching skills.

Teachers videotaped in each other's classrooms and used the video recordings as a means to generate feedback and to help teachers to reflect on their performances. Triads' meetings started by viewing the tape together, either viewing the complete lesson or focusing on a number of relevant fragments which the teacher-trainee selected beforehand. After observing the video, they discussed their observations. Instead of giving own analyses the peer coach had to help the colleague to reflect, mainly by asking open ended questions. At the end of each session participants also discussed the performance of the peer coach and the way the peer coach stimulated the reflection process of the colleague. The observations of the teacher in the role of observer functioned as input for this discussion. In Table 4.1 an overview is provided of the five basic design principles found in the literature study (Chapter 3 ) and the translation of each principle into the prototype of the PD program. 
Table 4.1 Translation of the basic design principles in the prototype

\begin{tabular}{|c|c|}
\hline Design principle & Translation into characteristics of the PD program (prototype) \\
\hline $\begin{array}{l}\text { 1. Collaborative learning } \\
\text { at the workplace in the } \\
\text { form of reciprocal peer } \\
\text { coaching }\end{array}$ & $\begin{array}{l}\text { - Cooperating in heterogeneous groups (participants differ in } \\
\text { subject, years of experience, team) }[A \text { and } B]^{*} \\
\text { - Peer dialogues on own and peer practice }[A \text { and } B]^{*} \\
\text { - Visiting and videotaping in each other's classrooms }[B]^{*} \\
\text { - Reciprocal peer coaching in subgroups }[B]^{*}\end{array}$ \\
\hline $\begin{array}{l}\text { 2. Focus on own practice } \\
\text { with the help of video } \\
\text { feedback }\end{array}$ & $\begin{array}{l}\text { - Dialogues on case stories from own practice, which are made } \\
\text { anonymous }[A]^{*} \\
\text { - Reflective dialogues on videotaped performances in own } \\
\text { classrooms }[B]^{*}\end{array}$ \\
\hline $\begin{array}{l}\text { 3. Teacher ownership of } \\
\text { learning goals }\end{array}$ & $\begin{array}{l}\text { - Teachers jointly choose topics for generating and discussing } \\
\text { own case stories }[A]^{*} \\
\text { - Teachers jointly choose topics for analyzing video recordings } \\
\text { of own practice in plenary meetings }[B]^{*} \\
\text { - Reciprocal peer coaching in subgroups on goal and excerpts of } \\
\text { video recordings chosen by the individual teacher himself }[B]^{*}\end{array}$ \\
\hline $\begin{array}{l}\text { 4. Focus on teacher's } \\
\text { inquiry stance and } \\
\text { outcomes in classroom }\end{array}$ & $\begin{array}{l}\text { - Generating feedback through observation and analysis of own } \\
\text { practice: } \\
\text { - Teachers analyze and reflect on own practice with the help } \\
\text { of their own case stories }[A]^{*} \\
\text { - Observing, reflecting and analyzing video recordings of } \\
\text { own and peer practice in groups of three }[B]^{*} \\
\text { - Observing, reflecting and analyzing video recordings of } \\
\text { own and peer practice in joint meetings of all participants } \\
{[B]^{*}} \\
\text { - Comparing own performances and views with performances } \\
\text { and views of peers }[A \text { and } B]^{*}\end{array}$ \\
\hline $\begin{array}{l}\text { 5. Creating conditions in } \\
\text { the school for PD and } \\
\text { PD program }\end{array}$ & $\begin{array}{l}\text { - Commitment of management to implement a PD program } \\
\text { based on reciprocal peer coaching and video feedback for } \\
\text { three years in a row }[A \text { and } B]^{*} \\
\text { - Participation is voluntary }[A \text { and } B]^{*} \\
\text { - Stimulating commitment of participants by the signing of a } \\
\text { contract and the supply of a bonus of } 300 \text { euro }[A \text { and } B]^{*} \\
\text { - Program implemented at the workplace }[A \text { and } B]^{*} \\
\text { - External expertise of a trainer of an expertise centre of the } \\
\text { - Open University is linked to school-based activity }[A]^{*} \\
\text { - External expertise of a teacher educator is linked to school- } \\
\text { based activity }[A \text { and } B]^{*}\end{array}$ \\
\hline
\end{tabular}

Note: * [refers to the part of the program involved] 


\subsection{METHOD}

\subsubsection{Participants}

Nine teachers of a school for secondary education volunteered to participate in the program. The teachers differed in the subject they taught, years of experience, and in their position in the school (Table 4.2). Participants wished to work on their individual professional skills by working together in a peer group. They signed a contract in which they promised to participate in the program during one year in their own spare time, for which, at the end of program, they would be rewarded with a bonus of 300 euro.

Table 4.2 Characteristics of participants in the program (prototype)

\begin{tabular}{ll}
\hline Number of participants (N) & 9 teachers \\
\hline Gender & 7 female / 2 male \\
\hline Subject taught & economics / sciences / languages / physical education \\
\hline Years of experience & 2 starters (less than 2 years) \\
& 2 beginners (2 to 5 years) \\
& 3 experienced (6 to 10 years) \\
& 2 senior experienced (more than 10 years) \\
\hline Position in the school & 1 participant was a teacher and also a team manager \\
& 2 participants were teacher and also school-based coach \\
\hline
\end{tabular}

All participants completed the program. They all took part in the joint meetings and also cooperated in groups of three of changing composition. In the groups of three, most teachers discussed two lessons of each participant, thus engaging in a total of 6 dialogues ( 3 participants $\times 2$ lessons). Only two teachers, working together as a duo, engaged in merely 2 dialogues (one lesson of each teacher). The dialogues about a videotaped lesson lasted from 15 minutes (in the subgroup of two teachers with only two dialogues) to more than 60 minutes in other subgroups.

\subsubsection{Data collection}

The program lasted one school year. Multiple methods were used to study relations between characteristics of the program and the learning process of the participants. Data were collected by using the following instruments:

- Documents (the planning of each plenary meeting and the binder with background materials and tools for the participants) and observational notes of the eight plenary meetings. 
- At the end of part 1 of the program, the teachers filled in the first questionnaire and another one at the end of part 2. The first questionnaire had already been developed by the expertise center (RdMC) of the Open University in the Netherlands to monitor implementations of a method called the Expert Meeting. The second questionnaire, carried out at the end of the school year, was constructed in line with the first questionnaire. Both questionnaires consisted of 66 statements around central topics. The first questionnaire focused on: knowledge of the method, individual gains, views on necessary competences of participants, own experiences and personal motives, and information about personal data. The second questionnaire focused primarily on: the teacher's experiences, individual gains (of the plenary meetings and the work in groups), their views on conditions necessary for implementation of the program, and personal wishes concerning the continuation of the program. Teachers responded to all statement using a 1-4 rating scale ranging from 1 (agree strongly) to 4 (disagree strongly). (See Appendix 1 and 2 for the questionnaires as administered in Dutch).

- At the end of the program, the teachers were interviewed on their learning experiences. Each semi-structured interview started by asking which competences they learned most in the program. Teachers were first asked to draw a storyline on their own learning processes. The individual storyline was then used as the starting point for the semi-structured interview, thus fitting in with participants' own experiences. The interview focused on clarification as to what they had learned from the program and which and how various characteristics of the program were important to their learning processes. All interviews were audio taped. Each interview lasted from almost one hour to a full two hours.

- A half year after the program had ended, the teachers were asked again to reflect on their experiences in a post-verification questionnaire consisting of eleven statements with a 1-4 rating scale ranging from 1 (agree strongly) to 4 (disagree strongly) and three open-ended questions. (See Appendix 3 for the questionnaire as administered in Dutch).

All teachers returned the first questionnaire. One teacher did not return the second questionnaire (on reciprocal peer coaching with video feedback), but did cooperate with the interview. The post-verification questionnaire was returned by six out of nine teachers: one teacher did not return the 
questionnaire, one teacher was on maternity leave, and one teacher had left the school. On the questionnaires, sometimes a single item was not scored by a participant or the answer of a single item could not be included (e.g. participant gave more than one score).

\subsubsection{Data analysis}

First, documents and observational notes were studied to describe the implementation of the program. Secondly, the frequencies on the questionnaires were computed. Thirdly, the audio taped interviews were transcribed verbatim. The researcher analyzed all interviews in search of statements concerning outcomes and their relation to the characteristics of the program. All statements were clustered around the five design principles. After this, all interviews were studied again in search of additional information. Next, for triangulation, the data of the interviews were compared with the scores of the relevant items on the questionnaire.

Data collected with different measurements, were combined to answer the research questions. Finally, results were discussed with the school-based coach and the school manager.

\subsection{Results}

\subsubsection{Participants' reactions}

All teachers were (very) positive in their evaluation of the open atmosphere. Almost all teachers liked to participate in the program, they found most of the components useful and they expressed interest in a follow-up in the future. They felt their time was well spent and they evaluated the program as well implemented. Almost all gave the highest rating to the positive working climate during meetings. (Table 4.3, 4.4, 4.5). 


\begin{tabular}{lllll}
\hline & $\begin{array}{l}\text { Strongly } \\
\text { agree }\end{array}$ & Agree & $\begin{array}{c}\text { Disagree } \\
\text { Strongly } \\
\text { disagree }\end{array}$ \\
\hline $\begin{array}{l}\text { I liked the working climate during the plenary } \\
\text { meetings }\end{array}$ & 6 & 2 & & \\
\hline The trainer was competent in structuring meetings & 2 & 7 & & \\
\hline I liked participating in the program & 2 & 6 & 1 & \\
\hline I found the program useful & 2 & 6 & 1 & 1 \\
\hline The method is new and surprising & & 6 & 2 & \\
\hline I want to stay involved with this project & 3 & 3 & 1 & \\
\hline
\end{tabular}

Table 4.4 Teachers' evaluation of Part B of the program: the four Plenary meetings $(N=8)$

\begin{tabular}{llll}
\hline & $\begin{array}{l}\text { Strongly } \\
\text { agree }\end{array}$ & Agree & $\begin{array}{c}\text { Disagree } \\
\text { I liked the working climate during the plenary }\end{array}$ \\
$\begin{array}{l}\text { meetings } \\
\text { disagree }\end{array}$ & $\begin{array}{l}\text { Strongly } \\
\text { dise meetings were well guided }\end{array}$ & 2 & 6 \\
\hline $\begin{array}{l}\text { I liked videotaping and discussing recordings of } \\
\text { own performances during plenary meetings }\end{array}$ & 2 & 6 \\
\hline $\begin{array}{l}\text { I liked discussing recordings of own performances } \\
\text { during plenary meetings }\end{array}$ & 2 & 6 \\
\hline $\begin{array}{l}\text { I found the number of plenary meetings to discuss } \\
\text { videos from classrooms sufficient }\end{array}$ & 2 & 6 \\
\hline
\end{tabular}

Table 4.5 Teachers' evaluation of Part B of the program: the Reciprocal peer coaching in triads $(N=8)$

\begin{tabular}{|c|c|c|c|c|}
\hline & $\begin{array}{l}\text { Strongly } \\
\text { agree }\end{array}$ & Agree & Disagree & $\begin{array}{l}\text { Strongly } \\
\text { disagree }\end{array}$ \\
\hline I liked the working climate during our dialogues & 6 & 2 & & \\
\hline I found the meetings in triads pleasant & 2 & 6 & & \\
\hline I found the meetings in triads useful & 3 & 5 & & \\
\hline I found the meetings in triads enriching & 3 & 5 & & \\
\hline $\begin{array}{l}\text { I found the amount of meetings in groups of three } \\
\text { sufficient }\end{array}$ & 2 & 6 & & \\
\hline $\begin{array}{l}\text { I want to stay involved in new programs with } \\
\text { groups of three }\end{array}$ & 2 & 5 & & \\
\hline
\end{tabular}

The teachers were positive about all three parts of the program ('Expert meetings', 'Plenary meetings', and the 'Reciprocal peer coaching dialogues in triads'). In interviews, all teachers reported to feel some stress as a result of videotaping their performances and discussing their recordings with peers, however, all teachers also reported to consider this as a (very) valuable experience. In addition to their answers on the questionnaire, in interviews, four participants indicated that they wished that in the program they could have spent more time discussing videotaped classroom performances in plenary meetings as well (in addition to the dialogues in groups of three). They valued these moments in the program and thought it helped them to study in more depth their performances as a result of the added expertise of the intern and extern coach. 
All parts of the program stimulated the teachers to discuss their practice with their peers: "Other programs make you focus only on techniques and on 'how to's'. In this program you are also stimulated to analyze and discuss your own goals and ideals as a teacher".

In the first part of the program (A), teachers jointly chose work situations they wanted to investigate and do homework on. Topics they chose were 'discipline in classrooms', 'active and self-regulated student learning', 'assessing student learning', and 'cooperation between teachers in task-focused teams'. Teachers reflected on their own experiences while doing homework and during the plenary meetings. There were no follow-ups, the next plenary meeting they focused on different topics.

During the second part of the program (B) in the plenary meetings, teachers jointly chose a topic ('stimulating active learning in students') on which everyone selected relevant video fragments they wanted to discuss with their colleagues. In their dialogues in groups of three, each teacher individually chose a topic to focus on, so in triads the topics could differ in the group dialogues. Overall, all teachers noted that coaching dialogues pertained to their self chosen topics and learning questions (Table 4.8).

Most teachers wanted to view their videotaped performances by themselves before showing them to colleagues, so most teachers saw them more than once. Some teachers studied the tape again after the video was discussed in their subgroup or in one of the plenary meetings. Five teachers did also view and discuss recordings with their partner or a friend at home, and two of them indicated this was also very instructive for them to gain further insight in their interpersonal skills.

Although the teachers were very positive about various parts of the program, this is consistently not the case for issues linked with theoretical knowledge. When asked: 'Do you want more information about supporting theories?', 'Have you studied the reader of the training?', 'Have you gained more theoretical knowledge?' or 'Do you think it is useful for a participant to have thorough knowledge of relevant theories?', most teachers reacted less positively than on other items (Table 4.6 and 4.7). 
On the questionnaires, both parts of the program (A and $B$ ) were noted to be effective for their learning processes, and in the interviews, teachers expressed having actively exchanged knowledge and having learned from the performance of colleagues in both parts of the program. The first part of the program (A) may have had a function in creating trust between colleagues ("In this program you expose yourself to your peers, but in part A you can introduce your problems more anonymously and first observe the way your peers react to them"). However, all teachers also expressed in the interviews - after the whole program had ended - that they considered the method in Part A (the 'Expert Meeting') as less effective than the method in Part B (reciprocal peer coaching with video feedback). All teachers expressed the wish to change the program in favor of this second part of the program.

\subsubsection{Participants' learning}

On the level of participants' learning most teachers noted they had learned of all activities in both parts of the program (Table 4.6 and 4.7). The teachers reported a variety of learning gains.

\section{Deepening reflection on own practice}

Teachers indicated they had learned to reflect more, and became aware of their automatisms (Table 4.6 and 4.7). Teachers reflected on their performance in classroom, but they also reflected on their role as a coach and on the way they learned during coaching. As scored most important on the second questionnaire (Table 4.7) were: 'Rethinking elements of my own professional performances that are happening routinely' (item 5), 'In discussing the video recordings of my lesson, I get new insights and ideas' (item 7), and 'Using video recordings of own classroom was meaningful' (item 12).

The teachers were critical about gaining theoretical knowledge. Although they were interested in gaining theoretical knowledge about effective teaching (Table 4.7, item 10), they reported limited gains. In the first part of the program (A), only one teacher indicated having outcomes concerning theoretical knowledge gains (Table 4.6). In the second part (B), five teachers reported gains of theoretical knowledge, however most of this knowledge concerned theories about coaching techniques (Table 4.7, item 8). 
The shared context of their own school and the teaching of the same student groups helped them to discuss experiences and made dialogues more interesting: "I know that particular student, I know that particular behavior and on video I see the solutions of my colleague and I realize, well, that's something that might be working for me too".

Table 4.6 Part A of the program: the four Expert Meetings ( $N=9$ )

\begin{tabular}{|c|c|c|c|c|}
\hline & $\begin{array}{l}\text { Strongly } \\
\text { agree }\end{array}$ & Agree & Disagree & $\begin{array}{l}\text { Strongly } \\
\text { disagree }\end{array}$ \\
\hline $\begin{array}{l}\text { 1. I learned to reflect by means of explicating and } \\
\text { clarifying what I'm doing and why I'm doing this }\end{array}$ & & 8 & 1 & \\
\hline $\begin{array}{l}\text { 2. By means of this method I rethink elements of my } \\
\text { own professional performances that are } \\
\text { happening routinely }\end{array}$ & 5 & 4 & & \\
\hline $\begin{array}{l}\text { 3. I used this method to hear how peers are working } \\
\text { and to learn from this }\end{array}$ & 1 & 6 & 2 & \\
\hline 4. I gained more theoretical knowledge & 1 & & 7 & 1 \\
\hline $\begin{array}{l}\text { 5. The method is useful to map specific professional } \\
\text { situations }\end{array}$ & 1 & 4 & 3 & \\
\hline
\end{tabular}

Table 4.7 Part B of the program: the plenary meetings and the reciprocal peer coaching in triads $(N=8)$

\begin{tabular}{|c|c|c|c|c|}
\hline & $\begin{array}{l}\text { Strongly } \\
\text { agree }\end{array}$ & Agree & Disagree & $\begin{array}{l}\text { Strongly } \\
\text { disagree }\end{array}$ \\
\hline $\begin{array}{l}\text { 1. I have received useful feedback about my } \\
\text { performances }\end{array}$ & 1 & 6 & 1 & \\
\hline $\begin{array}{l}\text { 2. I learned a lot from discussing video recordings } \\
\text { of own performance in classroom }\end{array}$ & 2 & 5 & & \\
\hline $\begin{array}{l}\text { 3. I learned a lot from discussing video recordings } \\
\text { of performances of peers in classroom }\end{array}$ & 3 & 5 & & \\
\hline $\begin{array}{l}\text { 4. I learned to reflect by means of explicating and } \\
\text { clarifying my thoughts and feelings concerning } \\
\text { videotaped own practice }\end{array}$ & 3 & 5 & & \\
\hline $\begin{array}{l}\text { 5. By means of this method I rethink elements of my } \\
\text { own professional performance that are happening } \\
\text { routinely }\end{array}$ & 4 & 4 & & \\
\hline 6. By observing my video I notice new aspects & 3 & 4 & 1 & \\
\hline $\begin{array}{l}\text { 7. By discussing my video with peers I get new } \\
\text { insights and ideas }\end{array}$ & 4 & 3 & 1 & \\
\hline 8. I have gained more theoretical knowledge & & 5 & 3 & \\
\hline 9. I gained more self-confidence as a teacher & 1 & 3 & 4 & \\
\hline $\begin{array}{l}\text { 10. I want more theoretical knowledge about } \\
\text { effective teaching }\end{array}$ & 1 & 5 & 2 & \\
\hline 11. I'm more open to collaboration with peers & & 8 & & \\
\hline $\begin{array}{l}\text { 12. Using video recordings of own classroom was } \\
\text { meaningful }\end{array}$ & 4 & 4 & & \\
\hline $\begin{array}{l}\text { 13. In triads I learned a lot from the dialogues about } \\
\text { my lesson }\end{array}$ & 1 & 6 & 1 & \\
\hline $\begin{array}{l}\text { 14. In triads I learned a lot from observing (video) } \\
\text { lessons of peers }\end{array}$ & 3 & 5 & & \\
\hline
\end{tabular}


Table 4.7 Part B of the program: the plenary meetings and the reciprocal peer coaching in triads $(N=8)$ (Continued)

\begin{tabular}{llll}
\hline & $\begin{array}{l}\text { Strongly } \\
\text { agree }\end{array}$ & Agree & $\begin{array}{c}\text { Disagree } \\
\text { Strongly } \\
\text { disagree }\end{array}$ \\
\hline $\begin{array}{l}\text { 15. In triads I learned a lot from the dialogues on } \\
\text { lesson of my peers }\end{array}$ & 1 & 7 & \\
\hline $\begin{array}{l}\text { 16. I use this method to see how my peers work and } \\
\text { to learn from it }\end{array}$ & 7 & 8 \\
\hline $\begin{array}{l}\text { 17. I 'm more open to collaboration with peers } \\
\begin{array}{l}\text { 18. I found participating in triads necessary for my } \\
\text { development as a teacher }\end{array}\end{array}$ & 2 \\
\hline $\begin{array}{l}\text { 19. I want to stay involved in new collaborative PD } \\
\text { programs }\end{array}$ & 2 & 5 \\
\hline
\end{tabular}

\section{Self-confidence as a teacher}

Video recordings provided an abundance of feedback. All teachers reported noticing all sorts of things they missed during teaching the classes. Teachers differed in their experiences when watching themselves. Although most teachers also noticed positive aspects (i.e. aspects they felt positive about), all teachers tended to focus on negative aspects: "I mostly notice the things that do not work well, I must learn to observe in a different manner."

The program, video feedback in particular, appeared to have an influence on their self-image. Half of the teachers reported gains in self-confidence, the other half felt their self-image in their role as teacher became more under pressure. Being a novice or an experienced teacher seemed to influence outcomes in selfconfidence. The four novice teachers (2 starters and 2 beginners) indicated an increase in self confidence after the peer coaching with video feedback, especially in cases in which the coach helped them to focus on empowerment by analyzing moments of success: "My negative feelings were much stronger after the lesson and not in line with the facts as shown on video" and "During the hectic moments of teaching I often do not focus on/notice the students who are studying well, but on video I did". They had negative feelings about their lessons after their lessons had ended. When they observed and analyzed these lessons with their peer coaches, they realized that their perception was too negative (e.g. student behavior was less disruptive than they themselves remembered, or the behavior of the student was more understandable and labeled less negative). After observing and analyzing the tapes, the beginners' self-confidence was strengthened and they were more motivated to interact in a positive way with students in their next lessons. Novice teachers also found it helpful to observe colleagues (in classrooms or on video) who were also struggling. As one teacher reported: "personal struggles with a class 
or with a student are not topics that are extensively discussed in other professional settings in the school. That makes you feel very lonesome sometimes".

In contrast, some of the experienced teachers reported becoming 'a student in their own lessons' while they viewed the tape. From this perspective they evaluated their own performance less positive than before: "I was faced with reality, I gave students too little own responsibility and I wasn't aware of that" (...) "I saw many things that went well, but that's what I already expected. I also saw things that went wrong and those things were confronting, I suddenly realized I also failed in a few things". The self-confidence of the experienced teachers got a slight blow.

\section{Clarifying own learning goals}

Dialogues about their videotaped lessons helped teachers to identify their individual learning goals (e.g. 'the importance to activate prior knowledge' or 'to talk more slowly') and to reflect on their daily routines. Their discussions with their colleagues in part A of the program, and video feedback and dialogues in triads in part $B$ of the program helped all of them to look from a different perspective at their performances and to shake up some routines (Table 4.6 and 4.7).

Teachers reported cases in which the learning goals and focus shifted as a result of analyzing the video: for instance, one dialogue started with the focus on 'organizational aspects' but during observing and analyzing the video tape, the focus shifted to 'formulating assignments for students'. However, the more abstractly formulated ultimate individual learning goal ('stimulating cooperative learning between students') stayed the same. Another teacher reported: "After the lesson I had a feeling that the students were not focused enough, then I looked at the video recordings and I could not find a real problem. With my peer coach we analyzed the whole video and I learned to relax more and to trust myself and my students." Her focus shifted from classroom management skills to interpersonal skills and to the need for selfconfidence. Video feedback and their peer's coaching and in-depth questioning in triads helped teachers to shift their reflection focus on 'the real thing'.

\section{Developing interpersonal coaching skills}

All teachers emphasized gains concerning interpersonal competences, more specifically: 'guiding', 'coaching', 'confronting' and 'stimulating students 
and/or others in a cooperative atmosphere'. All teachers noted having learned a lot from the coach training (see Table 4.8), although two teachers still felt not having acquired enough coaching skills. Teachers indicated they needed to learn how to coach, how to observe and analyze, and how to provide feedback.

Table 4.8 Part B of the program: learning the coach role $(N=8)$

\begin{tabular}{llll}
\hline & $\begin{array}{l}\text { Strongly } \\
\text { agree }\end{array}$ & Agree & $\begin{array}{c}\text { Disagree } \\
\text { Strongly } \\
\text { disagree }\end{array}$ \\
\hline $\begin{array}{l}\text { As a coach: In my role as coach, I could guide the } \\
\text { dialogue well }\end{array}$ & 6 & 2 \\
\hline $\begin{array}{l}\text { As a coach: The feedback of the peer-observer was } \\
\text { useful }\end{array}$ & 4 & 3 \\
\hline $\begin{array}{l}\text { As a trainee: The dialogues stayed focused on own } \\
\text { learning goal }\end{array}$ & 2 & 6 \\
\hline $\begin{array}{l}\text { As a trainee: The coaching of my peer did help me } \\
\text { grow }\end{array}$ & 3 & 4 & 1 \\
\hline Training: I learned a lot about coaching & 3 & 4 \\
\hline $\begin{array}{l}\text { Training: The number of meetings to train coaching } \\
\text { were sufficient }\end{array}$ & 2 & 6 \\
\hline $\begin{array}{l}\text { Training: Videotaping and discussing peer coach } \\
\text { dialogues in plenary meetings is meaningful }\end{array}$ & 8 & \\
\hline
\end{tabular}

In the interviews teachers reported the use of their newly acquired coaching skills in different professional work environments, not only in contacts with colleagues but also in interaction with students, or parents. Two teachers were stimulated by their peer coach dialogues to do inquiries into results in their own classroom, one focusing on improving own interaction with individual students and one focusing on introducing cooperative learning in own classroom. One teacher was stimulated by the program to study coaching (by buying and studying relevant literature) in order to obtain a position as schoolbased coach in the future.

All of the participants appreciated training in coaching skills. All teachers also reported difficulties in guiding the dialogues. Two teachers indicated at the end of the program they still lacked sufficient skills to coach their peers. Teachers considered the use of an observer during peer coaching meaningful and helpful for learning their role as peer coach. Especially observing their peers performing coaching dialogues was very instructive for developing their own coaching skills. On the other hand, half of the participants mentioned difficulties - such as fear of criticizing their peers - in introducing their observations into the dialogue during their subgroup meetings. 


\section{Training}

During the program it turned out that participants needed to be trained in making effective video recordings in each other's classroom. Important is an emphasis on good audibility (over fine pictures) and on interactions (thus zooming in on performance of teacher and students).

During the program, participants expressed their wish to investigate in more detail the way in which they could coach each other. A coach training was developed and implemented. The coach training fitted in with the ALACT model of reflection, emphasizing not only reflections on actions but also on pupils' perspectives, and reflections not only on thoughts but also on feelings and motives. Teachers also taped their reciprocal peer coaching dialogues for use during training sessions. The teachers found this training and the use of video feedback of own coaching dialogues meaningful and instructive (Table 4.9). The participants especially appreciated a training session in which the group observed a conversation led by a participant who was already an experienced school-based coach. In the chosen fragments (selected with her agreement) not everything went well, and she experienced some difficulties as a coach. This created trust ('we are permitted to fail') and stimulated other participants in the next sessions to present and discuss fragments of their own coaching dialogues.

Table 4.9 Part B of the program: the plenary meetings $(N=8)$

\begin{tabular}{llll}
\hline & $\begin{array}{l}\text { Strongly } \\
\text { agree }\end{array}$ & Agree & $\begin{array}{c}\text { Disagree } \\
\begin{array}{l}\text { Strongly } \\
\text { disagree }\end{array}\end{array}$ \\
\hline I learned a lot about coaching & 3 & 4 & \\
\hline $\begin{array}{l}\text { The amount of meetings to train coaching is } \\
\text { sufficient }\end{array}$ & 2 & 6 & \\
\hline $\begin{array}{l}\text { Videotaping and discussing own peer coach } \\
\text { dialogues is meaningful }\end{array}$ & 8 & & \\
\hline
\end{tabular}

Teachers reported trust and confidence as a necessary condition for sharing their video recordings of classroom performance and for having an openminded discussion. Mutual trust between teachers was stimulated by (a) working in a small reciprocal peer coaching group, (b) the reciprocal nature of opening up classroom practices, and (c) the well-defined roles which structured dialogues and the mandatory guideline of peers withholding own judgments. Teachers reported that their roles, especially the presence of the peer-observer, prevented that dialogues switched from more intensive reflections to more pleasant superficial talks. Two teachers indicated that their peer coach did not 
stimulate reflective thinking. Instead, their peer just supplied his own opinion and re-labeled the experiences of his peer from negative to positive. Although the two teachers reported that they appreciated the positive view of their coach, they also reported (a) not changing their own negative view and (b) not being helped in discovering how to improve their performance.

\subsubsection{Participants' use of new knowledge and skills}

Teachers reported increased self-awareness in classroom. Eight of the nine teachers indicated in the questionnaire and/or in the interviews that they felt stimulated by the program. Only two teachers - working together as a duo without an observer - reported in the interviews they felt less stimulated. All participants mentioned to be interested in new programs working with reciprocal peer coaching in triads (Table 4.5).

Some changes on the level of the participants' use of new knowledge and skills were indicated by the participants. In interviews, all but one teacher mentioned acquiring new insights or ideas. The program as a whole, the second part in particular, stimulated teachers to rethink their performances, as a teacher told: "I became stimulated to rethink and retry some aspects of my own performance. Six years ago I started fresh as a beginner but somehow some aspects have faded out in the reality of day-to-day teaching and now I feel a new impulse to work on it again" and another stated: "I get an impulse to change, to realize again my own pitfalls and to work on them". Another teacher also mentioned being especially stimulated by observing the videotape of a colleague "I was inspired by her enthusiasm and friendly approach to students - so open - that's the way I want to perform too."

The dialogues in both parts of the program focused on discussions of teachers' experiences and not on structured inquiries into student outcomes. The schoolbased coach, who also was co-designer of the program, expressed the fear that teachers' reflections in the program were insufficiently linked to establishing improvement in classroom performances and student outcomes. She advocated strengthening the part of the program in which teachers do inquiries into own practice in future programs.

All teachers emphasized having learned about coaching skills, such as 'guiding', 'coaching', 'confronting' and 'stimulating students and/or others in a cooperative atmosphere', although they also indicated that they felt their coaching skills were 
not good enough yet. Two teachers were stimulated by their peer coaching dialogues to do inquiries into results in their own classrooms, one focusing on improving her interaction with individual students, and the other focusing on introducing cooperative learning in his classroom. One teacher was stimulated to study for a position of school-based coach.

\section{Post verification}

To check whether the gains were lasting, the participants were asked to reflect again on their results six months after the program had ended. In the postverification measurement $(\mathrm{N}=6)$, all participants reported that as a result of the program they 'reflected more often on their professional skills' and they 'noticed the relation between my actions as a teacher and the reactions of student(s)', furthermore, five of the six participants reported to 'reflect more on their goals as a teacher and how to act on them in classrooms'. They also 'exchanged experiences with colleagues more often' and 'felt more positive about their role as a teacher'. All agreed that the program had been meaningful for them.

\subsubsection{Organizational support and change}

On the level of organizational support and change, we found that the participants were less satisfied with the context of the program. Teachers were pleased with their bonus, however, all teachers reported in the interviews a considerable lack of time and a lack of shared opportunities in their school schedules for their peer coaching dialogues. Although the school management supported the program, it did not change its policy by providing more time to participants. Dialogues could take a considerable amount of time (usually between 30 to 60 minutes). Therefore, almost all coaching dialogues were scheduled after working hours. Two teachers, blaming lack of time, chose a different approach. They were already located in the same staffroom and decided to cooperate together without a peer observer. They scheduled their dialogues in between lessons and engaged in merely two dialogues (one lesson per teacher). Although the peer coach role was to focus on in-depth questioning, this subgroup of two teachers (without an observer) fell back on old structures of expert peer coaching by mainly focusing on solutions and tips. Their dialogues were scheduled in twenty minute school breaks, did not start with joint viewings of the video tape and both teachers afterwards reported a lack of reflective questioning. The participants clarified their choices blaming lack of time, but regretted their choices afterwards. 
All teachers were (very) positive about the function of an external trainer who structured reflection processes during meetings in both parts of the program. Two teachers noted in the interviews that they themselves needed an external trainer to help with self-discipline. One of them (a team manager) indicated that his own learning process would have been even better stimulated if the trainer would have monitored more severely and would have forced him to invest more time in the program.

In the questionnaire and the interviews, all teachers reported increased confidence in their peers and increased readiness to cooperate with their colleagues. The management and school-based coach observed in the school that participants talked positively about the program with colleagues outside the program, and that the program became positively known within the organization.

All participants reported that they were not troubled by the heterogeneity of the group. They felt secure because all participants (including a team manager and two school-based coaches) opened up their practice and shared their concerns. Overall, as a result of the program, all teachers reported increased confidence in their colleagues (Table 4.7, item 17).

\subsection{CONCLUSIONS AND RECOMMENDATIONS FOR THE REDESIGN}

\subsubsection{Support of teacher learning in the prototype}

Overall, all participants were (very) positive in their program evaluation. They noted they had learned a lot. In the questionnaires, both parts of the program were viewed as effective for their learning processes. They indicated they learned to reflect more and became aware of their automatisms. They actively exchanged knowledge and learned from the performance of colleagues. Teachers considered the method during the first part (the 'Expert Meeting') less effective than the method during the second part (reciprocal peer coaching with video feedback). All teachers expressed the wish to change a future program in favor of this second part. 


\subsubsection{Characteristics of the prototype that stimulated teacher learning}

\section{A. Collaborative learning at the workplace}

In the program, teachers valued the second part of the program most (reciprocal peer coaching with video feedback). Part 1 of the program (the 'Expert Meeting') helped teachers to get acquainted with each other and helped them to learn to reflect on their own professional behavior in an open atmosphere. This first part of the program has contributed towards creating trust between colleagues. However, teachers reported that trust is created for most by explicitly sharing problems and showing vulnerability ('we all have problems and we are all learners') during all parts of the program. Teachers who expressed a clear need for help stimulated commitment in colleagues. As a result, peers became more interested and willing to think along and to help each other. According to a school-based coach, it also stimulated teachers to help each other outside of the program. Teachers considered working in peer groups enjoyable and instructive, and reported they had become more openminded towards cooperating with colleagues in the future. The shared context of their own school and teaching the same student groups helped them to discuss experiences and made dialogues more interesting.

Meetings in subgroups of three teachers, with well defined roles as learner, coach and observer of the coach role, helped the participants to focus and to create an effective work climate. The role of the observer in reciprocal peer coaching dialogues appeared to have been quite crucial for keeping focus. Because the coach was observed, and his skills were discussed, the participants became more serious in performing their role and the participants reserved more time for their coaching dialogues. Furthermore, the role of observer appeared to be also very important for 'coaching-the-coach'. The participants reported that observing the coaching of their peer and providing the coach with feedback not only helped their peer coach develop coaching skills, but also helped the observer to learn the coach role.

Trust between participants was stimulated by a team manager and a schoolbased coach who were both one of the first to show their video recordings and who were both willing to show 'weak moments' in their teaching and/or coaching. In doing so, they established a work climate in which it was acceptable to show own 'failure' and to collaboratively study own real work problems. 


\section{B. Feedback through observation and analyses of own practice}

In the first part of the program, teachers only received limited feedback and in an indirect manner. Only parts of their reflections (in their homework) were selected for discussions during meetings.

In the second part of the program, feedback on own practice was central in their learning processes. All participants considered the information created through video recordings of their lessons as rich and useful feedback. All teachers expressed the wish to focus the program more on the use of this tool, although all teachers also reported some stress as a result of being observed by colleagues. Video recordings provided abundant feedback on classroom performances to study again and again. It also provided opportunities to analyze and to gain feedback on own analysis by discussing recordings with peers. Viewing video recordings helped to relive classroom situations, and provided opportunities to study aspects the teachers were satisfied and unsatisfied with. It also provided opportunities to share practice between peers and study each other's classrooms.

Video feedback appeared to relate classroom performance to self-confidence. Regularly the self-confidence of beginners was stimulated noticing things that went well; in contrast the self-confidence of experienced teachers - expecting their lessons going well - got regularly a slight blow by observing things they still could improve.

\section{Teacher ownership of learning goals}

In the plenary parts of the program, teachers jointly chose topics they wanted to study and reflect on. In the reciprocal peer coaching subgroups each teacher chose his/her own focus according to own learning goals. Most participants reported that their peer coach actually coached on the chosen focus. In interviews the participants explained that the presence of the third person, their peer in the observer role, helped them to stay focused on their performance as coach and helped them to limit themselves to in-depth questioning instead of elaborating on own views or supplying own assessments and tips. The relatively low appreciation of theory seems to confirm the demand for school-based training focusing on teachers own practice and choosing own learning goals. 


\section{Inquiry of own practice focusing on classroom performances and student outcomes}

The teachers studied classroom performances. The dialogues in both parts of the program focused on discussions of their experiences and not on structured inquiries into student outcomes. Strengthening the function of teachers doing inquiries into own practice in future programs could be a useful addition to the program.

Some participants indicated that they wished the program had also provided more time for studying video tapes of own classroom during plenary meetings. As a reason for this they referred to the prompts of the external trainer in analyzing classroom performances.

\section{E. Creating conditions in the school for professional development}

All teachers, although strongly motivated, reported difficulties in creating enough time for fully participating in the program. Teachers are like performers ('the show must go on'), the core business (lessons and coaching students) always precedes all other activities. In the program there were difficulties in arranging meeting times for the joint gatherings, even though management was supportive and teachers were allowed to skip lessons. All participants reported real difficulties in finding shared free time in their school schedules for their dialogues in triads. Because of this, some subgroups combined coaching dialogues on lessons of all three members, and reserved a whole afternoon or evening for the three dialogues. Other subgroups made separate appointments for every dialogue. Although all participants were motivated, as a result of the lack of shared free time, it was not possible to have more reciprocal peer coaching dialogues.

Teachers reported they primarily participated on a voluntary basis with a personal commitment to own professional development. However, during the school year, participants also felt committed to the program through their signed contract and the prospect of the bonus.

External expertise appeared appreciated and important.

Participation of middle management (team manager and school-based coaches) seems no impediment for participation of other teachers in the program. Moreover, middle managers or experts who showed own vulnerability seems to stimulate other teachers to also open up own practice. 


\subsubsection{Conclusions and recommendations for the redesign of the program}

On the basis of the results of the implementation of the (prototype) program, the following recommendations for the redesign were formulated (for an overview see Table 4.10).

I. The most promising features of the existing program to be built into the next program

- The program should create structures that stimulate an atmosphere in which teachers are willing to share successes and failures. One way to stimulate trust between participants is the guideline of reciprocal peer coaching, in which all participants open up own practice and all teachers are considered learners.

- Cooperation in heterogeneous groups (teachers differing in years of experience, subject, team) can be functional provided there is trust created between the participants.

- It is useful to coach in reciprocal peer coaching groups consisting of three teachers with the well defined roles of teacher-trainee, teacher-coach and teacher-observer.

- Reciprocal peer coaching with video feedback is a valuable tool for the professional development of teachers.

- The program should provide ample opportunities to observe and analyze video recordings of own classroom practices. However, in this study it turns out that it is also very stimulating and instructive to have much opportunity to observe and analyze the videos of others. Observing and analyzing video recordings of colleagues stimulates:

- engagement between colleagues;

- the sharing of ideas and practices and community building;

- teacher learning and development by deepening reflection;

- relating self-confidence to classroom reality.

- Video recordings offer an abundance of feedback. Peer coaching helps to restrain information and gain in-depth dialogues and reflections.

- Participants need more training in coaching skills. Observing each other during reciprocal peer coaching, videotaping own peer coaching dialogues, and analyzing and discussing these during plenary meetings are useful tools for the training of coaching skills.

- The ALACT model for guiding and supporting reflective dialogues is useful for the training of peer coaching skills. 
- Peer coaching must pertain closely to the needs and feelings of the teachertrainee, and must therefore focus on individual learning goals set by the teachers themselves.

- Commitment in teachers who volunteer to participate can be reinforced further by contracts and/or bonuses. In schools there is always something happening and 'the show must go on', reinforcing teachers' commitment can help them maintain focus.

- An external trainer is useful for bringing in new expertise and for stimulating commitment and discipline in participants.

\section{Recommendations for changes in the design of the program}

- In the future, the first part of the program (expert meetings) should be skipped in favor of more time spent on reciprocal peer coaching with video feedback.

- Trust between participants is a necessary condition for the program. If the first part of the program is skipped, new structures for stimulating trust between participants may be necessary.

- It is helpful when participants with more power or prestige (e.g. middle managers or school coaches) are the first to open up own practice and show vulnerability and an intention to learn. This stimulates others to also show their practice (with successes and failures) and to focus on learning.

- Identifying own learning goals is a multilayered process, that needs to be sustained over time. Teachers often need more time and help to discover the deeper learning goals behind own experienced 'wondering' or 'problems'.

- It is unclear whether the program had outcomes in classrooms. Additional features may be needed for stimulating participants to investigate and implement own learning outcomes in classrooms.

- Conditions for participating need to be created within the school. Especially:

- Participants need provision of time and of timeslots for meetings and dialogues.

- Subgroups often need the same equipment at the same time, therefore a generous quantity of available video cameras and TV sets are a necessity. 
Table 4.10 Recommended characteristics for the redesign of the program

\begin{tabular}{|c|c|c|c|c|}
\hline \multirow{2}{*}{$\begin{array}{l}\text { Design } \\
\text { principle }\end{array}$} & \multirow{2}{*}{$\begin{array}{l}\text { Translation into characteristics of } \\
\text { the program } \\
\text { (prototype) }\end{array}$} & \multirow{2}{*}{$\begin{array}{l}\text { Results } \\
\text { (prototype) }\end{array}$} & \multicolumn{2}{|c|}{ Recommendations for redesign of the PD program } \\
\hline & & & $\begin{array}{l}\text { Most promising } \\
\text { characteristics }\end{array}$ & Recommended changes \\
\hline $\begin{array}{l}1 . \\
\text { Collaborative } \\
\text { learning at the } \\
\text { workplace in } \\
\text { the form of } \\
\text { reciprocal peer } \\
\text { coaching }\end{array}$ & $\begin{array}{l}\text { Cooperating in heterogeneous } \\
\text { groups (participants may } \\
\text { differ in years of experience, } \\
\text { subject taught, team, position } \\
\text { in the school). } \\
\text { - Peer dialogues on own and } \\
\text { peer practice. } \\
\text { - Visiting and videotaping in } \\
\text { each other's classrooms. } \\
\text { - Reciprocal peer coaching in } \\
\text { triads. }\end{array}$ & $\begin{array}{l}\text { Outcomes differed, but all } \\
\text { teachers felt stimulated. } \\
\text { Beginners felt more self- } \\
\text { confident by observing video } \\
\text { recordings of themselves and } \\
\text { by observing recordings of } \\
\text { other teachers. Experienced } \\
\text { teachers became aware of own } \\
\text { routines and reflected on them. } \\
\text { Much valued: visiting each } \\
\text { other's classroom and } \\
\text { reciprocal peer dialogues on } \\
\text { video recordings of classroom } \\
\text { practice. } \\
\text { Proposed: skip first part of the } \\
\text { program in favor of second } \\
\text { part. } \\
\text { First part of the program } \\
\text { (discussions on anonymized } \\
\text { case stories) created trust } \\
\text { between participants, but was } \\
\text { less valued than the second } \\
\text { part of the program (reciprocal } \\
\text { peer coaching with video } \\
\text { feedback). }\end{array}$ & $\begin{array}{l}\text { - Focus on reciprocal peer } \\
\text { coaching dialogues with } \\
\text { video feedback. } \\
\text { - Cooperation in } \\
\text { heterogeneous groups } \\
\text { (participants may differ } \\
\text { in years of experience, } \\
\text { subject taught, team, } \\
\text { position in the school). } \\
\text { A program must } \\
\text { stimulate an attitude in } \\
\text { which teachers are } \\
\text { willing to share } \\
\text { successes and failures. } \\
\text { Trust between } \\
\text { participants can be } \\
\text { stimulated by creating } \\
\text { equality through } \\
\text { reciprocal peer coaching } \\
\text { in which every teacher } \\
\text { opens up own practice } \\
\text { and in which every } \\
\text { teacher is a learner in his } \\
\text { own right. }\end{array}$ & $\begin{array}{l}\text { - In the future, the first } \\
\text { part of the program } \\
\text { (Expert meetings) should } \\
\text { be skipped in favor of } \\
\text { more time spent on } \\
\text { reciprocal peer coaching } \\
\text { with video feedback. } \\
\text { - Because the first part of } \\
\text { the program should be } \\
\text { skipped, additional } \\
\text { structures for } \\
\text { stimulating trust } \\
\text { between participants } \\
\text { may be needed. } \\
\text { To stimulate trust } \\
\text { between participants: } \\
\text { beginning of opening up } \\
\text { own practice and } \\
\text { showing vulnerability } \\
\text { and an intention to } \\
\text { learning by participants } \\
\text { with more power or } \\
\text { prestige (e.g. middle } \\
\text { managers or school } \\
\text { coaches). }\end{array}$ \\
\hline
\end{tabular}


Table 4.10 Recommended characteristics for the redesign of the program (Continued)

\begin{tabular}{|c|c|c|c|c|}
\hline \multirow{2}{*}{$\begin{array}{l}\text { Design } \\
\text { principle }\end{array}$} & \multirow{2}{*}{$\begin{array}{l}\text { Translation into characteristics of } \\
\text { the program } \\
\text { (prototype) }\end{array}$} & \multirow{2}{*}{$\begin{array}{l}\text { Results } \\
\text { (prototype) }\end{array}$} & \multicolumn{2}{|c|}{ Recommendations for redesign of the PD program } \\
\hline & & & $\begin{array}{l}\text { Most promising } \\
\text { characteristics }\end{array}$ & Recommended changes \\
\hline & & $\begin{array}{l}\text { Participants appreciated } \\
\text { cooperation in heterogeneous } \\
\text { groups and felt afterwards } \\
\text { more connected to their } \\
\text { colleagues. } \\
\text { - Differences in job positions did } \\
\text { not interfere with collaborative } \\
\text { learning on condition that } \\
\text { everyone is willing to open up } \\
\text { own classroom practice. }\end{array}$ & & \\
\hline $\begin{array}{l}\text { 2. Focus on } \\
\text { own practice } \\
\text { with the help } \\
\text { of video } \\
\text { feedback }\end{array}$ & $\begin{array}{l}\text { Dialogues on anonymized case } \\
\text { stories from own practice } \\
\text { around jointly chosen topics in } \\
\text { search of shared views } \\
\text { - Reflective dialogues on } \\
\text { videotaped performances in } \\
\text { own classrooms. }\end{array}$ & $\begin{array}{l}\text { Discussions on own } \\
\text { anonymized case stories (part } \\
1 \text { of the program) is not very } \\
\text { intrusive and a safe way of } \\
\text { generating feedback on own } \\
\text { practice through comparing } \\
\text { own practice and views with } \\
\text { the practice and views of } \\
\text { peers. } \\
\text { Viewing and discussing video } \\
\text { recordings of each other's } \\
\text { classroom practices appeared } \\
\text { to be a more powerful tool. }\end{array}$ & $\begin{array}{l}\text { Observing and analyzing } \\
\text { own video recordings } \\
\text { - Ample opportunities for } \\
\text { observing and analyzing } \\
\text { video recordings of } \\
\text { others. } \\
\text { - Peer coaching dialogues } \\
\text { on video recordings need } \\
\text { to focus and restrain } \\
\text { information and gain in- } \\
\text { depth dialogues. }\end{array}$ & \\
\hline
\end{tabular}


Table 4.10 Recommended characteristics for the redesign of the program (Continued)

\begin{tabular}{|c|c|c|c|c|}
\hline \multirow{2}{*}{$\begin{array}{l}\text { Design } \\
\text { principle }\end{array}$} & \multirow{2}{*}{$\begin{array}{l}\text { Translation into characteristics of } \\
\text { the program } \\
\text { (prototype) }\end{array}$} & \multirow{2}{*}{$\begin{array}{l}\text { Results } \\
\text { (prototype) }\end{array}$} & \multicolumn{2}{|c|}{ Recommendations for redesign of the PD program } \\
\hline & & & $\begin{array}{l}\text { Most promising } \\
\text { characteristics }\end{array}$ & Recommended changes \\
\hline & & $\begin{array}{l}\text { Video recordings of own } \\
\text { practice offer an abundance of } \\
\text { feedback. Dialogues on video } \\
\text { recordings need a structure } \\
\text { and a focus to restrain } \\
\text { information and gain 'in- } \\
\text { depth' dialogues and } \\
\text { reflections. } \\
\text { A peer can provide extra value } \\
\text { to feedback information on } \\
\text { video recordings. Sharing and } \\
\text { discussing own practices with } \\
\text { peers stimulated new insights. } \\
\text { Learning takes place as a result } \\
\text { of dialogues on video } \\
\text { recordings of own practice, but } \\
\text { also as a result of observing } \\
\text { and analyzing video } \\
\text { recordings of practices of } \\
\text { peers. }\end{array}$ & & \\
\hline
\end{tabular}


Table 4.10 Recommended characteristics for the redesign of the program (Continued)

\begin{tabular}{|c|c|c|c|c|}
\hline \multirow{2}{*}{$\begin{array}{l}\text { Design } \\
\text { principle }\end{array}$} & \multirow{2}{*}{$\begin{array}{l}\text { Translation into characteristics of } \\
\text { the program } \\
\text { (prototype) }\end{array}$} & \multirow{2}{*}{$\begin{array}{l}\text { Results } \\
\text { (prototype) }\end{array}$} & \multicolumn{2}{|c|}{ Recommendations for redesign of the PD program } \\
\hline & & & $\begin{array}{l}\text { Most promising } \\
\text { characteristics }\end{array}$ & Recommended changes \\
\hline & & $\begin{array}{l}\text { Observing and analyzing } \\
\text { video recordings of colleagues } \\
\text { stimulated: } \\
\text { - } \text { engagement between } \\
\text { colleagues } \\
\text { - } \text { the sharing of ideas and } \\
\text { practices and community } \\
\text { building } \\
\text { - } \quad \text { trying out of new ideas } \\
\text { - } \\
\text { self-confidence of teachers } \\
\text { (sometimes) }\end{array}$ & & \\
\hline $\begin{array}{l}\text { 3. Teacher } \\
\text { ownership of } \\
\text { learning goals }\end{array}$ & $\begin{array}{l}\text { Teachers jointly choose topics for } \\
\text { generating and discussing own } \\
\text { case stories and analyzing video } \\
\text { recordings of own practice } \\
\text { during plenary meetings. } \\
\text { - Reciprocal peer coaching in trios } \\
\text { on goals and excerpts of video } \\
\text { recordings chosen by the } \\
\text { individual teacher himself. }\end{array}$ & $\begin{array}{l}\text { Focusing on central topics } \\
\text { (during the first part of the } \\
\text { program) helped to share and } \\
\text { discuss own experiences. } \\
\text { - Coaching on learning goals } \\
\text { chosen by the teachers } \\
\text { themselves created trust } \\
\text { between participants in triads. } \\
\text { - Teachers primarily want help } \\
\text { with analyzing their own } \\
\text { practice and not compliments or } \\
\text { 'sizing down' from their peers. } \\
\text { - Actions in classroom but also } \\
\text { feelings, motives and } \\
\text { assumptions are all part of } \\
\text { learning processes and should } \\
\text { be studied. }\end{array}$ & $\begin{array}{l}\text { Video recordings offer an } \\
\text { abundance of feedback. } \\
\text { Teachers need to select } \\
\text { topics for discussion, } \\
\text { fitting in with the chosen } \\
\text { learning goal. } \\
\text { - Teachers need to be in } \\
\text { control of own } \\
\text { professional development } \\
\text { and decide themselves on } \\
\text { the focus of the dialogues } \\
\text { and own individual } \\
\text { learning goals. } \\
\text { - Peer coaching must fit in } \\
\text { closely with the needs and } \\
\text { feelings of the teacher- } \\
\text { trainee. }\end{array}$ & $\begin{array}{l}\text { - Identifying own learning } \\
\text { goals is a multilayered } \\
\text { process. Teachers need } \\
\text { support when analyzing } \\
\text { own performances, own } \\
\text { convictions and own } \\
\text { ideals and may also need } \\
\text { support with identifying } \\
\text { own learning needs and } \\
\text { goals. }\end{array}$ \\
\hline
\end{tabular}


Table 4.10 Recommended characteristics for the redesign of the program (Continued)

\begin{tabular}{|c|c|c|c|c|}
\hline \multirow{2}{*}{$\begin{array}{l}\text { Design } \\
\text { principle }\end{array}$} & \multirow{2}{*}{$\begin{array}{l}\text { Translation into characteristics of } \\
\text { the program } \\
\text { (prototype) }\end{array}$} & \multirow{2}{*}{$\begin{array}{l}\text { Results } \\
\text { (prototype) }\end{array}$} & \multicolumn{2}{|c|}{ Recommendations for redesign of the PD program } \\
\hline & & & $\begin{array}{l}\text { Most promising } \\
\text { characteristics }\end{array}$ & Recommended changes \\
\hline $\begin{array}{l}\text { 4. Focus on } \\
\text { teacher's } \\
\text { inquiry stance } \\
\text { and outcomes } \\
\text { in classroom }\end{array}$ & $\begin{array}{l}\text { - Generating feedback through } \\
\text { observation and analyses of } \\
\text { own practice: } \\
\text { - } \quad \text { Teachers analyze and } \\
\text { reflect on own practice } \\
\text { with the help of their own } \\
\text { case stories. } \\
\text { - } \quad \text { Observing, reflecting and } \\
\text { analyzing video } \\
\text { recordings of own and } \\
\text { peer practice in triads. } \\
\text { - Observing, reflecting and } \\
\text { analyzing video } \\
\text { recordings of own and } \\
\text { peer practice in joint } \\
\text { meetings of all } \\
\text { participants. } \\
\text { Comparing own performances } \\
\text { and views with performances } \\
\text { and views of peers. }\end{array}$ & $\begin{array}{l}\text { Some participants indicated } \\
\text { that they wished the program } \\
\text { had also spent more time on } \\
\text { studying videotaped } \\
\text { performances during plenary } \\
\text { meetings (besides their } \\
\text { dialogues in triads). They } \\
\text { motivated this by referring to } \\
\text { the added value of the } \\
\text { analyses of the trainer and the } \\
\text { malfunctioning of their } \\
\text { subgroup (e.g. with scheduling } \\
\text { of appointments). }\end{array}$ & $\begin{array}{l}\text { - Generating feedback } \\
\text { through observation and } \\
\text { analyses of video } \\
\text { recordings of own } \\
\text { practice and peer } \\
\text { practice in triads. } \\
\text { - Observing, reflecting and } \\
\text { analyzing video } \\
\text { recordings of own and } \\
\text { peer practice in joint } \\
\text { meetings with all } \\
\text { participants. } \\
\text { - Comparing own } \\
\text { performances and views } \\
\text { with performances and } \\
\text { views of peers. }\end{array}$ & $\begin{array}{l}\text { - Analyses of video } \\
\text { recordings in plenary } \\
\text { meetings with the help } \\
\text { of external expertise can } \\
\text { be an addition to the } \\
\text { dialogues in triads. } \\
\text { - Strengthening the } \\
\text { function of teachers } \\
\text { doing inquiries into own } \\
\text { practice in future } \\
\text { programs. }\end{array}$ \\
\hline
\end{tabular}


Table 4.10 Recommended characteristics for the redesign of the program (Continued)

\begin{tabular}{|c|c|c|c|c|}
\hline \multirow{2}{*}{$\begin{array}{l}\text { Design } \\
\text { principle }\end{array}$} & \multirow{2}{*}{$\begin{array}{l}\text { Translation into characteristics of } \\
\text { the program } \\
\text { (prototype) }\end{array}$} & \multirow{2}{*}{$\begin{array}{l}\text { Results } \\
\text { (prototype) }\end{array}$} & \multicolumn{2}{|c|}{ Recommendations for redesign of the PD program } \\
\hline & & & $\begin{array}{l}\text { Most promising } \\
\text { characteristics }\end{array}$ & Recommended changes \\
\hline $\begin{array}{l}\text { 5. Creating } \\
\text { conditions in } \\
\text { the school for } \\
\text { PD and PD } \\
\text { program }\end{array}$ & $\begin{array}{l}\text { - Commitment of management: } \\
\text { the professional development } \\
\text { program will be executed for } \\
\text { three consecutive years. } \\
\text { - Participation is voluntary. } \\
\text { - Participants sign contract and } \\
\text { receive a bonus of } 300 \text { euro at } \\
\text { the end of the program. } \\
\text { - Program is implemented at the } \\
\text { workplace. } \\
\text { - External expertise of a teacher } \\
\text { training college and of an } \\
\text { expertise center (RdMC) is } \\
\text { linked to school-based activity. }\end{array}$ & $\begin{array}{l}\text { Main motive for participating } \\
\text { was a desire to work on own } \\
\text { development. Further } \\
\text { commitment in teachers was } \\
\text { stimulated by contracts and } \\
\text { bonuses. } \\
\text { - Participating in own spare } \\
\text { time draws heavily from } \\
\text { teacher's energy. } \\
\text { - Due to the different schedules } \\
\text { of individual teachers it is } \\
\text { difficult to find shared free } \\
\text { time for dialogues in triads. } \\
\text { - School-based dialogues } \\
\text { increased commitment and } \\
\text { relevance; and helped to } \\
\text { realize the implementation of } \\
\text { the program } \\
\text { External expertise was } \\
\text { important for structuring } \\
\text { dialogues and for training in } \\
\text { coaching skills. It also } \\
\text { stimulated self-discipline in } \\
\text { participants. }\end{array}$ & $\begin{array}{l}\text { Program should be } \\
\text { school-based. } \\
\text { - Commitment in } \\
\text { volunteers can be further } \\
\text { stimulated by contracts } \\
\text { and/or bonuses. } \\
\text { - Addition of an external } \\
\text { trainer to the program } \\
\text { who can provide } \\
\text { structure and stimulate } \\
\text { commitment and } \\
\text { discipline in participants. }\end{array}$ & $\begin{array}{l}\text { Participants need } \\
\text { provision of time and of } \\
\text { timeslots for meetings } \\
\text { and video taping in each } \\
\text { other's classrooms. } \\
\text { - A generous quantity of } \\
\text { available video cameras } \\
\text { and TV sets. }\end{array}$ \\
\hline
\end{tabular}


Table 4.10 Recommended characteristics for the redesign of the program (Continued)

\begin{tabular}{|c|c|c|c|c|}
\hline \multirow{2}{*}{$\begin{array}{l}\text { Design } \\
\text { principle }\end{array}$} & \multirow{2}{*}{$\begin{array}{l}\text { Translation into characteristics of } \\
\text { the program } \\
\text { (prototype) }\end{array}$} & \multirow{2}{*}{$\begin{array}{l}\text { Results } \\
\text { (prototype) }\end{array}$} & \multicolumn{2}{|c|}{ Recommendations for redesign of the PD program } \\
\hline & & & $\begin{array}{l}\text { Most promising } \\
\text { characteristics }\end{array}$ & Recommended changes \\
\hline & $\begin{array}{l}\text { A need for strategies and skills for } \\
\text { professional development: } \\
\text { - Discussions on own cases have } \\
\text { a fixed format and are led by } \\
\text { trainer } \\
\text { - } \text { Reciprocal peer coaching with } \\
\text { well defined roles (teacher, } \\
\text { peer-coach, observer of coach } \\
\text { dialogue) } \\
\text { - A reader with theoretical } \\
\text { notions and guidelines on } \\
\text { 'coaching' and on 'teaching } \\
\text { and active learning'. }\end{array}$ & $\begin{array}{l}\text { - Teachers have not already } \\
\text { required the necessary } \\
\text { coaching skills. Teachers need } \\
\text { training in coaching skills. } \\
\text { - Structuring the dialogues in } \\
\text { subgroups helped to analyze } \\
\text { own practice. The ALACT } \\
\text { model for guiding and } \\
\text { supporting reflective dialogues } \\
\text { is useful within reciprocal peer } \\
\text { coaching settings. } \\
\text { - Fixed roles in subgroups (of } \\
\text { coachee, coach, and observer } \\
\text { of dialogue) are important for } \\
\text { creating more 'in-depth' } \\
\text { dialogues. } \\
\text { The role of observer of } \\
\text { coaching dialogue helped the } \\
\text { others stay focused on their } \\
\text { roles, observing each other's } \\
\text { coach dialogues helped the } \\
\text { participants to develop } \\
\text { coaching skills } \\
\text { Learned coaching skills were } \\
\text { also useful in other } \\
\text { professional work situations } \\
\text { with students and parents. }\end{array}$ & $\begin{array}{l}\text { - Professional dialogues on } \\
\text { own performance need to } \\
\text { be structured for creating } \\
\text { 'in-depth' dialogues. } \\
\text { - Reciprocal peer coaching } \\
\text { in subgroups consisting } \\
\text { of three teachers with } \\
\text { well-defined roles of } \\
\text { teacher-trainee, teacher- } \\
\text { coach and teacher- } \\
\text { observer. } \\
\text { - The role of observer in } \\
\text { dialogues in subgroups is } \\
\text { very influential. } \\
\text { - Teachers need to be } \\
\text { trained in coaching skills. } \\
\text { - The ALACT model for } \\
\text { guiding and supporting } \\
\text { reflective dialogues is } \\
\text { useful within peer } \\
\text { coaching settings. }\end{array}$ & $\begin{array}{l}\text { It is unclear whether the } \\
\text { program had outcomes } \\
\text { in classroom. Additional } \\
\text { features may be needed } \\
\text { for stimulating } \\
\text { participants to } \\
\text { investigate and } \\
\text { implement own learning } \\
\text { outcomes in classrooms. }\end{array}$ \\
\hline
\end{tabular}


Table 4.10 Recommended characteristics for the redesign of the program (Continued)

\begin{tabular}{|c|c|c|c|c|}
\hline \multirow{2}{*}{$\begin{array}{l}\text { Design } \\
\text { principle }\end{array}$} & \multirow{2}{*}{$\begin{array}{l}\text { Translation into characteristics of } \\
\text { the program } \\
\text { (prototype) }\end{array}$} & \multirow{2}{*}{$\begin{array}{l}\text { Results } \\
\text { (prototype) }\end{array}$} & \multicolumn{2}{|c|}{ Recommendations for redesign of the PD program } \\
\hline & & & $\begin{array}{l}\text { Most promising } \\
\text { characteristics }\end{array}$ & Recommended changes \\
\hline & & $\begin{array}{l}\text { - Teachers did not much study } \\
\text { the reader with theoretical } \\
\text { notions and guidelines on } \\
\text { 'coaching' and on 'teaching } \\
\text { and active learning'. They } \\
\text { preferred studying in } \\
\text { dialogues with peers (in } \\
\text { meetings or in subgroup } \\
\text { meetings). } \\
\text { - Teachers did not study } \\
\text { outcomes of their learning in } \\
\text { own classroom. }\end{array}$ & $\begin{array}{l}\text { Observing each other } \\
\text { during reciprocal peer } \\
\text { coaching and videotaping } \\
\text { own peer coaching } \\
\text { dialogues and discussing } \\
\text { them during training are } \\
\text { useful tools for } \\
\text { developing coaching } \\
\text { skills. }\end{array}$ & \\
\hline
\end{tabular}




\section{CHAPTER 5}

\section{Evaluating a professional development program with reciprocal peer coaching and video feedback}

In this chapter the design and the design process of the program "Learning to Notice" is described. This program has been implemented in the school for two successive years in a row, once in the context of voluntary participation and once in the context of a mandatory team effort. These implementations are evaluated with the help of, among others, questionnaires and semi-structured interviews. The results show that the program as a whole stimulates teacher learning in the context of the school. All basic design principles appear to be important for the creation challenging learning environment, principles and characteristics interacting with each other in the program. For a secure learning environment are crucial: reciprocal peer coaching, coach training, well defined roles for their dialogues, and an observer of the peer coach dialogue. Participation based on a mandatory team effort did not stimulate all teachers to learn due to various reasons.

\subsection{INTRODUCTION}

This study reports on the implementation and the results of the second cycle of a study on design principles for professional development programs based on teachers' collaborative learning and the sharing and studying of their own practice. In the first cycle of this design study, a prototype of a PD program for teachers was devised which incorporated different forms of collaborative reflective dialogues on own practice. This program was piloted and the results were evaluated (see Chapter 4 of this thesis). Based on the findings of this evaluation, recommendations for the redesign were formulated (Table 4.10), one of these recommendations was to construct the adapted program around one specific form of reflective dialogue; namely, reciprocal peer coaching with 
video feedback. The revised PD program was called 'Learning to Notice' [Bij Nader Inzien]. This PD program has been implemented and studied in two different settings: during the first year as a program for teachers who volunteered to participate (= Cohort $\mathrm{A})$ and during the second year as an mandatory team effort (= Cohort B). This provided the opportunity to study not only the program, but also the influence of (in)voluntary participation as one of the conditions in the school.

The following research questions were formulated for the evaluation of the PD program 'Learning to Notice':

1. To what extent did the PD program support the learning of teachers at the workplace?

2. Which characteristics of the PD program supported the learning of teachers at the workplace?

3. What was the influence of (in)voluntary participation on teachers' learning?

The effects of the program are described with the help of the research model presented in Chapter 1. This model is based on the PD evaluation model by Guskey (2000) and a similar model for studying effects of PD by Desimone (2009). Effects of the program are studied on the level of participants' reactions, participants' learning, participants' use of new knowledge and skills, outcomes in students, and the effects on the school organization.

The following paragraphs will first describe the PD program 'Learning to Notice'. The design of this program is based on the five design principles found in the literature search (Chapter 3) and on the outcomes of the evaluation of the design characteristics of the prototype (Chapter 4). Secondly, the method of the study will be outlined, followed by a description of the results. In the concluding paragraph, in order to answer the research questions, the findings will be related to the five design principles and to the design characteristics of the program. Finally, the influence of (in)voluntary participation will be discussed as one of the conditions in the school. 


\subsection{THE PROFESSIONAL DEVELOPMENT PROGRAM 'LEARNING TO NOTICE’}

\subsubsection{Background}

The PD program 'Learning to Notice' has been implemented in the school during the second and third year of the three-year cooperative project between a teacher training college and a school for secondary education. During the first year, a prototype of the program was developed, piloted and evaluated (Chapter 4). On the basis of the results of the evaluation (Table 4.10), the outcomes of a continuous literature study into effective characteristics of PD programs (Chapter 3), and our own personal knowledge base as teacher trainers, the PD program was redesigned and implemented in the school for the two remaining years - in the first of these two years in a context of voluntary participation and in the final year in the context of a mandatory team effort.

\subsubsection{Redesign of the program}

Overall aim/rationale

The program constitutes a carefully constructed and monitored process in which teachers come together to engage in a structured conversation designed to help establish a common language, to identify and probe individual practice and assumptions, and to examine the practice and assumptions of colleagues in a non-confrontational manner that respects each individual's professionalism while challenging each other to examine beliefs more rigorously. It is hypothesized, that through dialogues on own practice with peers and through the use of feedback in the form of video recordings, as well as with the aid of a trained peer coach and focused guidelines (such as active listening, open-ended questioning, and suspension of judgment), teachers would feel comfortable stating feelings and assumptions and would become receptive to exploring the validity of these and to studying own outcomes in classroom.

At the core of the program lies the concept of facilitating collaborative workplace learning and reflections on own practice by means of reciprocal peer coaching with video feedback. It concerns a strategy ideally driven by the learner's motivation and preference. Each teacher chooses individual learning goals and studies own practice and performance with peers and with the help of video feedback. In the program, teachers are stimulated to study own practice from an inquiry stance and to focus on outcomes in classroom. 
Teachers are challenged to make their personal knowledge explicit and to share, inquire into and reflect on their knowledge in a work context. Teachers use data obtained through video feedback and the informed judgment gained in their reflective peer coaching dialogues to rethink choices and devise new actions.

During the prototype phase, a school-based coach mobilized participation of teachers and negotiated the overall scheme. Through word of mouth, news of successes of the prototype helped to mobilize other teachers for the second year and it mobilized one of the team managers in the third year. Teachers were not facilitated with time or timeslots in their school schedules and had to establish their own arrangements for videotaping in classrooms and their peer coaching dialogues.

The overall design of the program included six plenary meetings and - in between two plenary meetings - reciprocal peer coaching with video feedback in triads consisting of three teachers (Figure 5.1).

\section{Plenary meetings}

During 2-3 hours meetings, teachers would familiarize themselves with the goals of reciprocal peer coaching, ways to develop own learning goals and learning strategies, and ways to study own learning outcomes. To stimulate teachers to implement learning outcomes in classroom, a new characteristic of the program was added in which teachers were asked to do an inquiry into own learning goals and learning outcomes in their classroom. In this way, the program should stimulate the teachers to focus on performances and experimentation in classrooms.

Teachers were trained in techniques of videotaping, in communicational skills and ways to guide coaching dialogues, and in doing inquiries into own practice. Teachers videotaped their coaching dialogues in triads and used these video recordings to train themselves in peer coaching. A binder was provided with information about coaching, developing own learning goals, and performing inquiries. At the end of the program, all teachers were asked to present their inquiries and learning processes to each other. 


\section{Small reciprocal peer coaching groups}

Between two plenary meetings the teachers had to join in small triads in reciprocal peer coaching settings. The goal was to study and reflect on own performances using video recordings of the classroom for feedback. A structure for their peer coaching was designed, consisting of the following basic characteristics.

A. Roles were defined for working in triads to stimulate professional dialogues and to maintain focus on learning goals. Within the triad, the three teachers took turns in different roles - as trainee, as coach and as observer of the coaching dialogue.

B. The role of the peer coach was well described and trained. The peer coach' role was not that of an expert giving assessments and tips and tricks, but focused on stimulating reflection in the peer instead, mainly by open-ended questioning. This helped counteract the pitfall of dialogues between colleagues becoming superficial and staying at the level of ' $\mathrm{I}$ 'm OK, you're OK'. More in-depth reflections on performances and on exploration of own professional knowledge and values were stimulated instead. One of the functions of the observer-role was to stimulate peers in staying focused on their roles and to prevent dialogues from becoming superficial.

C. The triads were composed by the trainers, taking into account, as much as possible, the variation in previous experience with coaching, the known likes and dislikes between participants, and the benefits of joining teachers of different subject departments. Heterogeneous triads were composed by the trainers to avoid conflicts of interest between members of the same department, and to create a structured, secure learning environment for all participants. In doing so, the program aimed at stimulating new strings of cooperation in the school as well.

D. Next, in triads the teachers were asked to focus on helping each other to reflect on own learning goals and on ways to register own progress. In line with the design principle of the teacher as owner of own learning goals, there was no pre-determined central focus for learning (top-down). Instead, each participant chose an individual scope and focus (bottom-up). The teachers used videotapes of classroom performances as a feedback instrument to help them to study and reflect on own competences. The teacher in the coach role videotaped in the classroom of his/her peer, focusing on teacher and student behavior. Teachers in the trainee role determined on which aspects of classroom performance the dialogue should 
focus. The teacher-trainee could choose to view the video recordings and select a number of relevant fragments to discuss beforehand, or the teachertrainee could choose to simply start viewing and discussing the complete lesson together in the triad. Instead of giving own analyses, the teachercoach should help his/her peer to reflect and to generate own feedback with the help of the video recordings.

E. Furthermore, as witnessed in the implementation of the prototype and in literature (Koopmans, Doornbos, \& van Eekelen, 2006), power positions can affect learning processes at the workplace. Power can be defined as the influence of one person over another as a result of individual characteristics, interpersonal relations, positions in the organization and acknowledged expertise. To diminish inequality in power between participants, a characteristic was added to the program in which middle managers or experts teachers were asked to provide a role model by opening up own practice and showing own vulnerability at the start of plenary meetings, before other participants were invited to show their video recordings. In this way, participants with 'power' (as a result of acknowledged expertise or organizational position) had to provide an example and demonstrate it was acceptable to have problems, to make mistakes, and to still be a learner.

F. Finally, in order to stimulate the development of coaching skills, at the end of each dialogue, the triad would also discuss the performance of the teacher-coach and the way the coach had stimulated the reflection process of the colleague. The third teacher, in the observer-role, provided feedback for this discussion.

This program was implemented for two consecutive years, each year within a different context. All of the above characteristics were the same for both years. Figure 5.1 gives an overview of the implementation of the program. 


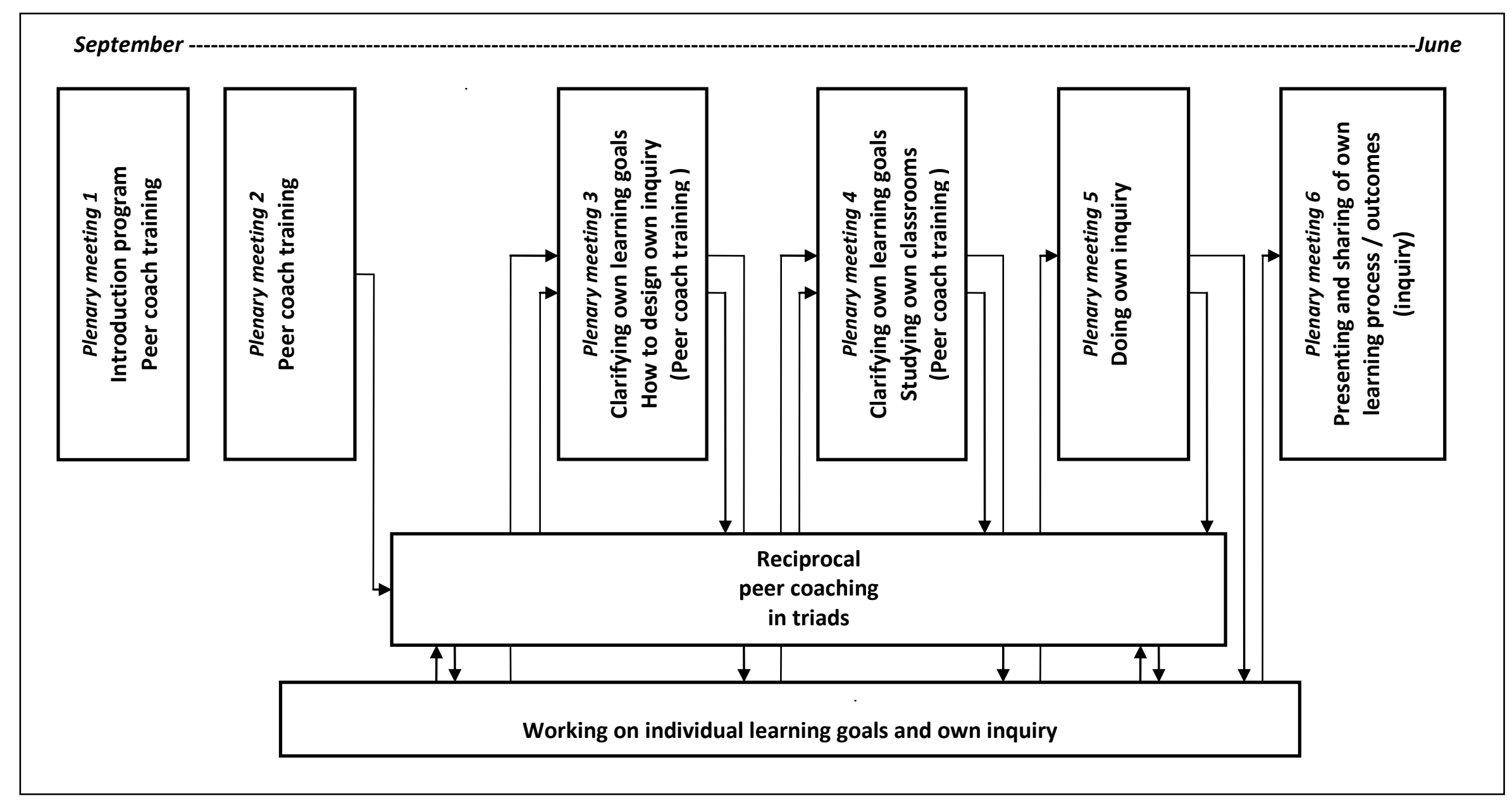

Figure 5.1 Overview of the program 'Learning to Notice' 


\subsection{METHOD}

\subsubsection{Participants and context of participation}

The program was implemented in a school for secondary education with a population of approximately 1200 students (12 to 18 year-olds) and approximately 100 employees in a middle-sized city in the Netherlands. Six teams of teachers operated in the school. Each team was responsible for the curriculum of a group of students at a specific curriculum level. The program was implemented for three consecutive years (including the prototype). Each year, the program fell under the responsibility of a new school manager (viceprincipal, principal, team leader), because two times in a row the manager involved left the school.

The participants in the program were teachers with different backgrounds as to gender, subject taught, years of experience, position in the school, and context of participation (Table 5.1).

Cohort $A$ included nine teachers who volunteered. They wished to work on their individual professional skills by working together in a peer group. They signed a contract, in which the school promised a bonus of 300 euro as compensation instead of provision of time. They discussed two (up to four) videos of each teacher. Each coaching dialogue took at least 30 minutes, up to a maximum of 90 minutes. The program was implemented by two trainers, a school intern coach and a teacher educator who was also the researcher of the program.

In Cohort $B$ the teachers themselves did not volunteer, but the manager of the team responsible for the curriculum for students in the bilingual school program proposed to participate as a team. The team consisted of 19 teachers, including the manager himself who also joined as a participant and the team coach who functioned as trainer in the program. One teacher withdrew before the program had started. There was no bonus offered in return for participation, only the scheduled plenary meeting times were facilitated. The participation of the teachers varied concerning the number of dialogues discussed (one to three videos of an individual teacher), and time spent on each dialogue (ranging from barely 10 minutes to up to 90 minutes on each video). 
The trainer of the program was the school intern coach connected to the participating team. The researcher cooperated with the design program and was also present as observer during plenary meetings.

Table 5.1 Characteristics of the participants in the two cohorts

\begin{tabular}{|c|c|c|}
\hline & $\begin{array}{l}\begin{array}{l}\text { Cohort A } \\
\text { (second year of the project) }\end{array} \\
\end{array}$ & $\begin{array}{l}\text { Cohort B } \\
\text { (third year of the project) }\end{array}$ \\
\hline $\begin{array}{l}\text { Number of } \\
\text { participants }(\mathrm{N})\end{array}$ & 9 participants & 17 participants \\
\hline $\begin{array}{l}\text { Context of } \\
\text { participation }\end{array}$ & $\begin{array}{l}\text { - } \text { Voluntary } \\
\text { - } \text { eontract and bonus (300 } \\
\text { - Teachers from various teams } \\
\text { and departments }\end{array}$ & $\begin{array}{l}\text { - } \text { Almost entire team } \\
\text { - } 1 \text { teacher withdrew before the } \\
\text { program started) } \\
\text { - } \text { Mandatory team effort } \\
\text { duraining was scheduled } \\
\text { time }\end{array}$ \\
\hline Gender & $\begin{array}{l}\text { - } 8 \text { females } \\
\text { - } 1 \text { male }\end{array}$ & $\begin{array}{l}\text { - } 10 \text { females } \\
\text { - } 7 \text { males }\end{array}$ \\
\hline Subject taught: & $\begin{array}{l}\text { - } 2 \text { Sciences } \\
\text { - } 2 \text { Biology } \\
\text { - } 4 \text { Language (Dutch, German, } \\
\text { Spanish) } \\
\text { - } 1 \text { Economics }\end{array}$ & $\begin{array}{l}\text { - } 2 \text { Sciences } \\
\text { - } 1 \text { Biology } \\
\text { - } 2 \text { Mathematics } \\
\text { - } 8 \text { Language (Dutch, English, } \\
\text { German, French) } \\
\text { - } 1 \text { History } \\
\text { - } 1 \text { Geography } \\
\text { - } 1 \text { Arts } \\
\text { - } 1 \text { Physical education }\end{array}$ \\
\hline $\begin{array}{l}\text { Years of experience } \\
\text { - Starters (less than } 2) \\
\text { - Beginners ( } 2 \text { to } 5) \\
\text { - } \quad \text { Experienced (6 to } 10) \\
\text { - Senior experienced } \\
\quad \text { (more than } 10 \\
\text { years) }\end{array}$ & $\begin{array}{l}\text { - } \\
\text { - } 2 \text { starters } \\
\text { - } 3 \text { beginners } \\
\text { - } 4 \text { experienced } \\
\text { - }(-) \text { senior experienced }\end{array}$ & $\begin{array}{l}\text { - } \\
\text { - }(-) \text { starters } \\
\text { - } 4 \text { beginners } \\
\text { - } 9 \text { experienced } \\
\text { - } 4 \text { senior experienced }\end{array}$ \\
\hline Position in the school & $\begin{array}{l}\text { - } 3 \text { teachers with a provisional } \\
\text { appointment }\end{array}$ & $\begin{array}{l}\text { - } 3 \text { teachers with a provisional } \\
\text { appointment } \\
\text { - } 1 \text { participant was also the } \\
\text { team manager }\end{array}$ \\
\hline Trainer & $\begin{array}{l}\text { - } 2 \text { trainers (school-based coach } \\
\text { and teacher educator) }\end{array}$ & - 1 trainer (school-based coach) \\
\hline
\end{tabular}

\subsubsection{Data collection}

The PD program lasted one school year. Multiple methods were used to study relations between characteristics of the program and the learning process of the participants. Data were collected by using the following instruments: 
- Documents and observational notes of the plenary meetings were collected. The researcher attended all plenary meetings. In context $A$ the researcher was also the co-trainer, in context $\mathrm{B}$ the researcher attended the meetings as an observer. The researcher was present in the school for one day a week during the whole project (of three years). This created opportunities for teachers for informal approaches with unsolicited comments on the process, thus providing another source of data.

- Questionnaire. At the end of the program each teacher filled in a questionnaire. As input for the design of the questionnaire we used the questionnaire of the study on peer coaching by Engelen (2002). This questionnaire consisted of 98 questions; most in the form of statements. Teachers responded to each statement using a Lickert rating scale ranging from 1 (certainly not) to 4 (certainly). The questions were gathered around four themes: goals and outcomes, invested time, coaching experiences and outcomes, and background of the participants. (See Appendix 4 for the questionnaire).

- Semi-structured interviews with individual teachers and with the (co)trainer of the program. One to three weeks after the program had ended, each teacher was interviewed on their learning experiences and how they related these to the different parts of the program. These interviews were conducted in a semistructured way (for the procedure and the topics see Appendix 5). In the interview the teacher got 12 cards, each one describing one characteristic of the program and was asked to select them in order of merits for his or her learning process. The purpose of the cards was to provide a structure to let the teachers tell their own stories about their experiences. The interview started with the item the respondent selected as most important, after which the one chosen as second most important was discussed and so on. The interview focused on clarification as to what they had learned from the program and how the various characteristics of the program had stimulated or inhibited their learning processes. Teachers were asked to concretize and illustrate their answers by describing situations and their related actions, thoughts, feelings and results. In this way, the teacher illuminated his or her learning process and outcomes and related these to the specific context and characteristic of the program. Every interview was audio taped. The interviews lasted from just under one hour to almost two hours. 
- Teachers' presentation of individual inquiries. During the last plenary meeting the teachers presented their learning process and outcomes to each other. Videotapes of these presentations and written reports by the participants were included in the analysis. A more detailed study of the inquiries will be presented in Chapter 6.

- To complete the picture, we also collected video recordings of peer coach dialogues. Each triad of three cooperating teachers was asked to record their peer coach dialogues. Six video recordings of peer coach dialogues were selected, fully transcribed, and analyzed; three dialogues of cohort A and three dialogues of cohort B. The results of these analyses of the coaching dialogues will be presented in Chapter 6 .

All instruments were used to study effects on the five different levels of evaluation of our research model: the level of participants' reactions, participants' learning, participants' use of new knowledge and skills, outcomes in students, and the effects on the school organization. In Table 5.2 an overview is presented of the relation between the research questions and the instruments used.

Table 5.2 Overview research questions and instruments

\begin{tabular}{|c|c|c|}
\hline \multicolumn{2}{|l|}{ Research questions } & Instruments \\
\hline \multicolumn{2}{|c|}{$\begin{array}{l}\text { To what extent did the program stimulate } \\
\text { teacher learning? }\end{array}$} & $\begin{array}{l}\text { - Questionnaire } \\
\text { - Semi-structured interview } \\
\text { - Teacher's inquiry }\end{array}$ \\
\hline \multirow{5}{*}{$\begin{array}{l}\text { Which design } \\
\text { principle and } \\
\text { characteristics of the } \\
\text { program supported } \\
\text { teacher learning? }\end{array}$} & $\begin{array}{l}\text { Reciprocal peer } \\
\text { coaching }\end{array}$ & $\begin{array}{l}\text { - Questionnaire } \\
\text { - Semi-structured interview } \\
\text { - Video recordings of peer coach dialogues }\end{array}$ \\
\hline & $\begin{array}{l}\text { Focus on own } \\
\text { practice with the help } \\
\text { of video feedback? }\end{array}$ & $\begin{array}{l}\text { - Questionnaire } \\
\text { - Semi-structured interview } \\
\text { - Video recordings of peer coach dialogues } \\
\text { - Teacher's inquiry }\end{array}$ \\
\hline & $\begin{array}{l}\text { Teacher ownership of } \\
\text { learning goals? }\end{array}$ & $\begin{array}{l}\text { - Questionnaire } \\
\text { - Semi-structured interview } \\
\text { - Teacher's inquiry }\end{array}$ \\
\hline & $\begin{array}{l}\text { Focus on teacher's } \\
\text { inquiry stance and } \\
\text { outcomes in } \\
\text { classroom? }\end{array}$ & $\begin{array}{l}\text { - Questionnaire } \\
\text { - Semi-structured interview } \\
\text { - Teacher's inquiry }\end{array}$ \\
\hline & $\begin{array}{l}\text { Conditions in the } \\
\text { school for PD and PD } \\
\text { program? }\end{array}$ & $\begin{array}{l}\text { - Questionnaire } \\
\text { - Semi-structured interview } \\
\text { - Documents and observational notes }\end{array}$ \\
\hline \multicolumn{2}{|c|}{$\begin{array}{l}\text { What was the influence of (in)voluntary } \\
\text { participation? }\end{array}$} & $\begin{array}{l}\text { - Questionnaire } \\
\text { - Semi-structured interview } \\
\text { - Documents and observational notes }\end{array}$ \\
\hline
\end{tabular}


In cohort A data of the questionnaire and the interview were collected from eight participants and from the co-trainer of the program, the ninth participant left the school before the evaluation of the program took place.

In cohort B data were collected from 17 participants and from the trainer. One teacher did not fill in the questionnaire, but did cooperate with the interview; and three teachers, for various reasons, did not participate with the interviews but did fill in the questionnaire.

\subsubsection{Data analysis}

Using these data sources the following approaches were employed to explore the outcomes of the PD program.

Firstly, the researcher analyzed documents and observational notes to describe the implementation of the program.

Secondly, the researcher computed the frequencies and mean scores on the questionnaires. Answers on open-ended questions were gathered. The data of the questionnaire were imported in SPSS and analyzed. The Mann-Whitney U test (2-tailed) was used to search for significant differences in results on the various items between cohort $A$ and $B$. The few significant differences found will be presented separately in paragraph 5.7 .

Thirdly, the audio taped interviews were transcribed and all statements were clustered around the five design principles. To establish reliability, two researchers studied the statements independently, searching for remarks about the effectiveness of the different characteristics on the learning processes of the teachers. The researchers compared and discussed their findings. In cases where their interpretations differed, the transcripts were re-examined and discussed until consensus was reached.

Next, to validate the findings, the conclusions were checked (a) by triangulation between data sources and (b) by 'member-checking' conversations with the trainer of the program and by the presentation of preliminary findings to the teachers to confirm the researchers understanding of phenomena and obtain feedback. 
In the presentation of the findings in the next paragraph, data from the questionnaire, the observations, the interviews and the inquiries are combined to gain more in-depth knowledge of some of the items. For reasons of privacy the names of participating teachers were anonymized.

\subsection{Results}

Results will be presented in different paragraphs each detailing a different evaluation scope as described in the research model (Chapter 1, Figure 1.2), namely, participants' reactions, participants' learning, participants' use of new knowledge and skills and student learning, and organizational support and change.

\subsubsection{Participants' reactions}

\section{Collaborative learning at the work place}

In the questionnaire, each teacher was asked to name three of their most positive and three of their least positive experiences with the program. Almost $50 \%$ of all reported positive experiences concerned the bonding and sharing between colleagues. Other positive experiences concerned their actual learning processes ( $26 \%$ of all statements) and their individual learning outcomes, such as personal growth, fresh ideas, and insights ( $24 \%$ of all statements) (Table 5.3). 
Table 5.3 Most positive experiences in the program $(N=24$ participants $x 3$ statements $=72$ statements)

\begin{tabular}{|c|c|}
\hline Theme & Examples of statements: \\
\hline $\begin{array}{l}\text { Community building } \\
\text { (Almost } 50 \% \text { of all statements) }\end{array}$ & $\begin{array}{l}\text { - Sharing experiences with colleagues } \\
\text { - Trusting my peer coach } \\
\text { - To be able to be of importance for colleagues by } \\
\text { - } \text { listening } \\
\text { - More intense contact with colleagues } \\
\text { - To talk with colleagues on instruction strategies and } \\
\text { - teaching } \\
\text { - } \text { Interaction with colleagues with regard to each other's } \\
\text { - To experience that you are not on your own and that } \\
\text { - } \text { support of colleagues can be a wonderful thing } \\
\text { be yourself } \\
\text { - To feel support without judgments }\end{array}$ \\
\hline $\begin{array}{l}\text { Own learning process } \\
\text { (26\% of all statements) }\end{array}$ & $\begin{array}{l}\text { - Learning to develop my own learning goals } \\
\text { - Learning to look at myself } \\
\text { - Getting insight in own weaknesses and assumptions } \\
\text { - To reflect again on my own daily rounds } \\
\text { - My 'Aha-erlebnis' during the coaching dialogue } \\
\text { - Doing practitioner research } \\
\text { - Using videos for reflection } \\
\text { - Observing my own lessons } \\
\text { - Seeing your students in a different way } \\
\text { - Procedures which enable us to learn }\end{array}$ \\
\hline $\begin{array}{l}\text { Own learning outcomes } \\
\text { ( } 24 \% \text { of all statements) }\end{array}$ & $\begin{array}{l}\text { - Personal growth } \\
\text { - Fresh ideas } \\
\text { - It prevents you getting in a rut } \\
\text { - Learning to coach, to listen, to ask relevant questions } \\
\text { - Insight: the necessity of constant attention for the } \\
\text { learning process itself } \\
\text { - Insight: students can do much more than you think } \\
\text { - Insight: small changes can have impact } \\
\text { - Insight: in my own learning / teaching } \\
\text { - More self-confidence as a teacher }\end{array}$ \\
\hline
\end{tabular}

As least positive experiences they reported (a) a lack of favorable conditions, especially concerning time issues (60\% of all statements), (b) negative feelings about the program (14\% of all statements), and (c) a lack of own competences for functioning well in the program (14\% of all statements) (Table 5.4). 
In the interviews, all teachers reported they felt more or less unnerved by the videotaping and the dialogues on own performances, especially at the start of the program.

Table 5.4 Least positive experiences in the program $(N=24$ participants $x 3$ statements $=72$ statements)

\begin{tabular}{|c|c|}
\hline Theme & Examples of statements: \\
\hline $\begin{array}{l}\text { Lack of conditions } \\
\text { (60\% of all statements) }\end{array}$ & $\begin{array}{l}\text { - Lack of time } \\
\text { - Time allocation: difficult to fit the developments within } \\
\text { my schedule and finding time to meet with colleagues } \\
\text { - Difficult to find shared free time in school schedules for } \\
\text { triad meetings } \\
\text { - Planning: preparing presentations of inquiry during the } \\
\text { school exam period } \\
\text { - Too many additional tasks in the school to function well } \\
\text { in the program } \\
\text { - Lack of video cameras and television sets }\end{array}$ \\
\hline $\begin{array}{l}\text { Negative feelings about the } \\
\text { program } \\
\text { (14\% of all statements) }\end{array}$ & $\begin{array}{l}\text { - Anxiety about being filmed } \\
\text { - A lack of true learning goals of a colleague can obstruct } \\
\text { the performances of all participants of the triad } \\
\text { - Feeling guilty because it was impossible to be there all } \\
\text { the time } \\
\text { - Trainer did not interfere when a triad did not function } \\
\text { - Time-consuming } \\
\text { - Lack of efficiency in triad } \\
\text { - This is not my way of developing; it sometimes felt as a } \\
\text { - The time span of the plenary meetings (three hours at } \\
\text { the end of the day is too long) }\end{array}$ \\
\hline $\begin{array}{l}\text { Lack of own competences } \\
\text { (14\% of all statements) }\end{array}$ & $\begin{array}{l}\text { - It is difficult to formulate your own learning goals } \\
\text { - It is difficult to coach and help somebody else with } \\
\text { gaining insight in his/her own learning goals } \\
\text { - The instruction and the teambuilding activities went too } \\
\text { fast for me in the beginning } \\
\text { - To realize that I myself as a teacher sometimes react } \\
\text { very negatively to students. }\end{array}$ \\
\hline $\begin{array}{l}\text { Other } \\
\text { (11\% of all statements) }\end{array}$ & $\begin{array}{l}\text { - Fear of a hidden agenda of the researcher } \\
\text { - Being new to the school, there was little time for me to } \\
\text { truly give this my 'all'. It's a wonderful concept, but it } \\
\text { was difficult for me to complete at this stage in my life }\end{array}$ \\
\hline
\end{tabular}

\section{Peer coaching in heterogeneous groups}

In both cohorts the participants differed in years of experience, subject taught, and position in the school. In the interviews, the teachers reported they 
appreciated collaboration with colleagues outside their own department. Only the art teacher preferred to cooperate solely with colleagues of her own department, because she felt that there were too many differences between teaching her subject and that of her colleagues. In contrast, the intention to form triads from different departments was not always adhered to and two teachers (one of cohort A and one of cohort B) reported difficulties in collaborating in their triad with a colleague of the same department. One teacher, being new to the school and not having yet enough status among her colleagues in her department, mentioned problems with the fixed roles in most departments:

"In entering a school you also enter and become - kind of by accident - locked up in a department [...] In my department everyone goes his own way and there exists a culture of 'I am not going to change because this is the way I'm doing this already for years and years' and a culture of 'this is my department and we are not going to change to new ideas' [...]. They are not seeking insight; they want to give you advice but they do not respect you and your ideas, and respect is what you need from a peer coach in this program". (Lisa, cohort A)

A similar issue surfaced in cohort B. One teacher felt let down in the past by a colleague of his/her own department. This fact interfered with collaboration with that same colleague inside the program. This created a difficulty for the trainer when composing the triads, resulting in the composition of a triad of three teachers teaching very different subjects (English, physics, and arts). This triad did not function well and ceased after two coaching dialogues. Participants blamed the differences between their departmental backgrounds. However, in this triad there were also differences in commitment to the program due to personal choices and one of the participants reported feeling severely hindered because her peers did not develop own learning goals and thus affected the trust between them.

\section{Trainers composing the triads}

During the interviews, looking backwards, two thirds of all teachers were content with the fact that the trainers composed the triads. They mentioned the following advantages:

- Creating new strings of cooperation with other colleagues, instead of taking the easy way out and choosing for familiar subgroups.

- It stimulates the forming of a 'professional group' which stays focused on the goals and not too much becomes a 'social club'. Working together with 
befriended colleagues can create such a safe climate, that every participant mainly gets confirmation and all participants avoid difficult questions that force to reflect on oneself.

- People tend to choose for collaboration with known and befriended colleagues - 'birds of a feather flock together' - thus preventing learning from other ways and views, and learning to appreciate those other ways and views.

- Newly recruited teachers become integrated more easily. It creates a safe learning environment for newcomers and the possibility for them to join in.

- Because most triads were composed of teachers from different departments, dialogues could not become departmental meetings. Teachers reported also to feel fewer tendencies to assess each other's lessons. Because they did not teach the same subject, they did not ask themselves whether they would do it in the same way (or better). Teachers felt less need to judge teachers of the other departments due to the fact that there were fewer common interests at stake. Instead they felt more distance and more focused on their role as coach.

- Almost all teachers reported they felt the program created a safe learning environment for collaboration and opening up of own classroom and own concerns. Only three teachers, out of the 22 interviewed teachers, afterwards expressed they wished they had been placed in a different triad.

However, the teachers also signaled some disadvantages of composing triads by trainers:

- At the start, most teachers were not pleased to hear they could not choose themselves (although afterwards most of them marked it as a benefit). Afterwards, teachers were content with their triad, but also warned that they did not believe that they would have wanted to collaborate with any colleague in such an intense program. So the composition of the triads by the trainer is functional but has to be done carefully and not at random.

- Working with fixed triads can cause problems if triads do not work well. Some triads in cohort B did not function well and the trainer did not interfere.

- One teacher also noted that the program was based around the notion of ownership and "getting rid of the top-down approach". Trainers composing triads may be in conflict with that basic concept. 


\section{The 'reciprocal' character of the coaching in triads and the notion of equality}

As expected, the notion of equality between participants proved to be important. Teachers were all videotaped in their classroom, were all regarded as learners, and functioned all in the same roles of learner, peer-coach, and observer-of-the-peer-coach. The importance of this notion of equality and the reciprocal character of the peer coaching in the program is underlined by John, who stressed that he knew no other coaching or mentoring situation in which he felt so secure and stimulated to open up and reflect on own practice.

"The advantage with this way of working, as I see it, is that everyone is at the same level. Which I think is what also makes it really effective. In a coach situation - even if you say it is not there - there is always a difference in power: the coach and you are talking about your lesson. And that's what I liked about this: it breaks up that kind of hierarchy. Everyone's just on the same level with reciprocal coaching. With reciprocal peer coaching I think you can be more open, it is less threatening. The hierarchy, you can't really get away from that with a regular coach. There's still a sense of you're being assessed. And it's difficult to get away from that. When there's a question you'll always think: why this question? What's behind all that? Hmm ... I know with our particular coach in our team I don't think for a minute there's a hidden agenda at all. And I completely trust that particular person. But I still think it is very difficult to get away from that particular feeling. Whereas in our reciprocal peer coach group you don't have that because you're just three teachers talking about your lessons. Everyone is looking into each other's lessons. And the feeling of being actually able to show parts of your lesson that were good and also the parts that were not so good, that could be better, is almost quite... well not liberating, but it's very ... I just found that very positive. Because you can start to sort of talk about your lessons in a way that you can't do in another context. It's kind of hard to be open and honest in any other context."(John, cohort B)

\section{Starting with opening up own practice by participants with more power or prestige}

In the prototype it appeared to be functional to ask participants with more power or prestige to start with opening up own practice and showing own videos. By showing own vulnerability they created trust (everybody needs to learn) and became a role model for learning in the program. In the program, a team coach (in cohort A) and the team manager (in cohort B) were asked to show video recordings of own practice and to get coached during one of the first plenary meetings. They pictured themselves not as 'see how flawless everything functioned with me'; instead they showed their own vulnerabilities, 
their own concerns, and their own problems, and by doing so also showed they were still learners. It helped create a more secure learning environment for all teachers. In the interviews the teachers reported that they felt no impediments by the involvement of middle managers as participants and they experienced them as equal and as fellow learners in their own right. Only one teacher, who had not yet obtained tenure, reported some reluctance due to the participation of a team manager.

Although formal positions in the school appeared to have no important influence in the program, a situation was observed in which recognized expertise of one of the teachers did have an influence. During a plenary meeting (cohort A) coaching techniques were trained by performing a coach dialogue in front of the group. The dialogue focused on the learning goal of the teacher trainee, in this case 'collaborative learning in classrooms'. The teacher used video recordings of his classroom to analyze the 'how' and 'why'. However, by chance, his peer coach was also considered an expert in the school on collaborative learning in classrooms. Although his peer coach kept asking open ended questions, the teacher interpreted them as closed and did not reflect on them. Instead his own reflection stopped and he struggled to find the 'right' answer, the answer he supposed the expert wanted to hear.

\section{Teacher ownership of learning goals and conditions for learning}

The commitment to the program varied and as a result triads functioned differently. The teachers in cohort A (voluntary participation) all worked together intensively and every triad discussed more than one video of every teacher. In cohort B (mandatory team effort) the picture is much more diverse. Of the six triads only one triad discussed more than one video recording of every participant, three triads discussed more than one video recording of two of the three participants, one triad discussed only one recording of every participant, and one triad (existing of two teachers) only discussed the recordings of one of the two participants. So there is much more variation between the teachers in the second cohort concerning the extent of experience with reciprocal peer coaching. The teachers (cohort B) who did limit their participation in the program, referred to reasons outside the program and to lack of commitment from peers: 
a. Having not enough energy left for the program,

- Due to demands of other professional activities such as the development of a new program or having extra other tasks for the organization (mentioned by 5 participants).

- The program did not fit with the stage of their life, for instance because of their home situation (mentioned by two male participants who became father during the time the program was implemented in the school), or because they were new to the school (mentioned by one participant): "Being new to the school, there was little time for me to truly give this my 'all'. It's a wonderful concept, but it was difficult for me to complete at this stage in my life" (Julia, cohort 2).

b. Resistance to top-down policy of the school management and therefore feeling no commitment with this team effort:

- The simultaneous introduction of a school wide, mandatory teacher portfolio for all employees.

- A mandatory placement in the involved team.

- The mandatory character of their participation in the PD program.

c. The triad did not function well enough due to lack of effort of one or two of their peers (mentioned by three participants of three different triads).

To conclude, the program is based on the notion of teachers' desire and need to learn. However, the program may not be suitable for all teachers in every stage of their lives. In cases where teachers participate who have no need or opportunity to make the effort, teachers may hamper or impede each other.

In the questionnaire the teachers were also asked whether they wanted to remain involved in similar programs in which they can discuss and share with colleagues in the future (Table 5.5). Teachers in both cohorts indicated they might be interested, with cohort A being more positive.

Table 5.5 In the future, I want to remain involved in similar programs where I can discuss and share with my colleagues $(N=23)$

\begin{tabular}{lcccc}
\hline & certainly not & maybe not & maybe & certainly \\
\hline Cohort A & - & 1 & 2 & 5 \\
\hline Cohort B & 1 & 5 & 5 & 4 \\
\hline
\end{tabular}




\subsubsection{Participants' learning}

\section{Learning goals}

Each teacher individually formulated his or her learning goal. Their goals varied and some teachers worked on more than one learning goal during the program. Ten teachers wanted to develop various learning and teaching methods to stimulate and motivate students to actively think and solve problems (students working independently or in groups). Seven teachers began to study classroom management (e.g. to reduce (over)controlling, to get control and reduce own frustrations, or to optimize the start of lessons). Two teachers studied ways to respond to differences in abilities of students, and two other teachers focused on maximizing the learning output of all their students. Another two teachers focused on developing own teaching aids. Finally, three teachers struggled and expressed at the end of the program that their learning goals were still not sufficiently clear enough to themselves. At the end of the program, almost all teachers indicated that they had learned in the program; and 22 of the 24 teachers indicated that they had approximately reached their own learning goals.

\section{Other benefits of the program}

Teachers also reported other outcomes. Figure 5.2 presents an overview of the benefits reported in the questionnaire. Almost all respondents felt their professional development was stimulated. Most of them got new ideas about ways to handle things. They felt especially stimulated to think more about their actions as a teacher and to reflect on automatisms in their classroom practice. They also felt more supported by their colleagues. At the end of the program, most teachers felt more open-minded towards collaborating with their colleagues, especially with the other participants in the program. 


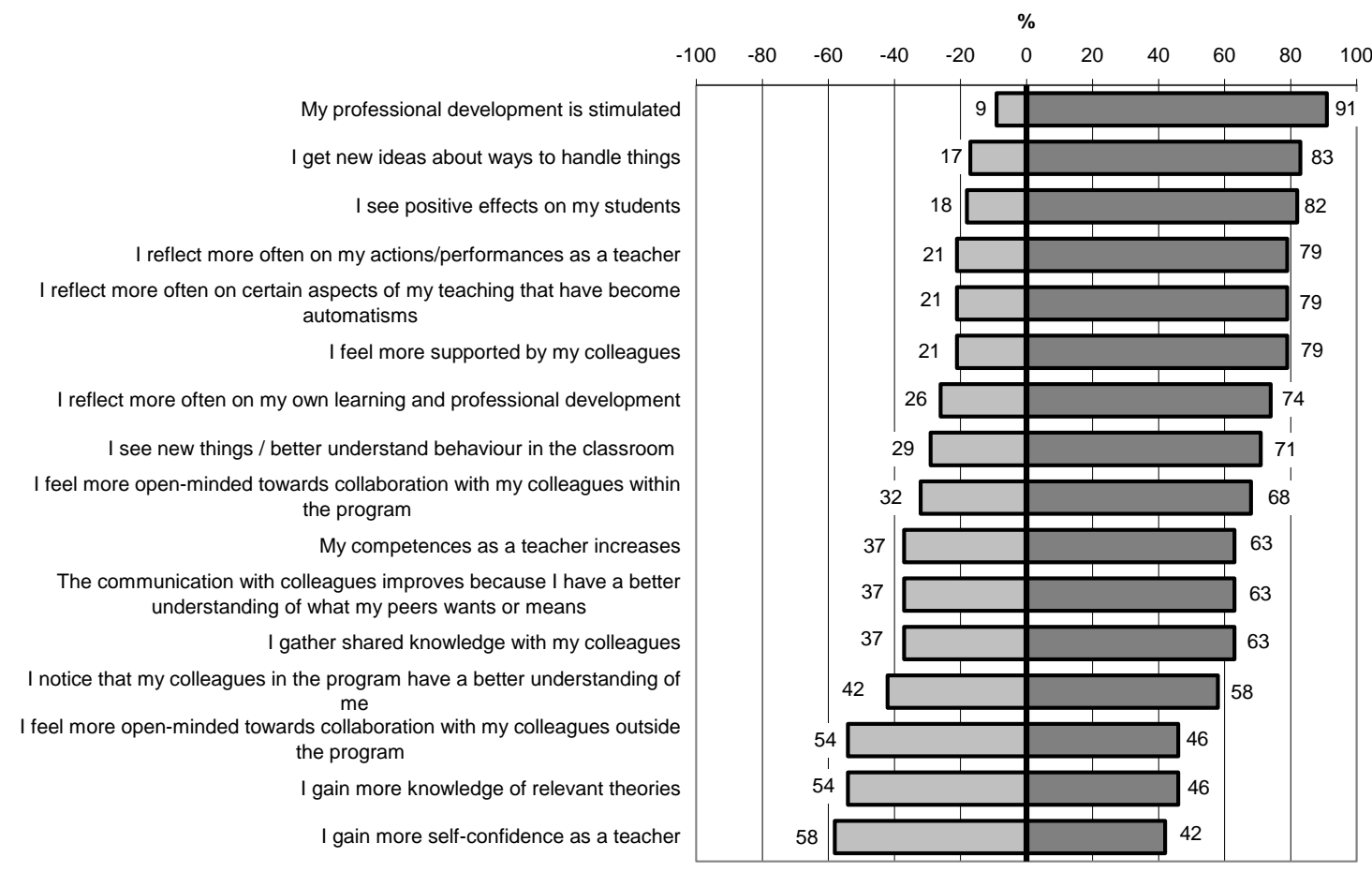

Figure 5.2 Outcomes of learning: general benefits $(\mathrm{N}=24)$

In the figure the scores 1 ('certainly not') and 2 ('maybe not') are represented on the left of the central line and the scores 3 ('maybe') and 4 ('certainly') are represented on the right side.

In the interviews, teachers expressed their surprise about the benefits of their coach training. Beforehand they had not realized that the program included training of skills such as open-ended questioning and active listening. However, most teachers realized that they still had to learn about this aspect and afterwards reported to be very content with their gained skills and that learning to coach was also very useful for their other professional roles (communication with students, parents, and colleagues).

\section{Characteristics of the program that stimulated teacher learning}

How useful were the different characteristics of the program? All participants were asked to rate different parts of the program on a 10 -point scale $(10=$ very useful, 1=not useful at all). On average, teachers in cohort B rated all parts of the program much lower than the teachers of cohort A (Table 5.6).

All teachers rated 'viewing and discussing videos of own lesson' as most useful, and the 'information in the binder concerning performing of inquiries' as one of the least useful. 
Table 5.6 How useful are the different parts of the program? $(N=24)$

\begin{tabular}{|c|c|c|c|c|}
\hline \multirow{2}{*}{$\begin{array}{l}\text { How useful did you find the different parts of the program? } \\
\text { Please rate each part on a } 10 \text {-point scale }(10=\text { very useful, } 1=\text { not useful at } \\
\text { all) }\end{array}$} & \multicolumn{2}{|c|}{ Cohort A } & \multicolumn{2}{|c|}{ Cohort B } \\
\hline & $\bar{x}$ & $s d$ & $\bar{x}$ & $s d$ \\
\hline 1. Viewing and discussing videos of my own lessons & 8.38 & 1.51 & 7.81 & 1.38 \\
\hline 2. $\mathrm{Vie}$ & 7.50 & 1.69 & 7.06 & 1.95 \\
\hline 3. Ac & 8.25 & 1.28 & 6.56 & 1.93 \\
\hline 4. Obs & 8.00 & 1.07 & 6.29 & 1.20 \\
\hline $\begin{array}{l}\text { ving and discussing coaching dialogues during the plenary } \\
\mathrm{s}\end{array}$ & 7.25 & 1.67 & 6.07 & 1.58 \\
\hline $\begin{array}{l}\text { 6. Reflecting on and formulating my own personal learning } \\
\text { objectives }\end{array}$ & 6.88 & 2.42 & 6.73 & 2.34 \\
\hline $\begin{array}{l}\text { 7. Discussing each other's personal learning objectives with my } \\
\text { peers }\end{array}$ & 6.63 & 1.30 & 6.38 & 1.96 \\
\hline 8. W & 7.13 & 1.13 & 6.31 & 2.29 \\
\hline 9. $\mathrm{Di}$ & 6.88 & 0.99 & 5.69 & 1.84 \\
\hline 10. T & 7.00 & 0.63 & 4.96 & 2.18 \\
\hline $\begin{array}{l}\text { 11. The information in the binder (and on the CD-ROM) } \\
\text { concerning 'performing inquiries' }\end{array}$ & 6.60 & 0.55 & 5.08 & 2.31 \\
\hline
\end{tabular}

\section{Learning in peer coach groups}

All teachers in both cohorts participated in peer coaching groups, however, the participation of the teachers in cohort B (mandatory team effort) varied more strongly. In this cohort, six teachers stated that they had only participated as teacher-learner in one or two reciprocal peer coaching dialogues. As reason they indicated: "the necessity to give priority to other tasks". All but one teacher functioned as peer coach in their triad. Some triads, who could not find shared meeting time, scheduled a number of their dialogues with only two teachers present, omitting a third teacher in the observer-role .

When there was trust in a group and the coach functioned well, the peer coach and especially the coaching dialogue could be very useful for the teachers' learning processes:

"It is not so much the analysis of my coach that was helping me along, but the fact that you are together observing and reflecting on the video recordings. Through dialogue you are stimulated to analyze the lesson by yourself. Putting things in words helps. I would have learned a lot less if I had only observed the video. When you are verbalizing your thoughts, you are at the same time also stimulated to analyze by yourself."

(Ruth, cohort 2) 
Teachers felt that reflecting in small groups was stimulating:

"Being in a small group with two other teachers, and being able to talk about our lessons in a way where you're sitting down specifically to talk about your lessons and where you can build up trust and be able to say certain things, which I don't feel in a bigger group necessarily..." (John, cohort B)

Figure 5.3 shows the scores on the questionnaire that the teachers gave to various functions of the coaching dialogues for their learning. They appreciated the function of the peer coach in stimulating their reflections most. The teachertrainees also felt stimulated by their coach to try out new things in the classroom. However, they were more critical about the insight they gained into the background of the behavior they observed on the video.

Other important aspects of peer coaching mentioned in the questionnaire were: 'confirmation that you are on the right track', 'strengthening of self-confidence as a teacher', 'stimulating awareness', and 'to observe with a new view, to see new things or to observe from another perspective'.

Important was the well defined peer coach role with a focus on 'stimulating and not threatening', e.g.:

"The importance of the role of the coach is the institutionalization aspect of the function. From just a colleague or a partner or your mother you do not always accept when they say certain things and friends do not always put you on the right track. (Kate, cohort $\mathrm{A}$ )

One teacher, about 60 years of age, expressed that just sharing and opening up her classroom to colleagues was the most important experience for her. An experience she had missed most of her working life. 


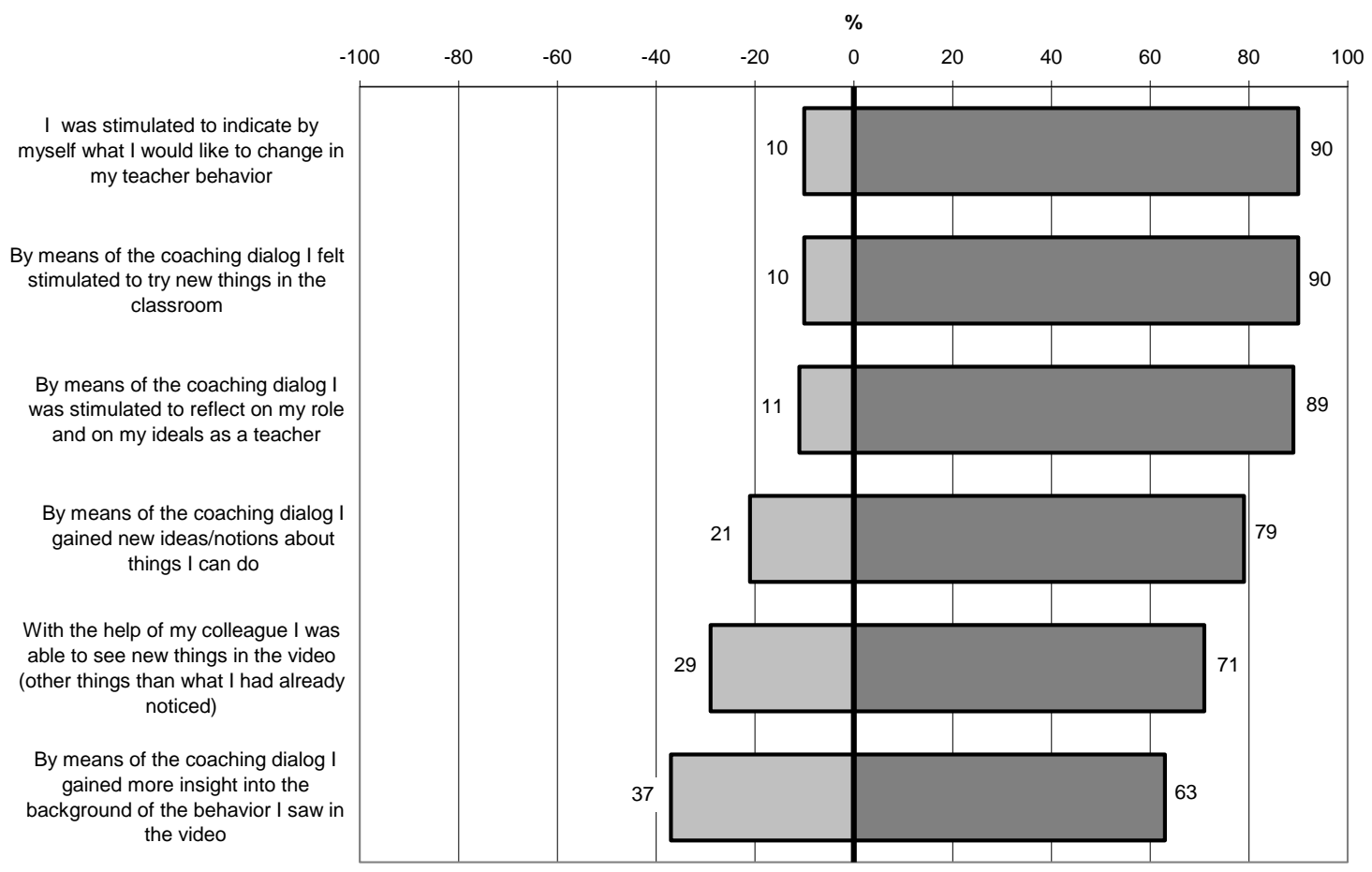

Figure 5.3 Function of coaching dialogues $(\mathrm{N}=24)$.

In the figure the scores 1 ('certainly not') and 2 ('maybe not') are represented on the left of the central line and the scores 3 ('maybe') and 4 ('certainly') are represented on the right side.

\section{Influences of the peer coach on teacher learning}

In the interviews, all teachers of cohort A could give all kinds of examples of performances of their peer coach which had been important for their individual learning process. In cohort B (mandatory team effort) there was a clear contrast between the teachers who indicated having functioned intensively in the program $(\mathrm{N}=8)$ and named many examples, and the teachers who had functioned limitedly $(\mathrm{N}=9)$ and gave only a limited number of examples.

The influences of the peer coach on teacher learning mentioned are (Table 5.7):

- The coach can 'help to notice'.

- The coach can help 'to notice also the aspects that went well', and the coach can 'help to put things in the right perspective'.

- The coach can 'challenge his/her peer to think for oneself'. 
- The coach can 'help to analyze and understand', e.g. by introducing a new perspective, or by focusing on the perspective of students in classroom, or by expanding the focus beyond focusing on performances but also on feelings, or by relating behavior with teacher's practical knowledge base or ideals.

- The coach dialogue can give a boost to energy and motivation.

Table 5.7 Influence of peer coach on teacher learning

\begin{tabular}{|c|c|}
\hline $\begin{array}{l}\text { Influence coach on learning peers } \\
\text { The coach can ... }\end{array}$ & Examples \\
\hline 'help to notice' & $\begin{array}{l}\text { "In discussing your video you get a new perspective, you are } \\
\text { looking at your own performance through the point of view of } \\
\text { your colleague. I knew how she teaches and I knew how she would } \\
\text { evaluate my lessons." (Ellen, cohort A) }\end{array}$ \\
\hline $\begin{array}{l}\text { 'help to notice also the aspects } \\
\text { that went well', and } \\
\text { 'Help to put things in the right } \\
\text { perspective' }\end{array}$ & $\begin{array}{l}\text { "I already noticed on the video what was happening, the dialogue } \\
\text { was not important in this. In the dialogue we reflected on my } \\
\text { feelings about it, and how I could get rid of my negative feelings. } \\
\text { We analyzed in the video that it was less negative than I had } \\
\text { remembered and that helped me." (Carol, cohort A) } \\
\text { "In our dialogue I discovered that much more went well than I } \\
\text { had realized in my classroom. It gave me a bit of peace. I thought } \\
\text { everything was going wrong. And this happened in my dialogue } \\
\text { with my second coach. The first coach just said 'oh the students } \\
\text { are doing this very well', but the rest of the dialogue we only paid } \\
\text { attention to the things that did not function well. What went well } \\
\text { did not really get across to myself. I was not forced to see it on the } \\
\text { video and that makes the difference for me. The second coach just } \\
\text { asked to look for myself and by putting questions forced me to } \\
\text { notice." (Lisa, cohort A) }\end{array}$ \\
\hline $\begin{array}{l}\text { 'challenge his/her peer to think } \\
\text { for oneself' }\end{array}$ & $\begin{array}{l}\text { "Important is a coach who guides you to important aspects in } \\
\text { such a way that it comes out of yourself. In this it is important } \\
\text { that you have to put it in words for yourself. I saw on the video } \\
\text { what was important but I could not really pin-point it, I could } \\
\text { not put it in words. And at the end of our dialogue I could." } \\
\text { (Kate, cohort A) }\end{array}$ \\
\hline $\begin{array}{l}\text { 'help to analyze and understand' } \\
\text { (e.g. by introducing a new } \\
\text { perspective, by focusing on the } \\
\text { perspective of students in } \\
\text { classroom, or by not only } \\
\text { focusing on performances but } \\
\text { also on feelings, or by relating } \\
\text { behavior with own practical } \\
\text { knowledge base or ideals) }\end{array}$ & $\begin{array}{l}\text { "With the help of the dialogue I noticed that I was contradicting } \\
\text { myself in lessons and that I must have felt an anxiety that I } \\
\text { wasn't quite aware of in the lesson. I recognized it on the video } \\
\text { and then talking about it enabled me to see one of the problems } \\
\text { behind it. The video and the questioning were both important, but } \\
\text { especially the questions that I was getting in my group were } \\
\text { enabling me to see things in a different way, to see things I wasn't } \\
\text { noticing by myself on the video. Especially through asking how I } \\
\text { felt at that particular moment during the lesson, because I hadn't } \\
\text { really thought about that. I identified the problem as I saw it, } \\
\text { when I was watching it by myself. I focused on it being a problem } \\
\text { that needed a solution, but it wasn't clear what the solution was. I } \\
\text { was not thinking about feelings and I didn't realize how my } \\
\text { feeling might have been linked to the way I had set up the task } \\
\text { during lesson... and by sort of going back I understood what was } \\
\text { really happening" (John, cohort B) }\end{array}$ \\
\hline
\end{tabular}


Table $5.7 \quad$ Influence of peer coach on teacher learning (Continued)

\begin{tabular}{ll}
\hline Influence coach on learning peers & Examples \\
The coach can ... & "The coach posed a number of questions pointing towards the \\
performances of the students. And then I observed that all the & students were very actively engaged with the curriculum. The \\
& problem was my own feelings and the idea that I had to be more \\
& active, that students learn when I am active and that when I have \\
& less to do, the students also will learn less. The coach just asked \\
& the right questions which made me realize my concept was \\
& wrong. The only one in that lesson who was not comfortable with \\
& the lesson was me. All the students are content and learning. \\
& That gave me the self-confidence to continue." (Frank, cohort B) \\
\hline "It was not that I noticed completely new things because of \\
my coach, but it was more a sense of 'you're on the right \\
track, continue with the way you're going.' It was a \\
comforting feeling for me. I needed that confirmation that I'm \\
on the right track, and all is going well. And I appreciate that. \\
It gives me confidence and energy... very much so." (Emily, \\
cohort B)
\end{tabular}

The 'here and now' of the peer coaching dialogues themselves can also influence learning. One teacher reported that the dialogue on her lesson in her triad became rather emotional. Her reaction in that peer coaching dialogue afterwards made her reflect on her own functioning in other communicative situations. In the interview she reported:

"This was the dialogue that helped me the most. I learned a lot from it. I asked myself: Why do I react in this way? What is the background of this way of reacting? And is this reaction functional? (Kate, cohort $\mathrm{A}$ )

In the second cohort of the program (mandatory team activity) there were problems in two groups with individual commitment of teachers with the program. This led to a lack of trust in one of the groups. Some of the participant did not open up themselves. The attitude (I have no learning goal at all / have no problems / do not need help from you, but ... I'm prepared to help you) did diminish trust between partners and resulted in obstructing the reflection process of their more committed peers. The working climate in those groups shrank, dialogues and reflection became more superficial instead of a shared quest and learning process, and triads meetings diminished. 
Most teachers showed their video of classroom practice to their partner or friends at home. Some teachers also showed the video of their peer coaching dialogue. One teacher told us that the showing of his peer coach dialogue at home was very instructive. He got 'that's just the way you always react' as feedback on his (defensive) performance in his triad. It made him reflect on his interpersonal skills, not only in classroom but also in his interactions with other parties.

\section{The skills of peer coaching}

After the program had ended the teachers evaluated their peer coach. On the questionnaire almost everyone reported they had experienced the coaching by their peer as: respectful, understanding, involved, motivating, enlightening and pleasant. Most of the time, the dialogues were conducted 'in an easy manner' and in a 'non-assessing' atmosphere. Most peer-coaches focused on the trainee's own learning goal, however, six teachers (out of 24) indicated that their coach failed to do so.

Most teachers felt the learning of coaching skills was 'difficult' but also 'enriching' and 'instructive for their own development'. To learn their role as peer coach, the coach training during the plenary meetings was helpful and the feedback of the peer observer was meaningful most of the time. However, seven teachers indicated that at the end of the program they still had not learned enough to function well as coach. As the most difficult aspects of coaching they reported 'not showing own opinions', 'to remain focused on the learning process of their partner', 'to structure the dialogue', and 'to understand and empathize with the learning needs and goals of your peer' (Table 5.8). 
Table 5.8 The most difficult aspects of coaching colleagues

\begin{tabular}{|c|c|}
\hline Category & Examples mentioned in questionnaire and/or interviews \\
\hline $\begin{array}{l}\text { Not showing } \\
\text { own opinions }\end{array}$ & $\begin{array}{l}\text { - Not giving (or thinking) own opinions. } \\
\text { - Not showing judgments/own views. } \\
\text { colleague. }\end{array}$ \\
\hline $\begin{array}{l}\text { Staying focused } \\
\text { on the learning } \\
\text { process of the } \\
\text { teacher-trainee }\end{array}$ & $\begin{array}{l}\text { - Staying open for the needs of my colleague, and noticing what he/she } \\
\text { wants. } \\
\text { - To focus on the learning goal of my partner. } \\
\text { - Staying concentrated during the whole dialogue. } \\
\text { - To discover the needs of my colleague and to avoid giving unsolicited } \\
\text { advice or tips. } \\
\text { - Helping others to find their own solutions. } \\
\text { - Thinking you already know what the learning goal of your partner } \\
\text { - } \text { should be, when your partner doesn't know it yet. } \\
\text { have to listen while at the same time think about useful questions and } \\
\text { the nature of the problem being discussed. }\end{array}$ \\
\hline $\begin{array}{l}\text { To structure the } \\
\text { dialogue }\end{array}$ & $\begin{array}{l}\text { - To formulate open-ended questions. } \\
\text { - To give structure and also formulate in a way you're not closing down } \\
\text { - } \text { the opportunities for the other person. } \\
\text { - To ask questions that will foster thought. } \\
\text { - To coach a colleague who doesn't stipulate a learning goal. } \\
\text { - To find a balance between steering and following in such a way that my } \\
\text { colleague was helped with clarifying own learning goals. }\end{array}$ \\
\hline $\begin{array}{l}\text { Empathic } \\
\text { understanding }\end{array}$ & $\begin{array}{l}\text { To get colleagues at ease to find the answer to their problems by } \\
\text { themselves. } \\
\text { - Difficulties with respecting the views and performances of your peer } \\
\text { when they are the opposite of your own views and ideals as a teacher. } \\
\text { - Sometimes the concerns or the learning goals of your peer are so much } \\
\text { apart from your own gained competences that they are difficult to } \\
\text { understand as peer coach. } \\
\text { - To empathize with your peer is sometimes difficult and consuming } \\
\text { much of your energy. }\end{array}$ \\
\hline
\end{tabular}

During the dialogues, the process of analyzing appears most important for the learning process. Peer coaches who just tried to reassure their colleague ('It went well'), thus denying the feelings of their peer, were ineffective ('It was nice to hear, but it did not really help me'). A coach appeared more effective by asking questions about what really happened ('What can we observe on the video about what is happening?'), and by relating experiences to teacher's own feelings and own ideals as a teacher. By starting of from the point of view of the 
teacher and thus analyzing the video together, coaches took the view of their peer seriously and helped them to reflect on performance and own identity as teachers.

A difficulty with peer coaching is that the video recordings and the dialogues also stimulated all kinds of associations in the mind of the coaches; associations that are connected with their own learning but that distracted the coaches from helping their peers in their learning processes. Another difficulty that was mentioned resulted from personal differences between coach and trainee. These peer coaches felt uneasy to coach colleagues who taught quite differently from their own teaching style. They struggled with putting their own judgment aside, staying patient, not expressing own judgment and giving unsolicited advice.

"The important part is to learn in which way you can help your partner to notice by herself and to stimulate her to think about the consequences of her actions and what that entails for her learning process." (Jane, cohort A)

"This role as peer coach was really difficult. How to reach the heart of the matter without prompting too much and asking suggestive questions? It is important to stay concentrated and to follow your peer and focus on what is important for him or her. However, you also want to make the most of the feedback on the video. After such a dialogue I was really exhausted." (Kate, cohort A)

"I'm going too fast... my questions follow each other quickly... I don't give a person a chance to think... my coaching is not in-depth. I learned from the training that I have to wait... I have to think about the answer of my peer... to ask why he says that or thinks that." (Mary, cohort A)

Although the performance of the coach is very important for the depth of the reflection, most important for the learning process remains the commitment of the teacher-learners themselves.

"I did not notice whether my coach had another view on things. It is not that important because the function of the coach dialogue is most of all determined by the energy you yourself are putting into it. It helps to reflect on things."

(Ellen, cohort A) 


\section{The role of the observer}

The presence of the observer guarded an atmosphere of trust in the triad, it made the dialogue more 'official' and each member more focused on his or her role, it also prevented dialogues becoming mere small talk between colleagues.

"When we got together, we just altered our attitude and we switched over to our roles: we were coach or teacher-trainee or observer... To talk in this way with your colleague is very rewarding, but it is also a little unnatural. That's where the role of the observer worked very well. You're sitting there with three persons, it is no longer just a conversation between two colleagues, you're focusing on your role and it starts to become a real coaching dialogue." (Jane, cohort A)

"I think two is a little bit too comfortable and I think you might have a tendency to not be demanding enough somehow. I think three people... somehow with that extra person in a discussion made me take it a bit more seriously. Just two people doesn't feel enough like 'a group'. There's also a psychological thing going on, I'm not sure what it is. Perhaps it is that idea of being watched by somebody, being observed. But you don't feel observed in a way that it's... a negative thing. I don't think it would have been the same if it was two people. And even four people would have been different again. That would have felt perhaps as if there were too many people. So three is somehow the right number. [...] That third person is making you do more than just having a conversation." (John, cohort B)

Serving as an observer also had outcomes for the learning of the coach role. Teachers learned from the observer's feedback on their own coach performance, but also from their role as observer noticing the performances of their peers during their dialogues.

"To see as observer the effect of not giving opinions and just in-depth questioning on the learning of the other... to see the effect of really touching upon things that matter, that was important for me". (Emma, cohort B)

\section{The role of video feedback}

To videotape lessons was not a normal procedure for the teachers. Only a few teachers had previous experiences with it. Some teachers in cohort B protested against videotaping of their lessons at the first plenary meeting with the introduction of the program. However, they still agreed to participate. At the end of the program, almost all participants, including the ones who protested at first, rated video feedback as the most appreciated characteristic of the program. 
Both cohorts appreciated the 'viewing and discussing videos of own lessons' as the most useful part of the program (Table 5.6). In the interviews, the teachers reported that the video feedback helped them to refreshing their memories, to notice things, to study classroom practice, to gain new insights, to clarify own learning goals, to create opportunities for feedback from colleagues, to share classroom practice and escape from the public loneliness of the profession, to stimulate self-confidence, to gain new ideas from the observation of peers, and to share their work with others outside the school (Table 5.9). 
Table 5.9 Function of video feedback

\begin{tabular}{|c|c|}
\hline Function of the video & Examples from teachers in the interviews \\
\hline Refreshing memory & $\begin{array}{l}\text { - "You are teaching so many classes and then when you are discussing that lesson afterwards much has faded away". (Jane, cohort } \\
\text { - "In another coach program the coach makes notes during the lesson. But when you discuss them you just are thinking 'what did } \\
\text { happen then and there, where was I standing, what was I looking at, what was I saying?' And in this program you can check, you } \\
\text { have evidence". (Paul, cohort B) }\end{array}$ \\
\hline Noticing & $\begin{array}{l}\text { - "You pick up a lot of things from that video: body language, the way you use language, the intonation, the sound of your voice, how } \\
\text { you react to things. Amazing to see how many inputs you get in a lesson... and how the students react to you." (Emily, cohort B) } \\
\text { - "Looking at the video, I noticed to my surprise 'I still can learn from it!' When the program was announced I thought: what will I } \\
\text { gain from this, I'm already that experienced and I have too much to do this year, I will have no energy left for this program. Often } \\
\text { you do not know beforehand how such a program can be useful for yourself and by joining in you discover things you can still } \\
\text { improve." (Ronald, cohort B) }\end{array}$ \\
\hline $\begin{array}{l}\text { Studying ov } \\
\text { practice }\end{array}$ & $\begin{array}{l}\text { - "I studied the recordings two times in a row. First I looked at my own performance and the second time I focused on the } \\
\text { performances of my students. I learned that students reacted often differently than I thought. I projected on my students much about } \\
\text { my own experiences as a student... but some students are different and I must develop a different approach to them." (Frank, } \\
\text { cohort B) } \\
\text { "I studied my own non-verbal behavior and I saw it was different in classes where I felt at ease and in classes in which I did not. } \\
\text { And on the recordings you saw the way the students reacted to that, from the moment they entered the classroom. And that I must } \\
\text { start in a more relaxed way and pay attention to individual students. And I deliberately started to act upon this." (Carol, cohort A) }\end{array}$ \\
\hline Gaining new insights & $\begin{array}{l}\text { " "One of my moments of insight came when I studied the recordings and I saw how my class reacted at the unexpected entrance of } \\
\text { their tutor. He came to lash out at someone. But just observing how all students reacted different to him than to me, and to see how } \\
\text { he tackled them... And I had observed a lesson from him before, but this was different. I could study that tape again and again. I } \\
\text { studied his performance, the non-verbal interactions, the reactions of the students. I focused on this and then on that. I did it by } \\
\text { myself and it was very instructive." (Carol, cohort A) }\end{array}$ \\
\hline
\end{tabular}


Table 5.9 Function of video feedback (Continued)

\begin{tabular}{|c|c|}
\hline Function of the video & xamples from teachers in the interviews \\
\hline $\begin{array}{l}\text { Clarifying own learning } \\
\text { Goals }\end{array}$ & $\begin{array}{l}\text { "You have to face yourself. You got a picture in your mind of how you teach, but it's a different picture from what you see on the } \\
\text { recordings. That is real life, in other words, how the students experienced you." (Emily, cohort B) }\end{array}$ \\
\hline $\begin{array}{l}\text { Opportunities for } \\
\text { feedback from colleagues }\end{array}$ & $\begin{array}{l}\text { - "I want to hear from colleagues what they think the best way of doing things is. What they observe with the students. Whether they } \\
\text { notice difference in enthusiasm in the manner in which they work at this subject." (Sue, cohort B) }\end{array}$ \\
\hline $\begin{array}{l}\text { Sharing classroom } \\
\text { practice and escape from } \\
\text { the 'public loneliness' of } \\
\text { the profession }\end{array}$ & $\begin{array}{l}\text { - "By seeing their videos I have gained an idea of their problems and although they are not the same as my problems, I have now more } \\
\text { - "Noterstanding of them." (Ronald, cohort B) } \\
\text { "Needed that, but also later in the program it was still reassuring to see colleagues who are also struggling. Look, if everything is } \\
\text { going smoothly, then no one needs to notice that struggling. But if things are not going all that well in your own classroom, then } \\
\text { you need that support. It makes problematic behavior of students less personal. And that is really a big, big advantage." (Paul, } \\
\text { cohort A) }\end{array}$ \\
\hline $\begin{array}{l}\text { Stimu } \\
\text { confic }\end{array}$ & $\begin{array}{l}\text { - "Another thing that came up with the first video was that disruptions in lessons were shorter than I was experiencing them when I } \\
\text { was in the lesson. So I felt that something was lasting a long time, but in fact it didn't. I felt that something was really disruptive, } \\
\text { but when I looked at it on the video, it was small: twenty seconds. And that was interesting. Just that one thing from the first video } \\
\text { made me realize that I could be a lot more relaxed about disruptions. It gave me a different perspective on those moments in the } \\
\text { lesson. And it gave me the confidence to just stand there for twenty seconds whilst it is happening." (John, cohort B) } \\
\text { - "Looking at the video I thought... well it is quite OK to be taught by me. I felt some self-assurance." (Anne, cohort A) }\end{array}$ \\
\hline $\begin{array}{l}\text { Gaining new ideas from } \\
\text { observing other teachers }\end{array}$ & $\begin{array}{l}\text { " "It was very interesting to see how different the group was in each lesson and I had not really realized how completely... almost like } \\
\text { the group is schizophrenic or something... Yeah, it is unbelievable how different they can be. So that was interesting and also to see } \\
\text { the way different teachers do things, the start of a lesson and the end of a lesson. So I found that interesting because it makes you } \\
\text { question what you're doing. And it makes you think how you could borrow things." (Emily, cohort B) }\end{array}$ \\
\hline $\begin{array}{l}\text { Sharing } \mathrm{V} \\
\text { outside tl }\end{array}$ & $\begin{array}{l}\text { - When asked during the interviews, half of all the participants indicated they watched the video at home with their } \\
\text { partner, a friend or a family member) }\end{array}$ \\
\hline
\end{tabular}




\subsubsection{Participants' use of new knowledge and skills, and student learning}

The teachers were asked whether the things they had learned have had a positive influence on their competences (Figure 5.4). Almost everyone felt that they had improved in reflecting on themselves as a teacher and on their values as a teacher and two thirds of the participants felt that they had also grown as a person due to their coach training.

Teachers indicated that the skills they learned during coach training were helpful not only inside but also outside of the program. They used their newly acquired coaching skills in various professional work environments with contacts with colleagues and in interaction with students and parents.

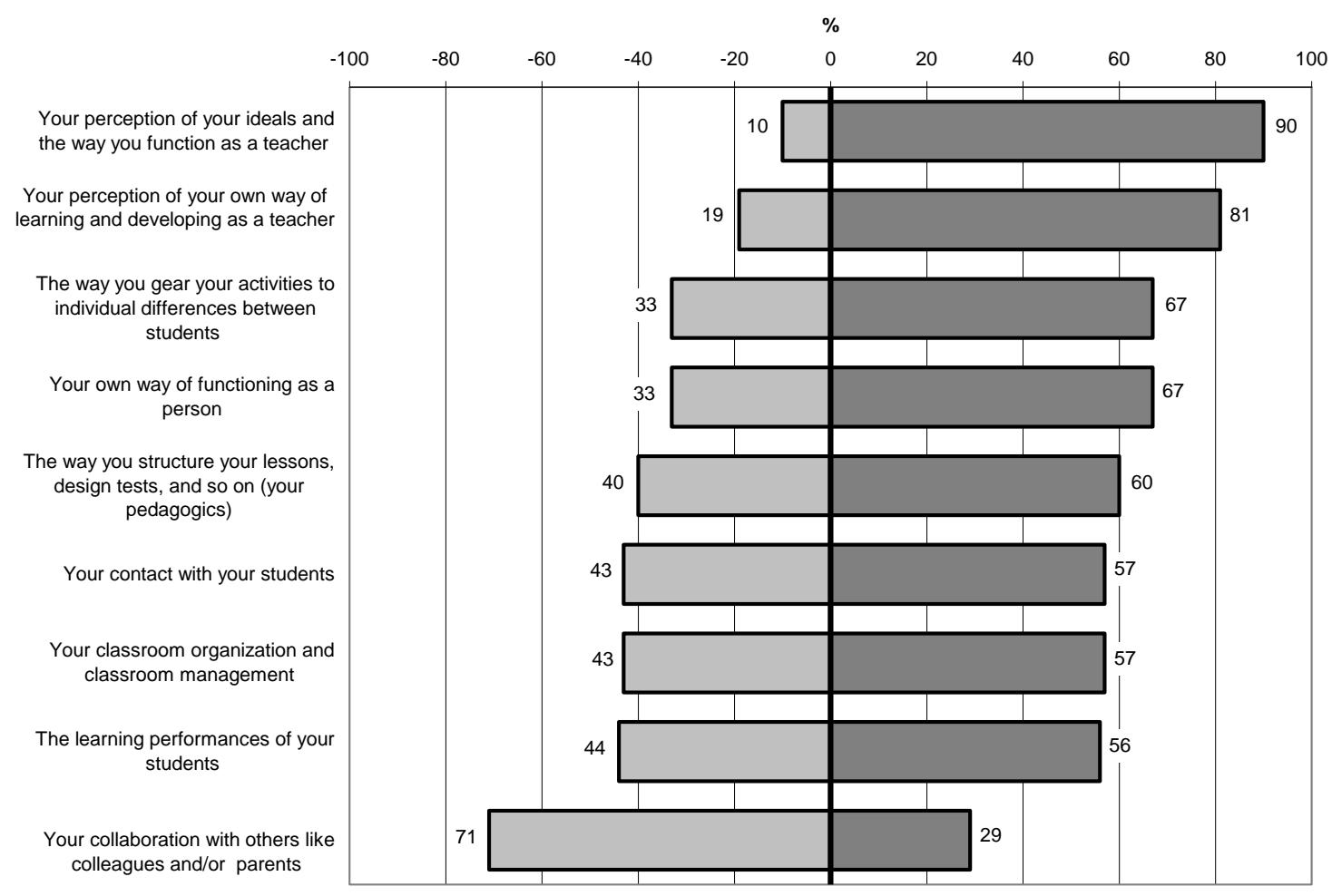

Figure 5.4 What I learned in the program has a positive influence on... ( $\mathrm{N}=24)$

In the figure the scores 1 ('certainly not') and 2 ('maybe not') are represented on the left of the central line and the scores 3 ('maybe') and 4 ('certainly') are represented on the right side.

All participants in both cohorts underlined the importance of personal gains in coaching skills:

"I found that very useful; the emphasis on open-ended questions. And listening and not kind of imposing an opinion on the person you're coaching... [are] just sort of almost new skills to think about. Listening and questioning skills are also 
useful for my teaching. There's sometimes a tendency to just give the answer to a student rather than to try turning it around and turning it in an open-ended question, to throw it back at them to try and find a solution. So that process we had to go through and that we had to think about and reflect on ourselves, I found that really useful." (John, cohort B)

"It is also useful in dialogues when you have to work at a solution with students or parents. For instance, I used it this year when I was a third party in a conversation between a student, his tutor and a teacher. I functioned as a panel chairman and I used skills I have learned in the program." (Paul, cohort B)

Noticeably, even two teachers from cohort B who did not bring in many video recordings of their own classroom practice still found this part of the program very useful for their own development:

"Coaching was the most important part of the program, learning skills, especially open-ended questioning and not imposing your own views. [...] I especially valued the discovery that I could be of significance to my colleague, to help her to discover her own learning goal." (Harry, cohort B)

The teachers were asked if they would continue practicing things they had learned in the program (Table 5.10 and 5.11). Both cohorts were very positive they would remain practicing the things they learned. With regard to their learning process, especially the use of video feedback for their own development, the teachers of cohort B were less positive: half of them thought they probably would and half thought they probably would not use video feedback in the future.

Table $5.10 \quad$ I will remain practicing the things I learned in the program $(N=21)$

\begin{tabular}{lccccc}
\hline & $\begin{array}{l}\text { certainly } \\
\text { not }\end{array}$ & maybe not & maybe & certainly \\
\hline Cohort A & - & - & 2 & 6 \\
\hline Cohort B & - & 1 & 6 & 6 \\
\hline
\end{tabular}

Table 5.11 In the future, I will continue to videotape my own lessons $(N=22)$

\begin{tabular}{lcccc}
\hline & $\begin{array}{l}\text { certainly } \\
\text { not }\end{array}$ & maybe not & maybe & certainly \\
\hline Cohort A & - & - & 2 & 6 \\
\hline Cohort B & 1 & 6 & 3 & 4 \\
\hline
\end{tabular}

\section{Effects on students}

In the questionnaire the teachers were asked whether they had seen positive effects on their students and whether they could describe two of those positive 
effects they had observed (items 2.15 and 2.16 on the questionnaire, see Appendix 4). Eighteen teachers (75\%) indicated on the questionnaire that they noticed positive effects on their students. Almost all mentioned influences on learning activities and on working climate and three teachers mentioned explicitly that the marks of their students had improved (Table 5.12).

Table 5.12 Positive effects the teacher observed on their students $(N=24)$

\begin{tabular}{|c|c|}
\hline Category & Examples mentioned in questionnaire \\
\hline $\begin{array}{l}\text { Students' learning } \\
\text { activities }\end{array}$ & $\begin{array}{l}\text { - Students are more focused and are more active because they enjoy } \\
\text { learning more } \\
\text { - Students have more power over the content of lessons } \\
\text { - Students give each other more support } \\
\text { - Students have more ambition and more engagement with activities } \\
\text { - Students understand the reason of certain tasks better } \\
\text { - Students engage more in cooperative learning }\end{array}$ \\
\hline Working climate & $\begin{array}{l}\text { - Students flourishing because I gave more compliments } \\
\text { - Improved work ethics + positive energy in class environment. } \\
\text { - More openness and more peace and quiet during lessons } \\
\text { - Trying new things stimulates the motivation of students } \\
\text { - Less loss of time at the start of the lesson thanks to better } \\
\text { preparation of my lessons } \\
\text { - Students are more responsive to my directions because they better } \\
\text { - } \quad \text { understand the 'what' and the 'why' }\end{array}$ \\
\hline Learning outcomes & $\begin{array}{l}\text { Better marks } \\
\text { students have more positive learning outcomes at tests because } \\
\text { responsibilities }\end{array}$ \\
\hline
\end{tabular}

\section{Inquiry stance}

The characteristics of the-program-as-a-whole stimulated teachers to a more investigating attitude:

"This thinking about how you are asking questions and this whole setting up in a triad...if you're an a situation where things are more equal and it is not about giving an opinion or being told how to do something, then I think you're creating a much more interesting environment for actually investigating what you're doing as teacher. Because you're not starting off with a preconceived idea of how to do something. And you are forcing yourself to be not preconceived about how you do something." (John, cohort B)

Not all teachers of cohort B did actually perform an inquiry, however, the teachers of cohort A did and felt stimulated by the obligation to do an inquiry:

- "Measuring results is very important, it makes you reflect more critically on your assumptions." (Jane, cohort A) 
- "Doing an inquiry gives me structure, I decided 'that's my goal, that's what I want to reach' and afterwards I checked my progress with the help of the outcomes of my students." (Kate, cohort A)

- "It is something you have to do once to know how valuable it can be." (Paul, cohort A)

- "Although I know I have to do it differently, I keep doing things that way for all sorts of reasons, for example lack of time. And while I can have the intention, it needs more to arrive at real actions and change. I need a good coach with that. And maybe for that reason the inquiry was good for me: you were forced even more to look at what you wanted to learn. And also you are forced to study if you really have learned and changed. Just observing the video is not enough." (Ellen, cohort A)

Teachers had to present their inquiry at the end of the program. Their preparation unfortunately coincided with the most hectic period in the school calendar and this fact did put an extra pressure on realization of the inquiry. Some teachers also felt that their learning process had already been completed and that drawing up their inquiry was an obligation and paperwork. Teachers' inquiries will be further studied and discussed in Chapter 6 .

\subsubsection{Organizational support and change}

\section{Facilitating}

Creating conditions in the school proved to be one of the most difficult principles to realize during the implementation of this program. School management was willing to reward volunteers with a bonus (300 euros), or team members with provision of time for plenary meetings, but that was it. Still, in all cases, teachers mentioned lack of time as one of the most negative aspects influencing their learning outcomes.

"I felt that we did have to do a lot of the work in our own time, especially the peer group meetings. And it was also quite difficult sometimes to find a time in the week that we all three could get together; the program create opportunities in our timetables in some way. And it shouldn't just be assumed that we'll do it our own time. I mean I'm not cross or angry but I think it is an issue to consider. If a school wants to do it then they need to make that kind of commitment." (John, cohort B)

Each triad had to make its own planning and time schedule. The teachers had to make time for videotaping in each other's classrooms, for the viewing of the tape, and for their joint dialogues in triads. The teachers had to make room for all of these activities in their own spare time. Most triads proved to be unable to 
perform as expected, whereby they would reflect on the learning process of every participant every five or six weeks, because the whole procedure took a lot of time, demanded a lot of own forward-looking scheduling, and all teachers had their own school schedule and had to search for shared opportunities for all of those activities. Timeslots in the school schedule for participants of the program would have helped them to organize their meetings. All teachers reported these difficulties with scheduling appointments. As a result, teachers also scheduled dialogues in which only two teachers were present and there was no observer, despite the fact that the teachers in both cohorts reported they found the attendance of an observer important.

Time pressure can also hamper the reflection process in the dialogues. Coaches displaying peace and quiet during the dialogues proved one of the most important conditions for the depth of the reflection of their peers.

"One of my coaches was quite relaxed and calm, she went on for as long as it took, and just continued in-depth questioning. Her attitude was 'it doesn't matter how long it will take'. In contrast, my first coach always gave me the idea that I had to hurry up, that she wanted to go home. Of course, everyone wants to go home at the end of the day, but when there is a continuous race against the clock you are not stimulated to really reflect. You have not enough time spans to inquire into your own thoughts, drives and motives. In the dialogue with the second coach we investigated a lot of things to see if they were the main concern. We explored a number of topics and she let me talk and reflect. And at the end, all came together. I think I did it myself, to see the connection and that was funny because beforehand I did not. I went home very cheerfully and with new spirits." (Lisa, cohort A)

\section{Training of necessary skills}

Training of coaching skills was mentioned by all teachers as important for their triad dialogues. Almost all teachers mentioned acquiring coaching skills as a bonus in the program that they did not anticipated, but that they all appreciated much. They also reported using their newly developed coaching skills in other situations.

"We trained coaching skills during plenary meetings and then we tried to put that into practice. I found that very useful: the emphasis on open-ended questions and listening and not kind of imposing an opinion on the person you're coaching. I found this very interesting and almost maybe something even outside of teaching maybe; sort of almost new skills to think about. Listening and questioning skills are also useful for my teaching as well; there's sometimes a tendency to just give the answer to a student rather than to try turn it around 
and turn it in an open-ended question to throw it back at them to try and find a solution. So that process we had to go through and that we had to think about and reflect on ourselves I found really useful." (John, cohort B)

\section{Participation: voluntary or mandatory}

All teachers in cohort A volunteered to participate. However, they were asked to sign a contract promising to finish the program, in which case they would receive 300 euro as a bonus. The school facilitated teachers in allowing them to skip lessons for plenary meetings. Teachers were supposed to do all other activities in their own spare time. The recruitment was done by a school-based coach who also invited starters to join in. This school-based coach was well respected among colleagues and teachers trusted her. In the interviews the participants reported this trust and linked it to their volunteering to participate.

The teachers in cohort B, all belonging to the same school team, were compelled to participate. Only one teacher withdrew beforehand, having had negative experiences with videotaping in another occasion. Although none of the other teachers refused to participate, in the interviews most teachers reported they had reservations at the start of the program because they had reservations about (a) videotaping in classroom, (b) the mandatory character of their participation in the program, and (c) transitions in the school organization towards assessments of teacher performance. Remarkably, during the interviews, four participants explicitly mentioned on the one hand their reservations at the start and on the other hand their satisfaction afterwards:

"When I heard of the program and what I had to do, I found it quite unnerving, because for me it is totally new. And I thought 'do I really want to do this?' And then I said 'why don't I want to do this? You have to face it.' You got a picture in your mind of how you perform. But on the video you see a different picture, in other words, then you see how the students may experience you. And then... it was amazing... I was positively surprised, something you should encourage everybody to do, not just the positives, but the negatives and all. Just to see, to observe yourself, your body language, your use of language, how you react to things, being in the energy field of that child and how they react to you. You can pick up a lot of things from that video." (Emily, cohort B)

Teachers' compulsory participation in cohort B resulted in four different kinds of commitment with the program. 
1. Teachers who were interested and were willing to participate and felt fully committed to the program (4 teachers).

2. Teachers who were reluctant at the start, but whose attitude changed during the program and who became fully committed to the program (4 teachers).

3. Teachers who had no real time or energy for the program for reasons outside the program due to personal or professional circumstances (getting a baby, being new to the school and having no energy left for the program, having other time-consuming duties in the school) (5 teachers). These teachers had a restricted commitment to the program.

4. Teachers who were reluctant or felt hostile towards the program (4 teachers). They did not commit to the program, participated as little as possible in their triad, did not invest much time in developing own learning goals and did not study own learning outcomes. They operated as bystanders and did not gain much experience with the program. At the end they all reported not being hostile to the program anymore, but also reported having no wish to continue the program in the future.

Due to the design of the program, the fourth group was difficult to reach. The program has been built on design principles that strengthen the teacher as an active participant in own professional development. Teachers who refuse to do so do not benefit themselves, but also create a problem for their peers in their triads. Not only are their peers unable to support the reluctant teacher, but they also affected the working climate in their triad and peers felt less secure in their groups.

\section{Context of the school}

Further, all kind of organizational aspects in the context of the school can interfere with the program. The implementation of the program in cohort $B$ coincided with the introduction of mandatory portfolios for teachers by the school management. Each teacher had to build his or her own teacher portfolio. Within the school there was resistance to this development. Although there was no direct connection between this procedure and our PD program, participants nevertheless associated the two. It created mistrust with some teachers, although not all teachers were hampered by it:

"Working on my professional development in the context of the program felt save and I got a lot from it, doing it. I wasn't really concerned about links to portfolio's and assessments because of being into this context where there wasn't a coach, there wasn't somebody that you felt was assessing you, which is exactly 
what I felt was so good about this program. It's more stimulating, it's allowing you to think about what you're doing in very trusting environment where you don't feel that you're being assessed as well. Which is coaching and professional development often associated with." (John, cohort B)

The team that participated in cohort B was the team that was responsible for the bilingual curriculum. Communication between team members was often in English due to team policy (English is the official language on team meetings) and also because four teachers were native English speakers. In every cohort, out of the three years the project lasted, there were participants with different native languages (Dutch, English, Spanish, German). In those cases in which triads were composed of teachers with different native languages, it was observed that language could form an obstacle for deepening their reflective dialogues (lacking enough competences for exchanging subtleties or using metaphors in a second language).

\section{Organizational impact}

During the three years of this PD project, each year the supporting school manager of the program changed due to reasons outside of the program (managers leaving the school). In the first year the program was implemented under the supervision of the deputy headmaster. In the second year the principal took over. In the third year a new principal entered the school and the program came under the supervision of a team manager. These changes eroded the commitment of the management for the program. However, the program survived and various characteristics of the program got a growing support in the school. The schoolbased coach noticed a growing commitment in the organization for collaborative learning and video feedback for professional development. For instance, after the PD program had ended, all team managers purchased video cameras for use in their teams, and new programs using video feedback and/or collaborative learning were introduced in the school by other school-based coaches and mentors trained their selves in coaching with video feedback of student-teachers.

The main gains for the organization according to the school-based coach (also the trainer in the program) were:

- "Teachers overcame their fear and opened up own practice, they discussed own strengths and weaknesses and developed more appreciation for each other and more respect for differences in teaching styles." 
- "Teachers have been stimulated to reflect on own learning goals, by which they are also more prepared for major changes in the following years when programs for staff development and staff assessments will be introduced."

- "This last year a whole team participated, they discussed in a new way with each other about teaching and about interactions in classrooms. I saw they started to really listen to each other and that's already quite an accomplishment."

- "Teachers developed new communicative skills they could use in other professional settings (with students, parents and even at home), for instance they learned that constructive conversation can be stimulated through an open attitude and open questioning and that it is not so important to give own opinions on everything. This is much more difficult than people often think."

- "For starters at the school it is a good introduction to school and colleagues."

- "Participation of a whole team helps also to grow as a team by sharing views, by discussing in a new way own teaching and classroom practice, by learning to understand and appreciate each other and existing differences between them. [..] It appeared still quite difficult for professionals to really open up to each other and to start listening and trying to understand instead of giving own opinions."

(Evaluation notes of the school-based coach)

She also noted a number of bottlenecks especially in the implementation with the second cohort. In cohort B, due to the size of the team, the trainer noted difficulties in creating and guaranteeing a secure and stimulating learning environment for all participants due to the size of the group.

"Firstly, to give ample opportunities to practice skills during plenary meetings the group needed to be split up. This solution was not very satisfying due to lack of possibilities to provide rich feedback to every individual teacher and peer group [trainer only half of the time present]. Still, development of enough peer coaching skills is necessary to create depth in dialogues. Secondly, on the one hand six plenary meetings is not enough for all that has to be done (training of coaching skills, helping in identifying personal learning goals, helping to design own inquiries, and sharing process and outcomes between participants). On the other hand you can not ask for more meeting time, because all activities have to be fitted in besides all regular school activities. Thirdly, it is unclear what to do with teachers who do not function well in the program. You can argue 'every gain is better than no gain at all', but with some teachers of the latter group [mandatory team effort] in my mind outcomes were very limited. Fourth, as trainer you have to make demands on participants. It is important to monitor progress. As a school-based trainer I find it difficult making demands on 
colleagues of which I know they have already an abundance of tasks and have to participate in their own spare time." (Evaluation notes of the school-based coach/trainer)

The trainer reported having difficulties in monitoring and assisting the triads during reciprocal peer coaching and a lack of real measures to act upon when groups operated dysfunctional, which was exacerbated by her own reluctance as an intern trainer and a 'trainer-of-colleagues'.

\subsubsection{Comparison between the findings of cohort A and B}

Although most teachers were positive about their learning processes there is a clear difference between the two cohorts. Teachers in cohort A scored overall clearly more positively in their answers than teachers in cohort B. Analyzing all scores on the questionnaire, using the Mann-Whitney U test (2-tailed), only a few significant differences can be found, mainly in scores on items relating to 'reached learning gains' and their 'experiences with the coaching of their colleagues' (Table 5.13). Teachers in cohort B felt significantly less stimulated in their reflection and professional development. Teachers in cohort B also felt significantly less positive about being coached by their peer. They felt more assessed and judged during coaching than teachers in cohort A, and they felt less stimulated to notice new aspects in their video feedback or to reflect more on own professional identity or professional values.

Table 5.13 Comparison between the findings of cohort A and cohort B - Reached learning goals and coaching

\begin{tabular}{lc}
\hline Item & $\begin{array}{l}\text { Significance level } \\
\text { Mann-Whitney U } \\
\text { (2-tailed) }\end{array}$ \\
\hline My professional development is stimulated & .004 \\
\hline I reflect more often on my actions and performances as a teacher & .030 \\
\hline $\begin{array}{l}\text { I reflect more often on my own way of learning and the way I develop as } \\
\text { a teacher }\end{array}$ & .017 \\
\hline Did you experience the coaching by your colleagues as assessing? & .021 \\
\hline $\begin{array}{l}\text { With the help of my colleagues I was able to see things on the video } \\
\text { (other things than I have already noticed) }\end{array}$ & .024 \\
\hline $\begin{array}{l}\text { By means of the coaching dialogues I was stimulated to reflect on my } \\
\text { role as a teacher and on my own values as a teacher }\end{array}$ & .002 \\
\hline
\end{tabular}

Teachers in cohort A reported approximately twice as many experiences as coach and as trainee and a longer duration of the dialogs. Although overall both cohorts thought that 'time spent in the program was worthwhile', the teachers in cohort B scored clearly lower and were less inclined to continue the program. 


\subsection{SUMMARY AND CONCLUSIONS}

\subsubsection{Did the program 'Learning to Notice' support the learning of teachers at the workplace?}

Teachers worked on various learning goals, such as learning of new teaching strategies, classroom management, and responding to differences between students. Out of 24 teachers 22 indicated that at the end of the program they approximately reached their own learning goal. The program also had other outcomes. Teachers learned coaching and communication skills, they learned to reflect more on own automatisms in classroom, they noticed new aspects in their classroom practice, they got new ideas, and they became more openminded towards collaboration with their colleagues.

The PD program challenges competences of teachers in classrooms and during their dialogues. However, coaching is difficult and all teachers felt challenged by their coach-role. Most teachers reported that, at the end of the program, they still felt that 'peer coaching is difficult' and they still had coaching skills to learn. However, most teachers also reported that the communication and coaching skills they had learned were very useful for them and that they could use (and had already used) their new coaching and communication skills for their other professional roles (communication with students, parents, colleagues).

\subsubsection{Which design principles and characteristics of the program supported the learning of teachers at the workplace?}

Overall, the design principles and characteristics as implemented in the program seem satisfactory for stimulating teacher professional development. The principles should not be used independently, because they work in a complementary way. The focus on teacher practice is important in changing education - and not merely for changing teachers' ideas. While theory learning was least appreciated, feedback by means of video recordings and feedback embedded in peer coaching was appreciated as a great contribution, provided that peer coaching is done in an open, non-judgmental way, so that teachers feel stimulated to develop ownership. Inquiry is important for teachers' focus on outcomes in classrooms. Coaching and inquiry are professional learning strategies that need to be learned. The collaborative setting of the program seems essential in doing so. 
The most important part of the program for the teachers' learning was the viewing and discussing of video recordings of own lessons. The other principles and characteristics of the program helped to extend the learning process, for instance: the learning from the observation of their recorded lessons was deepened by the open-ended questioning and active listening of their peers. This stimulated the verbalizing of own thoughts and beliefs, which, in turn, stimulated in-depth reflections.

Teachers reacted positively to collaborating, the sharing of practice, and community building in the PD program. At the start of the program, all teachers were anxious to be filmed. Afterwards, almost all teachers were positive about the outcomes of the process of videotaping, observing, and conducting peer coaching dialogues with video feedback.

Although teachers, at the start of the program, preferred to compose the triads themselves, it might be more functional to let the trainers assign teachers to a peer coaching triad. In such triads cooperation between different colleagues might be stimulated and it might help to integrate newcomers, preventing triads becoming mere 'social clubs', and preventing the 'birds of a feather flock together' effect, which precludes learning from other teaching strategies and views and precludes learning to appreciate those other strategies and views. Heterogeneous triads were chosen that included teachers teaching different subjects. There is a possibility of fixed roles in departments and of different interests and politics that interfere with cooperation in a triad. To avoid problems, it was preferred that teachers of the same department were put in different triads.

Various teachers were frustrated because their triad did not function well enough, especially in the cohort that participated in the context of a mandatory team effort. The program had no instruments to interfere, and teachers themselves felt that they had no possibilities to change their situation.

Coaches can stimulate the learning of their peers by 'helping to notice', by 'helping to notice things that go well and putting things in the right perspective', by 'challenging to think for oneself', and by 'helping to analyze and understand', furthermore, they can give a boost to energy and motivation. It proved difficult for peer coaches to stay focused on the learning process of 
their peers (instead of showing own emotions or opinions, or giving advice and tips), to structure the dialogue, and to listen actively and show emphatic understanding.

The observer-role was important for all participants in order to stay focused and to stay in their role. The observer-role helped to gain depth in the dialogues and also aided with the learning of coaching skills.

Video feedback helped teachers to refresh their memories, to notice things, to study classroom practice, gain new insights, clarify own learning goals, create opportunities for feedback from colleagues, share classroom practice and escape from the public loneliness of the profession, to gain self-confidence, generate new ideas from the observation of peers, and share their work with others outside the school.

It was also discovered that video feedback might have an important additional value. Emotional aspects of learning (concerning identity, motivation, and tolerance of uncertainty) seem to play an important role in the professional development of teachers (Bolhuis, 2001). Coaching dialogues that also incorporated reflection on feelings helped the participants to gain a better understanding of what was really happening, and helped with finding solutions. In contrast, the teachers showed no positive attitude towards learning through studying theoretical knowledge. This shows again that in professional development it is important to connect with the concerns and preferred learning strategies of the professional.

To conclude, video feedback can serve as an important catalyst for learning in PD programs by providing teachers with a new kind of access to classroom interactions. It offers unique affordances to teacher learning. Video, for example, provides a lasting record of instruction that can be examined repeatedly without the immediate pressures of teaching. However, as Sherin and Han (2004) pointed out, it is only through the use of video in particular professional development contexts that this potential can be realized. Features such as the selection of focus, the specific types of video excerpts that are selected for viewing, the interactions among the video club participants, the context of the program, and the creation of a secure learning environment could be of particular importance. 


\subsubsection{What was the influence of (in)voluntary participation on teacher learning?}

The program has been built on design principles that strengthen the teacher as an active participant in own professional development. Teachers who refuse to become an active participant do not benefit themselves, but also create a problem for their peers in their triads. Not only are their peers unable to support the reluctant teacher, but it also affects the working climate in a triad. The (in)voluntary nature of participation seems to be the most important factor influencing the participants' learning. Although participants in both groups evaluated the program positively, (i) the evaluations in cohort A were more positive than the scores in cohort $B$, and (ii) teachers in cohort B showed more differences between individual participants. One of the most appreciated guidelines in the program was the reciprocal peer coaching. However, it remains important to find out more about the requisite conditions. Most programs for peer coaching recommend participation on a voluntary basis, although Timperley et al. (2007) recommended not to worry too much about this aspect. In this study, the results are more positive in volunteer cohort A. Should the program be considered a failure for cohort B? The answer is both yes and no. The program did not reach all teachers; a few teachers displayed active resistance to it (by not really joining and not developing a learning goal) and a considerable number of teachers reserved not enough time for the program for it to be highly effective. On the other hand, a number of teachers despite having reported in the interviews that they felt stressed at the start, that they did not want to take part in it, and that they felt forced to do so, stated afterwards that they not only felt satisfied, but also were willing and sometimes eager to continue the program. This change in appreciation was likely the result of the characteristics of the program that invited them to be open about their concerns and their performances, to work on their own learning goals, and to be respectful of each other.

Although teachers in cohort A were more positive, there also might be risks attached to completely voluntary participation. In cases where only those teachers join who are already opening up their classroom to their colleagues, there will be no sharing within a team as a whole, and there will be no progress in the creation of a secure learning environment in which all teachers learn to cooperate and respect each other in a professional, person-centered relationship. To conclude, it may be wise for school leaders to exert some pressure on teachers to participate in development programs, but they should make sure that these programs are implementing the important guidelines described in this chapter. 


\title{
CHAPTER 6 \\ Learning from experience - a closer exploration of teachers' reflection on practice
}

\begin{abstract}
In the PD program teacher learning is expected to occur as a result of different learning strategies, through video feedback and observing professional performance, through deliberate reflective peer coaching dialogues on classroom practice and by teacher inquiries in classroom. The two sub-studies in this chapter studied more closely the peer coach dialogues and teacher inquiries to offer a better understanding of how the program characteristics influenced teacher learning in the PD program. The results showed that peer coach dialogues and teacher inquiry stimulated teachers to develop their professional vision i.e. the ability to notice and interpret significant features of classroom interactions.
\end{abstract}

\subsection{INTRODUCTION AND RESEARCH QUESTIONS}

Clarke and Hollingsworth (2002, p. 947) pointed out that "the optimization of the outcomes of a process is facilitated by the understanding of that process". Understanding the internal dynamics of professional learning, its context, and its occasions helps to design powerful and effective PD programs. Therefore we need to understand how our program stimulated teachers' inquiry stance and teachers' reflective dialogues to 'deep talk', the kind of talk which engages teachers in deep reflection and shared construction of meaning (Hall, 2009).

Influential educational researchers recommended reflective skills as a means of increasing teachers' professional development. They underlined the importance of thorough reflection on their own workplace, including reflecting on actions, feelings, beliefs, motives, and on the political and moral issues pertaining to education (Chapter 2). Researchers have postulated that conditions for 
improving teaching and learning are strengthened when teachers collaboratively discuss teaching routines and actively engage in supporting each other's professional growth (Chapter 3). Yet relatively little research examines the specific interactions and dynamics by which a professional community at the workplace constitutes as a resource for teacher learning, and little study has been done on fine-grained analyses of teacher learning through out-of-classroom dialogues between teachers (Little, 2003).

Teachers in the program reported that peer coaching dialogues on video feedback and teacher inquiries fostered productive reflections and increased their understanding of teaching and learning (Chapter 4 and 5). These evaluations served as a point of departure for the further exploration of teacher dialogues and inquiries in the PD program in the sub-study described in this chapter.

By studying the videotaped reflective dialogues and the inquiries of individual teachers in the implemented program more closely, this study tries to offer a better understanding of how the program characteristics influenced teacher learning in the PD program. The examination of the nature of the teachers' reflections might also provide additional evidence regarding the effectiveness of the program. The main research question to be answered in this Chapter is "How do the programs characteristics stimulate teachers' reflective dialogues and inquiries on own practice?"

The following sub-questions were formulated:

1. How did the teachers discuss own practice during their reciprocal peer coaching dialogues? (sub-study 1).

2. How did the teachers study their own practice in their inquiries? (sub-study 2).

\subsection{TEACHERS' REFLECTION IN RECIPROCAL PEER COACHING DIALOGUES (SUB-STUDY 1)}

\subsubsection{Three instruments to study reflection in peer coaching dialogues}

The sub-study presented in paragraph 6.2 aims to answer the first research question and explores how reciprocal peer coach dialogues with video feedback can support teacher learning and the development of 'professional vision'. Professional vision refers to the idea that as we become part of a professional 
discipline, we are trained to look at and see a certain set of phenomena in a particular way (Goodwin, 1994). Teachers' professional vision involves the ability to notice and interpret significant features of classroom interactions and is particularly important as teachers are asked to make many teaching decisions in the midst of instruction. It consists of two main processes: (a) selective attention - deciding what to attend to, and (b) knowledge-based reasoning reasoning about what one notices (Sherin, 2007). These processes interact, thus, what one notices, influences how one reasons about what is seen, but in addition, one's knowledge and experiences influence what one will pay attention to. Key elements in dialogues which tell us about teachers' professional vision are (a) the topic of teachers' reflections and comments, and (b) the scope of the perspectives they include in their reflections and comments and (c) the reasoning in teachers' dialogues.

We constructed three classifications to analyze each aspect: one for analyzing the topics, one for analyzing the scope of the teachers' perspectives in their dialogues (both providing information about teachers' selective attention), and one for analyzing reasoning and conversational routines (providing information about teachers' knowledge-based reasoning).

Sherin and Van Es (2009) found that participating in a video club influenced the teachers' professional vision as expressed in their meetings, but also in interviews outside of the video club and in the teachers' instructional practices. These results suggest that dialogues discussing excerpts of videotaped interactions in classroom have the potential to support teacher learning in ways that extend beyond the boundaries of the video club meetings themselves. With the examination of professional vision in teachers' dialogues this study will answer the first research question and illustrate teacher learning in the program, as well as examine the affordances of the design principles especially reciprocal peer coaching and video feedback - in the program.

\section{Classification of the topic of reflection}

Topic of reflection refers to the objects of the dialogues. These topics were analyzed with an adapted classification of the description of teacher competences as defined in the Dutch 'Professions in Education Act' [wet BIO] (Ministerie van Onderwijs, Cultuur en Wetenschap, 2004). This Act differentiates between the seven domains of competence: interpersonal, 
pedagogical, subject and methodological, organizational, cooperation with colleagues, cooperation with the community, and reflection and development. We divided 'topic of the reflections' in six categories (Table 6.1). For the classification in this study the first four domains were copied. Next, the categories 'cooperation with colleagues' and 'cooperation with the community' were combined into the category 'cooperating in the context of the school'. Finally, a new category was added: 'the learning processes of pupils/students'. This last category was added to comply with review studies, which, as described in Chapter 3, stated that teachers' collaborative learning should focus on the learning processes of students (Resnick, 2005; Timperley, 2005; Timperley et al., 2007), and also with studies on collaborative teacher dialogue on video recordings of practice (Borko et al., 2008; Sherin \& van Es, 2009; van Es \& Sherin, $2002,2005)$. It was assumed that studying video feedback could offer teachers a new view and focus on learning processes of students. In contrast to the first five topics, which mostly referred to competences and skills of teachers, this last category is exclusively focused on the learning behavior of the students.

Table 6.1 Topic of reflection

\begin{tabular}{ll}
\hline category & description \\
\hline Interpersonal competence & $\begin{array}{l}\text { Communication and contact in the classrooms and class } \\
\text { climate }\end{array}$ \\
\hline Pedagogical competence & Moral education and coaching children to adulthood \\
\hline $\begin{array}{l}\text { Subject / pedagogical content } \\
\text { knowledge (PCK) }\end{array}$ & $\begin{array}{l}\text { Actions of teachers to help students study subjects and } \\
\text { reach learning objectives }\end{array}$ \\
\hline $\begin{array}{l}\text { Classroom management and } \\
\text { organizational competence }\end{array}$ & $\begin{array}{l}\text { Creating an orderly working climate, e.g. organizing } \\
\text { learning materials, layout of classroom, time management } \\
\text { in classroom }\end{array}$ \\
\hline Cooperation in the context of the & $\begin{array}{l}\text { Cooperation in school context, e.g. with colleagues, } \\
\text { management, parents, working together as a team, school } \\
\text { facilities }\end{array}$ \\
\hline Learning process student & $\begin{array}{l}\text { Actions of student(s) which demonstrate learning / } \\
\text { thinking }\end{array}$ \\
\hline
\end{tabular}

\section{Classification of the scope of perspectives in reflection}

Scope of reflection referred to the various perspectives by which the teachers studied the chosen topics. Different perspectives of teachers' reflections were derived from the models of reflection as described in Chapter 2 (Ghaye \& Ghaye, 1998; Kelchtermans, 2007; Korthagen, 2001; Korthagen \& Vasalos, 2005). Scope refers to different points of view for reflection (teacher, student, existing theoretical notions) and different domains of reflection (action-oriented, emotion-oriented, mission/moral-oriented). The term 'scope' is used here 
instead of 'level'. The term 'level' suggests a hierarchy, in which some levels are better than others. That is not the case here. There is no fixed order for reflection and various types of reflection supplement each other and broaden the scope of the reflection. We assume that analysis of the topic and the width of the scope can illustrate teachers' considerations of their classroom practice and teachers' beliefs and values which underpin own professional behavior. The scope of the 'perspective of reflection' is divided into five categories, namely: (a) technicalinstrumental or action-oriented perspective, (b) ego perspective, (c) student(s) perspective(s), (d) theoretical perspective, and (e) the perspective of professional identity, ideals, beliefs, and moral/political notions (Table 6.2).

Table $6.2 \quad$ Scope of perspectives

\begin{tabular}{|c|c|c|c|}
\hline perspective & description & Signaling words & example \\
\hline $\begin{array}{l}\text { Action- } \\
\text { oriented } \\
\text { perspective }\end{array}$ & $\begin{array}{l}\text { Descriptions of work } \\
\text { situations, events and } \\
\text { relating them to } \\
\text { solutions for } \\
\text { experienced problems. } \\
\text { The focus is on } \\
\text { solutions, tips and } \\
\text { possible alternatives } \\
\text { without explicitly } \\
\text { relating them to other } \\
\text { underlying } \\
\text { perspectives or in- } \\
\text { depth analyses. }\end{array}$ & $\begin{array}{l}\text { Verbs expressing actions, } \\
\text { e.g. saying, talking, } \\
\text { explaining and words like: } \\
\text { and, then, }\end{array}$ & $\begin{array}{l}\text { And then happened... and } \\
\text { then...; the student did...; } \\
\text { the assignment was...; next } \\
\text { time you could try to...; } \\
\text { next time..., you can try... }\end{array}$ \\
\hline $\begin{array}{l}\text { Ego } \\
\text { perspective }\end{array}$ & $\begin{array}{l}\text { Reflecting on work } \\
\text { situations, events and } \\
\text { actions and relating } \\
\text { them to own } \\
\text { perspective in that } \\
\text { specific work situation } \\
\text { (own actions, } \\
\text { thoughts, feelings, } \\
\text { motives). }\end{array}$ & $\begin{array}{l}\text { 'I' in combination with: } \\
\text { expressions of thoughts, } \\
\text { emotions, feelings, } \\
\text { frustration, } \\
\text { and in combination with a } \\
\text { conjunction: because I...; as } \\
\text { a result of this I...; hence } \\
\text { I...; next time I don't want } \\
\text { to become so.... }\end{array}$ & $\begin{array}{l}\text { And then I went..., I felt..., } \\
\text { I thought..., I wanted ... }\end{array}$ \\
\hline $\begin{array}{l}\text { Student } \\
\text { perspectives } \\
\text { (or } \\
\text { perspective } \\
\text { of other } \\
\text { actors) }\end{array}$ & $\begin{array}{l}\text { Reflecting on work } \\
\text { situations, events and } \\
\text { (possible) actions and } \\
\text { relating them to the } \\
\text { perspectives of } \\
\text { students in that } \\
\text { specific work situation } \\
\text { (students' actions, } \\
\text { thoughts, feelings, } \\
\text { motives). }\end{array}$ & $\begin{array}{l}\text { Words like he/she/they in } \\
\text { combination with } \\
\text { expressions of thoughts, } \\
\text { emotions, feelings, } \\
\text { frustration, } \\
\text { and in combination with a } \\
\text { conjunction: } \\
\text { Because they wanted...; as a } \\
\text { result he was ...; therefore } \\
\text { she thought... }\end{array}$ & $\begin{array}{l}\text { He/she/they did, felt, } \\
\text { thought, wanted... }\end{array}$ \\
\hline
\end{tabular}


Table 6.2 Scope of perspectives (Continued)

\begin{tabular}{|c|c|c|c|}
\hline perspective & description & Signaling words & example \\
\hline $\begin{array}{l}\text { Theoretical } \\
\text { perspective }\end{array}$ & $\begin{array}{l}\text { Reflecting on work } \\
\text { situations, events and } \\
\text { (possible) actions and } \\
\text { relating them to theore- } \\
\text { tical and professional } \\
\text { knowledge base. } \\
\text { Deliberative, weighing } \\
\text { theoretical viewpoints } \\
\text { and theoretical notions } \\
\text { to understand } \\
\text { practice. }\end{array}$ & $\begin{array}{l}\text { References to verbs like: } \\
\text { reading, learning, hearing, } \\
\text { understanding... } \\
\text { References to: schools, } \\
\text { programs, books, articles, } \\
\text { definitions, instructions... }\end{array}$ & $\begin{array}{l}\text { I read about this in an } \\
\text { article...; } \\
\text { I learned during a PD } \\
\text { program that...; the } \\
\text { directions in the manual } \\
\text { recommend...; I noticed in } \\
\text { the past that... will work... }\end{array}$ \\
\hline $\begin{array}{l}\text { professional } \\
\text { identity and } \\
\text { perspective } \\
\text { of ideals, } \\
\text { mission, } \\
\text { and moral/ } \\
\text { political } \\
\text { notions }\end{array}$ & $\begin{array}{l}\text { Reflecting on work } \\
\text { situations, events and } \\
\text { (possible) actions and } \\
\text { relating them to own } \\
\text { professional identity, } \\
\text { ideals, mission and/or } \\
\text { relating them to moral } \\
\text { and political notions } \\
\text { concerning teaching, } \\
\text { school and education. }\end{array}$ & $\begin{array}{l}\text { References to verbs like: } \\
\text { Wanting, hoping, striving, } \\
\text { believing... } \\
\text { Nouns like: } \\
\text { Drive, ideal, ambition, } \\
\text { responsibility, aim, } \\
\text { justice,... }\end{array}$ & $\begin{array}{l}\text { Reflections on own ideals as } \\
\text { a teacher, relating actions } \\
\text { with assumptions or ethical } \\
\text { questions about learning / } \\
\text { school / education / or } \\
\text { broader social issues like } \\
\text { 'equality'. }\end{array}$ \\
\hline
\end{tabular}

\section{Classification of conversational routines}

Because we are interested in the ways dialogues in the program offered opportunities for professional learning, we adopted the classifications that Horn and Little (2010) developed. They described conversational routines, i.e. patterned and recurrent ways that conversations unfold within teacher dialogues, and conversational moves, i.e. a question, an answer, an expression, or a statement of a teacher. Horn and Little identified two basic patterns of conversational routines in which teachers respond to each other in professional dialogues: teachers may react to problems introduced by their peer (a) by normalizing, and (b) by collaborative problem solving through teaching replays and teaching rehearsals.

By normalizing, teachers let each other know that their experiences and problems are not unique and that these are shared by others. Normalizing moves offer reassurance ('You'll be fine, don't worry') and establish solidarity ('It happens to all of us'). The routine of nurturing can be followed by ending of the conversation, changing the topic, providing advice or tips, or a generative question which stimulates more in-depth analysis. Horn and Little (2010) distinguished nurturing moves that steer the conversation away from the teaching and nurturing moves that steer the conversation towards the teaching as an object of collective attention. 
In the first case, steering away from teaching, the conversation drifts away from more in-depth consideration of the problem. Teachers limit themselves to expressions of sympathy or reassurance, or they move directly (and briefly) to advice or familiar aphorisms before moving on to other topics. This turning away tends to obscure the ability of teachers to notice and interpret significant features of classroom interactions and relate them to dilemmas of teaching (a class of problems), while positioning the narrator as relatively helpless in the face of circumstances beyond his or her control or as a passive recipient of others' advice. In the second case, steering towards teaching, teachers treat the shared and expected (normal) nature of a problem as a starting point for detailed discussion of specific classroom instances and for problem solving.

During problem solving teachers the first of the two conversational routines Horn and Little describes is called teaching replay. This are recounts in detail of actual events. In this routine teachers create vivid reconstructions of classroom experience, narrating their own part in it, and supplying the voices of students as well. The second routine refers to teaching rehearsals that are enactments of anticipated, potential, or prototypical events.

Based on this framework of Horn and Little we developed a classification for studying conversational routines and moves to explore the effects of teacher-toteacher interactions in the PD program and the affordances they provided for reflection (Table 6.3). The adaptation occurred in an iterative process between the developed framework and the analysis of the peer coach dialogues. Additional literature helped to refine categories. Our framework consists of the following six categories.

- The first conversational routine relates to establishing a common framework for the peer coach dialogue. Its aim is exchange of information: Which lesson will be discussed? Which student group is involved? Which learning goal and research question will be studied?

- The second conversational routine refers to the nurturing of a safe and open learning environment. Teachers can do this by various conversational moves.

- Peers can stimulate the self-confidence of teachers by 'normalizing' moves, normalizing problems of practice by reassurance and/or immediate offers of advice (Horn \& Little, 2010). 
We added two other moves aiming at a safe and open learning environment, namely:

- by confirming the self-confidence of the teacher,.

- by restoring the principle of teacher ownership of learning goal and giving back the lead to the teacher.

- A third routine concerns teaching replays. In contrast to the research of Horn and Little in which teaching replays took place with the help of descriptions, in our program video supplied most of the information of the teaching replays. With the help of the recorded lesson, teachers can reconstruct practice and study the perspectives of their colleague and students. With the help of video feedback peers can coach each other to notice new aspects and to attend to noteworthy features of instruction that the teacher himself overlooked (Borko et al., 2008; Sherin, \& van Es, 2009). We distinguish between teaching replays aiming at:

- describing and recalling the lesson with the help of video feedback,

- elucidating and aiming at noticing important features of classroom practice.

- We added a fourth routine fitting experiences and/or learning goal in a (new) framework. Teachers interpret, explain and fit insights into own practical knowledge base. Kennedy (2004) found that there were at least three different ways of thinking by teachers: (a) teachers saw a situation and tried to read/interpret that situation so that they could act on the situation or formulate an intention to act on it; (b) teachers' thoughts activated a set of accumulated principles of practice about how to respond to certain situations; and (c) "teachers often justified their principles of practice by referring to a set of standing beliefs and values" (pp. 9-10). Comparably, results were found by Gholami and Husu (2010, p. 1527) who studied how teachers reasoned about practices and their practical knowledge. Their findings indicated that teachers supported their acting and problem solving by practical knowledge claims using two significant warrants when they spoke about their practical knowledge: "moral ethos" arguments (referring to pedagogical obligations) and "efficiency of action" arguments. We split this last category in two categories: (i) arguments referring to 'what works' notions of teachers' practical knowledge base, (ii) arguments referring explicitly to theoretical notions, educational theories and of the theoretical knowledge base of their profession. 
- The fifth routine refers to teaching rehearsals formulating alternatives and aiming at experiments and solutions in classroom. Moves including arguments based on the same three warrants as before, arguments referring to moral ethos, efficiency of action, and to educational theories.

- The last conversational routine contains the evaluation of the peer coach dialogue. This conversational routine was built into the program. Every peer coach dialogue should end with a mutual evaluation of the dialogue on how informative and supportive the dialogue had been for the teacher and the role of the peer coach at this.

Table 6.3 Conversational routines and moves in peer coaching dialogues

\begin{tabular}{|c|c|c|}
\hline Phase & Routines and moves & Examples of moves \\
\hline Start & $\begin{array}{l}\text { 1. Establishing a common } \\
\text { frame of reference for the } \\
\text { peer coach dialogue. }\end{array}$ & $\begin{array}{l}\text { - Which lesson will be discussed? } \\
\text { - Which student group is involved? } \\
\text { - Which learning goal will be discussed? }\end{array}$ \\
\hline \multirow[t]{3}{*}{$\begin{array}{l}\text { Analyzing } \\
\text { lesson }\end{array}$} & $\begin{array}{l}\text { 2. Nurturing a safe and open } \\
\text { learning environment. } \\
\text { Moves: } \\
\text { - normalizing. } \\
\text { - confirming the self- } \\
\text { confidence of the teacher. } \\
\text { - restoring ownership of } \\
\text { learning goals and } \\
\text { agency of the teacher as } \\
\text { ultimate interpreter of } \\
\text { own lesson. }\end{array}$ & $\begin{array}{l}\text { - Well, that could happen to all of us. } \\
\text { - It is just a matter of experience, it will get better. } \\
\text { - Our students are just like that. } \\
\text { - I found it very good, the way you handled that } \\
\text { - I think you're too critical about yourself and I } \\
\text { don't think that is necessary. How do you think } \\
\text { the children experienced your lesson when } \\
\text { you're looking back on it? } \\
\text { - OK, let's go back to the point you wanted to } \\
\text { discuss... }\end{array}$ \\
\hline & $\begin{array}{l}\text { 3. Teaching replays. Moves: } \\
\text { - Recalling of the lesson } \\
\text { - (describe). } \\
\text { - Learning to notice } \\
\text { important features of } \\
\text { classroom practice } \\
\text { (elucidate). }\end{array}$ & $\begin{array}{l}\text { - I wrote down point by point what I saw } \\
\text { happening in the video. You started with... } \\
\text { - And then I divided the group in sub-groups, } \\
\text { - } \text { placing students with differing abilities together. } \\
\text { - } \text { How did the student react in the video? } \\
\text { - On the video I noticed not all students were } \\
\text { working, however during the lesson... }\end{array}$ \\
\hline & $\begin{array}{l}\text { 4. Fitting experiences and/or } \\
\text { learning goal in a (new) } \\
\text { framework } \\
\text { (interpreting, explaining, } \\
\text { and fitting insights into own } \\
\text { practical knowledge base). } \\
\text { Including arguments for } \\
\text { interpretation and } \\
\text { explanation based on: } \\
\text { - 'what works' notions, } \\
\text { - theoretical notions, } \\
\text { - moral notions. }\end{array}$ & $\begin{array}{l}\text { - Let us look at what has happened to find out } \\
\text { why it did not function? } \\
\text { - If you would use different classroom } \\
\text { management would you reach the form of } \\
\text { differentiation you are aiming for? } \\
\text { - My goal is not so much to differentiate but to } \\
\text { better motivate students. } \\
\text { - I always compose the subgroups myself to } \\
\text { prevent the old-boys network which always } \\
\text { leaves out the same children. You have to guard } \\
\text { those children to prevent them being bullied. }\end{array}$ \\
\hline
\end{tabular}




\begin{tabular}{|c|c|c|}
\hline Phase & Routines and moves & Examples of moves \\
\hline $\begin{array}{l}\text { Analyzing } \\
\text { alternatives } \\
\text { and } \\
\text { wrapping } \\
\text { up }\end{array}$ & $\begin{array}{l}\text { 5. Teaching rehearsals } \\
\text { (possible alternatives, } \\
\text { experiments in classroom, } \\
\text { solutions) and next steps. } \\
\text { Including arguments based } \\
\text { on: } \\
\text { - 'what works' notions, } \\
\text { - theoretical notions, } \\
\text { - moral notions. }\end{array}$ & $\begin{array}{l}\text { - Are there other ways to activate students [to } \\
\text { learn]? } \\
\text { - Next time I will do... } \\
\text { - I will experiment with... and assess if it works } \\
\text { through... } \\
\text { - What would be your dream scenario? What does } \\
\text { it look like? What is your role as a teacher in that } \\
\text { scenario? } \\
\text { - Are you going to give special attention and help } \\
\text { - to those students? } \\
\text { - How can you see in your next lesson, that... } \\
\text { your learning goal? }\end{array}$ \\
\hline $\begin{array}{l}\text { Evaluating } \\
\text { the process }\end{array}$ & $\begin{array}{l}\text { 6. Evaluating peer coach } \\
\text { moves and its effects on the } \\
\text { reflection process }\end{array}$ & - What was helpful for you? \\
\hline
\end{tabular}

\section{Research question for sub-study 1}

The research question for this sub-study read as follows: "How did the teachers discuss own practice during their reciprocal peer coaching dialogues?"

To answer this question the following sub-questions were formulated:

1. On which topics did teachers reflect during their peer coaching dialogues?

2. With what kind of perspective did the teachers reflect during their peer coaching dialogues?

3. Which conversational routines were employed during their peer coaching dialogues?

\subsubsection{Method}

\section{Participants and data collection}

In the PD program, teachers were asked to record their reciprocal peer coaching dialogues on video. During the implementation of the program the availability of video cameras proved to be a problem. During their dialogues teachers needed two cameras: one camera connected to a TV-set to observe and discuss their recordings of own classroom, and one to record their peer coaching dialogues. Often there was a lack of available video cameras resulting in only a limited number of dialogues actually being recorded (Table 6.4). 
Table 6.4 Overview of recorded peer coaching dialogues in PD program 'Learning to Notice'

\begin{tabular}{lll}
\hline Implementation context & triad & $\begin{array}{l}\text { Number (and code) of recorded and handed in } \\
\text { peer coaching dialogues of each triad }\end{array}$ \\
\hline $\begin{array}{l}\text { Cohort A } \\
\text { (volunteers; }\end{array}$ & A - I & $3(\mathrm{~A} 1, \mathrm{~A} 2, \mathrm{~A} 3)$ \\
$\begin{array}{l}\text { coming from different } \\
\text { teams) }\end{array}$ & A - II & 2. \\
A - III & 6 \\
\hline $\begin{array}{l}\text { Cohort B } \\
\text { (mandatory team activity; }\end{array}$ & B - I & $3(\mathrm{~B} 1, \mathrm{~B} 2, \mathrm{~B} 3)$ \\
$\begin{array}{l}\text { all of the teachers teaching } \\
\text { in the bilingual stream) }\end{array}$ & B - III & 3 \\
& B - IV & 1 \\
& B - V & 2 \\
\hline
\end{tabular}

For the analyses we used the videotapes of one triad from each cohort (A-I and B-I, Table 6.4); dialogues of the other triads were also transcribed and used for the development and testing of our research instruments.

\begin{tabular}{l|lll} 
Table 6.5 & Overview of studied dialogues & & \\
\hline \multirow{2}{*}{ Triad } & Subject teachers & $\begin{array}{l}\text { Experience } \\
\text { (in years) }\end{array}$ & $\begin{array}{l}\text { Dialogue duration } \\
\text { (in minutes) }\end{array}$ \\
\hline \multirow{2}{*}{ A-I } & Biology & $\begin{array}{l}8 \text { (and new to this } \\
\text { school) }\end{array}$ & 41 \\
& Economics & $\begin{array}{l}17(\text { mostly in primary } \\
\text { education) }\end{array}$ & 37 \\
\cline { 2 - 4 } & & 7 & 31 \\
\cline { 2 - 4 } & Dutch & 10 (mostly abroad) & 27 \\
\hline \multirow{2}{*}{ B-I } & Biology & $\begin{array}{l}27 \text { (all abroad, and } \\
\text { new to this school) }\end{array}$ & 45 \\
\cline { 2 - 4 } & Mathematics & 7 & 32 \\
\cline { 2 - 3 } & English & & \\
\hline
\end{tabular}

Both subgroups under study were composed of teachers with different backgrounds regarding subject taught, age and experience. Nobody was accustomed to working closely together with the peers in their triad. Triad A-I consisted of three female teachers (biology, economics and Dutch). In triad B-I two female teachers (biology and mathematics) and one male teacher (English) cooperated (Table 6.5).

\section{Data analysis}

All six dialogues were fully transcribed. Data of the questionnaire and semistructured interview, collected to evaluate the program (Chapter 5), were used for a better understanding and triangulation of the results. For reasons of privacy the names of participating teachers were changed. 
In order to study the topic and the scope of perspectives of reflection:

- The researcher divided the transcripts in segments. Each time the conversation shifted between peer coach and teacher it was coded as a new segment, ignoring small utterances such as 'uh' or 'yeah'. In this way, the transcripts of the six dialogues under study resulted in a total of 938 segments.

- One segment, defined as the time that one speaker would talk without interruption, could encompass more than one topic or more than one scope. In such cases only the main topic or scope was scored. Evidently, scoring the topic and the scope of reflection does not capture all the complexity inherent in teachers' reflection. However, it should serve as a useful indicator of teachers' attention, because it points to the issues that are their primary focus at that moment. Similarly, teachers' knowledge-based reasoning encompasses a wide variety of cognitive skills; investigating the scope in which teachers reflect on video feedback addresses only some components of the process.

- Two researchers tested the coding categories on a transcript of one of the dialogues of subgroup A3. This dialogue was not included in the further data analysis of this study. The researchers compared coding and clarified or revised the coding definitions.

- Next, each segment of the selected dialogues of subgroup A1 and B1 was coded independently by two researchers for the dimensions topic and scope. Scores were compared and differences were discussed until agreement was reached.

In order to study the conversational routines and moves:

- The interaction context of each dialogue was summarized, describing participants and focus of the dialogue.

- The dialogues were mapped again in new segments, boundaries this time defined by shift of topic of conversation (instead of changes in speaker). Within each segment the topic was described and the conversational routines and moves were mapped with the help of the developed framework for conversational routines (Table 6.3).

\subsubsection{Results}

\section{Topics discussed in teachers' dialogues}

Almost all dialogues centered on issues around motivating and activating students. Most of the time, the teachers focused their dialogues on subject and methodological issues such as 'how to stimulate students to engage actively with the subject matter' (Figure 6.1). Teachers discussed among others their 
chosen approach, their own instructions, their use of learning time, and their own thoughts and worries during their lessons. Secondly, the teachers spent a considerable amount of time studying the learning processes of their students. Often the dialogues about ways to teach their subject got intertwined with reflection on learning of students. The third main topic of their reflections revolved around issues of classroom management. Discussions about other issues were scarce.

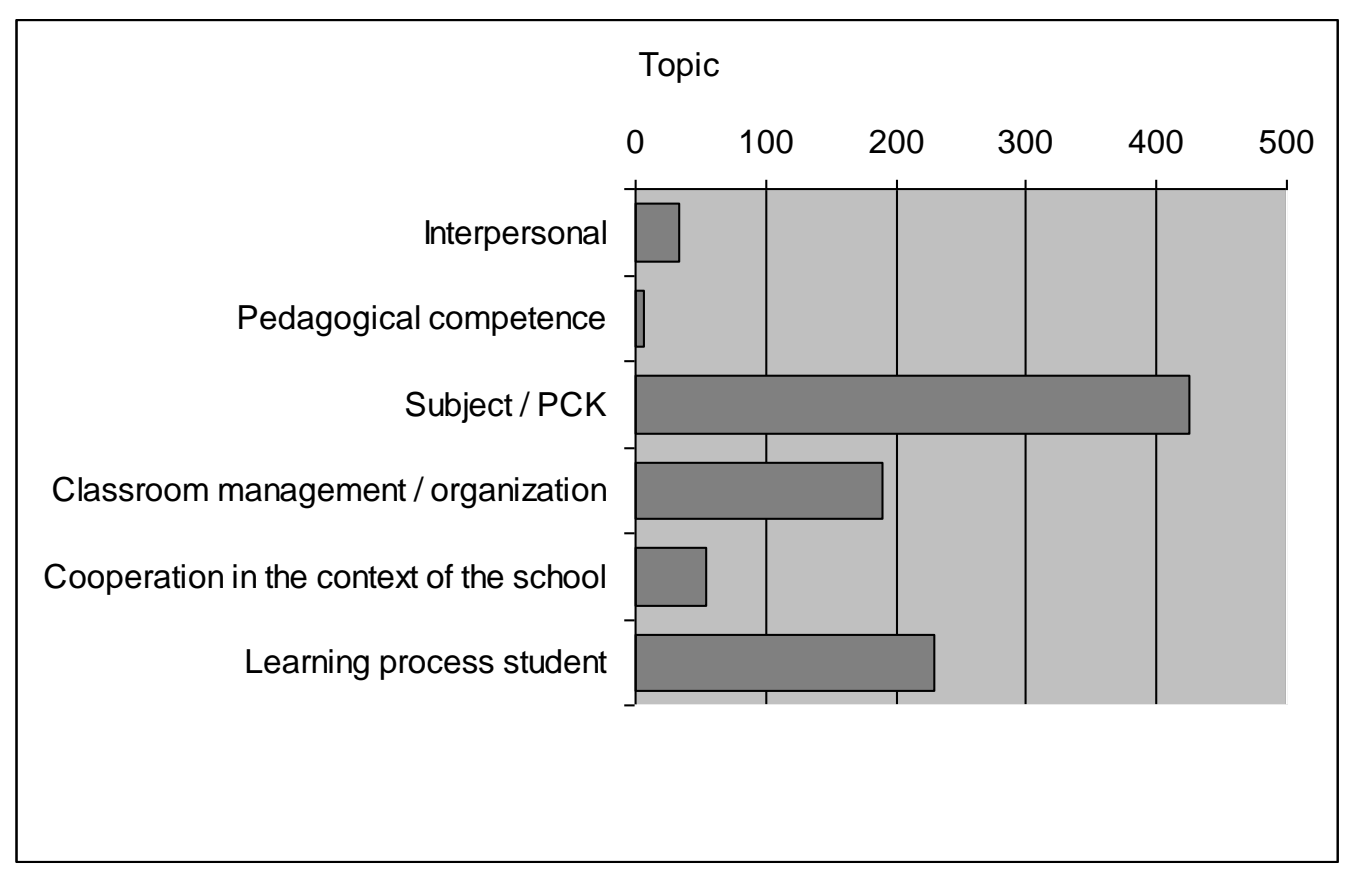

Figure 6.1 Topic of teachers' dialogues ( $\mathrm{N}=938$ dialogue segments)

The teachers in subgroup B1 added a specific characteristic to their reflective dialogues and their video feedback. These teachers worked in the same team, however taught different subjects. They discovered that because of these conditions, they were teaching the same student groups. The three teachers decided to focus their dialogues on lessons taught in one of their shared student groups. In this way they enlarged the shared context of their lessons and could study differences in reactions and learning activities of the same students in each lesson and relate them to differences in teaching styles and teaching methods. In their interviews, these teachers reported this as a very useful experiment:

"To see how different the group was in each lesson, and I'd not really realized how completely different, almost like the class is schizophrenic or something... it is unbelievable how different they can be. To see the way different teachers do 
things, the start of a lesson and the end of a lesson. It was interesting because it makes you think how you could do things differently in your own lessons." (John, subgroup B1, interview)

In three dialogues (A1, B1, and B2), teachers expressed surprise at the differences between 'experienced reality in classroom' and the feedback observed on video. For instance, one teacher (dialogue A1) was surprised that students appeared much more active and involved in learning than she had noticed during her lesson. The reflections in these dialogues centered on the 'why' of these differences, including exploring goals, feelings, and ideas about teacher and student roles, and on their conclusions for structuring future lessons.

\section{Scope in terms of perspectives addressed}

With what scope of perspectives did the teachers discuss their experiences? Most of the time their dialogues were action-oriented conversations in which they analyzed their experiences, valuing them and looking for alternatives and solutions for the problems they experienced (Figure 6.2). Teachers analyzed classroom situations nearly as much starting from their own perspective (i.e. own actions, feelings, thoughts and motives) as starting from the perspectives of their students. There were almost no dialogue segments in which the teachers clearly discussed from a theoretical perspective reflecting on theories of teaching and the theoretical knowledge base of their profession, besides their own practical knowledge base. Theoretical knowledge was not explicitly introduced into their discussions. A small number of discussions started from an action-oriented point of view, which then broadened and became connected with explicit reflections on own moral views about school and their role as a teacher. 


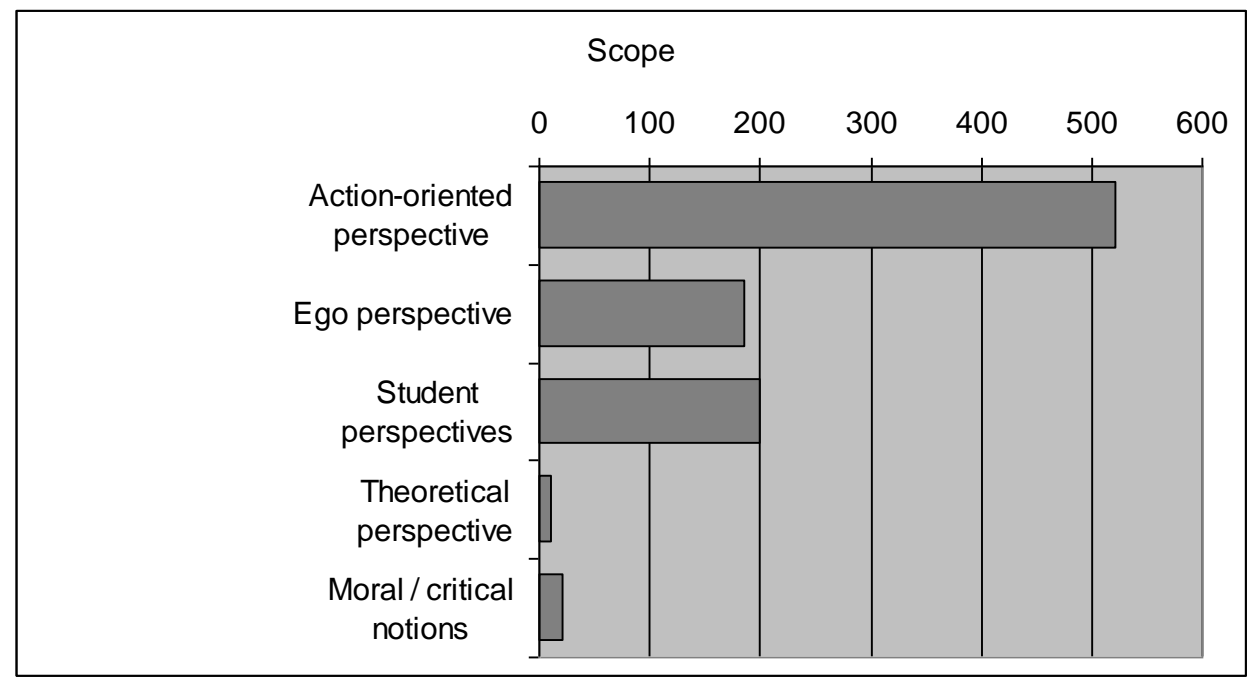

Figure 6.2 Scope of teachers' reflections in dialogues $(\mathrm{N}=938$ dialogue segments)

\section{Combining topic and scope of perspectives}

Combining the topic the scope of teachers' reflections, a more detailed two dimensional view on their dialogues can be obtained (Table 6.6). Most of the reflections about pedagogical content knowledge emanated from an actionoriented point of view, and also in some cases from an ego-perspective or from the student-perspective. In discussions on 'the learning process of students' teachers paid clearly much more attention to the student-perspective. In the few cases that a theoretical perspective was dominant in the conversations, this view was also related to pedagogical content knowledge. However, these instances were very limited (only $1 \%$ of all segments). 
Topic and scope of reflections ( $N=938$ dialogue segments)

\begin{tabular}{|c|c|c|c|c|c|c|c|}
\hline & $\begin{array}{l}\text { Inter- } \\
\text { personal } \\
\text { / class } \\
\text { climate }\end{array}$ & $\begin{array}{l}\text { Peda- } \\
\text { gogical } \\
\text { / goals }\end{array}$ & $\begin{array}{c}\text { Peda- } \\
\text { gogical } \\
\text { content } \\
\text { knowledge }\end{array}$ & $\begin{array}{c}\text { Learning } \\
\text { process } \\
\text { student }\end{array}$ & $\begin{array}{c}\text { Classroom } \\
\text { manage- } \\
\text { ment }\end{array}$ & $\begin{array}{l}\text { Coope- } \\
\text { ration in } \\
\text { the } \\
\text { context } \\
\text { of the } \\
\text { school }\end{array}$ & Total \\
\hline $\begin{array}{c}\text { Action } \\
\text { oriented }\end{array}$ & $1 \%$ & $0,5 \%$ & $27 \%$ & $12 \%$ & $12 \%$ & $3 \%$ & $\begin{array}{c}56 \% \\
N=521\end{array}$ \\
\hline $\begin{array}{c}\text { Ego } \\
\text { perspective }\end{array}$ & $1 \%$ & - & $9 \%$ & $4 \%$ & $5 \%$ & $2 \%$ & $\begin{array}{c}20 \% \\
N=186\end{array}$ \\
\hline $\begin{array}{c}\text { Student } \\
\text { perspective }\end{array}$ & $1 \%$ & $0.5 \%$ & $8 \%$ & $8 \%$ & $4 \%$ & $1 \%$ & $\begin{array}{c}21 \% \\
N=200\end{array}$ \\
\hline $\begin{array}{l}\text { Theoretical } \\
\text { perspective }\end{array}$ & - & - & $1 \%$ & $0 \%$ & $0 \%$ & $0 \%$ & $\begin{array}{c}1 \% \\
\mathrm{~N}=10\end{array}$ \\
\hline $\begin{array}{c}\text { Perspective } \\
\text { of ideals/ } \\
\text { moral } \\
\text { notions/ } \\
\text { profession- } \\
\text { nal identity }\end{array}$ & - & - & $1 \%$ & $1 \%$ & $0 \%$ & - & $\begin{array}{c}2 \% \\
N=21\end{array}$ \\
\hline total & $\begin{array}{c}4 \% \\
N=34\end{array}$ & $\begin{array}{c}1 \% \\
N=6\end{array}$ & $\begin{array}{c}45 \% \\
N=425\end{array}$ & $\begin{array}{c}25 \% \\
N=230\end{array}$ & $\begin{array}{c}20 \% \\
N=189\end{array}$ & $\begin{array}{c}6 \% \\
N=54\end{array}$ & $100 \%$ \\
\hline
\end{tabular}

Note: A cell with a hyphen (-) refers to a cell with no scores at all.

A cell with the score $0 \%$ refers to a cell with less than $0,5 \%$ of all scores.

The introduction of new topics or scopes

From our experiences of coaching student-teachers we learned that studentteachers' reflections tend to take on ego-perspective and action-oriented problem solving. Judging from this background, we supposed that peer coaches would be important in introducing new topics and perspectives in the dialogues.

At the start of each dialogue, the teacher was free to choose his or her personal learning goal and the stated goal determined the main focus of their conversation. During the dialogues new topics were introduced, often as a result of observing and analyzing the video recordings. The peer coach introduced a new topic or perspective mostly by using open-ended questioning. For instance, coaches changed the perspective from actions to motives, feelings or thoughts of the teacher or those of their students. Noticeably, contrary to our experiences with student-teachers, the teachers themselves (instead of their 
coach) often introduced the perspective of his/her students (Table 6.7). It appeared that video feedback provided enough information for most teachers to trigger reflection from the perspective of their students.

Table 6.7 Introduction of the ego and the student perspective (N=386 dialogue segments)

\begin{tabular}{ccc}
\hline & Ego perspective & Student perspective \\
\hline Teacher-trainee & $48 \%$ & $65 \%$ \\
\hline Teacher-coach & $45 \%$ & $32 \%$ \\
\hline Teacher-observer & $7 \%$ & $3 \%$ \\
\hline & $100 \%(\mathrm{~N}=186)$ & $100 \%(\mathrm{~N}=200)$ \\
\hline
\end{tabular}

\section{Conversational routines}

Analyses of the course of the conversation supplied another indication of teacher learning. Various questions and reactions offered different learning opportunities. Still, in each of the dialogues forms of reflective talk were found. The dialogues contained signs of thinking such as pauses and unfinished sentences, the teachers referred to their thought processes ('looking back and thinking about it, maybe...') and reformulated their sentences. They also explained their thoughts, gave arguments for their analyses and reacted to prompts of their colleague. All of these signs indicated that these ideas were generated by new and more careful consideration of classroom practice.

To establish that a dialogue was potentially conducive to professional learning, this study sought evidence that the dialogue did more than simply report on or point to problems of practice, or brainstorm quick advice. To search for teacher reflection we used the framework for conversational routines described in Table 6.3.

\section{Establishing a common frame of reference}

As planned in the program dialogues started with the establishment of a common frame of reference. The peer coach checked what to talk about, which lesson, which student group involved, and which learning goal and research question of the teacher-learner to be discussed. After having established a common point of departure, almost all dialogues continued with forms of 'teaching replays' in which teachers recalled and analyzed step by step from the lesson or lesson fragments linked to the chosen learning goal of the teacher. One coach (dialogue B1) took as line of approach to start replay by focusing on the feelings of frustration of the teacher instead of recapitulating actions. 
In all six dialogues the learning goal of the teacher-learner was discussed, however, the coach also opened up regularly the discussion and focused their reflection, through questioning on what at first hand appeared to be straightforward, non-problematic recordings of classroom, for instance by asking 'the why' of chosen strategies or by pointing at the perspective of the students.

\section{Nurturing a safe and open learning environment}

All dialogues had short or longer moments in which teachers 'normalized problems'. One of the most common instances was ways of bonding, in which teachers linked experiences to their position in alliance with one another (e.g. 'that's just happened to me too' or innocent jokes about school or students). Such reactions, as Horn and Little (2010) pointed out, also helped to interpret classroom experiences by limiting the range of explanations. For instance, in one fragment the teachers discussed whole class teaching. By normalizing (laughing: "I would never be able to get them listen to me for ten minutes") the coach indicated that the listening of students was a normal problem of all teachers, but also presented a teaching principle to the teacher to reflect on ('restrict moments of student listening to 10 minutes in a row').

Another way to secure an open learning environment is shown in dialogue B1. The peer-coach had already met the teacher in the corridors and knew that the teacher was not satisfied with his lesson. She chose to start discussing these feelings and to confront these feelings (which she thought were not justified with the videotaped lesson) (Fragment 6.1). As demonstrated in the fragment, the teacher benefitted from this normalizing of problems (through video feedback and dialogue) and even reported using his new found peace and quiet attitude in one of his next lessons. 


\begin{tabular}{|c|c|}
\hline & \\
\hline coach & So, first of all, how did you feel about your lesson? \\
\hline teacher & $\begin{array}{l}\text { First of all, I felt a little bit frustrated and I came and talked to you straight after } \\
\text { the lesson because of the disruptions taking place towards the end of the lesson. } \\
\text { So, that sort of initially colored my view of the lesson. Because I didn't complete } \\
\text { my plan, because of the disruption that took place. And I got rather angry with } \\
\text { the class. So I felt a bit disappointed initially and I came and talked to you and } \\
\text { you had a rather different perspective, which was quite... }\end{array}$ \\
\hline coach & $\begin{array}{l}\text { Yeah, I did sense that you were feeling angry, just because at the end you felt } \\
\text { that it had been different than you had expected. But I don't think it is fair of you } \\
\text { to say that that colored the whole lesson. But, as you said when you spoke to me, } \\
\text { we found that a bit frustrating. }\end{array}$ \\
\hline teacher & $\begin{array}{l}\text { Yeah, so that was good, to talk to you straight away... to maybe just not feel so } \\
\text { frustrated. }\end{array}$ \\
\hline coach & In your point of view maybe the class is a sounding board sometimes, eh? \\
\hline teacher & $\begin{array}{l}\text { Yeah and then when I watched it, I got a different perspective again. Because I } \\
\text { think that was one of the things I found interesting: that my perception and what } \\
\text { I felt in the lesson at the time of any disruption really was very different to what } \\
\text { you then see on the video. So even just the sense of something last [long } \\
\text { interrupting behavior], you feel that it lasts, and it doesn't really. So I found that } \\
\text { quite interesting and it has made me think that I can be a bit more... not relaxed, } \\
\text { but just not so tense. }\end{array}$ \\
\hline coach & $\begin{array}{l}\text { And how do you think that you're going to establish that? That you don't get } \\
\text { this tense, because that is easier said than done sometimes. Any ideas on how } \\
\text { you can approach that? }\end{array}$ \\
\hline teacher & $\begin{array}{l}\text { I think watching the lesson allows you, when you're in that situation again, to be } \\
\text { able to take a step back, because you can sort of remind yourself of what it is like } \\
\text { when you're watching it. And that it is not actually as bad or whatever it is you } \\
\text { think it is at the time. So you can sort of put yourself in that perspective again. } \\
\text { And even just being prepared too. What I did in the lesson today, just stand } \\
\text { there for twenty, thirty seconds to wait to get their attention. I think that getting } \\
\text { that perspective on the lesson has helped me to be more realistic. }\end{array}$ \\
\hline
\end{tabular}

However, not all normalizing moves were functional. In the continuation of this dialogue (B1), as a pattern, the peer coach tried to reassure the teacher. Too much normalizing of problems could also be counterproductive, as the teacherobserver pointed out during their evaluation of this dialogue (Fragment 6.2). 
Fragment 6.2 (Evaluation, dialogue B1)

\begin{tabular}{|l|l|}
\hline observer & $\begin{array}{l}\text { Somehow everything he said got turned in a very positive way, so it could have } \\
\text { gotten another spin but it didn't, the coach was very positive. [...] I mean the } \\
\text { thing is, you are talking about an assignment and then maybe there is some } \\
\text { more under the surface that needs to... [be explored]. }\end{array}$ \\
\hline coach & $\begin{array}{l}\text { Maybe I don't have enough... counseling, coaching questions. I am not drawing } \\
\text { enough from you [teacher-learner]. I need to learn somehow, to really coach you, } \\
\text { because I have been listening to you, but have I sent you in any other direction } \\
\text { than you can also find for yourself? Because I didn't ask the right questions, yet, } \\
\text { for you to go and look at things from another angle. }\end{array}$ \\
\hline observer & $\begin{array}{l}\text { Maybe, something that you could have done in a part of this conversation is to } \\
\text { help him begin to formulate what types of activity it is that he will do in the } \\
\text { future [analyzing alternatives]. He had said he hadn't thought about it and it } \\
\text { would be nice to start brainstorming about possibilities. [...] }\end{array}$ \\
\hline coach & $\begin{array}{l}\text { I find that extremely difficult. I wouldn't know how to guide you on the subject } \\
\text { matter. Guiding as a person, I think I have. My experience was very positive. But } \\
\text { how do I get to that other thought [teaching a different subject]? I am not sure. }\end{array}$ \\
\hline observer & $\begin{array}{l}\text { That means as an outside observer, watching you talk as such, it is all very } \\
\text { positive, but on the other hand perhaps it is also a bit superficial... how do you } \\
\text { get to that...? }\end{array}$ \\
\hline cobut I mean coaching is I think not a positive or a negative, it should be a \\
neutral...
\end{tabular}

In the above evaluation, the observer put forward her observation that their dialogue lacked depth. This had two consequences, first their reflection dialogue on the lesson started over again and broadened, secondly, they learned about their peer coaching role and about questioning techniques. As this fragment showed, two characteristics of the program - (a) the structure of ending all coaching dialogues with an evaluation of that dialogue, and (b) the role of the observer (observing the performance of the coach) - appeared to be 
important to improve peer coaching and to learn to get around the pitfalls of normalizing problems in their dialogues. A third characteristic, the coach training, also helped:

"During this meeting [training] I realized that our peer coach dialogues were alright, however they were still lacking enough in-depth. We should focus more on the influence of our performances on our students. That implies that our dialogues also have to become more confronting by holding a mirror up to each others face". (Jane, written inquiry report).

Peer coaches also used other ways to restore feelings of safety. Most of the other dialogues contained short fragments of peer coaches who tried to affirm their peer at moments the coach thought the dialogue might become too critical by 'giving back the lead to the teacher'. Other strategies teachers used were 'compliments' and 'pointing at things that went well'.

For instance, the peer coach brought up a new point to reflect on, however, she asked the teacher to decide whether she preferred to investigate this point or to go back to the original learning goal. In dialogue A2 the learning goal of Anne was to use her teaching time more efficiently. Her peer coach had a different idea about the problem and changed the focus from 'teacher and teaching time' to 'students and learning time' and to strategies to stimulate and activate students in their learning. She confronted Anne with her viewpoint, introduced reflection on the perspective of her students and asked her to think about challenging students to problem solving in subgroups instead of her teaching in front of classroom. Anne reacted with keeping her distance and not joining in with the line of reasoning of her peer. After failing a number of times to focus the teacher on the perspective of her students and on re-thinking choices for teaching methods, the peer coach changed her strategy. She started pointing at things that went well and giving compliments ("and then you ... and I think that was very good of you to..."). After her doing so, Anne opened up to reflecting from the point of view of her peer. In this case this reassuring move was important to give the teacher 'room to breathe' and a break to move from a defensive mood into a reflective mood. During their evaluation of the dialogue, the teacher noticed:

"I experienced that perspective as refreshing. To look also at the perspective of the students and not only how I use the time span [ego perspective]."

(Anne, dialogue A2). 


\section{Fitting experiences in a new framework}

In most dialogues teachers gained new insights as a result of the video feedback and their peer coach efforts. Such was the case with Anne who did learn to evaluate her lesson through the perspective of her students. Other teachers learned that their own experiences in classroom not always corresponded with registered reality on video as in the case of John who noticed that his emotions influenced his (unrealistic) evaluation of his lesson. Or Jane who promoted active and self-regulated learning in her lesson, but felt unsatisfied afterwards. By studying video feedback and by the questioning of her peer she realized that it was not the outcomes in her students that was the problem, but her own felt identity as a teacher (who was less needed in classroom to help and regulate all students all the time).

In dialogue A2 another remarkable thing happened. Due to time constrains the teacher had videotaped a lesson in a 'model' student group, a situation from which the teacher thought there was not much to learn. In the dialogue she was confronted with the differences between her teaching strategies in that student group (full of bright students), and the strategies she used in more average student groups in which she had put much more effort. That forced the teacher to reflect not only on notions about 'what works', but also to reflect on 'moral' notions and her duty to create optimal learning conditions for all students. At the end of this dialogue the teacher summarized this as a new or renewed view she got from their dialogue. So, by 'incidental' videotaping in a not-selected student group and her peer's coaching she was stimulated to reflect on the moral notion and to discover by chance that she still had lots to learn - also in the 'elite' group of students which never had posed any problem for her - if she wanted to get the best for all her students.

\section{Teaching replays and rehearsals}

Teaching replays and teaching rehearsals were the core of the dialogues. Video recordings were the main source for the recalling of lessons. Teachers all observed the lesson on video beforehand and teachers referred to what they had observed during their discussions. Only in one dialogue (A1) teachers had a problem with recalling and analyzing the lesson due to the time span between the videotaping and observing of the lesson and the actual date of their dialogue. Teachers in this dialogue had to spend more time on verbally recalling the course of the lesson. Another consequence of this delay was that 
the dialogue got hindered by a decreased involvement of the teacher because she felt it all occurred too long ago. The practice in schools (and thus the attention of the teacher) is often dominated by the upcoming lesson.

Of course, not all situations and dilemmas of practice, as shown on video, were taken up at length in teachers' dialogues. Coaches structured dialogues by recalling some aspects of the lesson, followed by in-depth questioning about the 'who, what, why, and with what outcomes' of what happened. In all dialogues there were conversational routines focused on teaching rehearsals in which teachers considered alternatives for teaching strategies mostly based on 'what works notions' and on 'moral notions'. Seldom did the teachers refer explicitly to theoretical notions from the knowledge base of their profession in their argumentation for or against certain solutions. Prompts referring to reflection on 'what works', stimulated the teachers to recapitulate possible strategies they could try out in classroom.

All dialogues focused for a large part on solutions and ideas for experimentation. Sometimes these ideas came very quickly after viewing the video and they were already implemented in classroom before the dialogue had even started.

"Actually the effect that [observing the videotape of] the lesson had. I had a second lesson of similar nature on Thursday [...] but then to make things easier, I... [teacher explained what he changed in his teaching strategy]. And it went so much better. Because students weren't all calling 'is this right? Is this right? Is this right?' [...] And that worked much better the second time." (John, dialogue B2).

But not all learning happened so straightforward as observing and experimenting in the next lesson. For instance, dialogue A1 circled for a long time around teaching strategies for differentiating and motivating. The teacher put forward that she wanted to differentiate in the classroom and had introduced group work into her classroom. However, during the dialogue it became more and more clear that her main goal was not to differentiate and give individual students various guidance and instructions, but that she wanted all students to be active and motivated and to work hard at answering the exercises from the school book (doing the homework). In fragment 6.3 of their dialogue, the peer observer interfered with the dialogue and brought in a 
number of teaching principles to reflect on, for instance, 'differentiating alone does not make students active motivated learners' and 'making students curious helps to activate students'.

Fragment 6.3 Dialogue A1

\begin{tabular}{|c|c|}
\hline teacher & $\begin{array}{l}\text { Yes, because by differentiating you can of course also activate students. For if at } \\
\text { some time you have already seen something ten times, and you already get it and } \\
\text { the teacher is going to explain it again, well... that does not make you active. }\end{array}$ \\
\hline observer & $\begin{array}{l}\text { Yes, concerning this it is very important to find out maybe what is most important } \\
\text { for you, because your learning goal in fact contains three very big elements: } \\
\text { activating, motivating and differentiating. So what is the most important thing for } \\
\text { you? [ Approving noises ] } \\
\text { For you can keep students very passive, but still differentiate. If you... well, I was } \\
\text { interrupting really, ... but if you are working very controlled, you can still } \\
\text { differentiate. }\end{array}$ \\
\hline teacher & $\begin{array}{l}\text { Yes, that is true. Yes indeed, what I do find most important, I think... I find, if I am } \\
\text { giving a lesson and then - when was that, yesterday or the day before? - the } \\
\text { students are working very well indeed, and you have this idea of... well, you are } \\
\text { all very good... Well, you know, I like it when you can stimulate students, when } \\
\text { you can motivate them indeed, when you feel something like... them being } \\
\text { touched, you know? }\end{array}$ \\
\hline observer & $\begin{array}{l}\text { But then, what makes somebody curious? What happens to someone when he is } \\
\text { curious? }\end{array}$ \\
\hline teacher & $\begin{array}{l}\text { Well, he goes searching. Say, he starts asking questions, he is stimulated, he has an } \\
\text { experience, he has... usually it is a connection with the world they know. That is } \\
\text { often very important. Like 'hey!'... they recognize something... how does that } \\
\text { work exactly? That's it mostly. }\end{array}$ \\
\hline observer & And, when they have to do assignments from the book, the student still thinks... \\
\hline teacher & $\begin{array}{l}\text { No, I don't think so. That's exactly what I don't like at all in this book. For } \\
\text { economics is so far from the experience of the students. Really far away. For } \\
\text { instance 'taxes'. What does a child know about tax brackets and rates? That is why } \\
\text { I send my students into the supermarket, you know, 'go compare prices'. And } \\
\text { then I try to explain price rises in this way, inflation and those kind of things. But } \\
\text { phew... tax brackets, try to create something for that ... [ ... ] }\end{array}$ \\
\hline observer & $\begin{array}{l}\text { Well, I think you don't have to activate students all the time by connecting to their } \\
\text { world. If it is possible, that is perfect. But you can also use other strategies. }\end{array}$ \\
\hline teacher & Tell me? Give me an example. \\
\hline
\end{tabular}

The dialogue continued with examples for alternative strategies that the teacher could use within the context of her own classroom and within the context of the 'mandatory' use of the school book. 


\subsubsection{Summary and conclusion sub-study 1}

Part 1 of this study focused on how the teachers discussed own practice during their reciprocal peer coaching dialogues and the way teachers' dialogues supplied opportunities for professional learning.

On which topic did the teachers reflect during their peer coaching dialogues?

Most of the time, the teachers focused their dialogues on subject and methodological issues. Teachers discussed among others their chosen approach, their own instructions, their use of learning time, and their own thoughts and worries during their lessons.

Secondly, the teachers spent a considerable amount of time studying the learning processes of their students. Often the dialogues about ways to teach their subject got intertwined with reflection on learning of students.

The third main topic of their reflections revolved around issues of classroom management, almost all related to issues of motivating and activating students. Discussions about other issues were scarce.

With what kind of perspective did the teachers reflect during their peer coaching dialogues? Most of the time teachers' dialogues were action-oriented conversations in which they analyzed and valued their experiences and looked for alternatives and solutions for experienced problems. Teachers analyzed classroom situations nearly as much starting from their own perspective (i.e. own actions, thoughts, feelings, motives) as starting from the perspectives of their students. References to the theoretical knowledge base of their profession were not explicitly introduced into their discussions. A small number of discussions started from an action-oriented point of view, which then broadened and became connected with reflections on own moral views about school and their role as a teacher.

Which conversational routines were employed during their peer coaching dialogues?

This study found similar conversational patterns as Horn and Little described in their research (2010). Teachers reacted to problems of colleagues by normalizing them and giving reassurance and support and by problem solving through studying video feedback and discussing analysis and alternatives strategies. Besides the patterns also identified by Horn and Little, this study 
described additional routines and moves. We identified 'what works notions' and 'moral notions' in the deliberation of teachers and we detected additional recurring patterns for creating safe learning environments in teacher dialogues.

Teachers employed moves to create a safe learning environment such as giving compliments, pointing out things that went well, giving back the lead to the teacher-learner, and indicating that problems were shared in the profession. Moves to create and maintain a safe and open learning environment are very important for teacher learning, however teachers must be aware that too much normalizing can be counterproductive and can make dialogues superficial. In our study the role of observer focusing on effective coaching and an evaluation phase in which teachers analyze their coaching performance and their learning can help to notice pitfalls and subsequently may help to increase effectiveness of dialogues.

The video recordings helped to make classroom performances (verbal and nonverbal) noticeable and discussable and to link them to 'feelings, motives and reasons behind observable behavior'. Teachers' dialogues focused mostly at problem solving and 'what works notions' and seldom discussed at length own ideals or moral and political aspects of teaching and schools. However, 'moral notions' were used in their arguments and in their choices.

In most dialogues teacher talk moved back and forth between observed moments of the videotaped classroom and general principles of teaching. Like Horn and Little (2010), this study argues, that the movement between the particular and the general provided the teachers the opportunity to learn and to develop own practical knowledge that is rooted in the context of own practice an that on the basis of identified patterns teacher learning in dialogues is apparent. Dialogues stimulated making implicit knowledge more conscious and accessible to teachers themselves and to share personal practical knowledge with their peers. As Kelchtermans (2007, p. 97) noted "collectively sharing and challenging reflective narratives constitutes a powerful perspective for genuine professional development." Although it cannot be concluded from this part of the study whether teachers' understanding of discussed practice also was used in own classroom, it certainly was made available to the participating teachers. 
The conversational routines Horn and Little found were displayed in conversations of groups of four to nine members of one subject department, who organized themselves to work collaboratively on shared interests. This study showed that dialogues in small reciprocal peer coach groups existing of three teachers of different departments can have comparable structures and depth in their reflections.

Productive reflection and inquiry are characterized by a willingness to investigate teacher-learning connections. However, as Nelson et al. (2010, p. 176) stated: "although some people have a natural inclination towards asking questions that help a group get beyond a superficial sharing of ideas, it is a rare group that is characterized by this practice". We argue that a program of reciprocal peer coaching and video feedback, with well defined roles, an emphasis on open-ended questioning and a training of the coach role helps to establish collaborative norms and in-depth questioning, both characteristics that build the group's capacity for deep reflection and for using individual practical knowledge as starting point for collaborative problem solving.

\subsection{TEACHERS' INQUIRIES INTO OWN PRACTICE (SUB-STUDY 2)}

\subsubsection{Inquiry as a professional learning strategy}

In the PD program teacher learning is expected to occur as a result of different learning strategies: (a) through video feedback and observing professional performance - both own performance and of others - , (b) through deliberate reflective peer coaching dialogues on classroom practice and developing new ideas and impulses, (c) and by teacher inquiries on personal learning goals, experimenting and studying outcomes in classroom. The present sub-study focuses on teacher inquiries in the program.

Inquiry as a professional learning strategy can stimulate teachers' professional development (Bolhuis, 2009a; Cochran-Smith \& Lytle, 2009; Dana \& YendolHoppey, 2009; Kools, 2009) and can play an important role in advancing a critical attitude and data driven decision making towards own professional performance (Lunenberg, Ponte \& Van de Ven, 2006; Ponte, 2002; Zeichner \& Noffke, 2001). “A growing body of evidence suggests that when teachers collaborate to pose and 
answer questions informed by data from their own students, their knowledge grows and their practice changes" (David, 2009, p.87).

Inquiry is a promising, but not an easy, strategy. Teachers can conduct cycles of inquiry individually in their classrooms, but rarely do so on their own. Structured collaboration seems to add both motivation and value. In contrast, when working alone by themselves teachers tend to rely on anecdotes and intuition (David, 2009). Necessary conditions are: a stimulating environment in the school-based on shared practice and mutual commitment, protocols to guide the inquiry process, provision of facilities and time to learn the necessary skills, and treating practitioner research as a continuing process which implies patience and no quitting after the first setbacks (Bolhuis, 2009a). Constraining factors may be time, the absence of necessary skills to carry out inquiries, teachers not wanting to improve their practice through inquiries, and the challenging character of a chosen research method (Ponte, 2002).

The characteristic 'teacher inquiry' in the program is seen as a form of selfreflective study undertaken by teachers in classroom in order to improve their own practices and their understanding of these practices and the situations in which the practices are carried out (Brookfield, 1995; Cochran-Smith \& Lytle, 2009). The notion of inquiry in the program refers to inquiry as a time-bound project or activity within the PD program and is distinct from inquiry as stance which refers to a long-term and consistent positioning or way of seeing (Cochran-Smith et al., 2009). The overall goal of the PD program is to stimulate the teacher as reflective practitioner and inquiry as a stance i.e. as an integral part of teaching itself, a goal to which all program characteristics contribute.

Teacher inquiry is about systematically examining classrooms, and it represents a wide range of options in terms of duration, complexity, rigorous processes employed, types of data emphasized for analysis and reflection, and topics being studied. Through inquiries teachers create some distance from actions in the present moment and learn to observe their own practice and school context in more systematical and critical ways (Kools, 2009). Inquiry in the program can be defined as a specific way of reflection on practice, using characteristics of research strategies, and should - as all forms of research - incorporate two main characteristics: 
- First, the approach is conducted systematically, and includes a number of steps from the exploration of the problem and formulating of research questions, data gathering and analysis, to the formulation of conclusions and (possibly) new research questions.

- Second, the conclusions are based on data, that is: conclusions are underpinned.

Based on a review study of three well documented models - Japanese lesson study, action research, and the Getting-Result-Network-model - Ermeling (2010) identified four important features of teacher inquiry:

- identifying and defining important and recursive instructional problems specific to the local context of the teacher;

- planning and implementing instructional solutions;

- utilizing evidence to drive reflection, analysis, next steps;

- and persistently working towards detectable improvements.

We added another feature, the reporting and the presentation of an inquiry as part of the sense-making process. Although formally reporting and presenting an inquiry might feel like an unnecessary step for teachers primarily interested in improving their individual teaching, taking the time to do this encourages further collaboration among peers and stimulates further reflection (Dana \& Yendol-Hoppey, 2009).

\section{Research question for this sub-study (2)}

The kinds of data available to an inquiry matter. Data sources must be rich enough to evoke curiosity or point to problem areas, but should also provide a basis for considering alternatives and guidance for improvement (CochranSmith \& Lytle, 1999b). In the program teachers were asked to study own classroom practice with the help of peer coaching, video feedback, and with depending on teacher's learning goal -other strategies for data gathering such as questionnaires, interviews, and standardized test scores. Teachers were owner of their personal learning goals born out of curiosity, dissonance, or a need for solutions in their classroom practice. In line with features of inquiry identified in literature (Dana \& Yendol-Hoppey, 2009; Ermeling 2010), teachers were focused on four different phases for their inquiry during the course of the program in plenary meetings (Figure 6.3). 


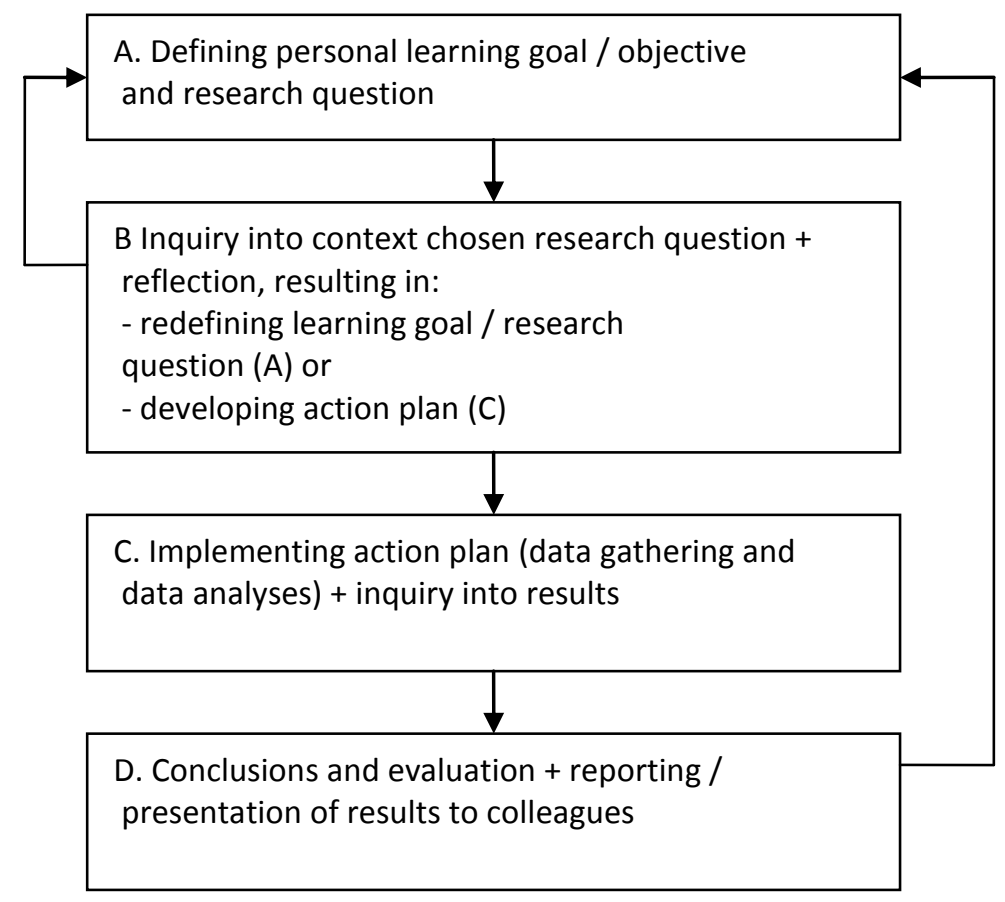

Figure 6.3 Phases in inquiry

The central aim of this sub-study is to explore the way(s) in which the design characteristic 'teachers inquiring into own practice' contributed to the learning processes of the teachers in the program. The central research question for substudy 2 read: "How did the teachers study their own practice in their inquiries?"

Two sub-questions were formulated:

1. What did the teachers study and how did the teachers structure their inquiries into own practice?

2. What was the function of video feedback as a source of information for teachers' inquiries into own practice?

To answer these questions, we explored the written reports and the presentations of teachers' inquiries and studied how the teachers used inquiries for their reflection on practice.

\subsubsection{Method}

\section{Program, participants, and data collection}

In the PD program 'Learning to Notice' teachers were asked to develop personal learning goals, to reflect on own classroom with the help of video feedback and reciprocal peer coaching, and to inquire into own practice. During 
plenary meetings teachers were introduced to the goals of the program and to the design process of an inquiry. In reciprocal peer coaching groups teachers helped each other to define their learning goals and to develop their inquiry to study their own classroom (Chapter 5). At the end of the program teachers wrote up and presented their learning process and their inquiries to each other in a plenary meeting. Written reports differed in size; some were more elaborate than others. All presentations were recorded on videotape. For the present substudy we investigated the written reports and the video recordings. In cohort A all teachers wrote up and presented their inquiries, with the exception of one teacher who was leaving the school. For various reasons, mostly outside the program, a rather high number of teachers in cohort B either did not participate in the presentation or did not produce a written report (Table 6.8).

Table 6.8 Overview of the number of presentations and written reports of teachers' inquiries (cohort $A$ and $B$ )

\begin{tabular}{|c|c|c|c|}
\hline Cohort A & $\begin{array}{l}\text { Done } \\
\text { Not done }\end{array}$ & $\begin{array}{l}\text { Presentation at plenary meeting } \\
8 \text { teachers } \\
1 \text { teacher: } \\
\text { - teacher was leaving the school }\end{array}$ & $\begin{array}{l}\text { Written report } \\
8 \text { teachers } \\
1 \text { teacher: } \\
\text { - teacher was leaving the school }\end{array}$ \\
\hline Cohort B & $\begin{array}{l}\text { Done } \\
\text { Not done }\end{array}$ & $\begin{array}{l}10 \text { teachers } \\
7 \text { teachers } \\
\text { reasons known: } \\
\text { - } 1 \times \text { emigrating abroad } \\
\text { - } 1 \text { x abroad for a school } \\
\text { excursion (teacher did } \\
\text { submit report) } \\
\text { - } 1 \times \text { hospital visit } \\
\text { - } 1 \times \text { driving test } \\
\text { - } 1 \times \text { no time for inquiry (due to } \\
\text { other duties in the school) } \\
\text { - } 2 \times \text { no time for inquiry due to } \\
\text { becoming father }\end{array}$ & $\begin{array}{l}8 \text { teachers } \\
9 \text { teachers } \\
\text { reasons known: } \\
\text { - } 1 \text { x emigrating abroad } \\
\text { - } 1 \times \text { no time for inquiry (due to } \\
\text { other duties in the school) } \\
\text { - } 2 \times \text { no time for inquiry due to } \\
\text { becoming a father } \\
\text { - } 1 \text { x own inquiry is still running } \\
4 \text { x reasons unclear (no report } \\
\text { made or / no report presented to } \\
\text { the researcher) }\end{array}$ \\
\hline
\end{tabular}

We used data from the questionnaire and the interview, collected for the evaluation of the program (Chapter 5), to search for additional information or discrepancies.

\section{Data analysis}

To answer the research questions the following steps were taken:

- Data were organized, permitting the researcher to get a thorough look at it. This involved creating tables with the profile of each teacher, putting 
together information about background, reciprocal peer coaching group, and personal starting point.

- Secondly, data (the written report and/or the presentation) of individual teacher's inquiry on own learning goals and own learning outcomes were added to the description.

- Thirdly, the way in which each teacher used the video recordings as a data source for their inquiries, was incorporated.

- Finally, for a better understanding and triangulation, we used data from the questionnaire and the interview (Evaluation of the program, Chapter 5) to search for additional information or discrepancies.

- For reasons of privacy the names of participating teachers were changed.

\subsubsection{Results}

\section{Learning goals and research questions of teacher inquiries}

In the program teachers were asked (a) to do inquiries to (re)define their learning goal and research question, (b) to do inquiries to notice important features in classroom related to their learning goal and to interpret and explain phenomena, and (c) to do inquiries into possible solutions and outcomes in classroom.

The program started with dialogues on clarifying and framing their individual learning goals and research questions. From our participation and observation in the program and from the interviews, we learned that this appeared to be much more difficult than we had anticipated. Individual participants differed strongly in time and coaching they needed to master the first two phases of the inquiry process (Figure 6.3). Some teachers had clear goals and directly began inquiring into context and possible causes and developed, implemented and evaluated their action plan. Other teachers had very broad learning goals and had to start with an inquiry to narrow down their goal and to pinpoint the exact problem. Some teachers changed their learning goals during the school year, for instance, as a consequence of changing needs or attaining previous learning goals.

There was considerable variation in how teachers posed and framed research questions and the way they conducted their inquiry. It was no surprise that almost all inquiries were related to 'how-to' questions in own classroom practice. Most inquiry questions revolved around issues of activating and motivating students. However, the focus varied much and was tailored to each individual needs, e.g.: 
- How can I make my lessons and my subject more 'meaningful' to students?

- How can I activate students in a more positive manner (instead of threatening with punishments)?

- How can I restrict my own need to control students' learning and give some of the control back to my students?

- How can I differentiate and/or coach individual students in classroom?

- How can I use collaborative teaching strategies in my classroom?

- How can I restrict the time I am speaking in favor of more time for students verbally practicing the language themselves?

Some teachers had a different focus, such as the development of learning materials for specific aspects of their subject, or the improvement of their time management in classroom. Two teachers (participants of the same subgroup) had no real learning goal and decided to study the video to see 'whether there was still room for improvement'.

Some of these issues and ideas transformed into productive inquiries analyzing classroom practice. Especially the peer coaching dialogues with in-depth questioning and collaborative analysis of the video feedback helped to link particular teaching methods to broader and better understanding of student behavior, student learning, and learning environment. In Appendix 6, a complete overview is given of all the teachers in cohort A and B, their individual learning goals, a short description of personal inquiries and outcomes, and the ways in which teachers gave their account of their leaning processes and inquiries.

Teachers regularly had difficulties in analyzing and defining own learning objectives behind their learning needs and to translate these into an approach for their inquiry. This process resembles the situation of a patient who is seeing a doctor with one complaint only to discover by discussing and questioning that the complaint was no more than a symptom of some other underlying problem. It appeared that this phase of highlighting own learning goals and objectives often demanded an own inquiry and no rush and plenty of time. Rushing this phase appeared to be counterproductive. For instance, Lisa (Cohort A) started out with a 'how-to' question (how to create a more efficient start of her lessons). However, during a plenary meeting she analyzed in a coach dialogue with the trainer the classroom recordings minute by minute, 
and concluded that there were no great flaws in her lesson start. Her feelings of frustration were due to her need to do everything perfect and not coping with stress. She had to redefine her learning goal and focus on managing own time management and dealing with unexpected situations in classroom. Other teachers developed similar patterns in which their first experiences or first analysis of their classroom had to be reconsidered and other aspects appeared to be more relevant for their chosen learning goal.

Doing an inquiry and peer coaching dialogues with video feedback may very well be complementary. Take for instance, Janet (Cohort A). On the one hand, she wished to learn how to use active and self-regulated student learning in her classrooms. However, during peer dialogues she discovered that this learning goal on the other hand, collided with her identity as a teacher being the central figure in classrooms in need of control. For teachers struggling with this contradiction, the peer coaching dialogues were much more important for their reflection and understanding.

This dilemma of Janet was apparent with at least two other teachers. One of them, a language teacher, realized this beforehand and realized a possible conflict between possible future outcomes of an inquiry (learning gains as a result of active and self-regulated student learning) and her own identity as a teacher in need of control. She limited beforehand her investigation to subject areas in which she was prepared to change:

"To diminish my central role in the classroom completely is not a way fitting in with my identity as a teacher. So I choose the domain 'speaking and listening' because there my dominance can really cause problems, leaving students with no opportunity to practice their selves. In that domain I wanted to make progress in diminishing my own verbal dominance. But not overall in all lessons." (Betty, presentation)

\section{Learning activities and structuring own inquiries}

Teachers inquired in very different ways. All used the video recordings for their inquiry to a degree. Furthermore, teachers studied the classrooms of colleagues, experimented in own classrooms, used test results of students, and used student questionnaires or interviews for their evaluations. The case description of Anne illustrates such a process of inquiry. She noticed a friction between her lesson planning and its implementation in classroom, especially concerning time 
management. She started inquiring into possible causes using observations in classroom, self-reflection, studying video feedback with her peers, and investigating existing practices in school. She immediately translated learned lessons into improvements of own behavior and evaluated the results with the help of classroom observations and the peer coaching dialogues with video feedback. Next, she started to work on another learning goal (Case description Anne).

\section{Case description}

Anne, Biology, cohort A

Anne is an experienced teacher, but new to this school. During the beginning of the school year she notices that often she cannot finish the subject matter staged for that lesson in time. She formulated a learning question: 'How can I improve my planning of the lessons in such a way that within one lesson I can finish all subject matter in time, without ending up with spare time'. Before she can elaborate about possible solutions, she needs to have insight into possible causes. She starts an inquiry analyzing her problem and reflects about hypotheses about possible causes. To find out the causes she draws up an inquiry, consisting of:

1. Self-investigation (reflection on her own performance and on her own goals for each lesson). Based on this, she makes a plan to 'economize' on learning materials to be treated during lessons.

2. An investigation of existing practices within the school (activity term planners, expected lesson cancellations, modes of operation of colleagues). She noticed that especially in the lower grade classes she runs out of time because she has to compensate for lost time, e.g. time lost due to the cancellation of lessons. Based on this, she decides to train her lower grade pupils in working with activity term planners and in continuing to work independently in the case of cancelled lessons.

3. A study of video recordings of her own lessons (where do I notice that I loose time during teaching, where can I be more efficient?) Based on this study she makes new arrangements with pupils for a more efficient start of the lessons, and for the treatment of questions of pupils during lesson. Taking stock, she finds that in reality her instruction on average takes more time than she thought and she decides to make her instruction more concise and more efficient.

She translates her findings immediately into her lessons. She tests this new approach in her next lessons. Together with the colleagues of her subgroup she analyzes the video recordings of the new setup of her lessons, and together they conclude that the changes improve her lessons and that her learning goal in these student groups is accomplished for the most part.

For the remainder of the year she sets up a new inquiry (how to adapt own teaching style and vocabularies to a new kind of student population). Anne focuses her inquiry at better understanding the specific learning styles of these student groups. Activities undertaken are: videotaping own lessons, class visits with peers, gather and study completed assignments of students, interviews with students. 
Inquiring is important for the learning of teachers, not only to discover own learning needs, but also to study outcomes in classroom.

"I think the action research idea for teachers is a really effective way of professional development. Because we could just sit down in team meetings and have a presentation about pedagogical theories or something, but it's only when you're actually taking ideas and testing them out in a classroom situation and in your own specific situation that you're actually learning." (John, cohort B, interview)

Learning through inquiries assumes teachers who are already capable of identifying areas for professional growth. Anne, one of the teachers who participated in the first cohort, had a learning style that fitted in perfectly with the guidelines of the program concerning learning by setting goals and doing inquiries. She had already all kinds of professional learning strategies and techniques at her disposal and used them to optimize her classroom performance. She identified problem areas in her own classroom and studied and reflected on possible solutions. She tried them out in her classroom, resulting in outcomes in classroom for improving practice. The program had no function for her in learning these strategies but stimulated her to invest time and energy into these inquiries and provided her with new resources for feedback and reflection, namely video recordings and peer coaching dialogues.

What worked well in the program were teachers who focused on a restricted goal, for instance, the development of a new strategy or some new student assignments, experimenting with them in the classroom, and evaluating outcomes in the classroom

\section{Factors affecting teacher learning in teacher inquiries}

\section{Impediments}

Teachers experienced problems with their inquiries due to various reasons. Some teachers reported having no problem areas and also not wondering about specific aspects of classroom practice. For instance, Harry (cohort B), an experienced teacher of physical education, joined in - as part of his team without having real learning goals or issues he wanted to invest in. For years he has reached good results with students. With his peer coaching group he studied the videotapes of his own classroom, their conclusion was that maybe the organization of materials could be improved in order to create a moment of 
rest at the start of the lesson. As Harry admitted during the presentation of his inquiry, "sometimes you become a little sloppy after years of practice". During his presentation he declared that the most interesting part for him was the training of coaching skills in the program, and not so much the improvement of classroom practice. Jill, an arts teacher, who took part in the triad, also struggled with the program. Jill was a declared opponent of the (simultaneous) introduction of teacher portfolios and assessments in the school and assumed the program was part of this new management strategy. In the first plenary meeting Jill opposed the mandatory nature of her participation and declared that she felt that her privacy in the classroom was violated by the videotaping. Grumbling she joined the program. Her background and learning process in the program had many similarities with those of Harry: she also was an experienced teacher who reached good results in students and she also had trouble to identify own learning goals. Jill declared at the end of the program (in the interview and on the questionnaire) that she felt resistance during the whole program. It felt to her as 'a must' and as something not fitting in with her own style of professional development. She declared that only colleagues of her own subject can be helpful for this. Harry's and Jill's absent or limited inquiring into own practice can be explained in two ways. One is own experience of an abundance of competences and a view of not needing professional learning and a lack of an inquisitive and open attitude. Another explanation can be the belief that own classroom practice (arts and physical education) is too much different from that of their colleagues. A last possible explanation is resenting mandatory participation in the program and therefore resistance to taking agency in the program. In the latter case the mandatory character conflicted with the needs of a working climate of trust in the PD program.

Personal background factors may also interfere with joining in and gaining results. For at least three teachers the program did not fit in with the stage of their personal lives, two teachers were becoming a father and one teacher prepared for emigration, therefore all three having too little energy left to put into the program. Stages in professional life may create similar problems. Julia, for example, was a teacher who just started at this school and afterwards declared:

"It would have been better to embark on this program in a year or two, because I was just in my first year here. Being new to the school, there was little time for me to truly give this my 'hundred percent'! Being a part-timer also had a huge influence. It's a wonderful concept, but it was difficult for me to complete at this 
stage in my life. I have done this before at my previous place of employment".

(Julia, cohort B, questionnaire)

Time issues did play a role in the program. Firstly, participation in the program was mostly (cohort B) or entirely (cohort A) done in teachers' spare time. There were quite a number of actions to be taken for the different parts of the program (training, video taping in classrooms, observing video recordings, peer coaching dialogues, developing own learning objectives and inquiries, reporting inquiries, and helping peers). Secondly, especially teachers who were less familiar with performing inquiries had to learn to develop an evaluation plan. Because all parts of the program were new to the teachers, teachers tended to focus on their inquiries in a rather late stage:

"Looking back on my inquiry with the benefit of data, I now think that I should have built in from the beginning a clearer method of evaluating results. [...] For any future research I am now aware of the need to plan from the onset a detailed method of evaluating data. Video evidence was able to provide me with an insight into my lessons that I had not experienced before. However, if I want to evaluate the students' language performance and/or attitudes to lessons, other tools are needed to do this."

(John, cohort B, inquiry report)

Another factor that emerged was the competence and experience in doing research. Anne had a university training, while some other teachers had more limited experiences with the setting up of inquiries and still had a lot to learn, for example Ruth reported:

"To see how they designed a structure for their inquiries, and how they guided themselves through it... and to force themselves to do that step by step... I feel that I have much to learn on that front. I could grow a bit more in this." (Ruth, cohort B, interview).

\section{Reporting and presenting results}

Having to present own learning processes and learning outcomes to each other stimulated the participants to investigate outcomes and set up inquiries. In their evaluations, performing inquiries was one of the least appreciated characteristics of the program. Teachers felt they were already learning enough and were not always happy to invest a lot of energy in reporting their inquiries in the busy last quarter of the school year. 
Asking teachers to present their inquiries had a double goal, to create a trigger for the implementation of inquiry as a learning strategy and to simulate reflection on practice, and secondly to learn from each other. This last goal was not completely attained. Teachers' investments in their inquiries differed considerably, which created a working climate during the plenary presentation of each teacher's results in which teachers who had less to present, felt guilty and were hesitant to discuss the results of the others, and teachers who had done more were sometimes left without enough feedback and reflective dialogue:

"I didn't think that the feedback I was given at the plenary meeting was as useful as in other meetings. More like 'thank you' and that's it. Some useful comments have been made, but I didn't walk away from it empowered, other meetings were much more thought provoking." (John, cohort B, interview).

\section{The function of video feedback as a data source for teachers' inquiries into own practice}

The design characteristic video feedback appeared to help teachers in various ways to connect their reflection and learning with inquiry into own practice. We noticed seven functions of the use of video feedback for the inquiry process of teachers:

a. Video feedback helped teachers become aware of learning needs and the identification of learning goals.

b. Video feedback helped with the identification of important factors in classroom related to the chosen learning goal, which in cases led to the redefining of learning goals.

c. Video feedback helped to translate learning goals into research questions for inquiries.

d. Video feedback helped to analyze causal connections and the development of an action plan.

e. Teachers used video feedback to monitor the implementation of the action plan.

f. Teachers used video feedback to register and evaluate outcomes in classroom and the setting of new learning goals.

g. Teachers used video recordings to explain or illustrate own inquiries to others.

As shown in the overview, teachers employed video feedback in various stages of their learning process. None of the teachers used video feedback in their inquiries in quite the same way, nor did they all individually use all seven functions during their inquiry process. 
During the first stages of an inquiry, video feedback can aid in clarifying individual learning goals and help to translate them into learning questions, observable behavior and outcomes. In dialogues, for instance, teachers regularly expressed to be surprised by the differences between 'experienced reality in classroom' and the video feedback, see for instance John, wondering about his time management:

"I was quite critical about the way in which I had planned the lessons, for instance, the amount of time I was giving for tasks. I hadn't realized that I was sometimes contradicting myself in lessons, that I would say 'right I'm going to give you five minutes to do this task' while actually I would be giving students ten minutes. I noticed that in the video, I hadn't realized it in the lessons." (John, cohort B, interview).

Such observations could be the starting point of deliberative reflections and further investigations.

\subsubsection{Summary and conclusion sub-study 2}

Part 2 of this study studied the design principle 'teachers inquiring into own practice' and explored how this principle stimulated teacher learning in the program.

What did the teachers study and how did the teachers structure their inquiries into own practice?

Almost all teachers started with learning goals connected to problems or dilemmas experienced in classroom. However, for most teachers it turned out to be functional to start with an inquiry into backgrounds of the chosen learning goal to define a concrete research question. Video feedback and peer coaching can be helpful for this task.

We noticed that in order to learn from inquiries, teachers need: an urgency to learn and a learning goal, commitment and taking agency, and a stage in their personal and professional life in which teachers can put energy into their own professional development. Competence and experience in doing research proved helpful, but was not a prerequisite. 
Some teachers developed an inquiry stance and saw inquiries as an ongoing and integral process of everyday teaching to support reflection on practice and as an enlightening for their teaching and learning. Most teachers treated teacher inquiry as a project that was mandated by the PD program. Teachers experienced inquiries as time-consuming and had the tendency to postpone their inquiry. The design characteristic 'presenting inquiries to each other' enforced teachers to implement inquiries into own classroom. Because they had to report their inquiries to colleagues, most teachers felt urged to study more closely their own experiments in classroom.

The planning of the program ended in the last quarter of the school year, a period in which teachers (at least at this school) were feeling stressed due to school exams, student grading, school excursions and lesson cancellations. In future it would be better to schedule presentations to earlier periods of the school year and regularly during the program. The second recommendation has to do with the way teachers presented their inquiries to each other. In the first cohort every teacher had made a comparable contribution to the program and all performed inquiries. In the second cohort the contribution differed more between participants: not all teachers had performed an inquiry and presentations were not always followed by substantive discussion. In the latter case another form of presentation is recommended to stimulate collaborative reflection during this last plenary meeting, for instance presentations in subgroups or the help of a facilitator to prompt reflective questions.

What was the function of video feedback as a source of information for teachers' inquiries into own practice?

Video feedback helped teachers to identify learning goals and define learning objectives. Teachers used it to study causal connections and to develop an action plan and/or to monitor the implementation of their action plans. Video feedback also gave teachers the opportunity to register progress and results. For detecting results - especially in students - teachers also used other instruments such as test results and student questionnaires. Video recordings of own practice helped to collaboratively reconstruct, share and reflect on practice, both in their dialogues in subgroups and during their presentation of their inquiries to all teachers. 


\subsection{DISCUSSION AND CONCLUSION: TEACHERS' REFLECTION ON PRACTICE}

The main research question of the two studies reported in this Chapter reads: How do program characteristics stimulate teachers' reflective dialogues and inquiries on own practice? In Chapter 4 and 5 the PD program was evaluated mainly based on data obtained with interviews and questionnaires. In this Chapter we explored the learning process of teachers as it occurred in teachers' coaching dialogues and in teachers' inquiries reports.

We studied teachers' dialogues and noticed moments that signaled reflection on professional practice, treating the frequency and nature of such moments as indicators of the learning potential of peer coach dialogues for teacher learning. Our study confirmed research (Sherin, 2007; Sherin \& van Es, 2009) showing that in dialogues teachers develop their professional vision i.e. the ability to notice and interpret significant features of classroom interactions. Classrooms are complex environments, with many things happening at once. Video and peer coaching dialogues helped recognize aspects that were particularly important in relation to own chosen goals and own classroom context. In teachers' dialogues we observed reflection on practice and knowledge-based reasoning about what was noticed in the video.

Just bringing teachers together does not guarantee a learning environment. Bringing a group of teachers together to view one another's teaching can be a frightening, intimidating experience for them. Many have never viewed themselves teach, nor have they seen their colleagues teach. There is an affective dimension to facilitating peer coaching with video feedback that includes creating a safe environment with characteristics of intimacy and vulnerability in which teachers feel comfortable sharing their work and examining each other's teaching. However, research studies also warned for superficial conversations as a result of school cultures based on congeniality and avoidance of conflict, resulting in teachers keeping away from asking each other questions or probing each other's ideas and beliefs, performances, and outcomes in students (Nelson, Deuel, Slavit, \& Kennedy, 2010). Also (school) politics and power relations can affect what can be said and what is valued (Lefstein \& Snell, 2011). The characteristics of the PD program helped to prevent most of the above signaled problems. 
The program provided structures for non-hierarchical, non-evaluative, respectful, reciprocal, collaborative peer relationship that reduced power differences and afforded opportunities for taking learning-related risks. Moves to create and maintain a safe and open learning environment are essential for teachers learning from dialogues, however teachers must be aware that too much normalizing can be counterproductive and can make dialogues superficial. The role of observer focusing on effective coaching and an evaluation phase in which teachers analyze their coaching performance and their learning can help to notice pitfalls and subsequently may help to increase effectiveness of dialogues. Teachers tried to coach their peer through in-depth questioning eliciting reflections on practice. Training of necessary coaching skills proved important to stimulate the learning of peers, and subsequently, to enhance the effectiveness of the program.

Teachers' learned quickly through noticing, experimenting, and concluding. This process is very useful, but can have pitfalls as well, such as the risk of jumping to (false) conclusions and not noticing and therefore not working on essential flaws in classroom (Rosaen et al., 2008; van Es \& Sherin, 2002). Other related pitfalls are a lack of inquiry resulting in overlooking possible opportunities, solutions and consequences, or basing conclusions on beliefs rather than data. Rushing can be counterproductive. Highly effective inquiries should analyze classroom practice and pursue 'what could be' and not merely focus on 'what works' and the impact of a particular technique. Dialogues on and inquiry into 'what' and 'why' are as central to reflective practice as the question of 'how' (Cochran-Smith et al., 2009). Reflective practice involves a repeating, virtually never-ending process of asking questions, looking carefully at the data from practice, altering practice based on insights and ideas emerging from the data, asking new questions, and so on. Peer coaching aimed at open-ended questioning - asking after the 'when', 'why', or 'how' of teachers understanding - can enhance teacher inquiries. Important is a school focus on professional development as a continuous process which needs ample time and energy.

Research on study groups often underlined the importance of a collective purpose, stated beforehand (Little, 2007). In our study we let all teachers choose their own goals, and teachers could diverge widely in topics they wanted to study in their classrooms. Still, most individual goals had considerable overlap in focus (most dialogues circling around issues of motivating and activating 
students), and a shared interest and deepening of the reflection seemed to emerge spontaneously during the program.

By focusing on teachers' dialogues and inquiries we explored the learning potential of the program. Researchers have suggested that secondary school reforms are unlikely to yield improvements at the level of the classroom without a means to foster in-depth interaction, mutual support, and professional learning opportunities among teachers (Little, 2003; Horn \& Little, 2010). Peer coaching dialogues with video feedback and teachers inquiring into own practice might just do that. 


\title{
CHAPTER 7 \\ General discussion, conclusions and recommendations
}

\begin{abstract}
In this final chapter, the findings of the study are summarized and reflected upon. The chapter starts with a brief recapitulation of the context of the study, the research aims, main research question and sub-questions, and the research approach. Thereafter, the main findings of the sub-studies are presented, followed by reflections on the research approach and study outcomes. This leads to the final conclusions of this study and to recommendations for future research and implications for practice.
\end{abstract}

\subsection{RECAPITULATION OF THE STUDY}

\subsubsection{Context of the study}

The theme of this study originated from a need, felt in a school for secondary education in the Netherlands, to support teacher workplace learning. Especially teachers who were already experienced and had been working for a number of years, were lacking a new stimulus for professional learning at the workplace. The researcher (also a teacher educator who coached student-teachers during their internship at this school) responded to this call and designed in close operation with the school-based coach a professional development (PD) program that included the use of reciprocal peer coaching and video feedback to support teacher learning at the workplace.

Previous research points to the problem that existing PD practice in schools is still too much separated from engagement with authentic work experiences and too much focused on delivering content, rather than enhancing learning (Webster-Wright, 2009). The most effective teacher learning is shown to happen when there are meaningful interactions among community members. However, 
a particular condition in the professional working context of schools appears to be that teachers work mostly in isolation and only have limited chances to observe their colleagues or talk intensively about their teaching work. PD programs that stimulate meaningful interaction at the workplace can stimulate teacher learning and help to build a shared language and a way of working that is consonant with the school's local context and culture.

This study places teacher learning and PD in the service of improving professional performances and outcomes in the classroom. The design of the PD program is based on the notion that professional learning is continuing, active, social, constructive, and closely connected to practice. Therefore, we argued that in order to support teacher learning, teachers need PD programs that create opportunities in the school for teacher learning which:

a. take place as highly social activities which require interaction and dialogue with a focus on co-constructing professional knowledge, and

b. use the problems and dilemmas that individual teachers experience in own practice as a starting point, and

c. involve reflecting on past experiences and the planning of future activities with a focus on in-depth reflection and analysis of own and collective practice, professional identity, beliefs and assumptions - aiming for better individual and collective practice.

\subsubsection{Aims of the study and research questions}

Traditional PD programs are often perceived by teachers as fragmented, disconnected, and irrelevant to the real problems of classroom practice. Teaching is a highly complex activity in which many things happen simultaneously. PD programs should help teachers make sense of their experiences and improve their own practice.

In this study, the researcher designed, implemented, evaluated, and redesigned a professional development program suited to all those involved. In partnership with a school of secondary education and a teacher college, a (three-year) project started with the following aims:

1. To design, implement, and evaluate a concrete PD program stimulating teacher learning in the context of the school.

2. Studying learning processes and outcomes of participating teachers with the intent to contribute to the development of design principles for PD programs. 
3. Strengthening innovation of coaching practices in the participating school and teacher college.

4. Stimulating and supporting the professional development of individual participants.

For the design of the PD program, the researcher performed a review of literature to identify and describe design principles (guidelines or heuristics) and design characteristics (concrete, workable design specifications) of effective PD programs. Reflective peer dialogues on own classroom practice and the use of videotaped interactions in own classrooms for studying and generating feedback were chosen as core features for the design of the PD program. The program focused on experienced teachers, however, beginning teachers who wanted to participate were also welcome to join the program.

Research questions

The overall research question to be answered in this study was defined as:

Which design principles and characteristics of a PD program (based on reflective peer dialogues and video feedback) support teachers' workplace learning?

To answer this research question two sub-questions were formulated:

1. Which design principles and design characteristics can be derived from literature in order to construct a professional development program that effectively supports teachers' workplace learning?

2. What is the practicality and effectiveness of the developed professional development program in supporting teachers' workplace learning?

To answer this second research question, we evaluated the professional development program with the help of the following evaluation questions:

2.1. How did the teachers react to the program?

2.2. Which learning outcomes did teachers report as a result of their activities in the program?

2.3. Which outcomes in practice in teachers' professional performance and/or learning outcomes in students did the teachers report as a result of their activities in the program?

2.4. Did the school organization meet conditions for the professional development program and did the program have an impact on the organization? 


\subsubsection{Research approach}

This study adopted a design-oriented research approach. Educational design research aims both at improvements in practice and development of theories about the process of learning and the means designed to support that learning. The goal is not merely to find out whether the design 'works', but also to understand the relationship between the learning process and the design. To a greater extent than most other research approaches, design research aims at making both scientific and practical contributions and underlines the importance of involving stakeholders in the process and in judging the overall desirability of a design.

Design principles and characteristics were identified based on a literature study. On the basis of these findings and analyses of the school context, a prototype of the PD program was designed, implemented and evaluated. Guskey's model of evaluation (2000) was employed to evaluate outcomes (Table 7.1). The results of this evaluation were used to revise the prototype. The revised PD program was implemented and evaluated during two consecutive years in two different contexts in the school (voluntary and mandatory participation).

Table 7.1 The levels of Guskey's evaluation model (2000) as used in this study

1. Teachers' reactions Did the PD program meet their expectations? Did the teachers like it? Did they consider the content, process, and context of the program useful and relevant?

2. Teachers' learning

Did the program stimulate teacher learning? Did the teachers acquire professional knowledge, skills, and/or attitudes in the program?

3. Outcomes in classroom:

3.a Teachers' use of the new

Did what the teachers learned affect their classroom knowledge and skills, and practice?

3.b Student learning outcomes

What is the impact of the professional development on outcomes in student learning, behavior, attitude, and/or self-efficacy?

4. Organizational support and outcomes

Was the implementation of the PD program supported by the school? Did the PD program affect PD practice in the school?

To gain in-depth knowledge and to stimulate triangulation (Miles \& Huberman, 1994), data were obtained using several observational and self report instruments, and both deductive and inductive analyses were executed. Data were collected with questionnaires, semi-structured interviews, videotaping of 
coaching dialogues in triads, and videotaping of the plenary presentations of teachers' inquiries, documents and observational notes of the plenary meetings, and teachers' reports of their inquiries.

Consecutive cycles of the PD program were implemented for three years in a row and data were gathered from 35 teachers. Each year the program started with a new group of participants and each program was implemented during one school year. In both the first and the second year 9 teachers from various teams in the school participated voluntarily. In the third year, a team (consisting of 17 teachers) participated on a mandatory basis. The researcher functioned as co-trainer in the program during the first two years, and participated as an observant during the third year.

\subsection{RECAPITULATION OF THE MAIN FINDINGS}

\subsubsection{Which design principles and design characteristics can be derived from literature in order to construct a professional development program that effectively supports teachers' workplace learning (research question 1)?}

Development of a theoretical framework and design principles and characteristics of the program

A framework was developed based on literature study of the concept of workplace learning and on design principles and characteristics of effective PD programs for teachers. Teacher learning has been studied in several different and often unconnected research traditions, one focusing on workplace learning and the other focusing on teacher PD (Hodkinson \& Hodkinson, 2005; Hoekstra et al., 2009). Both areas are important for understanding teacher learning and for designing PD programs that effectively support teacher learning in the context of the school.

The first part of the literature study took a close look at the concept of workplace learning. It focused the attention on the need to incorporate two basic notions (meta-principles) for the design of the PD program: (a) the importance of school-based PD connected with more non-formal workplace learning, and (b) the importance of reflective practice for teacher development. 
The second part of the literature study is a collection of review studies to establish an overview of what is internationally known about design principles and design characteristics of PD programs that effectively support teachers learning in the context of the school. Five design principles for PD programs were identified: (1) collaborative learning at the workplace, (2) focus on own practice with the help of video feedback, (3) teacher ownership of learning goals, (4) focus on teacher's inquiry stance and on outcomes in classroom, (5) creating conditions in the school for professional development and the PD program. All of the review studies present a clear idea about which principles are important for stimulating teachers' professional development. However, the further translations and integration into specific design characteristics and to the context in the school were still missing, shortcomings that were also signaled in a recent review study by Van Veen et al. (2010).

The third part of the literature study took a closer look at each of the five design principles in order to better understand and translate each principle into concrete design characteristics of a PD program. (See also Table 3.1 and 3.2).

1. Review studies underlined the importance of collaborative learning at the workplace. They describe various forms such as working in study groups or reciprocal peer coaching groups with or without the provision of structures to stimulate reflective dialogues. Important for collaborative teacher learning are structures to stimulate equality and trust between teachers and for collaboration as a non-hierarchical, collaborative process. Development of communities of practice can be based on working in heterogeneous groups. All of these aspects were incorporated into the design of the PD program in the form of (a) reciprocal peer coaching in a small video study group consisting of three teachers taking turns in the well-defined roles of teacher, peer coach, and observer of the coaching dialogue, and (b) training of the peer coach role and of necessary coaching skills for in-depth questioning to stimulate reflective dialogues and to safeguard peer coaching as a non-hierarchical and collaborative process.

2. A focus on own practice with the help of video feedback. Video recordings of own practice provide rich and powerful feedback. It creates possibilities to study practice, to identify problems and to raise awareness of successful classroom interactions, and to analyze and discuss own performance, beliefs and drives and outcomes in students. Working in a video study group, collaboratively studying video feedback, as a means to (a) share individual 
practice, (b) observe, reflect, and develop professional vision, and (c) focus on own performance and outcomes in classroom.

3. Teacher ownership of learning goals. PD programs should create structures to help realize teacher ownership of learning goals. Ownership of learning goals requires the acknowledgement of differences between teachers in concerns, learning goals, starting points, and learning pace. To define learning goals asks for reflection on performance as well as on underlying assumptions and values. We incorporated these characteristics into the design by building into the program (a) an extensive explorative phase to identify own learning goals at the start of the program, (b) a binder with tools to identify own learning goals and with theoretical background information to help transform learning goals into learning processes, and (c) a well defined coach role as a facilitator of the learning process of his/her peer, to keep individual teachers in control of their own learning processes.

4. Focus on teacher's inquiry stance and on outcomes in classroom. Teacher inquiry as a professional development process of purposeful engagement with school practice in a systematic, planned and collaborative way aiming at informed action and improvement. Teacher inquiry includes various forms of study and data sampling such as classroom studies, video feedback, questionnaires and interviews, focus on outcomes in classroom and in students. To stimulate reflective practice and an inquiry stance, teachers in the PD program are asked to (a) do an inquiry in classroom related to their own learning goals, and (b) present their inquiries to each other in a plenary meeting at the end of the program.

5. Creating conditions in the school for professional development and the PD program. Supportive conditions in the school are crucial; among others supply of time and timeslots for meetings; supply of necessary resources such as video cameras; availability of internal and external expertise; rewards; and the support and attention by the school management throughout the program.

Based on this conceptual framework a prototype of the PD program was designed.

Design and formative evaluation of the prototype of the professional development program

The prototype consisted of two different parts in which teachers discussed own practice, one part using anonymized narratives of own practice, and another part using peer coaching with video feedback. Teachers appreciated both parts, 
but all recommended to focus on the second part in future programs. Teachers evaluated the program as valuable for their personal development. They learned much from discussing own narratives in the first part of the program. During the second part of the program, teachers learned from the discussion of own videotaped classroom practice and from the observations and discussions of the videos of their peers. The program stimulated their engagement with colleagues and the sharing of ideas and practices. Video feedback helped to relate self-confidence to classroom reality. Being a novice or an experienced teacher appeared to influence outcomes in self-confidence. Video feedback could reassure insecure beginners by helping them notice things that worked well, and it could shake up confident, experienced teachers by pointing out worn-out routines. In their evaluations teachers stressed the importance of reciprocal peer coaching for strengthening trust and enhancing an atmosphere in which teachers were willing to share successes and failures. In future, learning the coach role will need more attention. Commitment to the program could be reinforced by contracts and bonuses, and an external trainer. When participants with more power or prestige (e.g. team leaders or school coaches) were the first to open up own practice and showed vulnerability and an intention to learn, this stimulated others to also show their practice (with successes and failures) and to focus on learning. These findings were incorporated as new guidelines in the program. It was unclear whether the program had outcomes in classrooms. Additional features for stimulating participants to investigate and implement own learning outcomes in classroom were needed. A safe learning environment that can foster an atmosphere of mutual trust between participants, as well as provision of time and timeslots in the school schedule proved to be crucial conditions for the program.

\section{Design of the professional development program 'Learning to Notice'}

Based on the evaluation outcomes of the prototype and the outcomes of the literature study on effective characteristics, an adapted program called 'Learning to Notice' [Leren bij Nader Inzien] was designed. The overall design of the program included six plenary meetings and - in between two plenary meetings reciprocal peer coaching with video feedback in small subgroups consisting of three teachers taking turns in different roles: as trainee, as coach and as observer of the coaching dialogue. Teachers worked together in heterogeneous subgroups. There was no predetermined central focus for learning. In line with the design principle of the teacher as owner of own learning goals, each participant chose an 
individual scope and focus. In plenary meetings, teachers were trained in coaching skills and at the end of each dialogue the triad also discussed the performance of the teacher-coach and the way the coach had stimulated the reflection process of the colleague. Teachers studied outcomes in classroom and at the end of the program they reported and presented these outcomes to their peers. The program was supported by the school management; however, most of the activities in the program were done in teachers' spare time.

This program was implemented in the school during two consecutive years, once in the context of voluntary participation and once as a mandatory team activity. The learning experiences and outcomes were evaluated with the help of a questionnaire, a semi-structured interview, and documents and observations of the implementation. To gain more in-depth knowledge of teachers' learning in the program, six triad dialogues and teachers' inquiries into own classrooms were studied.

\subsubsection{What is the practicality and effectiveness of the developed professional development program in supporting teachers' workplace learning?}

How did the teachers react to the program (evaluation question 2.1)?

Bonding and sharing between colleagues were rated the most positive experience with the program. Beforehand all teachers felt more or less unnerved by the videotaping and by their role as peer coach of their colleagues. Teachers were also afraid they lacked coaching skills and that they would interrupt the learning process of their peers by directing too strongly. Training for the peer coaching roles appeared an important characteristic. Afterwards, all teachers rated these characteristics - video feedback and (training for) peer coaching - as a very valuable experience.

Teachers appreciated the reciprocal peer coaching process and overall were very positive about it. Teachers who were not completely happy about their peers' coaching performance complained about: their peers' lack of efforts (not enough possibilities to make appointments); poor dedication (always looking at the clock); taking over of ownership by colleagues of the same department as a result of fixed roles ('you are new here, so listen and learn from the way we always have done this'); and the erosion of trust due to a peer who did not admit being a learner herself ('everything is going well in my classrooms, but let's talk about yours'). 
At the end of the program, the teachers were positive about collaborating in heterogeneous groups outside their own departments and about the fact subgroups being composed by the trainers. Although at the start of the program most teachers were displeased to hear they could not choose subgroups themselves, afterwards almost all valued the new bonds with colleagues, and they appreciated that in this way a 'professional group' was formed rather than a 'social club'.

The 'inquiry into own classroom' was the least appreciated characteristic of the program. However, having to present own inquiries to each other stimulated teachers to focus on their inquiries and most teachers felt urged to study their own experiments in classroom more in-depth.

Two aspects of this plenary presentation could be improved upon in the program. First of all, the program ended during the last quarter of the school year, a period in which teachers felt stressed due to school exams, student grading, and school excursions. It would be better to schedule the presentations during an earlier period of the school year. The second improvement has to do with the way teachers presented their inquiries to each other. To stimulate learning and reflective dialogues it is important that every teacher has actively performed an inquiry (to stimulate exchange and an open attitude) and that there is plenty of time for dialogue and reflection. A facilitator and/or reflection guidelines to steer the discussion might be helpful to stimulate in-depth questioning.

The teacher groups who participated on a voluntary basis (cohort A) were overall clearly more positive in their evaluations of the program than the teachers of the team that participated mandatorily (cohort B). In the mandatory program, teachers' participation and evaluation was more diverse. Not all teachers in this team participated fully or developed individual research questions and inquiries into own classroom, and there were large differences between teachers in their evaluations, which ranged from 'one of the best things I have ever done' to 'not for me'. By coincidence, the program for this group (mandatory team effort) was ill-fated due to the simultaneous (unrelated) introduction of other obligations in the school, such as teacher portfolios and teacher assessments. This confluence of events caused distrust of the consequences of participation in the PD program and the first plenary meeting in the program was dominated by discussions about the undesirability of all 
these obligations. As a result of the mandatory nature of their participation, not all teachers felt fully committed to the program; teachers clarified their lack of dedication by referring to a lack of motivation, a shortage of time or shared free time in school schedules, and the planning of the program being incompatible with their stage of personal (e.g. becoming farther) or professional life (e.g. as starter also having other PD activities).

In cohort A (volunteer group) every teacher had made a comparable contribution to the program and all performed inquiries. In cohort B (mandatory team effort) the contributions were more varied, not all teachers had performed an inquiry and not all plenary presentations were always followed by substantive talk. In the first two implementations of the program (volunteer groups), almost all teachers indicated to be interested in remaining involved in similar programs in the future. In the mandatory program only nine out of seventeen were sure they wanted to continue the program the following year.

Which learning outcomes did teachers report as a result of their activities in the program (evaluation question 2.2)?

At the end of the program, almost all teachers felt that their professional development was stimulated and that they had learned from the program. Teachers worked on various learning goals, such as learning of new teaching strategies, classroom management, and responding to differences between students. The program also had learning outcomes beyond the individual learning goals they set for themselves. Teachers reported they learned coaching and communication skills, they learned to reflect more on own routines in classroom, they noticed new aspects in their classroom practice, they got new ideas, and they became more open-minded towards collaboration with their colleagues. Especially the learning of coaching skills was appreciated, and teachers reported also using these newly acquired skills in other professional roles; in classrooms, for example, by formulating open-ended questions which stimulate students' thinking, and during communication with parents. Other work-related outcomes concerned community building through the bonding and sharing between colleagues. Teachers reported outcomes such as increased trust in their colleagues and team, more openness, and learning from each other.

As a result of participation in the program teachers revised their assumptions about their performance. Some teachers noticed own rut and sloppiness as a 
result, other teachers gained awareness of own weaknesses, a stage necessary for further professional development. Noteworthy is the observed difference between beginning and experienced teachers. Beginning teachers became more positive about their own performance while observing their videos. During the unnerving experience of videotaping their lessons, they often felt insecure about their own performance and they experienced classroom incidents often as complete and utter chaos. Having observed their videos - and also having been stimulated by their coach to really notice what actually happened - they became aware of (a) the relative impact of the incident ("I thought it lasted for a far longer time span"), and (b) their own development as a teacher, because they also noticed many aspects that went well and they therefore evidently had learned to handle. In contrast, the self-confidence of the experienced teachers regularly became somewhat dented. They expected everything to go well, but noticed afterwards on the videotape and through their dialogues that there were still things to learn and to improve.

It turned out to be much more difficult than expected for teachers to determine own learning goals and to translate them to learning processes. Often a separate inquiry was needed in which classroom practice was studied to analyze the underlying problem. In the program teachers' learning processes tended to develop very quickly as a result of their dialogues with video feedback: teachers noticed, interpreted and drew conclusions. This process is very helpful, but also has pitfalls such as the risk of overlooking possible solutions and consequences, or basing conclusions on limited or false interpretations. To enhance their learning, teachers had to take their inquiry stance a little bit further. This is discussed in the findings of the next evaluation question.

There was a clear difference between the individual teachers belonging to the mandatory group: some teachers reported many learning results while others had difficulties reporting any at all. In this cohort a number of teachers felt no commitment to the program and did not develop learning goals and did not inquire into own classroom. At the end of the program, they mostly reported outcomes concerning sharing with colleagues and the learning of coaching skills, but only few learning outcomes in own classroom. A lack of true learning goals of a colleague can obstruct the learning of all participants because it erodes feelings of equality and trust between teachers. 
Which outcomes in practice in teachers' professional performance and/or learning outcomes in students did the teachers report as a result of their activities in the program (evaluation question 2.3)?

This question focuses on learning outcomes in terms of teacher performance and outcomes in students. All teachers of both cohorts indicated that the PD program stimulated collaboration, the de-privatization of practice, reflective dialogues on practice, and a focus on student outcomes; characteristics which are predictive of improving schools and increased student learning (Bryk et al., 2009; Louis, Marks, \& Kruse, 1996).

Teachers studied outcomes in classroom performance and outcomes in student learning with the help of teacher inquiries. Competence and experience in doing research proved helpful, but were not a prerequisite. Almost all research questions of the teacher inquiries started with how-to questions. Only two teachers in cohort B did not formulate a specific research question for their inquiry and chose to study video recordings to investigate whether there were still any aspects they could improve upon in their lessons.

The way in which each teacher inquired into outcomes in classroom varied much. All used video recordings for their inquiry to a degree. Furthermore, teachers studied classrooms of colleagues, experimented in own classrooms, studied students' test results, and used student questionnaires and student interviews for their evaluations.

Different learning activities in the program may serve different learning issues, as was suggested by the struggle two teachers reported about. They experienced a dilemma between, on the one hand, their wish to promote active and self-regulated student learning, and, on the other hand, their identity as a teacher who needs to be in control and who forms the central figure in the classroom. For teachers struggling with this contradiction, the peer coaching dialogues were much more clarifying and important to learn from than their inquiry. Their peer's coaching increased their scope of reflection and did not limit their reflections to observations and possible actions, but stimulated inquiries into the background of their performance and studying collaboratively teacher's beliefs and drives and their relation to classroom performance. 
Teachers reported using learning outcomes in classrooms and in other professional roles. Many teachers (75\%) noticed positive effects on their students; most reported were improvements in students' learning activities and in student behavior, as well as improvements in the working climate in their classrooms. A small number of teachers reported having directly established concrete increases in learning outcomes as a result of their new approach in classroom. All but one teacher indicated that they most likely will continue practicing things they had learned in the program.

Almost all teachers indicated that the skills they learned during coach training were not only helpful inside, but also outside of the program. They used their newly acquired coaching skills in various professional working environments and in different professional roles during their contact with colleagues and during interaction with students and parents. Two thirds of the teachers felt that they had grown as a person as well due to their coach training. Also two thirds of the teachers felt that they had improved in reflecting on themselves as a teacher and on their values as a teacher.

\section{Did the school organization meet conditions for the professional development program and did the program have an impact on the organization (evaluation question 2.4 )?}

The program created conditions for learning, most importantly a structure of equality between participants. This structure helped to create mutual trust and a safe and an open learning environment for all participants: beginning teachers, experienced teachers and team leaders. In order to nurture mutual trust, it proved useful to have the participants with more power or prestige start with opening up own practice. By showing their own problems and by being learners themselves, leaders and coaches modeled a learning environment in which every teacher was a learner in their own right. The program further stimulated trust between teachers by (a) the reciprocal nature of their peer coaching; (b) defining the peer coach role as a 'prompter' focusing on open-ended questioning and not as an assessor focusing on offering feedback and advice; and (c) by training of the coach role.

The (in)voluntary nature of the participation seems to be the most important factor influencing the participants' learning. Although participants in both groups evaluated the program positively, first of all, on the whole the 
evaluations in cohort A were more positive than the scores in cohort B, and secondly, teachers in cohort $B$ showed much more differences in scores between individual participants.

Creating favorable conditions in the school proved to be one of the most difficult principles to realize during the implementation of this program. School management was willing to reward volunteers with a bonus (300 Euro), or team members with provision of time for plenary meetings, but that was it. All teachers reported a lack of time as well as common timeslots for their triad meetings. Peer coaches displaying peace and quiet in dialogues and who did not rush things proved to be one of the most important conditions for the depth of the reflection of their peers. Appointments with ample time and a fixed timeslot for triad meetings can help to reduce time pressure.

Furthermore, all kinds of organizational aspects in the context of the school interfered with the program. The simultaneous introduction of mandatory portfolios for teachers caused teachers' in the mandatory condition to distrust the PD program. Changes in management decreased the attention for the program in the school. During the three years of this PD project, for each year another school leader was in charge. In the first year the program was implemented under the supervision of one of the deputy headmasters. He left the school and during the second year the principal took over, he retired at the end of that year however. In the third year a new principal entered the school and the program came under the supervision of a team leader. These changes eroded the commitment and the much-needed continuing interest and support of the management for the program.

However, the program survived during the three years of the project. Moreover, various characteristics of the program were valued and got spontaneous follow up in the school. The school-based coach noticed a growing commitment in the organization for collaborative learning and video feedback for professional development. For instance, at the end of the third year, all team leaders purchased video cameras for use in their own teams. New programs using video feedback and/or collaborative learning were introduced in the school by other school-based coaches in the following year, and a number of mentors trained themselves in coaching student-teachers with video feedback. Thus, in spite of some unfavorable circumstances, the program had an impact on the school. 
Which design principles and characteristics of a PD program (based on reflective peer dialogues and video feedback) support teachers' workplace learning?

Based on the previous evaluations, the conclusion concerning the overall research question is that all five principles and the characteristics as derived from research literature and integrated into the PD program 'Learning to Notice' proved important for stimulating teacher professional learning including outcomes in professional performance. The principles and characteristics with some proposed amendments will be further discussed in 7.4.

\subsection{REFLECTIONS ON THE RESEARCH METHODOLOGY}

In this study, design research has provided the methodology for a stepwise analysis, design, and evaluation of a professional development program for teacher workplace learning. The design research approach brings with it quality criteria and certain methodological problems and dilemmas that are discussed below.

\section{Quality assurance}

McKenney, Nieveen and van den Akker (2006) defined tenets which are important in the analysis, design and evaluation cycle of design research and which also have a function in quality assurance: local relevance, collaboration with participants, and research rigor.

For relevance, products should be carefully tailored to the context and culture in which they will be implemented, they "must be based on a working knowledge of the target setting, and be informed by research and development activities taking place in naturally occurring test beds" (McKenney et al., 2006, p. 77). In the present study, the researcher, having been a teacher educator for years and being linked to the school and institute involved, was quite familiar with the context of the program and the school setting. Furthermore, the PD program was designed and tailor-made in close cooperation with a school intern coach and the stakeholders at the school.

As for collaboration: "If design research activities are to contribute to the professional development of participants, then design and development must 
be conducted in collaboration with and not for those involved. Additionally, data collection procedures should be mutually beneficial - addressing research needs while simultaneously offering meaningful experiences for the participants" (McKenney et al., 2006, p. 77). In the present study, in order to ensure internal validity of the findings and to ensure that the principles and characteristics fitted the needs of practitioners, the researcher worked in cooperation with the participants. The program was developed in close collaboration with the school intern coach and all participants were involved in the evaluation process. The participating teachers not only supplied data by answering questions, but also studied their own learning outcomes; the results of teachers inquiries became part of the evaluation process.

Concerning rigor: design research yields knowledge in the form of design principles and characteristics. Providing an explicit conceptual framework offers the opportunity to make analytic generalizations. This study's design research activities are rooted in an underlying rationale, evolved through literature review and through discussions with critical friends and others during conferences. The actual design of the program is based on (a) formal theoretical knowledge obtained through a literature review on design principles for PD programs stimulating teacher's workplace learning and (b) on informal practical knowledge obtained through years of training and coaching of teachers by the researcher (as a teacher educator) and by her co-constructor (the school-based coach).

This study has invested in analytical forms of generalization to support readers in their own attempts to explore the potential transfer of the research findings to theoretical propositions in relation to their own context (van den Akker, 1999). In order to help the readers determine whether the findings of this study are applicable to their own context or situation and to facilitate analogical reasoning, this study provides a comprehensive description of the theoretical background of the chosen design principles and characteristics and a contextrich description of the research situation, design decisions, and the formative and summative results. By providing these rich descriptions, others can estimate how to translate the reported situation to their own specific context.

To address the research question and increase the internal validity, the study used triangulation (Merriam, 1988; Miles \& Huberman, 1994). This approach rests on the premise that the weaknesses of each single data source, method, 
theory, or data type will be compensated or counterbalanced by the strength of another. In order to validate our results and conclusions we used triangulation by source (thick descriptions of learning processes of different participants and participants' groups in different contexts) and by method (questionnaire, interview, participant observation, transcripts of recorded coaching dialogues and teachers' inquiry reports).

\section{Multiple roles}

Design researchers who participate in the design, implementation and evaluation process can find themselves in conflicting roles. On the one hand, participation helps to gain in-depth knowledge of the process and outcomes. On the other hand, involvement in the design process may increase the chances of an evaluator effect. Participants may react differently due to the designer's presence during formative evaluation, and the designer may be (unintentionally) less receptive to criticism. When the designer performs evaluation activities (s)he needs to make efforts to obtain neutrality. "Rather than pretending to be objective observers, we must be careful to consider our role in influencing and shaping the phenomena we study. This issue is obvious when individuals take on multiple roles of researchers, teachers, teachers of teachers" (Putnam \& Borko, 2000, p. 13).

The multiple roles of the researcher can also be considered a productive force that contributes to balanced solutions. McKenney et al. (2006, p. 84) doubt the possibility of meaningful in-depth research from a complete outsider, a 'cultural stranger': "In many situations, participants are sometimes hesitant to be completely open with researchers from different cultural contexts. Toward earning participant trust and building an understanding of the context, the importance of collaboration and mutually beneficial activities cannot be overemphasized, as these are the two main avenues available to a researcher who prioritizes the 'insider' perspective."

In this study, the researcher worked in close cooperation with a school of secondary education and combined her role as researcher, especially during the first year, with the roles of program co-designer and co-trainer in the program, as well as with her role as teacher educator. In the latter two years the researcher shifted her attention to the researcher's position and functioned increasingly as observer instead of co-trainer in the program. The insider's role 
helped to understand the functioning of the design and to evaluate the prototype of the program. The inside perspective was enhanced through informal interactions during the weekly presence of the researcher at the school. Playing this combined role proved to be beneficial during the design process as well as to the study outcomes:

- The close relation between researcher and school helped to shape the design to the context of the school.

- It helped to obtain collaboration with the research program and established a direct entrance for the researcher to the participating teachers and their experience. It contributed to more in-depth analysis of the evaluation findings and a better understanding of teachers' experiences and evaluations.

- Teachers indicated the helpfulness of someone from outside the school to bring themselves to reserve enough time for activities in the program ('outside scrutiny puts you on your best behavior'). However this influence of the researcher was limited to her role as facilitator in the plenary meetings.

- Although the researcher was regularly present at the school, she was not part of the school organization and teachers were free to give their evaluations and remarks on the questionnaire or during the interview.

\section{Studying teacher learning}

An issue that concerned us when carrying out this study is the identification of reliable criteria for determining if and when a teacher has truly learned. Teacher learning is complex and includes changes in teachers' knowledge, beliefs, attitudes, motivation, emotions and immediate or future changes in teacher practice (Bolhuis, 2006; Zwart, 2007). In the present study we examined outcomes with the help of various levels for PD evaluation (Guskey, 2000). To gain insight in learning results we used a number of strategies. First, we questioned teachers on their learning and learning outcomes with questionnaires and semi-structured interviews. Secondly, we asked the teachers to inquire into their own learning outcomes in classroom and to present their results. By stimulating the teachers to study and critically examine their own outcomes in classroom, teachers gained more insight into their own learning processes, and simultaneously provided us with more information about learning outcomes for our research. Finally, we analyzed the learning process of the teachers as it arose in teachers' peer dialogues and teachers' inquiry reports. 
In the program teachers could learn as a result of the video feedback and their collaborative reflections, as a result of experimenting and inquiring in classroom, as a result of observing lessons of peers, and as a result of their roles as coach and observer in their triad dialogues. Although we used multiple data sources the reported outcomes are mostly based on the self-reported data of the teachers. As a consequence:

- We did not study outcomes in student learning directly. The conclusions about student learning are based on teachers' inquiries into their own classrooms, which they presented to each other.

- The reported outcomes, affordances, and constraints in the program may not be exhaustive. It is possible teachers did not see or mention an outcome or an affordance or constraint due to the implicit nature of their learning process.

- Furthermore, learning to do something often requires a longer period of experimenting, including unlearning former habits, an aspect that is often overlooked by learners as an important learning outcome.

\subsection{DISCUSSION AND GENERAL CONCLUSIONS}

In the following paragraphs the design principles and characteristics for PD programs that support teachers' workplace learning will be discussed and general conclusions will be formulated. Although we discuss the principles and characteristics separately, it should be remembered that in a PD program the principles are intertwined and strengthening each other. This also shows in the separate discussion.

\subsubsection{Collaborative learning at the workplace}

The PD program provided a space for teachers to share with their colleagues what they do in their classroom and use their teaching as the focus of their professional development. Mutual trust and support are the most important for teachers for investigating and learning by themselves. These two appear to be stimulated by the reciprocal nature of peer coaching, reflection in triads with well-defined roles, the training of the coach role, and an emphasis on own learning goals. Moreover, integrating team leaders and expert teachers as participants who provide a role model by showing own video recordings and own vulnerabilities, has a clear positive influence on commitment and trust 
between participants in the program. Collaboration with colleagues creates opportunities to connect more formal and directed PD activities with nonformal learning at the workplace. Reciprocal peer coaching with video feedback proved to be one of the effective structures to turn everyday work activities into opportunities for learning collaboratively. Important characteristics for PD programs aiming at developing collaboration and mutual learning in school communities are:

- Relating PD activities to teachers' authentic experiences, to their practice, and to their learning needs and goals.

- Building developmental relationships. Essential is an open atmosphere of mutual trust and support and concern with each other's learning. Teachers in the program must have room to fail and make mistakes and to be a learner in their own right.

- Teachers giving each other access to own classroom practice.

- Teachers are asked to raise and express issues and learning needs to each other and nurture a safe environment in which concerns can be put out for examination and analysis. By open-ended questioning, listening and continuous questioning peer coaches stimulate the understanding of other perspectives, and the reframing and creation of new perspectives. Important for peer coaches is an emphasis on empathy and on a non-evaluative attitude.

- In their dialogues teachers have to question implicit presuppositions, and own definitions of problems, and then transform these. Besides rational argumentation, coach dialogues should also focus on the emotional aspects that are important for learning. Feelings, beliefs and drives usually emerge when discussing critical events or issues, aspects that needs to be explored jointly. Most teaching performance is rooted in deeper layers of a teacher's professional identity. In contrast, coaching often focuses primarily on performance and solutions without thoroughly investigating their dependence on deeply held convictions and assumptions about what constitutes teaching, learning, a teacher's role and schools. As we ourselves also noticed in our own practice as teacher educators, teachers rarely learn and change substantively without clarifying and inquiring into the deeper layers of their professional identity. For instance, teachers do not learn to use more active and self-regulated student learning strategies, when the teachers' professional identities remain rooted in the belief that they are the pivot for all learning activities. 
- The PD program needs to cultivate a peer coaching relationship that is based on equal, holistic, helping relationships instead of relationships that are more unidirectional, solely action-oriented, and transactional in nature. To promote this type of peer coaching four measures are important in the PD program:

- Training of the peer coach role and of necessary coaching skills for indepth questioning to stimulate reflective dialogues and safeguard peer coaching as a non-hierarchical and collaborative process.

- Reciprocal peer coaching in subgroups consisting of three teachers taking turns in the well-defined roles of teacher, peer coach, and observer of the coaching dialogue. To add an a third person, the observer, to the peer dialogues (a) to focus peer coaches on their role and to prevent dialogues becoming superficial conversations, and (b) to help evaluate jointly the coaching dialogue and to learn coaching.

- Composing of the subgroups by program facilitators to integrate all teachers and prevent study groups becoming social clubs. Trainers can opt for nonheterogeneous subgroups of teachers belonging to the same department. A great benefit is that teachers can exchange their pedagogical content knowledge and study the teaching-learning context of their classrooms indepth. However, heterogeneously subgroups also have benefits. Existing role patterns and conflicts of interest in departments are avoided, teambuilding is stimulated, and teachers may experience eye-openers seeing their own student group react to different approaches by their colleagues teaching them other subjects. Just to see own students react to different approaches is very persuasive and opening up reflection.

- Both peers need to be motivated to learn and need to contribute actively and equally to the process. Dysfunctional subgroups should be rearranged to prevent learning of motivated teachers becoming in a rut.

Peer coaching is a process that requires engagement, and also takes time, practice and continuous debriefing to sharpen the necessary skills. Sometimes it does not develop at all, and peer coaching becomes unidirectional in nature. These findings are consistent with the findings of Parker, Hall and Kram (2008). This study made us realize again that the coaching-learning relation can be viewed in profoundly different ways. One is the expert's or authority's perspective, in which the peer is the expert and the one who tells the learner what to think and what to do. The other is a more democratic perspective in which the peer role is to help the learner become an expert in his own right. We 
find this difference in coach and mentor roles throughout our educational system, for instance in this illustrative quote:

"Cooperating teachers were also regularly confronted with three typical dilemmas: to help the pre-service teachers or to evaluate them; to transmit their own knowledge or to help them think for themselves; and to help them teach or to learn how to teach." (Chaliès, Ria, Bertone, Trohel, \& Durand, 2004, p. 779).

Our study shows that PD programs need to build on a clear vision, overcoming the traditional hierarchic view and picturing truly professional learning of teachers.

\subsubsection{Focus on own practice with the help of video feedback}

The program showed the enormous power of video recordings to capture the complexity of classroom processes and to make it accessible to teacher learning, especially if coaching takes place in a safe environment as already mentioned. Peer coaching helped to elaborate, reconsider, or revise teachers' understanding of complex teaching situations while providing support and feedback. Video feedback in PD is very rich feedback medium, providing the following guidelines are used:

- Peer coaches have to 'let the video do the work' and avoid giving "own verbal feedback and thus slipping into supervisory, evaluative comments despite their intentions to avoid them" (Showers \& Joyce, 1996, p. 15). Although not always intended that way, comments and unsolicited advice by peers are often experienced as judgmental and as rejections and therefore corrupt the open learning environment.

- Peer coaches need to be trained in using video feedback with open endedquestioning at all scopes of reflection and thus stimulate their peers to evaluate and reflect themselves. Most schools will need an external facilitator to provide an adequate peer coach training.

- Teachers need sufficient time for peer dialogues with video feedback. We experienced that often the first analyses of classroom situations turned out to be incomplete or too shallow.

To conclude, in line with other research (Borko et al., Dicks, 2005; 2008; Sherin, 2007; Sherin \& van Es, 2009), this study proves that collaboratively studying video feedback is very useful for sharing individual practice, for observing, reflection and developing professional vision, and for focusing on own performance and outcomes in classroom. People interpret the world around 
them all the time. Collaboratively studying the video recordings of own classrooms offers teachers opportunities to reconsider existing interpretations, become sensitive to new information and clues, and to develop their professional vision as well as new teaching strategies.

Reports of individual experiences and personal anecdotes are very persuasive in human communication and provide a rich basis for teacher learning (Miller \& Zhou, 2007). Sharing video recordings of own practice is a form of sharing personal anecdotes, supplying direct access to each other's practice, including opportunities to observe own students in other classrooms to compare to own practice.

\subsubsection{Teacher ownership of learning goals}

In the program, placed centrally is teacher learning around each teacher's personal interests and concerns. Learning from real-life experiences at work is ideally driven by the learner's motivation and preference (Poell, Yorks, \& Marsick, 2009). When teachers work on things they are puzzled about they are internally motivated. A number of studies underlined the importance of this approach to PD in which teachers themselves determine 'what' and 'how' they want to learn (Black, 2005; Bonner, 2006; Colbert, Brown, Choi, \& Thomas, 2008; Frietman, Kennis, \& Hövels, 2010; GTCE, 2007; Sparks, 2004).

An essential condition is that the teacher not only gets control but also stays in control of own learning goals during the learning process, thus having a peer coach who follows and supports the learner. Another prerequisite for ownership and teacher learning is the teacher taking agency in the program. Mandatory participation may present a problem, as it may trigger active resistance or cause problems due to the PD timing not fitting in with a stage in personal or professional life.

PD programs can create structures to help realize teacher ownership of learning goals by:

- Acknowledgement of differences between teachers in concerns, learning goals, starting points, and learning pace.

- Stimulating reflection to analyze learning needs and define learning goals, focusing on performance as well as on other perspectives and underlying assumptions and values. 
- Structures for collaboration and communication in subgroups such as welldefined roles and questioning techniques.

The collaborative peer coaching approach makes it possible for both the teacher and the peer to regard themselves as learners. The explicit and primary purpose of the relationship is to service both parties' learning.

Ownership does not imply that teachers should have the individual autonomy to do as they see fit on their own, the program proved also to support community building by sharing practice, concerns and own learning process. In a PD program, the ownership of learning goals should be with the teachers themselves for reasons of effectiveness as well as for reasons of professional emancipation.

\subsubsection{Focus on teacher's inquiry stance and on outcomes in classroom}

The program makes a direct link between working and learning and connects formal learning within the PD program to non-formal workplace learning. Reflection and inquiry-as-a-stance triggered by video feedback may become even more meaningful if it is combined with inquiry-as-a-project, including planning, action and evaluation. Inquiry is a spiral process of purposeful engagement with school practice in a systematic, planned and collaborative way aimed at informed action. Inquiry helps to prevent teacher dialogues becoming teacher talk characterized by exchange of unproved assumptions. Inquiry includes various forms of study and data sampling such as classroom studies, video feedback, questionnaires and interviews, focused on outcomes in classroom and in students.

In our study teachers experienced inquiries in classroom as time consuming and had the tendency to postpone their inquiry, because they did not yet really saw the surplus value. Teacher inquiry is a learning strategy that teachers have to be trained in during the program, just as they had to be trained in coaching techniques and in studying video feedback. Structures to focus teachers from the start on inquiries in classroom should be strengthened in the program.

Teacher inquiry is required when teachers encounter unclear and puzzling situations for which knowledge from previous experience is unavailable or inadequate. In order to develop a satisfactory way of dealing with this situation, it is necessary to develop an inquiry stance, question implicit presuppositions and definitions of problems, and critically investigate their validity in practice. 
The following characteristics are important to adequately realize teacher inquiry adequately (in combination with peer coaching):

- Teacher inquiry is clearly connected to improvement of classroom practice. Activities are focused on improvements that the teacher involved aims to bring about.

- Teachers can do this by defining the competence they need and by developing approaches that stimulate learning in that direction. Peer coach dialogues and video feedback aim to support this process.

- Teachers need guidance to acquire inquiry skills, including clear formulation of own questions, experimenting in classroom, and evaluating outcomes. A mixture of different inquiry methods can help to construct new connections between elements that were not linked before, and to develop and evaluate new teaching strategies. Teacher inquiry in this program starts with video feedback and peer coaching dialogues, but other research methods also need attention, such as observation, interviewing, formulating and administering student questionnaires, use of student evaluations and test results.

- Teacher inquiry-as-a-product needs to be carefully planned:

- Individual inquiries-as-a-product need to be planned ahead in the program, taking into account school activities, because school activities may interfere with teachers' planning of the implementation of own inquiries.

- Reporting and presenting own inquiries to each other in a plenary meetings helps to focus teachers' attention to planning and implementing inquiries-as-a-product. Sessions in which teachers share and present their inquiries to each other should be planned regularly during the program (and avoid periods with more than normal work load such as the full scheduled period at the end of each school year).

\subsubsection{Creating conditions in the school for professional development and the PD program}

As every study shows again and again supportive conditions in the school are essential (Resnick, 2005; Schwille et al., 2007; Timperley et al, 2007; VilegasReimers, 2003). In the program, this concerns conditions such as supply of time and timeslots for meetings, supply of necessary resources such as cameras, availability of internal and external expertise, some kind of reward, and - last but not least - the support and continuous attention throughout the program by school leaders. Our study confirmed the importance of these conditions. 
The combination of an internal and an external facilitator adds value the program. To create goodwill and a broadly based commitment with the program in the school, it proved very helpful to have a well-respected internal program facilitator who is taking the lead. However, making claims to colleagues proved to be difficult for an internal facilitator as a result of being part of the same organization and being subject to shared interests and a 'the show must go on' culture within the organization. An external facilitator can help to maintain focus and stimulate teachers to reserve time and energy for the program. An external facilitator can also be functional for introducing new knowledge and skills related to the learning goals of the teachers into the organization. In this way, tailored to the teachers' needs, the practical professional knowledge base of teachers at the school can be connected to the professional knowledge base of their profession.

The voluntary or mandatory participation in PD programs needs careful attention. As a result of mandatory participation, this study identified four kinds of commitment by teachers with learning in the program. Firstly, there were the teachers (like the teachers in the cohort that volunteered), who were interested and willing to participate and who were fully committed to the program and the study of own practice. Secondly, there were teachers who were reluctant at first, but whose attitude changed during the program and who became fully committed. Thirdly, there were teachers who had no real time or energy for the program for reasons outside of the program, for example, due to personal or professional circumstances; these teachers therefore had a limited commitment to the program. Finally, there were some teachers who were reluctant or felt hostile towards the program. They did not take agency, participated as little as possible in their triad, did not invest much time in developing own learning goals and did not study own learning outcomes. They operated as bystanders and did not gain much experience with the program. To oblige teachers to participate can create active and passive resistance (Van Driel, 2006). Often peer coach programs focus on volunteers. Although not all teachers will be reached, this study shows that teachers' 'will to learn' (van Eekelen, 2005) can be triggered by peer coach programs and that teachers can change their commitment to the PD program can change considerably as a result of their experiences in the program. In case of mandatory participation in the program special care should be provided for how well triads are functioning, because passive resistance of one teacher can obstruct the learning of the other two teachers in the triad due to the eroding of trust. 
Summary of the conditions in the school for the PD program:

- Supply of other necessary resources: time and timeslots for meetings, video cameras, facilitators, possibly a trigger with a kind (reward and/or contract) to not only start but also finish the program.

- A combination of an internal and external facilitator. A well chosen internal facilitator can create trust and commitment with the program. A external facilitator to:

- provide an adequate peer coach training and training of inquiry skills.

- provide new prompts to extend teachers' professional vision (Borko et al., 2008; van Es \& Sherin, 2002).

- Support and attention by the school management throughout the program. Motivation for participation is strengthened by recognition, and by other forms of rewards.

- A balanced decision on voluntary or mandatory participation needs to be made, adapted to school context. Enticing teachers to take agency and to join in collaborative knowledge construction is far more effective than mandatory participation. However, there might also be benefits to a mandatory team effort, for instance, in our study all teachers indicated that they felt more involved with their team and that they sympathized more with their colleagues. Furthermore, there also might be risks attached to restricting the program to voluntary participation. In cases where only those teachers join who are already opening up their classrooms to colleagues, there will be no sharing within a team as a whole, and there will be no progress in creating an open learning environment in which all teachers learn to cooperate and respect each other in a professional person-centered relationship.

- Motivation for participation may also be enhanced by the participation of school leaders, team leaders and well known experts in the school. Joining and showing they are still learners stimulates team and community building. Inequality in power relations can be reduced by starting the program with school leaders and other experts in the school showing video recordings of problems in own practice, discussing own concerns and showing own vulnerability.

The principles and characteristics as presented in this study provide a useful framework for school leaders to help realize professional development in their school. 


\subsection{RECOMMENDATIONS}

\subsubsection{Recommendations for further research}

The PD program in our study has been built on design principles and characteristics that seek to connect more formal teacher learning strategies with non-formal learning at the workplace. The program aims to stimulate teacher learning and as a result help teachers to improve practice, this, however, is not intended as a once-only event. The program also aims to strengthen learning strategies in teachers for reflective practice as a professional habit. In the PD program teachers are challenged to use various learning strategies, such as dialogues with peers, observations in classroom, video feedback, and inquiry into classrooms, all of which are directly related to workplace learning. Learning these strategies can stimulate reflective practice and help teachers make informed decisions to improve practice, now and in the future. The findings of this study have provided evidence of the initial impact of the PD program 'Learning to Notice'. Teachers gained strategies and methods they could use in classroom as well as increased trust, more willingness to cooperate with colleagues and increased reflection, inquiry, and coaching skills.

- Future research will need to explore the extent to which teachers will use outcomes of the program in their classrooms after the PD program has ended, and also the conditions that help or hinder them to do so.

Due to a changing world, the pace of teacher learning must increase and teachers need the tools for continuous professional learning to be self-directed, confident, capable learners. Peer coaching, video feedback and inquiry offer important tools, which can be used not only in the program but also for nonformal learning in all working situations.

- When teachers learn learning strategies such as peer coaching, video feedback and inquiry, do they actually use these 2, 5 or 10 years later, and what factors influence whether these learning strategies are used or how well they are used? We need more long-term research on developmental outcomes (Parker, et al., 2008).

By studying own practice and by tapping into one another's unique practical knowledge base all parties will learn and the productivity of teachers and teams will increase. 
Knowledge sharing was one of the primary benefits of the program. Teachers learned by explicating and studying own practical knowledge base, by discussing the practical knowledge base of their peers, through experimenting, and through imitating or internalizing the model of their peers. In short, in the program teachers learned through all kind of learning processes turning tacit knowledge into explicit knowledge, or internalizing and converting explicit knowledge to tacit knowledge. Bryant and Terborg (2008) found that especially by the removal of the hierarchical-power relation in traditional mentoring, peer coaching provided a strategy that is qualitatively different in content and method, that is how knowledge is shared turning tacit knowledge in explicit knowledge. In addition, video recordings may transfer tacit-to-tacit knowledge through modeling and teacher inquiry may convert implicit to explicit practical knowledge through studying practice and the theoretical knowledge base of the teaching profession.

- Further research is needed to study the degree to which the various design principles and characteristics are related to different learning processes and different learning outcomes in term of implicit and explicit knowledge and teacher performance.

The program has been designed for, and evaluated in a specific school for secondary education. A similar design was introduced by the researcher in a PD program for teacher educators and the initial results seem promising. In the present study we found that teachers in peer groups can study the complexity of teaching processes and coach each other to learn to notice and to enlarge their professional vision. However, we do not know to what extent this is also the case for student-teachers. The fact that student-teachers experience video feedback as compelling might imply that video feedback is easily interpreted and used for own learning. Such is clearly not the case. Other research also demonstrated that (student-)teachers need to learn to notice important aspects (Miller \& Zhou, 2007; Rosaen et al., 2008; van Es \& Sherin, 2002). Based on our own practical knowledge as teacher educators we expect that the program should be adjusted to fit in with the education of student-teachers during their internship. We expect that the professional vision of student-teachers is not yet developed enough to notice and interpret all kinds of basic elements, and that video study groups of student-teachers need to be supplemented by an more experienced teacher or teacher educator to help them to identify important aspects of classroom interaction and performance. 
- Future research will need to investigate the extent to which the developed program will be suited to (or perhaps needs to be adapted to) teachers in other schools for secondary education or other forms of education, such as primary schools, vocational education, and higher education.

- Future research will need to investigate the extent to which the developed program will be suited to or needs to be adapted to student-teachers in their internships.

The design principles and characteristics aim to stimulate workplace learning by teachers, who as professionals, from moment to moment, have to react and make informed decisions in volatile and complex work situations. The concept of peer coaching has been applied in several other professional fields including nursing and medical education, professionals who also work in complex environments (Parker, et al., 2008).

- Future research will need to investigate in what way the design principles and characteristics identified in our study also apply or need adaptation for PD programs in other comparable professional fields.

\subsubsection{Implications for practice}

Verbiest and Vandenberghe (2002) argued for school communities in which teachers and school leaders invest in their professional knowledge base in mutual consultation. Our program 'Learning to Notice' was developed to stimulate such a dialogue. The findings of this study show that a PD program based on the reported design principles and characteristics can provide a potentially powerful learning environment for teachers. The PD program can be high-impact, just-in-time, self-renewing, low-cost, and relatively easily to learn and implement.

The question is how school practice can stimulate teachers to make optimal use of the opportunities which they are given in the program or in similar PD initiatives. A condition for teacher learning is teachers taking agency. Teachers need agency to become committed to PD programs and their professional learning. Agency also implies that teachers can decide whether participation is suitable for them at a certain time in life. As we noticed in our research teachers may be in a stage of personal or professional life in which it is difficult to fully commit to the program. School leaders can offer this kind of PD on a regular basis, for instance every third year, so that teachers can choose to participate 
whenever it suits them in such a 'just in time' model. Less time-consuming PD activities may be offered in the meantime.

Peer coaching as envisioned in the program, is a non-hierarchical process that is based on holistic, supportive relationships. To build this kind of peer learning relationships teachers need various coaching and communication skills; competences that not all teachers possess as we have discovered through our research. For the development of a learning community in which teachers reciprocally coach each other's learning, teachers have to be trained in the necessary coaching competences. In our research, teachers reported that the coaching and communication skills developed during the PD program were not only important for their role as peer coach, but were also useful in all kinds of other professional situations such as the coaching of students in and outside of classrooms, and in their contacts with parents. The design principles and characteristics may also be useful for designing a PD program solely aimed at developing coaching and communication skills in teachers. This could be very useful in view of the overall importance of communication skills for the teaching profession and in view of the growing importance of the coaching of students and the communication with parents due to the ever-growing variation in student populations in schools today. A similar recommendation can be made for the training of inquiry skills and performing teacher practitioner research.

Teachers reported that as a result of their joint activities in the program they felt more connected to their peers and felt more supported by their peers. Teachers need openness and mutual respect, also in their relationships with the school management. In a time in which there is a culture of increasing assessment and control from government in schools, school leaders can foster relationship and empower teachers by PD based on trust in professionals and in their power to learn and improve professional practice. Crucial for a successful implementation of PD is the continuing interest and support of school leaders for the program. School leaders can show their support in all kinds of ways, for example, by facilitating, by participating in the program, and by following progress not merely incidentally but on a continuous basis.

To conclude, teachers' PD often used to be delivered in the form of formal programs from external sources that taught teachers the necessary knowledge to apply in their classrooms. Such PD programs are often perceived by teachers as 
fragmented, disconnected, and irrelevant to the real problems of classroom practice. In contrast, the PD program 'Learning to Notice' is based on the idea that the starting point for professional learning is best located in schools and classrooms, where teachers can learn in particular by collaboratively framing and solving problems of practice. The PD program created a learning environment that fostered collaboration, honest talk, inquiry into classrooms, and a commitment to teachers' professional growth and development. The program was based on the assumption that teachers are not mere technicians who implement the ideas of others, but that they are professionals themselves, examining practice themselves, and trying out new ideas, reflecting collaboratively on successful strategies and the reasons behind them, and who construct and share knowledge-of-practice together. In doing so, the program not just stimulated the professional development of the teachers, but also reduced teacher isolation and promoted the development of a learning community within the school in which teachers could learn from and with each other. 


\section{REFERENCES}

Admiraal, Th. J. (2009). Loopbaanontwikkeling als middel om competent te leren omgaan met organisatieontwikkeling in het onderwijs. Praktijkgericht wetenschappelijk onderzoek naar de bruikbaarheid van loopbaanmethodieken voor Human Resource Management. University of Tilburg: Doctoral dissertation.

Allen, T. D., \& Finkelstein, L. M. (2003). Beyond mentoring: Alternative sources and functions of developmental support. Career Development Quarterly, 51, 346-356.

Anderson, G. L., Herr, K., \& Nihlen, A. S. (2007). Studying your own school: An educator's guide to practitioner action research. Second edition. Thousand Oaks, CA: Corwin Press.

Avalos, B. (2010). Teacher professional development in teaching and teacher education over ten years. Virtual Special Issue on Teacher Professional Development in Teaching and Teacher Education over ten years.

Baker, T. L. (1999). Doing social research. Boston: McGraw-Hill.

Bakkenes, I., Vermunt, J. D., \& Wubbels, T. (2010). Teacher learning in the context of educational innovation: Learning activities and learning outcomes of experienced teachers. Learning and Instruction, 20(6), 533-548.

Becta (2009). Final report to Becta concerning the use of video-stimulated reflective dialogue for professional development in ICT. Accessed on 20/12/10 from http://research.becta.org.uk/upload-

dir/downloads/page_documents/research/video_stimulated_reflective_dialogue_re vised.pdf

Bergen, T., Engelen, A., \& Derksen, K. (2006). The quality of coaching in relation to the professional development of teachers. In F. K. Oser, F. Achtenhagen, \& U. Renold (Eds.), Competence oriented teacher training. Old research demands and new pathways (pp. 97-114). Rotterdam/Taipei: Sense Publishers.

Beijaard, D., Meijer, P., Morine-Dershimer, G., \& Tillema, H. (Eds.). (2005). Teacher professional development in changing conditions. Dordrecht, Netherlands: Springer.

Biesta, G. J. J. (2010). Why 'what works' still won't work: From evidence-based education to value-based education. Studies in Philosophy and Education, 29(5), 491-503.

Billett, S., Fenwick, T., \& Somerville, M. (Eds.). (2006). Work, subjectivity and learning: Understanding learning through working life. Dordrecht, Netherlands: Springer.

Billett, S. (2009). Personal epistemologies, work and learning. Educational Research Review, 4(3), 210-219.

Black, C. (2005). Issues regarding the facilitation of teacher research. Reflective Practice, 6(1), 107-122.

Blijleven, P. (2005). Multimedia-cases: Naar een brug tussen theorie en praktijk. Doctoral dissertation. Enschede: University of Twente. 
Bolhuis, S. (2001). Learning in the workplace: New theory and practice in teacher education. In J. N. Streumer (Ed.), Perspectives on learning at the workplace: Theoretical positions, organizational factors, learning processes and effects. Proceedings Second Conference on HRD Research and Practice Across Europe 2001 (pp. 57-66). Enschede: University of Twente.

Bolhuis, S. (2004). Leerstrategieën, leren en verantwoordelijkheid. Oratie 15 oktober 2004. Fontys Lerarenopleiding Tilburg. Also published by Coutinho, Bussum, and as Studiehuisreeks 60, Tilburg: MesoConsult.

Bolhuis, S. (2006). Professional development between teachers' practical knowledge and external demands. Plea for a broad social-constructivist and critical approach. In F. K. Oser, F. Achtenhagen, \& U. Renold (Eds.), Competence oriented teacher training. Old research demands and new pathways. (pp. 237-249). Rotterdam/Taipei: Sense Publishers.

Bolhuis, S. (2009). Leren en veranderen. Third revised print. Bussum: Coutinho.

Bolhuis, S. M. (2009b). Onderzoek in de school? In S. Bolhuis, P. Leenheer, \& G. van Luin (Eds.), Dat zoeken we zelf uit, Over onderzoek in de school door docenten, teamleiders en (midden)management. MESO-focus, 73. Alphen aan de Rijn: Kluwer.

Bolhuis, S., Buitink, J., \& Onstenk, J. (2010). Leren door werken in de school. (In press). Uitgave in het kader van de Beleidsagenda Lerarenopleidingen van het Ministerie van OCW onder verantwoordelijkheid van de Interdisciplinaire Commissie Lerarenopleidingen (ICL).

Bonner, P. J. (2006). Transformation of teacher attitude and approach to math instruction through collaborative action research. Teacher Education Quarterly, 33(3), 27-35.

Borko, H. (2004). Professional development and teacher learning: Mapping the terrain. Educational Researcher, 33(8), 3-15.

Borko, H., Jacobs, J., Eiteljorg, E., \& Pittman, M. E. (2008). Video as a tool for fostering productive discussions in mathematics professional development. Teaching and Teacher Education, 24, 417-436.

Borko, H., \& Putnam, R. (1995). Expanding a teachers' knowledge base: A cognitive psychological perspective on professional development. In T. Guskey, \& M. Huberman (Eds.), Professional development in education: New paradigms and practices (pp. 35-66). New York: Teachers College Press.

Boud, D., Keogh, R., \& Walker, D. (1985) Reflection. Turning experience into learning. London: Kegan Page.

Boyle, B., Lamprianou, I., \& Boyle, T. (2005). A longitudinal study of teacher change: What makes professional development effective? Report of the second year of the study. School Effectiveness and School Improvements, 16, 1-27.

Bransford, J., Brown, A., \& Cocking, R. (Eds.) (2000). How people learn: Brain, mind, experience, and school. Washington DC: National Academy Press.

Brookfield, S. D. (1995). Becoming a critically reflective teacher. San Francisco, CA: Jossey-Bass.

Brophy, J. (Ed.) (2004). Advances in research on teaching: Vol. 10: Using video in teacher education. Oxford, UK: Elsevier.

Brouwer, N. (2007). Verbeelden van onderwijsbekwaamheid: Een literatuurstudie naar het gebruik van digitale video ten behoeve van opleiding en professionele ontwikkeling van leraren. Heerlen: Open University, Ruud de Moor Centrum. 
Brouwer, N. (2009). Teacher peer coaching with digital video. Evaluation of a four-year professional development program. Paper presented at the Annual Meeting of the American Educational Research Association, April 2009.

Bruce, C. D., \& Ross, J. A. A. (2008). Model for increasing reform implementation and teacher efficacy: Teacher peer coaching in grades 3 and 6 Mathematics. Canadian Journal of Education, 31(2), 346-370.

Bryant, S. E., \& Terborg J. R. (2008). Impact of peer mentor training on creating and sharing organizational knowledge. Journal of Managerial Issues, 20, 11-29.

Bryk, A. S., Sebring, P. B., Allensworth, E., Luppescu, S., \& Easton, J. Q. (2009). Organizing schools for improvement: Lessons from Chicago. Chicago: University of Chicago Press.

Buczynski, S., \& Hansen, C. B. (2010). Impact of professional development on teacher practice: Uncovering connections. Teaching and Teacher Education, 26(3), 599-607.

Butler, D. L., \& Winne, P. H. (1995). Feedback and self-regulated learning: A theoretical synthesis. Review of Educational Research, 65(3), 245 -281.

Chaliès, S., Ria, L., Bertone, S., Trohel, J., \& Durand M. (2004). Interaction between preservice and cooperating teachers and knowledge construction during post-lesson interviews. Teaching and Teacher Education, 20, 765-781.

Chung Wei, R., Andrée, A., \& Darling-Hammond, L. (2009) How nations invest in teachers. High-achieving nations treat their teachers as professional. Educational Leadership, 66 (5), 28-33.

Clandinin, D. J., \& Huber, M. (2005). Shifting stories to live by: Interweaving the personal and professional in teachers' lives. In D. Beijaard, P. Meijer, G. Morine-Dershimer, \& H. Tillema (Eds.), Teacher professional development in changing condition (pp. 43-59). The Netherlands: Springer.

Clarke, D. J., \& Hollingsworth, H. (2002). Elaborating a model of teacher professional growth. Teaching and Teacher Education, 18, 947-967.

Cochran-Smith, M., \& Lytle, S. L. (1999). The teacher research movement: A decade later. Educational Researcher, 28(7), 15-25.

Cochran-Smith, M., \& Lytle, S. L. (1999b). Relationships of knowledge and practice: Teacher learning in communities. Review of Research in Education, 24, 249-305.

Cochran-Smith, M., \& Lytle, S. L. (2001). Beyond certainty: Taking an inquiry stance on practice. In A. Lieberman, \& L. Miller (Eds.), Teachers caught in the action: Professional development that matters (pp. 45-58). New York: Teachers College Press.

Cochran-Smith, M., \& Lytle, S. L. (2009). Inquiry as stance: Practitioner research for the next generation. New York: Teachers College Press.

Cochran-Smith, M., Barnatt, J., Friedman, A., \& Pine, G. (2009). Inquiry on inquiry: Practitioner research and students' learning. Download http://tne.bc.edu/documents/INquiryonInquiry.pdf (18 November 2010). To be published in E. Pultorak (Ed) "Research on teacher reflectivity: The impact on teaching and learning", Action in Teacher Education, 31(2), (special issue, Fall 2009).

Colbert, J. A., Brown, R. S., Choi, S-H, \& Thomas, S. (2008). An investigation of the impacts of teacher-driven professional development on pedagogy and student learning. Teacher Education Quarterly, 35(2), 135-154.

Commissie Dijsselbloem. (2008). Tijd voor onderwijs. Eindrapport. Den Haag: Tweede Kamer.

Conley, S., Bas-Isaac, E., \& Scull, R. (1995). Teacher mentoring and peer coaching: A micropolitical interpretation. Journal of Personnel Evaluation in Education, 9, 7-19. 
Cordingley, P., Bell, M., Rundell, B., \& Evans, D. (2003). The impact of collaborative CPD on classroom teaching and learning. In Research Evidence in Education Library. London: EPPI-Centre, Social Science Research Unit, Institute of Education, University of London.

Cordingley, P., Bell, M., Evans, D., \& Firth, A. (2005a). What do teacher impact data tell us about collaborative CPD? In Research Evidence in Education Library. London: EPPICentre, Social Science Research Unit, Institute of Education, University of London.

Cordingley, P., Bell, M., Thomason, S., \& Firth, A. (2005b) How do collaborative and sustained CPD and sustained but not collaborative CPD affect teaching and learning? In Research Evidence in Education Library. London: EPPI-Centre, Social Science Research Unit, Institute of Education, University of London.

Cornelius-White, J. (2007). Learner-centered teacher-student relationships are effective: A meta analysis. Review of Educational Research, 77(1), 113-143.

Creswell, J. W., \& Miller, D. L. (2000). Determining validity in qualitative inquiry. Theory into Practice, 39, 124-130.

CUREE (Centre for the Use of Research and Evidence in Education). (2005). Mentoring and coaching for learning: Summary report of the mentoring and coaching CPD capacity building project 2004 - 2005. Coventry: CUREE.

Dana, N. F., \& Yendol-Hoppey, D. (2009). The reflective educator's guide to classroom research ( $2^{\text {nd }}$ edition): Learning to teach and teaching to learn through practitioner inquiry. Thousand Oaks, CA: Corwin Press.

Darling-Hammond, L. (1997). The right to learn: A blueprint for creating schools that work. San Francisco: Jossey-Bass.

Darling-Hammond, L., \& Bransford, J. (Eds.). (2005). Preparing teachers for a changing world. Report of the committee on teacher education of the national academy of education. San Francisco: Jossey Bass.

Darling-Hammond, L., \& Berry, B. (1998). Investing in teaching. Retrieved from Education Week on the web. Http: //www.edweek.org/ew/vol17/37darlin.h17

Darling-Hammond, L., \& Richardson, N. (2009). Research review. Teacher learning: What matters? Educational Leadership, 66(5), 46-53.

Day, C. (1993). Reflection: A necessary but not sufficient condition for professional development. British Educational Research Journal, 19(1), 83-92.

Desimone, L. M. (2009). Improving impact studies of teachers' professional development: towards better conceptualizations and measures. Educational Researcher, 38(3), 181-199.

Dewey, J. (1933). How we think: A restatement of the relation of reflective thinking to the educative process. Boston: D.C. Heath.

De Wolf, A. (2002). Onderwijsonderzoek en -praktijk. Tilburg: IVA, instituut voor sociaalwetenschappelijk beleidsonderzoek en advies.

Dicks, M. J. (2005). Show me the way. Educational Leadership, 63(3), 78-80.

Elliott, J. (1990). Teachers as researchers: Implications for supervision and for teacher education. Teaching and Teacher Education, 6(1), 1-26.

Ellström, P. E. (2002). Integrating learning and work: Problems and prospects. Human Resource Development Quarterly, 12(4), 421-435.

Engelen, A. (2002). Coaching binnenstebuiten. Een onderzoek naar coaching van docenten door docenten. Doctoral dissertation. Nijmegen: Radboud University Nijmegen. 
Englert, C. S., \& Tarrant, K. (1995). Creating collaborative cultures for educational change. Remedial Special Education, 16, 325-336.

Eraut, M. (2004). Informal learning in the workplace. Studies in Continuing Education, 26(2), 247-273.

Eraut, M. (2007). Learning from other people in the workplace. Oxford Review of Education. $33(4), 403-422$.

Ermeling, B. A. (2010). Tracing the effects of teacher inquiry on classroom practice. Teaching and Teacher education, 26, 377-388.

Evans, L. (2008). Professionalism, professionality and the development of education professionals. British Journal of Educational Studies, 56(1), 20-28.

Evans, L. (2010). Enhancing our understanding of professional development: A new conceptual model and framework. Paper presented at the Annual Conference of the British Educational Research Association, September 2010.

Feiman-Nemser, S., \& Floden, R. (1986) The cultures of teaching. In M. Wittrock (Ed.), Handbook of research on teaching (3rd ed.) (pp. 505-526). New York: Macmillan.

Festinger, L. (1957). A theory of cognitive dissonance. Stanford: University Press.

Fook, J., White, S., \& Gardner, F. (2006). 'Critical reflection: A review of contemporary literature and understandings'. In S. White, J. Fook, \& F. Gardner (Eds.), Critical reflection in health and social care (pp. 3-20). Maidenhead: Open University Press.

Freire, P. (1972). Pedagogy of the oppressed. London: Sheed \& Ward.

Frederiksen, J. R., Sipusic, M., Sherin, M. G., \& Wolfe, E. (1998). Video portfolio assessment: Creating a framework for viewing the functions of teaching. Educational Assessment, 5 (4), 225-297.

Friedman, A., \& Phillips, M. (2004). Continuing professional development: Developing a vision. Journal of Education and Work, 17 (3), 361-376.

Frietman, J., Kennis, R., \& Hövels, B. (2010). Het managen van informeel leren: Hoe ver kun je gaan? Een verkennende studie naar kwaliteitsmanagement van het informeel leren van leraren. Rapport 6. Heerlen: Open University, Ruud de Moor Centrum.

Fukkink, R. G., Trienekens, N., \& Kramer, L. J. C. (2010). Video feedback in education and training: Putting learning in the picture. Educational Psychology Review, 10.1007/s10648-010-9144-5, published on line 16 October 2010.

http://www.springerlink.com/content/9m51q62188613672/(Download 2 Februari 2011).

Fuller, A., \& Unwin, L. (2002). Developing pedagogies for the contemporary workplace. In K. Evans, P. Hodkinson, \& L. Unwin (Eds.), Working to learn (pp. 95-111). London: Kogan Page.

Garet, M., Porter, A., Desimone, L., Birman, B., \& Yoon, K. S. (2001). What makes professional development effective? Results from a national sample of teachers. American Educational Research Journal, 38(4), 915-945.

General Teaching Counsel for England [GTCE]. (2005). Research for teachers: Teachers' professional learning. London: General Teaching Council for England: www.gtce.org.uk (Download: 18 December, 2005).

General Teaching Counsel for England [GTCE]. (2007). Making CPD better: Bringing together research about CPD. London: General Teaching Council for England. 
Geringer, J. (2003). Reflections of professional development: Toward high-quality teaching and learning. PHI Delta Kappan, 84(5), 373.

Ghaye, A., \& Ghaye, K. (1998). Teaching and learning through critical reflective practice. London: David Fulton.

Gholami, K., \& Husu, J. (2010). How do teachers reason about their practice? Representing the epistemic nature of teachers' practical knowledge. Teaching and Teacher Education $26,1520-1529$.

Glazer, E. M., \& Hannafin, M. J. (2006). The collaborative apprenticeship model: Situated professional development within school settings. Teaching and Teacher Education, 22(2), 179-193.

Goes, M., Dresen, M., \& van der Klink, M. (2005). Zonder leraren geen meesterlijke ontwikkeling. Het uitwerken van kenmerkende beroepssituaties. Heerlen: Open University, Ruud de Moor Centrum.

Goodwin, C. (1994). Professional vision. American Anthropologist, 96(3), 606-633.

Gravani, M. N. (2007). Unveiling professional learning: Shifting from the delivery of courses to an understanding of the processes. Teaching and Teacher Education, 23(5), 688-704.

Gravemeijer, K., \& Cobb, P. (2006). Design research from a learning design perspective. In J. van den Akker, K. Gravenmeijer, S. McKenney, \& N. Nieveen (Eds.), Educational design research (pp. 17-51). London: Routledge.

Grossman, P., \& Wineburg, S. (1997). Creating a community of learners among high school English and social studies teachers. Paper presented at the annual meeting of the America Educational Research Association, Chicago.

Grossman, P., Wineburg, S., \& Woolworth, S. (2001). Towards a theory of teacher community. Teachers College Record, 103, 942-1012.

Groundwater-Smith, S., \& Mockler, N. (2006). Research that counts: practitioner research and the academy. In J. Blackmore, J. Wright, \& V. Harwood (Eds.), Counterpoints on the Quality and Impact of Educational Research. Review of Australian Research in Education-a special issue of The Australian Educational Researcher (Vol. 6) (pp. 105 - 117). Gruyere, Vic: AARE.

Groundwater-Smith, S., \& Mockler, N. (2009). Teacher professional learning in an age of compliance. Mind the gap. Rotterdam: Springer.

Guskey, T. R. (2000). Evaluating professional development. Thousand Oaks, CA: Corwin Press.

Guskey, T. R. (2003). What makes professional development effective? Phi Delta Kappan, 84 (10), 748-750.

Guskey, T. R., \& Sparks, D. (1996). Exploring the relationship between staff development and improvements in student learning. Journal of Staff Development, 17(4), 34-38.

Guskey, T. R., \& Yoon, K. S. (2009). What works in professional development? PHI Delta Kappan, 90(7), 495-500.

Hall, E. (2009). Engaging in and engaging with research: Teacher inquiry and development. Teachers and Teaching: Theory and Practice, 15(6), 669-681.

Hammerness, K. (2006). Seeing through teachers' eyes: Professional ideals and classroom practice. New York: Teachers College Press.

Hargreaves, A. (Ed.). (1997) Rethinking educational change with heart and mind: The 1997 ASCD yearbook. Alexandria, VA: Association for Supervision and Curriculum Development. 
Hattie, J. (2005). What is the nature of evidence that makes a difference to learning? Conference Papers. Melbourne: ACER.

<http://www.acer.edu.au/workshops/documents/Proceedings_000.pdf>

Hattie, J. (2009). Visible learning. A synthesis of over 800 meta-analyses relating to achievement. London/New York: Routledge.

Hattie, J., \& Timperley, H. (2007). The power of feedback. Review of Educational Research, 77 (1), 81-112.

Hatton, N., \& Smith, D. (1995). Reflection in teacher education: Towards definition and implementation. The University of Sydney: School of Teaching and Curriculum Studies. Download (4-3-2011) http://www2.edfac.usyd.edu.au/LocalResource/Study1/ hattonart.html

Heckman, P. (1987). Understanding school culture. In J. Goodlad (Ed.), The ecology of school renewal (pp. 63-78). Chicago: University of Chicago Press.

Hoban, G. F. (2002). Teacher learning for educational change. A systems thinking approach. Buckingham/Philadelphia: Open University Press.

Hodkinson, H., \& Hodkinson, P. (2005), Improving schoolteachers' workplace learning. Research Papers in Education, 20(2), 109-31.

Hoekstra, A. (2007). Experienced teachers' informal learning in the workplace. Doctoral dissertation, Utrecht University.

Hoekstra, A., Beijaard, D., Brekelmans, M., \& Korthagen, F. (2007). Experienced teachers' informal learning from classroom teaching. Teachers and Teaching, 13(2), 191-208.

Hoekstra, A., Korthagen, F., Brekelmans, M., Beijaard, D., \& Imants, J. (2009). Experienced teachers' informal workplace learning and perceptions of workplace conditions. Journal of Workplace Learning, 21(4), 276-298.

Hodkinson, H., \& Hodkinson, P. (2005). Improving schoolteachers' workplace learning. Research Papers in Education, 20, 109-131.

Hofman, R. H., \& Dijkstra. B. J. (2010). Effective teacher professionalization in networks? Teaching and Teacher Education, 26(4), 1031-1040.

Hord, S. M., (1997). Professional learning communities: Communities of continuous inquiry and improvement. Austin, TX: Southwest Educational Development Laboratory.

Horn, I. S., \& Little, J. W. (2010). Attending to problems of practice: Routines and resources for professional learning in teachers' workplace interactions. American Educational Research Journal, 47(1), 191-217.

Huber, S. G. (2011). The impact of professional development: A theoretical model for empirical research, evaluation, planning and conducting training and development programmes. Professional Development in Education, 37(5), 837-853.

Huston, T., \& Weaver, C. L. (2008). Peer coaching: Professional development for experienced faculty. Innovative Higher Education, 33(1), 5-20.

Iacoboni, M. (2008). Het spiegelend brein. Over inlevingsvermogen, imitatiegedrag en spiegelneuronen. Amsterdam: Nieuwezijds.

Jay, J. K., \& Johnson, K. L. (2002). Capturing complexity: A typology of reflective practice for teacher education. Teaching and Teacher Education 18, 73-85.

Jordell, K. J. (2006). Learning to teach: A review and a discussion. Report no. 1. University of Oslo: Institute for Educational Research. 
Joyce, B., \& Showers, B. (1980). Improving inservice training: The messages of research. Educational Leadership, 37, 379-385

Joyce, B., \& Showers, B. (2002). Student achievement through staff development. Alexandria: ASCD.

Kazemi, E., \& Hubbard, A. (2008). New directions for the design and study of professional development. Journal of Teacher Education, 59, 428-441.

Keay, J., \& Lloyd, C., (2009). High-quality professional development in physical education: The role of a subject association. Professional Development in Education, 35(4), 655-676.

Kelchtermans, G. (2007). Capturing the multidimensionality of teacher professionalisme: Broad and deep reflection. In J. van Swet, P. Ponte, \& B. Smit (Eds.), Postgraduate programmes as platform; a research-led approach (pp. 97-110). Rotterdam/Taipei: Sense.

Kelchtermans, G., \& Hamilton, M. L. (2004). The dialectics of passion and theory: Exploring the relationship between self-study and emotion. In: J. J. Loughran, M. L. Hamilton, V. Kubler LaBoskey, \& T. Russell (Eds.), International handbook of self-study of teaching and teacher education practices (pp. 785-810). Dordrecht: Kluwer Academic Publishers.

Kelchtermans, G., \& Vanassche, E. (2010). “Stel een andere vraag en je krijgt een ander antwoord". Reflecties over onderzoek door leraren. Pedagogische Studiën, 87, 296-305.

Kennedy, M. M. (2004). Reform ideals and teachers' practical intentions. Educational Policy Analysis Archives, 12(13), 1-34.

Klarus, R., \& Oosterheert, I. (Eds.) (2005). Ontwikkelen van competenties op de werkplek. Werkplekleren, ingewikkeld, uitdagend en inspirerend. Hogeschool van Arnhem en Nijmegen: Faculteit Educatie, kenniskring 'Ontwikkelen van competenties op de werkplek'.

Kohler, F. W., McCullough Crilley, K. M., Shearer, D. D., \& Good, G. (1997). Effects of peer coaching on teacher and student outcomes. The Journal of Educational Research, 90(4), 240-250.

Kools, Q. H. (2009). Wat levert het doen van praktijkonderzoek op voor docenten? Praktijkervaringen uit begeleidingstrajecten. In S. Bolhuis, P. Leenheer, \& G. van Luin (Eds). Dat zoeken we zelf uit, Over onderzoek in de school door docenten, teamleiders en (midden)management. MESO-focus, 73. Alphen aan de Rijn: Kluwer.

Kools, Q. H., \& Bolhuis, S. M. (2008). Double knowledge creation: Learning experiences from teachers doing their own practitioner research and experiences arising from the program for teacher practitioner research. Paper presented at the Practice Based and Practitioner Research Conference on Learning and Instruction, Bergen, Norway.

Koopmans, H., Doornbos, A., \& van Eekelen, I. (2006), 'Learning in interactive work situations: It takes two to tango; why not invite both partners to dance?' Human Resource Development Quarterly, 17, 135-158.

Korthagen, F. A. J (2001). Specific instruments and techniques for promoting reflection. In F.A.J. Korthagen, J. Kessels, B. Koster, B. Lagerwerf, \& Th. Wubbels (Eds.), The pedagogy of realistic teacher education. Mahwah, New Jersey: Lawrence Erlbaum Associates.

Korthagen, F. A. J., Kessels, J. P. A. M., Koster, B., Lagerwerf, B., \& Wubbels, Th. (2001). Linking practice and theory. The pedagogy of realistic teacher education. Mahwah, New Jersey: Lawrence Erlbaum Associates.

Korthagen, F. A. J., \& Vasalos, A. (2005). Levels of reflection: Core reflection as a means to enhance professional development. Teachers and Teaching: Theory and Practice, 11(1), 47-71. 
Korthagen, F., \& Vasalos, A. (2007). Kwaliteit van binnenuit als sleutel voor professionele ontwikkeling. VELON-Tijdschrift, 28(1), 17-23.

Kwakman, K. (1999). Leren van docenten tijdens de beroepsloopbaan. Studies naar professionaliteit op de werkplek in het voortgezet onderwijs. Doctoral dissertation, University of Nijmegen.

Kwakman, K. (2003a) Factors affecting teachers' participation in professional learning activities. Teaching and Teacher Education 19, 149-170.

Kwakman, K. (2003b). Professional learning throughout the career. International Journal of Human Resources Development and Management, 3, 180-190.

Lave, J., \& Wenger, E. (1991). Situated learning: Legitimate peripheral participation. Cambridge UK: Cambridge University Press.

Lavié, J. M. (2006). Academic discourses on school-based teacher collaboration: Revisiting the arguments. Educational Administration Quarterly, 42(5), 773-805.

Lefstein, A., \& Snell, J. (2011). Professional vision and the politics of teacher learning. Teaching and Teacher Education, 27, 505-514.

Lieberman, A. (1996). Practices that support teacher development: Transforming conceptions of professional learning. In M. W. McLaughlin, \& L. Oberman (Eds.), Teacher learning: New policies, new practices (pp. 185-201). New York: Teachers College Press.

Lieberman, A., \& Pointer Mace, D. H. (2008). Teacher learning: The key to educational reform. Journal of teacher education, 59 (3), 226-234.

Little, J. W. (1982). Norms of collegiality and experimentation: Workplace conditions of school success. American Educational Research Journal, 19(3), 325-340.

Little, J. W. (1993a). Teachers' professional development in a climate of education reform. Educational Evaluation and Policy Analysis, 15, 129-151.

Little, J. W. (1993b). Professional community in comprehensive high schools: Two worlds of academic and vocational teachers. In J. W. Little \& M. McLaughlin (Eds.), Teachers' work: individuals, colleagues and contexts (pp. 137-164). New York: Teacher College Press.

Little, J. W. (2003). Inside teacher community: Representations of classroom practice. Teachers College Record, 6, 913-945.

Little, J. W. (2006). Professional community and professional development in the learning-centered school. University of California, Berkeley. Download:

http://citeseerx.ist.psu.edu/viewdoc/download?doi=10.1.1.159.5197\&rep=rep1\&type $=\mathrm{pdf}$

Little, J. W. (2007). Teachers' accounts of classroom experience as a resource for professional learning and instructional decision making. In P. Moss (Ed.), Evidence and decision making: 2007 NSSE Yearbook (pp. 217-240), National Society for the Study of Education, Vol. 106 (1).

Loughran, J. J., Hamilton, M. L., LaBoskey, V. K., \& Russell, T. L. (Eds.). (2004). The international handbook of self-study of teaching and teacher education practices. Dordrecht: Kluwer Academic Publishers.

Louis, K. S., Marks, H. M., \& Kruse, S. (1996). Teachers' professional community in restructuring schools. American Educational Research Journal, 33 (4), 757-798.

Lu, H-L. (2010). Research on peer coaching in preservice teacher education - A review of literature. Teaching and Teacher Education, 26, 748-753. 
Lunenberg, M., Ponte, P., \& van de Ven, P.H. (2006). Waarom zouden docenten en opleiders geen onderzoek mogen doen? Een kennistheoretische verkenning. VELONTijdschrift, 27(2), 4-12.

Mansvelder-Longayroux, D. D., Beijaard, D., \& Verloop, N. (2007). The portfolio as a tool for stimulating reflection by student teachers. Teaching and Teacher Education, 23, 47-62.

Marsick, V. J. (2009). Towards a unifying framework to support informal learning theory, research and practice. Journal of Workplace Learning, 21(4), 265-275.

Marsick, V. J., \& Volpe, M. (1999). The nature and need for informal learning. Advances in Developing Human Resources, 1(3), 1-9.

Marsick, V. J., \& Watkins, K. E. (2001), Informal and incidental Learning. New Directions for Adult and Continuing Education, 89, 25-34.

Martens, R., \& de Laat, M. (2011). Professionalisering op de werkplek. Onderwijsinnovatie, september 2011, 11-13.

McDougall, M., \& Beattie, R. S. (1997). Peer mentoring at work: The nature and outcomes of non-hierarchical developmental relationships. Management Learning, 28, 423-437.

McKenney, S., Nieveen, N., \& van den Akker, J. (2006). Design research from a curriculum perspective. In J. van den Akker, K. Gravenmeijer, S. McKenney, \& N. Nieveen (Eds.), Educational design research (pp. 67-90). London: Routledge.

McLaughlin, M. (1993). What matters most in teachers' workplace context? In J. W. Little, \& M. McLaughlin (Eds.), Teachers work (pp. 79-103). New York: Teachers College Press.

McLaughlin, C., McIntyre D., \& Black-Hawkins, K. (2004). Researching teachers, researching schools, researching networks: A review of the literature. University of Cambridge: Faculty of Education.

Meirink, J. (2007). Individual teacher learning in a context of collaboration in teams. Doctoral dissertation, Leiden University.

Meirink, J. A., Meijer, P. C., \& Verloop, N. (2007). A closer look at teachers' individual learning in collaborative settings. Teachers and Teaching: Theory and Practice, 13, 145-164.

Meijer, P. (1999). Teachers' practical knowledge. Teaching reading comprehension in secondary teaching. Doctoral dissertation, Leiden University.

Merriam, S. (1988). Case study research in education. San Francisco: Jossey-Bass.

Mezirow, J. (1981). A critical theory of adult learning and education. Adult Education, 1, 324.

Mezirow, J. (1990). Fostering critical reflection in adulthood. A guide to transformative and emancipatory learning. San Francisco/Oxford: Jossey-Bass.

Michalak, J. M. (2010). Supporting a culture for quality improvement in teacher education: Towards a research partnership. In B. Hudson, P. Zgaga, \& B. Åstrand (Eds.), Advancing quality cultures for teacher education in Europe: Tensions and opportunities, (pp. 69-86). Umeå University, Sweden: Umeå School of Education.

Miles, M. B., \& Huberman, A. M. (1994). Qualitative data analysis. Second edition. London: Sage.

Miller, K. F., \& Zhou, X. (2007). Learning from classroom video: What makes it compelling and what makes it hard. In R. Goldman, R. Pea, B. Barron, \& S. Derry (Eds.), Video research in the learning sciences (pp. 321-334). Mahwah, NJ: Erlbaum.

Ministerie van Onderwijs, Cultuur en Wetenschap. (2004). Blijf groeien. Wet op de beroepen in het onderwijs. Download: www.minocw.nl/werkinonderwijs/ 
Moon, J. (2005) 'Guide for busy academics no. 4: Learning through reflection'. The Higher Education Academy. Download:

http://www.heacademy.ac.uk/assets/York/documents/resources/resourcedatabase /id69_guide_for_busy_academics_no4.doc (accessed 24 June 2011).

Munby, H., \& Russell, T. (1990). Metaphor in the study of teachers' professional knowledge. Theory into Practice, 29(2), 116-121.

Murray, S., Ma, X., \& Mazur, J. (2009). Effects of peer coaching on teachers' collaborative interactions and students' mathematics achievement. Journal of Educational Research, 102(3), 203-212.

Nelson, T. H., Deuel, A., Slavit, D., \& Kennedy, A. (2010). Leading deep conversations in collaborative inquiry groups. The Clearing House, 83, 175-179.

Onderwijsraad. (2003). Kennis van onderwijs: Ontwikkeling en benutting. Den Haag: Onderwijsraad.

Onderwijsraad. (2006). Naar meer evidence based onderwijs, Advies uitgebracht aan de minister van Onderwijs, Cultuur en Wetenschap. Nr. 20050450/840. Den Haag: Onderwijsraad.

Onstenk, J. (2004). Leren leren tijdens het werk. In J. Streumer, \& M. van der Klink (Eds.), Leren op de werkplek (pp. 33-49). 's Gravenhage: Reed Buseness Information.

Onstenk, J., Kallenberg, T., \& Koster, B. (2007). De onderzoekende leraar en schoolontwikkeling. MESO Magazine, 27(157), 4-8.

Parker, P., Hall, D. T., \& Kram, K. E. (2008). Peer coaching: A relational process for accelerating career learning. Academy of Management Learning and Education, 7(4), 487503.

Plomp, T., \& Nieveen, N. (Eds.). (2010). An introduction to educational design research. Proceedings of the seminar conducted at the East China Normal University, Shanghai (PR China), November 23-26, 2007, Enschede: SLO.

Poell, R. F., Yorks, L., \& Marsick, V. J. (2009). Organizing project-based learning in work contexts. A cross-cultural cross analysis of data from two projects. Adult Education Quarterly, 60(1), 77-93.

Ponte, P. (2002). Actie-onderzoek door docenten: Uitvoering en begeleiding in theorie en praktijk. Doctoral dissertation. Leuven/ Apeldoorn: Garant.

Putnam, R., \& Borko, H. (2000). What do new views of knowledge and thinking have to say about research on teacher learning? Educational Researcher, 29(1), 4-15.

Qualters, D. M. (2009). Creating a pathway for teacher change. Journal of Faculty Development, 23(1), 5-13.

Reeves, T. C. (2006). Design research from a technology perspective. In J. van den Akker, K. Gravenmeijer, S. McKenney, \& N. Nieveen (Eds.), Educational design research (pp. 5266). London: Routledge.

Resnick, L. B. (Ed.). (2005). Teaching teachers: Professional development to improve student achievement. Research Points: Essential Information for Education Policy, 3(1), 1-4. Download: www.aera.net.

Rogers, R. R. (2001). Reflection in higher education: a concept analysis. Innovative Higher Education, 26(1), 37-57.

Rosaen, C. L., Lundeberg, M., Cooper, M., Fritzen, A., \& Terpstra, M. (2008). Noticing noticing: How does investigation of video records change how teachers reflect on their experiences? Journal of Teacher Education, 59(4), 347-360. 
Runhaar, P., \& Loeffen, E. (2009). Professionele ontwikkeling van leraren: Juist ook tijdens het werk. 's Hertogenbosch: KPC Groep.

Schön, D. A. (1983). The reflective practitioner: How professionals think in action. Aldershot, UK: Arena.

Schön, D. A. (1987). Educating the reflective practitioner. Jossey-Bass, San Francisco.

Schwille, J., Dembele, M., \& Schubert, J. (2007) Global perspectives on teacher learning: Improving policy and practice. Paris: UNESCO IIEP. Download: http://www.unesco.org/iiep/

Seashore Louis, K. (2001). Teachers' professional development for vital middle schools: What do we know and where should we go? Report of the Center for Applied Research and Educational Improvement, University of Minesota. Extracted 12-11-2007 from website: http://cehd.umn.edu/CAREI/Reports/default.html

Seidel, T., Stürmer, K., Blomberg, G., Kobarg, M., \& Schwindt, K. (2011). Teacher learning from the analysis of videotaped classroom situations: Does it make a difference whether teachers observe their own teaching or that of others? Teaching and Teacher Education, 27, 259-267.

Sherin, M. G. (2004). New perspectives on the role of video on teacher education. In J. Brophy (Ed.), Advances in research on teaching: Vol. 10: Using video in teacher education (pp. 1-27). Oxford, UK: Elsevier.

Sherin, M. G. (2007). The development of teachers' professional vision in video clubs. In R. Goldman, R. Pea, B. Barron, \& S. Derry (Eds.), Video research in the learning sciences (pp. 383-395). Hillsdale, NJ: Lawrence Erlbaum.

Sherin, M. G., \& Han, S. Y. (2004). Teacher learning in the context of a video club. Teaching and Teacher Education 20, 163-183.

Sherin, M. G., \& van Es, E. A. (2009). Effects of video club participation on teachers' professional vision. Journal of Teacher Education, 60(1), 20-37.

Showers, B., \& Joyce, B. (1996). The evolution of peer coaching. Educational Leadership, 53 (6), 12-16.

Shute, V. J., (2008). Focus on formative feedback. Review of Educational Research, 78(1).

Siegers, F. (2002). Handboek supervisiekunde. Houten/Mechelen: Bohn Stafleu Van Loghum.

Sipusic, M. (1994). Access to practice equals growth: Teacher participation in a video club. Paper presented at the annual meeting of the American Educational Research Association, New Orleans, LA.

Snow-Renner, R., \& Lauer, P. (2005). Professional development analysis. Denver, CO: MidContinent Research for Education and Learning.

Snoek, M. (2007). Leernetwerken: Hot of hype? Presentation, Velonconferentie, Amsterdam.

Sparks, D. (2004). The looming danger of a two-tiered professional development system. PHI Delta Kappan, 86(4), 304-308.

Sparks-Langer, G. M., \& Colton, A. B. (1991). Synthesis of research on teachers' reflective thinking. Educational Leadership, 48(6), 37-44.

Stenhouse, L. (1985). Research as a basis for teaching. London: Heinemann.

Sternberg, R. J., \& Caruso, D. R. (1985). Practical modes of knowing. In E. Eisner (Ed.), Learning and teaching the ways of knowing: Eighty-fourth yearbook of the national society for the study of education (pp. 116-132), Chicago: The National Society for the Study of Education. 
Stoll, L., Bolam, R., McMahon, A., Wallace, M., \& Thomas, S. (2006). Professional learning communities: A review of the literature. Journal of Educational Change, 7, 221-258.

Talbert, J. E., \& McLaughlin, M. (1994). Teacher professionalism in local school contexts. American Journal of Education, 102(2), 123-153.

Thomas, G., Wineburg, S., Grossman, P., Oddmund, M., \& Woolworth, S. (1998). In the company of colleagues: An interim report on the development of a community of teacher learners. Teaching and Teacher Education, 14(1), 21-32.

Thompson, M. (2010). Where reflection and motivation meet. Professional Development in Education, 36(3), 393-397.

Tigelaar, D. E. H., Dolmans, D. H. J. M., Meijer, P. C., de Grave, W. S., \& van der Vleuten, C. P. M. (2008). Teachers' interactions and their collaborative reflection processes during peer meetings. Advances in Health Sciences Education, 13(3), 289-308.

Timperley, H. S. (2005). Instructional leadership challenges: The case of using student achievement information for instructional improvement. Leadership and Policy in Schools, 4(1), 3-22 Retrieved: http://dx.doi.org/10.1080/15700760590924591

Timperley, H., Wilson, A., Barrar, H., \& Fung, I. (2007). Teacher professional learning and development: Best evidence synthesis iteration. Wellington, New Zealand: Ministry of Education. Retrieved: http://educationcounts.edcentre.govt.nz/goto/BES

Tochon, F. V. (1999). Video study groups for education, professional development, and change. Madison, WI: Atwood.

Tynjälä, P. (2008). Perspectives into learning at the workplace. Educational Research Review 3, 130-154.

Tynjälä, P., Välimaa, J., \& Sarja, A. (2003). Pedagogical perspectives on the relationships between higher education and working life. Higher Education, 46(2), 147-166.

van den Akker, J. (1999). Principles and methods of development research. In J. van den Akker, R. M. Branch, K. Gustafson, N. Nieveen, \& T. Plomp (Eds.). Design approaches and tools in education and training (pp. 1-4). Dordrecht: Kluwer Academics.

van den Akker, J., Gravemeijer, K., McKenney, S., \& Nieveen, N. (Eds.). (2006). Educational design research. London: Routledge.

van den Berg, E. (2001). An exploration of the use of multimedia cases as a reflective tool in teacher education. Research in Science Education, 31(2), 245-265.

van Driel, L. (2006). Professionalisering in school. Een studie naar verbetering van het pedagogisch-didactitisch handelen. Doctoral dissertation, Utrecht University.

van Eekelen, I. (2005). Teachers' will and way to learn. Studies on how teachers learn and their willingness to do so. Doctoral dissertation. Maastricht University.

van Eekelen, I., Vermunt, J. D., \& Boshuizen, H. P. A. (2006). Exploring teachers' will to learn. Teaching and Teacher Education, 22(4), 408-423.

van Es, E. A. (2006). Participants' roles in the context of a video club. Paper presented at the Annual Meeting of the American Educational Research Association, San Francisco, CA.

van Es, E. A., \& Sherin, M. G. (2002). Learning to notice: Scaffolding new teachers' interpretations of classroom interactions. Journal of Technology and Teacher Education, 10 (4), 571-596. 
van Es, E. A., \& Sherin, M. G. (2005). The influence of video clubs on teachers' thinking and practice. Paper presented at the Annual Meeting of the American Educational Research Association, Montreal, Canada.

Van Manen, M. (1991). The tact of teaching: The meaning of pedagogical thoughtfulness. Albany, NY: State University of New York Press.

van Veen, K., Zwart, R., Meirink, J. \& Verloop, N. (2010). Professionele ontwikkeling van leraren. Een reviewstudie naar effectieve kenmerken van professionaliseringsinterventies van leraren. Leiden University: ICLON, Expertisecentrum Leren van Docenten.

van Wessum, L. (1997). De sectie als eenheid: Samenwerking en professionaliteits- opvattingen van docenten in het voortgezet onderwijs. Doctoral dissertation. Utrecht University.

Veerman, J. W., \& van Yperen, T. A. (2007). Degrees of freedom and degrees of certainty: A developmental model for the establishment of evidence-based youth care. Evaluation and Program Planning 30, 212-221.

Verbiest, E., \& Vandenberghe, R. (2002). Professionele leergemeenschappen een nieuwe kijk op permanente onderwijsvernieuwing en ontwikkeling van leerkrachten. School en Organisatie, 1, 57-86.

Verloop, N., van Driel, J., \& Meijer, P. (2001). Teacher knowledge and the knowledge base of teaching, International Journal of Educational Research, 35(5), 441-461.

Villegas-Reimers, E. (2003). Teacher professional development: An international review of the literature. Paris: UNESCO International Institute for Educational Planning.

Walker, D. (2006). Towards productive design studies. In J. van den Akker, K. Gravenmeijer, S. McKenney, \& N. Nieveen (Eds.) Educational design research (pp. 8-13). London: Routledge.

Waslander, S. (2007). Leren over innoveren. Overzichtsstudie van wetenschappelijk onderzoek naar duurzaam vernieuwen in het voortgezet onderwijs. Utrecht, VO-project Innovatie.

Wasley, P., \& Hampel, R. (1997). The puzzle of whole-school change. PHI Delta Kappan, 78 (9), 690-697.

Webster-Wright, A. (2009). Reframing professional development through understanding authentic professional learning. Review of Educational Research, 79(2), 702-739.

Wenger, E. (1998). Communities of practice: Learning, meaning, and identity. Cambridge, UK: Cambridge University Press.

Wideen, M., Mayer-Smith, J., \& Moon, B. (1998). A critical analysis of the research on learning to teach: Making the case for an ecological perspective on inquiry. Review of Educational Research, 68(2), 130-178.

Windschitl, M. (2002). Framing constructivism in practice as the negotiation of dilemmas: an analysis of the conceptual, pedagogical, cultural, and political challenges facing teachers. Review of Educational Research, 72(2), 131-175.

Wilson, S., \& Berne, J. (1999). Teacher learning and the acquisition of professional knowledge: An examination of research on contemporary professional development. Review of Research in Education, 24, 173-209.

Wise, A. E., Darling-Hammond, L., McLaughlin, M. W., \& Bernstein, H. T. (1984). Teacher evaluation: A study of effective practice. Santa Monica, CA: Rand Corporation.

Witziers, B., Sleegers, P., \& Imants, J. (1999). Departments as teams; functioning, variations and alternatives. School Leadership and Management, 19, 293-304.

Wubbels, T. (1992). Taking account of student teachers' preconceptions. Teaching and Teacher Education, 8(2), 137-149. 
Yin, R. K. (2002). Case study research, design and methods, $3^{\text {rd }}$ ed. Newbury Park, Sage.

Yusko, B. P. (2008). The uses of digital video for collaborative teacher reflection and learning. Paper presentation Velonconference.

Zhang, M., Lundeberg, M., Koehler, M. J., \& Eberhardt, J. (2011). Understanding affordances and challenges of three types of video for teacher professional development. Teaching and Teacher education, 27, 454-462.

Zeichner, K. M., \& Noffke, S. (2001). Practitioner research. In V. Richardson (Ed), Handbook of research on teaching, $4^{\text {th }}$ ed. (pp. 298-332). Washington, DC: American Educational Research Association.

Zeichner, K. M. (2008). A critical analysis of reflection as a goal for teacher education. Educação Sociedade, 29(103), Download (20-6-2011), http://www. scielo.br/scielo.php?pid=S0101-73302008000200012\&script=sci_arttext\&tlng=en

Zwart, R. (2007). Teacher learning in a context of reciprocal peer coaching. Doctoral dissertation. Radboud University Nijmegen.

Zwart, R. C., Wubbels, T., Bergen, T. C. M., \& Bolhuis, S. (2007). Experienced teacher learning within the context of reciprocal peer coaching. Teachers and Teaching: Theory and Practice, 13, 165-187.

Zwart, R. C., Wubbels, T., Bolhuis, S., \& Bergen, Th. C. M. (2008). Learning through reciprocal peer coaching; an analysis of activity sequences. Teaching and Teacher Education, 24(4), 982-1002. 


\section{NEDERLANDSE SAMENVATTING Leren bij Nader Inzien Leraren coachen leraren met videofeedback}

\section{DOEL VAN HET ONDERZOEK EN PROBLEEMSTELLING}

Het onderwerp van deze studie kwam voort uit de behoefte van een school voor voortgezet onderwijs om werkplekleren van ervaren leraren een nieuwe stimulans te geven. Omdat traditionele nascholing in de vorm van cursussen en workshops vaak weinig rendement op blijkt te leveren, is gekozen voor een driejarig samenwerkingsproject tussen de school en een lerarenopleiding met als doel om werkplekleren in de school te ondersteunen. In dit samenwerkingsproject is in het kader van dit promotieonderzoek een professionaliseringsprogramma (PD) ontwikkeld, uitgevoerd en geëvalueerd.

Er is uitgebreid onderzoek gedaan naar het leren van docenten in verschillende en vaak ongerelateerde onderzoekstradities. Een van die onderzoekstradities is gericht op het professionaliseren van leraren en een andere op werkplekleren, maar er worden weinig onderlinge relaties tussen deze beide tradities gelegd (Hodkinson \& Hodkinson, 2005; Hoekstra et al., 2009). Voor dit promotieonderzoek zijn resultaten van beide onderzoeksrichtingen bestudeerd en gebruikt voor het opstellen van een coherente set van ontwerpprincipes en kenmerken voor een PD programma voor leraren in de school. De centrale onderzoeksvraag luidt:

Welke ontwerpprincipes en - kenmerken van een professionaliseringsprogramma (gebaseerd op reflectieve peer dialogen en video feedback) ondersteunen het werkplekleren van leraren? 
Om deze vraag te beantwoorden zijn twee deelvragen gesteld. De eerste vraag richt zich op het opsporen van wat er reeds bekend is over ontwerpprincipes en kenmerken van effectieve professionaliseringsprogramma's, de tweede vraag richt zich op het onderzoek naar de effectiviteit en bruikbaarheid van het ontwikkelde programma en een verdere verheldering van de werking van de onderliggende principes en kenmerken.

\section{ONDERZOEKSAANPAK}

In het onderzoek is gebruik gemaakt van ontwerponderzoek. Dit type onderzoek heeft als doel op onderzoek gebaseerde oplossingen te ontwikkelen voor complexe problemen uit de onderwijspraktijk en door het evalueren van deze oplossingen bij te dragen aan wetenschappelijke kennis. Ontwerponderzoek vindt in een aantal cycli en altijd in nauwe samenwerking met de schoolpraktijk plaats. Van cruciaal belang hierbij is om de belangrijkste ontwerpproblemen grondig te begrijpen, de meest veelbelovende kenmerken voor het ontwerp te identificeren, op basis hiervan prototypen te ontwerpen en deze in de praktijk uit te proberen (Walker, 2006).

Gestart is met een uitgebreid literatuuronderzoek naar principes en kenmerken van aantoonbaar effectieve professionaliseringsprogramma's. Op basis hiervan en in samenspraak met de school is een prototype ontwikkeld. Dit programma is een jaar lang met negen leraren in de school uitgevoerd en geëvalueerd. Op basis van de uitkomsten is het programma bijgesteld. Dit bijgestelde programma, genaamd 'Leren bij Nader Inzien', is twee jaar achter elkaar in dezelfde school uitgevoerd in twee verschillende contexten, eenmaal met leraren die zich vrijwillig hadden aangemeld en eenmaal met een team van leraren in het kader van een verplichte teamontwikkeling. Voor de evaluatie van het programma is gebruik gemaakt van het evaluatiemodel van Guskey (2000). Er is onderzocht of en hoe de kenmerken van het programma bijdroegen aan de uitkomsten: van de reacties van de deelnemers tot en met hun (veranderde) gedrag in de klas.

Ten behoeve van het valideren van de onderzoeksresultaten door middel van triangulatie is (a) het programma bij verschillende groepen uitgevoerd en (b) is gebruik gemaakt van verschillende onderzoeksinstrumenten zoals 
vragenlijsten, interviews, opnamen van coachgesprekken van leraren, verslagen van leraren over hun eigen praktijkgericht onderzoeken in de klas, onderzoeksnotities en observaties.

\section{RESULTATEN VAN HET ONDERZOEK}

\section{Ontwerpen van een theoretisch raamwerk}

In het literatuuronderzoek stond de eerste onderzoeksvraag centraal: "Welke ontwerpprincipes en kenmerken kunnen afgeleid worden uit de literatuur voor het construeren van professionaliseringsprogramma's die het werkplekleren effectief ondersteunen?" Vanuit drie deelstudies is een theoretisch raamwerk opgebouwd bestaande uit ontwerp principes en kenmerken voor een professionaliseringsprogramma voor leraren.

\section{Werkplekleren en reflectie}

Het eerste deel van de literatuurstudie richtte zich op het professionaliseren van leraren in de school. Hieruit kwamen twee belangrijke aspecten naar voren: werkplekleren en de leraar als reflecterende professional.

Ten eerste, leraren leren voornamelijk non-formeel van hun handelen en ervaringen in de dagelijkse onderwijspraktijk. Dit werkplekleren gebeurt vaak ongemerkt tijdens het werk in interactie met de sociale werkomgeving. Hoewel werkplekleren de belangrijkste bron van leren van leraren vormt, is dit leren niet erg proactief en kan resulteren in verbeteringen van eigen handelen, maar ook in het aanleren van slechte of niet (meer) effectieve gewoonten. De leeropbrengsten zijn minder gecontroleerd en bestaan vooral uit impliciete kennis en routinehandelingen. Dit in tegenstelling tot het meer formeel leren op school en tijdens traditionele nascholing waarbij de leerdoelen van te voren zijn vastgesteld, opbrengsten vooral bestaan uit expliciete kennis en het leerproces voor een groot deel door anderen wordt gecontroleerd. Wat bij deze vorm van leren vaak tegenvalt, is de transfer van de leersituatie naar het handelen in de werksituatie.

Het onderscheid tussen formeel en non-formeel leren is niet absoluut en een professionaliseringsprogramma kan het best kenmerken van beide vormen van leren inbouwen om meerdere redenen: 
- Reactief en incidenteel werkplekleren vindt voornamelijk onbewust plaats en levert vooral impliciete kennis en routines. Deze leerresultaten zijn moeilijk te veranderen daar waar dat wenselijk is, bijvoorbeeld daar waar slechte gewoontes zijn aangeleerd of routines niet meer effectief zijn door veranderende leerlingen en omstandigheden.

- In de huidige tijd veranderen de scholen en het vak van onderwijzen in een rap tempo. Impliciet en reactief werkplekleren kan onvoldoende garanderen dat de ontwikkeling van de kennis en kunde van leraren dit tempo bij kan houden.

- Het koppelen van meer doelbewuste en geplande leeractiviteiten aan werkplekleren in de context van de school kan helpen om het non-formele leren meer te structureren en impliciete kennis te expliciteren. In professionaliseringsprogramma's is het gewenst om het informele werkplekleren aan te vullen met het gezamenlijk expliciteren van en reflecteren op eigen handelen en denken. Expliciete kennis kan gedeeld worden met collega's en kan leiden tot een verdere ontwikkeling van expertise bij leraren.

Reflecteren houdt in: het evalueren van het eigen handelen in de klas, inclusief vanzelfsprekend lijkende routines en vooronderstellingen, gerelateerd aan de bedoelde en onbedoelde uitkomsten van eigen handelen in de klas. In de literatuur werden diverse reflectiemodellen gevonden. Deze onderstrepen het belang van een brede reflectie, waarin niet alleen hoe-vragen geanalyseerd worden, maar ook wordt gereflecteerd op emoties, overtuigingen, motieven, morele en politieke vraagstukken en vanuit verschillende perspectieven wordt gekeken naar de onderwijspraktijk. Inherent aan de aard van het onderwijzen is dat de persoon van de leraar even belangrijk is als zijn kennis, kunde en houding. Reflectie is gericht op het verbeteren van de praktijk en is verbonden met feedback en het onderzoeken van bewijzen voor aannamen en conclusies.

\section{Review studies van professionaliseringsprogramma's voor leraren}

Het tweede deel van het literatuuronderzoek richtte zich op negen review studies naar kenmerken van effectieve professionaliseringsprogramma's voor leraren. Op basis van de uitkomsten van dit onderzoek zijn vijf basisprincipes geformuleerd voor het ontwerpen van een programma:

A. samenwerkend leren op de werkplek, in de vorm van wederzijdse peer coaching;

B. een focus op de eigen praktijk met behulp van video feedback; 
C. de leraar is eigenaar van zijn eigen leerdoelen;

D. een focus op een onderzoekende houding en op onderzoek van leraren in de eigen klassenpraktijk;

E. het creëren van gunstige condities voor professionalisering en voor het programma in de school.

\section{Ontwerpen van een conceptueel raamwerk}

Het derde deel van het literatuuronderzoek richtte zich op een aanvullende studie naar elk van de vijf basisprincipes. Dit deel van het literatuuronderzoek liep parallel aan het gehele onderzoek. Gezocht is naar nadere aanbevelingen voor het ontwerp van het programma en naar gegevens om de werking van de verschillende principes beter te kunnen begrijpen en beter te kunnen vertalen in concrete kenmerken van het ontwerp.

\section{Ontwerpen van een professionaliseringsprogramma}

Gebruikmakend van de resultaten van het literatuuronderzoek is in samenspraak met de school een professionaliseringsprogramma ontwikkeld en drie jaar achter elkaar uitgevoerd. Centraal stond de tweede onderzoeksvraag: "Wat is de effectiviteit en de bruikbaarheid van het ontworpen professionaliseringsprogramma voor het ondersteunen van het werkplekleren van leraren?"

\section{Ontwerp en evaluatie van het prototype}

In het eerste jaar is een prototype ontwikkeld bestaande uit twee delen. In een deel bediscussieerden leraren gezamenlijk eigen (geanonimiseerde) praktijkvoorbeelden rond een aantal kenmerkende beroepssituaties. In het andere deel observeerden en bespraken de leraren in drietallen video-opnamen van eigen klassensituaties. Het programma was verspreid over het schooljaar en de beide onderdelen wisselden elkaar af. Uit de evaluatie van het programma bleek dat het programma de leraren had gestimuleerd om te reflecteren en van elkaar te leren. Belangrijkste conclusies voor het herontwerp van het programma:

- Alle leraren gaven aan het meest geleerd te hebben van het tweede onderdeel van het programma (wederzijds coachen met video feedback) en bevalen aan het eerste deel van het programma te laten vervallen ten gunste van het tweede deel.

- Het trainen van de coach rol verdiende meer aandacht.

- Het is aan te bevelen dat leraren die door hun hiërarchische positie of door hun kennis en expertise binnen de groep deelnemers een hogere status hebben het 
voorbeeld geven en als eerste ter bespreking video-opnamen van hun eigen klassen inbrengen inclusief sterke en zwakke punten. Als zij laten zien ook nog lerend te zijn, dan vergroot dat het gevoel van veiligheid in de groep en stimuleert het anderen om ook hun klassenpraktijk open te stellen voor elkaar.

- De volgende aspecten waren belangrijk voor de facilitering van het programma: tijd en gereserveerde tijden in het lesrooster om gezamenlijke activiteiten te plannen; contracten en kleine bonussen om de betrokkenheid van deelnemers ook in drukke tijden te helpen vasthouden; en de combinatie van een externe en een interne begeleider in het programma, omdat deze elkaar versterken.

- Het was onduidelijk of het programma ook resultaten had op het niveau van de klassen- praktijk. Aanvullende richtlijnen zijn nodig om leraren te stimuleren om in hun eigen klassen te experimenteren en resultaten te onderzoeken.

De leerresultaten bleken samen te hangen met de ervaring van de docenten. Beginnende leraren voelden hun zelfvertrouwen versterkt door de activiteiten in het programma. Ze voelden zich ondersteund, merkten dat ook collega's nog aan het leren waren en merkten bij de video feedback allerlei zaken op die beter gingen dan ze zelf in hun herinnering hadden. Ze vergeleken hun huidige lessen met de start en ontdekten dat hun competenties inmiddels gegroeid waren. In tegenstelling hiermee verwachtten de ervaren leraren dat hun lessen weinig problemen zouden kennen. Deze leraren werden zich door de video feedback bewust van aspecten van sleur en versleten klassenroutines in hun lessen.

\section{Ontwerp van het professionaliseringsprogramma "Leren bij Nader Inzien"}

Het bijgestelde programma omvatte zes centrale bijeenkomsten waarin de leraren werden getraind in coachen en in praktijkgericht onderzoek doen. Tevens was er aandacht voor het door de leraren aan elkaar presenteren van de resultaten van hun leerproces en praktijkgericht onderzoek. Tussen deze bijeenkomsten door coachten de leraren elkaar in drietallen wederzijds met behulp van video feedback. Er waren goed omschreven rollen van leerder, coach en observant van het coachproces. De drietallen waren heterogeen samengesteld (leraren verschilden in ervaring en vakgebied) door de trainers van het programma. De leerdoelen werden door de betrokken leraar zelf bepaald. De leraren werd gevraagd om naast hun gesprekken ook kleine praktijkgerichte onderzoeken te doen in hun eigen klas gerelateerd aan het 
eigen leerdoel. In het tweede onderzoeksjaar namen negen leraren op basis van vrijwilligheid deel aan dit bijgestelde programma en in het derde jaar nam een team bestaande uit 17 leraren op basis van een verplichte teamontwikkeling deel. Bijna alle activiteiten in het programma werden door de leraren in eigen vrije tijd uitgevoerd.

\section{Evaluatie van het programma "Leren bij Nader Inzien"}

Het programma werd geëvalueerd op het niveau van (1) reacties op het programma, (2) leeropbrengsten van leraren, (3) veranderingen in eigen gedrag in de klas en resultaten bij leerlingen, (4) de condities binnen en de impact op de school.

Hoe reageerden de leraren op het programma? (evaluatievraag 1)

De leraren waren positief over hun samenwerking en het 'kijken in elkaars keuken'. Voor het programma startte zagen leraren vaak op tegen het laten maken van video opnamen in hun eigen klas, maar achteraf waren ze zo goed als unaniem in hun oordeel over video feedback als een erg rijke en zinvolle leerervaring. Ze waardeerden het peer coach proces, maar vonden het goed coachen van collega's moeilijk. Enkele leraren waren niet geheel tevreden met het coachen van hun collega en klaagden over gebrek aan inspanning (moeilijk afspraken mee te maken), gebrek aan toewijding (altijd met een schuin oog naar de klok kijkend), en het overnemen van het eigenaarschap door een collega uit de zelfde vaksectie (je bent nieuw hier, luister en leer hoe we dit hier geregeld hebben) en het afbrokkelen van vertrouwen omdat een collega zichzelf niet als lerend zag (alles gaat goed in mijn klassen, dus laten we over jouw klassen praten).

De leraren waren achteraf positief over het samenstellen van de subgroepen door de trainers hoewel sommigen bij de start van het programma liever de groepen zelf hadden samengesteld. Als voordelen noemden ze onder andere dat nieuwe collega's gelijk opgenomen werden en dat het hielp om een echte professionele leergroep te worden en niet een gezelligheidsclub.

Het minst in trek was het doen van praktijkgericht onderzoek. Het moeten presenteren van eigen leerproces en praktijkgericht onderzoek stimuleerde leraren om er aandacht aan te besteden. Leraren hadden echter de neiging dit uit te stellen en verschoven de rapportage naar het eind van het schooljaar, een periode waarin afspraken moeilijk te plannen waren en iedereen het druk had 
met extra taken rond buitenland reizen, eindexamens en proefwerken. In het laatste jaar (verplichte teamactiviteit) hadden echter niet alle leraren een praktijkgericht onderzoek uitgevoerd. Dit belemmerde het leren van elkaar en de discussie over de resultaten.

De leraren die op basis van vrijwilligheid deelnamen waren tijdens de evaluatie over het algemeen duidelijk positiever in hun evaluaties dan de leraren die deelnamen als verplichte teamactiviteit. Deelname in deze groep werd gehinderd doordat sommige leraren zich verzetten tegen het verplichte karakter, wantrouwend waren door de gelijktijdige verplichte invoering van portfolio's, of niet genoeg tijd hadden in verband met specifieke privé of werkomstandigheden.

Welke leeropbrengsten rapporteerden de leraren als resultaat van hun activiteiten in het programma? (evaluatievraag 2)

Aan het eind van het programma vonden bijna alle leraren dat hun professionele ontwikkeling gestimuleerd was en dat ze geleerd hadden van het programma. Leraren hadden gewerkt aan verschillende doelen, zoals het leren van nieuwe werkvormen, klassenmanagement en omgaan met verschillen in de klas. Leraren leerden ook zaken los van hun persoonlijke leerdoelen, zoals coachtechnieken en communicatievaardigheden. Ze deden nieuwe ideeën op en voelden zich meer verbonden met en stonden ook meer open voor de inbreng van hun collega's. Vooral de coach- en communicatievaardigheden werden gezien als een extra, onverwachte bonus, en leraren meldden dat ze deze nieuwe vaardigheden ook gebruikten in andere werksituaties.

Het bleek moeilijker dan van te voren was ingeschat om de eigen leerdoelen vast te stellen. Vaak waren er peer coach gesprekken en/ of een vooronderzoek nodig om te ontdekken wat er achter de schijnbaar simpele vraag allemaal meespeelde (zowel in de situatie als in eigen aannamen, vooronderstellingen en motieven) en om de eigenlijke leerbehoefte te definiëren.

Er waren duidelijke verschillen met betrekking tot concrete leerresultaten tussen de leraren binnen de groep die deelnam in het kader van een verplichte teamactiviteit. Sommigen vermeldden veel verschillende leerresultaten en anderen noemden slechts een enkel concreet leerresultaat. 
Welke veranderingen in eigen professioneel gedrag en/of resultaten in het leren van hun leerlingen rapporteerden de leraren als resultaat van hun activiteiten in het programma? (evaluatievraag 3 )

In de evaluatie rapporteerden leraren dat hun samenwerking met collega's versterkt was, dat de deuren van hun klaslokaal naar elkaar open gezet waren en dat ze meer reflecteerden op hun lessen en op de leerresultaten van hun leerlingen; kenmerken die voorspellend zijn voor het verbeteren van de schoolpraktijk en leerlingresultaten (Bryk et al., 2009; Marks \& Kruse, 1996). Daarnaast rapporteerden de leraren ook concrete verbeteringen in de klas.

Veel docenten $(75 \%)$ gaven aan dat ze directe leerresultaten bij hun leerlingen zagen als gevolg van hun activiteiten in het programma. Meestal betrof dat verbeteringen in leeractiviteiten, gedrag van hun leerlingen en in het klassenklimaat. Een klein aantal leraren meldde in hun praktijkgericht onderzoek directe verbeteringen in leerresultaten en toetsresultaten van hun leerlingen te hebben waargenomen.

De praktijkgerichte onderzoeken startten bijna altijd met 'hoe-vragen', maar de wijze waarop leraren hun praktijkgericht onderzoek uitwerkten verschilde sterk. Iedereen maakte op de een of andere wijze gebruik van videodata voor het verhelderen van het probleem, en/of voor het registreren van experimenten en vooruitgang, en/of voor het presenteren van hun leerproces aan elkaar. Daarnaast gebruikten de leraren in hun praktijkgerichte onderzoeken andere instrumenten zoals: observaties, toetsresultaten, leerling-vragenlijsten en leerling-interviews.

De coachtraining bleek onverwachts ook directe opbrengsten te hebben voor de leraren buiten het programma. Leraren meldden dat ze hun nieuw verworven communicatie vaardigheden direct gebruikten in de klas bijvoorbeeld bij het doorvragen in de klas om het denken van leerlingen te stimuleren en in andere professionele werksituaties zoals gesprekken met ouders.

Realiseerde de school de noodzakelijke condities voor het programma en had het programma invloed op de schoolorganisatie? (evaluatievraag 4)

Het realiseren van gunstige omstandigheden in de school bleek moeilijk. Leraren kregen tijd om deel te nemen aan de plenaire bijenkomsten, maar moesten verdere activiteiten zoals opnamen maken in elkaars klassen, de gesprekken in subgroepen en het praktijkgericht onderzoek in hun eigen vrije tijd doen. In de eerste twee jaren kregen de leraren een kleine geldelijke 
beloning aan het eind van het jaar als blijk van waardering. De vele wisselingen in het schoolmanagement doorbraken de gewenst continue aandacht en interesse voor deelnemers vanuit schoolleiders. Daarnaast had het programma in het derde jaar te lijden onder negatieve gevoelens in de school over het gelijktijdig introduceren van verplichte leraren portfolio's.

Het realiseren van gunstige omstandigheden in het programma is wel gerealiseerd. Met behulp van de ontwerpprincipes werd een veilige en stimulerende leeromgeving gecreëerd. Vooral het goed functioneren van de peer coach was bepalend voor de diepgang en leerrendement van de dialoog. Delen van het programma en met name het werken met videofeedback, vond ingang in de school en bleef in gebruik ook nadat het programma geëindigd was.

\section{THEORETISCHE EN PRAKTISCHE IMPLICATIES}

Gebaseerd op bovenstaande evaluaties, is de eindconclusie met betrekking tot de onderzoeksvraag, dat alle vijf de ontwerpprincipes en kenmerken - zoals ze afgeleid zijn uit de literatuur en geïntegreerd zijn in het programma - belangrijk zijn voor het leren van leraren in de context van de school. De beschrijving en de uitkomsten van dit onderzoek stellen anderen, zoals schoolleiders, in staat om het professionaliseringsprogramma aan te passen aan de eigen schoolcontext. De volgende conclusies in relatie met de ontwerpprincipes en kenmerken kunnen worden gelezen als aanbevelingen voor het ontwerpen van professionaliseringsprogramma's voor leraren in de school.

A. Samenwerkend leren op de werkplek, in de vorm van wederzijdse peer coaching:

- Relateer professionalisering direct aan de eigen werksituatie van leraren en aan de leerdoelen en leerbehoeften van de betrokken leraren.

- Essentieel is een open leeromgeving gebaseerd op onderling vertrouwen, gelijkwaardigheid en ondersteunen van elkaar. Falen en fouten maken tijdens het leren mag.

- Elkaar toegang geven tot eigen klassenpraktijk.

- Coachen met nadruk op open vragen, doorvragen, luisteren en empathie.

- Dialogen in drietallen met goed omschreven rollen van leerder, peer coach en observant van de peer coach dialoog.

- Trainen van de coachrol. 
B. Een focus op de eigen praktijk met behulp van video feedback:

- De video als rijke bron van feedback: in eigendom van de leraar zelf, zo vaak te bekijken als gewenst en rijk materiaal als input voor de coach dialoog.

- Neem genoeg tijd voor de dialoog om de video te gebruiken als bron om eigen handelen, achtergronden en resultaten samen te onderzoeken.

C. De leraar is eigenaar van zijn eigen leerdoelen:

- Erkennen van de verschillen tussen individuele leraren met relatie tot leerdoel, startpunt en leertempo.

- Professionalisering is gericht op het verbeteren van de eigen praktijk. Om eigen praktijk te verbeteren is het wenselijk om zowel te reflecteren op eigen handelen als op de onderliggende aannamen, vooronderstellingen, waarden en motieven, en om werksituaties te analyseren vanuit verschillende perspectieven.

- Een duidelijke rolomschrijving van de coach als 'volger' tijdens het coachproces de leraar eigenaar latend van zijn eigen leerdoel, is essentieel. De peer coach vraagt door, maar geeft geen evaluaties.

- Eigenaarschap wordt pas professionalisering als de leraar actieve betrokkenheid neemt voor eigen leerdoel en leerproces (taking agency).

D. Een focus op een onderzoekende houding en op praktijkgericht onderzoek van leraren in de eigen klassenpraktijk:

- Onderzoek heeft als doel concrete verbeteringen van de eigen praktijk.

- Focus is een onderzoekende grondhouding voor het beroep. Praktijkgericht-onderzoek-als-houding wordt in alle verschillende activiteiten in het programma gestimuleerd.

- Praktijkgericht onderzoek-als-project moet zorgvuldig gepland worden:

- Training en/of begeleiding bij het verwerven van noodzakelijke onderzoeksvaardigheden.

- Stapsgewijze planning van het praktijkgericht onderzoek afgestemd op schooljaarprogramma. Coaching is nodig om te voorkomen dat het praktijkgerichte onderzoek te lang op de plank blijft liggen, dat er onvoldoende tijd voor gereserveerd wordt, of dat het onderzoek te weinig vooruit gepland wordt.

- Belangrijk is rapportage en presenteren van eigen leerproces en praktijkgericht onderzoek aan elkaar. Planning van de presentaties en actieve uitwisseling is moeilijk te realiseren in de laatste drukke periode van het schooljaar en zou meer in stappen tijdens het jaar gepland kunnen worden. 
E. Het creëren van gunstige condities voor professionalisering en voor het programma in de school:

- Zorg voor goede faciliteiten: tijd, roosterband voor activiteiten, camera's en mogelijk een trigger (kleine beloning en/of contract) om de aandacht gedurende het jaar bij het programma te houden.

- Een combinatie van een interne en externe trainer/begeleider. Een goed gekozen interne begeleider kan vertrouwen in het programma scheppen en het karakter van werkplekleren in de school bewaken; een externe trainer kan zorgen voor een adequate coachtraining en (indien gevraagd) extra input vanuit een specifieke deskundigheid.

- Schoolleiders die gedurende het hele programma belangstelling tonen naar deelnemers en ondersteuning bieden.

- Balans tussen vrijwillige en min of meer verplichte deelname. Het programma werkt beter bij vrijwillige deelname, maar in verband met school- en teamontwikkeling is het functioneel om ook zo veel mogelijk andere leraren proberen te verleiden tot actieve deelname in het programma.

- Personen met macht en prestige, bijvoorbeeld schoolleiders, teamleiders of experts in de school, die zelf deelnemen aan het programma, eigen praktijk openen (video beelden) en problemen en leervragen uit eigen praktijk delen, en zo laten zien dat iedereen fouten mag maken en nog lerend is.

\section{Toekomstig onderzoek}

Ten eerste heeft het onderzoek een concreet programma opgeleverd voor het professionaliseren van leraren in de context van de eigen school en klas. Het programma creëert een rijke leeromgeving die samenwerking en open dialogen tussen leraren mogelijk maakt en een onderzoekende houding en betrokkenheid bij eigen professionele ontwikkeling bij leraren stimuleert. Toekomstig onderzoek moet uitwijzen in hoeverre de aangereikte leerstrategieën, zoals het gebruik van video feedback, wederzijds coachen en praktijkgericht onderzoek, ook na 2, 5 of 10 jaar nog door de leraren gebruikt worden voor eigen professionalisering. We hebben ook lange termijn onderzoek naar het leren van leraren nodig.

Ten tweede hebben de studies een aantal gevalideerde ontwerpprincipes en kenmerken van effectieve programma's geïdentificeerd, en wel: wederzijds peer 
coachen, video feedback, de leraar als eigenaar van eigen leerdoelen, praktijkgericht onderzoek, en het creëren van gunstige condities in de school. De studies in dit proefschrift hebben het inzicht vergroot in de werking van deze onderliggende ontwerpprincipes bij professionalsering van leraren in het voortgezet onderwijs. Daarnaast zouden deze principes en kenmerken relevant kunnen zijn voor professionaliseringsprogramma's voor andere beroepsgroepen van docenten zoals docenten in het middelbaar - of hoger onderwijs.

Het onderzoek sluit aan bij het werkplekleren van leraren die als professionals in hun werk zelfstandig gefundeerde beslissingen moeten nemen in complexe werksituaties, een werksituatie die overeenkomsten heeft met professionals in beroepsgroepen buiten het onderwijs zoals de verpleging of de medische sector.

Aanbevolen wordt om de principes en kenmerken als uitgangspunt te nemen voor ontwerponderzoek naar professionalisering bij andere beroepsgroepen.

Ten derde heeft het onderzoek aangetoond dat leraren in de school elkaar effectief kunnen coachen en ondersteunen en het heeft een aantal kernfactoren geïdentificeerd hoe deze peer coaching effectief kan worden. Essentieel zijn het wederzijdse karakter van peer coachen in het programma, de wel omschreven rollen voor de dialogen in drietallen, een goede training van de leraren in coach- en communicatievaardigheden, de rol van de observant en het na afloop evalueren van de coachdialoog. Deze nieuw verworven coach- en communicatievaardigheden blijken ook bruikbaar in andere professionele werksituaties zoals bij het begeleiden van leerlingen in de klas en in oudergesprekken. Competenties zoals luisteren, geven van feedback aan leerlingen en doorvragen op antwoorden om het denken en reflecteren bij leerlingen te stimuleren, zijn essentiële competenties voor leraren. Het bestaande programma blijkt de professionalisering van leraren hierin te stimuleren. Veelbelovend lijkt een aangepast ontwerp van het programma, dat specifiek gericht is op het verder ontwikkelen van dit soort begeleidingscompetenties bij leraren. Het is aan te bevelen om dit met behulp van ontwerponderzoek verder uit te zoeken.

Ten vierde blijkt video feedback een heel rijke bron te zijn voor het leren van leraren. Daarbij doorbreekt video feedback het 'public loneliness' karakter van het beroep, waarin leraren weinig mogelijkheden hebben om andere 
professionals aan het werk te zien. Video feedback blijkt een zeer krachtig hulpmiddel bij het ontwikkelen van een leergemeenschap in de school doordat het leraren helpt om van en met elkaar te leren en hun praktische kennisbasis te vergroten. Kleine en goedkope videocamera's zijn tegenwoordig in overvloed beschikbaar. Het is aan de beroepsgroep om hier standaard gebruik van te gaan maken voor hun professionalisering.

Het is aan te bevelen om ontwerponderzoek te doen naar factoren die het gebruik van video feedback voor professionalisering op de werkplek verder stimuleren. 


\section{APPENDICES}

\section{APPENDIX 1:}

Questionnaire on part 1 the 'Expert Meetings'

(Prototype PD program)

(Chapter 4)

\section{APPENDIX 2:}

Questionnaire on part 2 the 'Reciprocal peer coaching with video feedback'

(Prototype PD program)

(Chapter 4)

\section{APPENDIX 3:}

Post-verification questionnaire

(Prototype of PD program)

(Chapter 4)

\section{APPENDIX 4:}

Questionnaire

(PD program 'Learning to Notice')

(Chapter 5)

\section{APPENDIX 5:}

Interview protocol of the semi-structured interviews

(PD program 'Learning to Notice')

(Chapter 5)

APPENDIX 6:

Overview of individual teacher's inquiries

(PD program 'Learning to Notice')

(Chapter 6) 


\section{APPENDIX 1 \\ Questionnaire on part 1 the 'Expert Meetings' (prototype PD program) (Chapter 4)}

Vragenlijst ten behoeve van flankerend onderzoek Assessment

\section{A. Kennis van methode en gehanteerde begrippen}

1. Ik ben op de hoogte van de wet $\mathrm{BIO}$

(Beroepen in het onderwijs)

2. Het begrip kenmerkende beroepssituatie is bekend

3. Het begrip competentie is bekend

4. Op mijn school is er sprake van competentiegericht leren.

5. Ik ben betrokken bij competentiegericht leren

6. De achtergrondinformatie (cirkel en competenties) is interessant

7. De achtergrondinformatie (cirkel en competenties) is duidelijk

\section{B. Opbrengsten van de methode}

De expertsessies leveren het volgende op:

Voor het Ruud de Moorcentrum:

8. De set beschrijvingen van kenmerkende beroepssituaties is herkenbaar

9. De resultaten zijn duidelijk omschreven

10. De gedragingen die nodig zijn om de resultaten te bereiken zijn goed omschreven

11. Het overzicht van deze gedragingen gekoppeld aan de SBL competenties (de competentiematrix) is duidelijk

12. Deze methodiek is een goede manier om de dagelijkse praktijk van een docent te beschrijven

$\begin{array}{llll}\mathbf{1} & \mathbf{2} & \mathbf{3} & \mathbf{4} \\ \text { zeer mee } & \text { mee } & \text { mee } & \text { zeer mee } \\ \text { eens } & \text { eens } & \text { oneens } & \text { oneens }\end{array}$

$\begin{array}{llll}0 & 0 & 0 & 0\end{array}$

$\begin{array}{llll}0 & 0 & 0 & 0\end{array}$

$0 \quad 0 \quad 0 \quad 0$

$0 \quad 0 \quad 0 \quad 0$

$0 \quad 0 \quad 0 \quad 0$

$0 \quad 0 \quad 0 \quad 0$

$\begin{array}{llll}0 & 0 & 0 & 0\end{array}$

13. Anders 
Voor mijzelf:

14. Ik leer te reflecteren door te verwoorden en verduidelijken van wat ik in mijn lesgeven doe en waarom $\begin{array}{lllll}0 & 0 & 0 & 0\end{array}$

15. Ik leer helder te kunnen verwoorden wat mijn gedachten zijn

16. Ik bezit meer theoretische kennis

$\begin{array}{llll}0 & 0 & 0 & 0\end{array}$

17. Ik gebruik deze methode om te kijken hoe collega's werken en om daarvan te leren

18. Ik wissel kennis uit met collega's

$\begin{array}{lll}0 & 0 & 0\end{array}$

19. Ik sta weer eens stil bij bepaalde onderdelen die er zijn ingeslopen en eigenlijk op automatisme gebeuren

20. Anders

C. Hoe denkt men over zichzelf en de ander: relatieve positie Welke kwaliteiten denk je dat een expert voor onze sessies dient te hebben?

21. Gemotiveerd zijn om mee te denken over de te volgen methodiek

22. Consciëntieus zijn

23. Een aantal jaren onderwijservaring hebben

24. Goed kunnen verwoorden, duidelijk kunnen uitleggen

25. Een rijke theoretische achtergrond hebben

26. Zich kwetsbaar durven opstellen

27. Open staan voor andere meningen/opvattingen

28. Anderen kunnen motiveren

29. Goed kunnen luisteren

30. Goed kunnen samenvatten

31. Goed kunnen nadenken over eigen handelen

32. Een gemotiveerd iemand zijn die nog steeds bezig is met allerlei ontwikkelingen / vernieuwingen in onderwijs

$\begin{array}{llll}0 & 0 & 0 & 0 \\ 0 & 0 & 0 & 0 \\ 0 & 0 & 0 & 0 \\ 0 & 0 & 0 & 0 \\ 0 & 0 & 0 & 0 \\ 0 & 0 & 0 & 0 \\ 0 & 0 & 0 & 0 \\ 0 & 0 & 0 & 0 \\ 0 & 0 & 0 & 0 \\ 0 & 0 & 0 & 0 \\ 0 & 0 & 0 & 0 \\ 0 & & & \\ 0 & 0 & 0 & 0 \\ 0 & 0 & 0 & 0 \\ 0 & 0 & 0 & 0\end{array}$

33. Iemand die voor veranderingen open staat

34. Iemand die mondig is

35. Anders

Welke kwaliteiten denk je dat de gespreksleider voor onze sessies dient te hebben?

36. Goed kunnen verwoorden, duidelijk kunnen uitleggen

37. Zich kwetsbaar durven opstellen

38. Durven in te grijpen bij discussies

39. Open staan voor andere meningen/opvattingen

40. Anderen kunnen motiveren

41. Goed kunnen luisteren

42. Goed kunnen samenvatten

43. Een aantal jaren onderwijservaring hebben

44. Een rijke theoretische achtergrond hebben

45. Anders 


\section{Hoe wordt de methode beleefd?}

46. Deze werkwijze is een goede methode om de

kenmerkende situaties in kaart te brengen.

47. De cirkel maakt het duidelijk en compleet.

$\begin{array}{llll}0 & 0 & 0 & 0 \\ 0 & 0 & 0 & 0 \\ 0 & 0 & 0 & 0 \\ 0 & 0 & 0 & 0 \\ 0 & 0 & 0 & 0 \\ 0 & 0 & 0 & 0 \\ 0 & 0 & 0 & 0 \\ 0 & 0 & 0 & 0\end{array}$

48. De methode van de expertsessie vind ik nieuw en verrassend

49. Ik vind de tijdsbesteding voor de opdrachten reëel

50 . Ik heb problemen om de opdrachten digitaal te verwerken

51. Ik vind het gekozen tijdstip gunstig

52. Ik vind de tijdsduur van de sessie voldoende

53. Ik vind het aantal personen geschikt

54. Ik vind de gespreksleider geschikt voor het leiden van de sessies

55. Anders

\section{E. Hoe wordt met de methode gewerkt? Strategie}

56. Hoe heeft $\mathrm{u}$ de huiswerkopdracht verwerkt?

a. Ik werk de opdracht uit zoals hij gegeven is: dus eerst de algemene situatie, dan het resultaat, dan naar mijn eigen situatie, dan complexiteit en dan naar de gedragsindicatoren.

b. Gegeven is de algemene situatie. Ik begin bij het resultaat, dan naar mijn eigen situatie, dan complexiteit en dan naar de gedragsindicatoren.

c. Gegeven situatie, welk resultaat wil ik, welke situatie is van belang. Daarna laat ik me leiden door de complexiteit, om vervolgens de gedragsindicatoren (dus mijn manier van handelen te bepalen) samen te stellen.

d. Ik vind het prettig als situatie gegeven is en eventueel ook het beoogde resultaat. Zelf uitzoeken met welk gedrag je dit zou kunnen bereiken en welke complexiteitsfactoren een rol spelen.

e. Gegeven situatie, resultaat, eigen situatie, dan nagaan wat maakt de eigen situatie makkelijk of moeilijk, welk gedrag toon ik om het resultaat te bereiken.

f. Ik beschrijf eerst mijn eigen situatie en bepaal daarvan de gewenste resultaten, complexiteitsfactoren en gedragingen.

g. Ik houd me niet aan een bepaalde volgorde, bekijk dit per keer

h. Anders

Mijn werkwijze past het beste bij 


\section{F. Persoonlijke motieven}

57. Ik vond het leuk om mee te doen

$\begin{array}{llll}0 & 0 & 0 & 0\end{array}$

58. Ik vond het zinvol om mee te doen

$\begin{array}{llll}0 & 0 & 0 & 0\end{array}$

59. Ik vond de sfeer goed

$\begin{array}{llll}0 & 0 & 0 & 0\end{array}$

60. Ik wil betrokken blijven bij dit project

0

61. Mogen we je dus nog eens vragen

0 ja

0 nee

\section{G. Algemene gegevens}

1 Naam:

2 Geslacht:

0 Man

0 Vrouw

3 Leeftijd:

0 tussen de 20 en 30 jaar

0 tussen 30 en 40 jaar

0 tussen 40 en 50 jaar

0 boven de 50 jaar

4 Werkzaam bij schooltype:

0 PO

$0 \mathrm{VMBO}$

$0 \mathrm{MBO} / \mathrm{BVE}$

$0 \mathrm{VO}$ onderbouw

$0 \mathrm{VO}$ bovenbouw

$0 \mathrm{HBO} / \mathrm{WO}$

5 Aantal jaren werkzaam in het onderwijs:

0 korter dan 2 jaar

0 tussen de 2 en 5 jaar

0 tussen de 5 en 10 jaar

0 tussen de 10 en 15 jaar

0 langer dan 15 jaar

6 Vak: 


\title{
APPENDIX 2 \\ Questionnaire on part 2: \\ the 'Reciprocal peer coaching with video feedback' (prototype PD program) (Chapter 4)
}

\author{
Deel 1 \\ De vragen in deel 1 gaan over de vier gemeenschappelijke bijeenkomsten op de maandagmiddag waarin \\ we gewerkt hebben aan collegiaal ondersteund leren (col) met behulp van video-opnamen.
}

\begin{tabular}{|c|c|c|c|c|c|}
\hline \multicolumn{6}{|c|}{$\begin{array}{l}\text { A. Het trainen in het houden van col-gesprekken } \\
\text { In het intervisietraject zijn een aantal gemeenschappelijke bijeenkomsten gebruikt voor het trainen in 'het } \\
\text { voeren van col-gesprekken'. }\end{array}$} \\
\hline & & $\begin{array}{c}1 \\
\text { zeer } \\
\text { mee } \\
\text { eens }\end{array}$ & $\begin{array}{l}2 \\
\text { mee } \\
\text { eens }\end{array}$ & $\begin{array}{l}3 \\
\text { mee } \\
\text { oneens }\end{array}$ & $\begin{array}{c}4 \\
\text { zeer } \\
\text { mee } \\
\text { oneens }\end{array}$ \\
\hline 1. & $\begin{array}{l}\text { Ik vind de werksfeer tijdens de } \\
\text { trainingsbijeenkomsten prettig }\end{array}$ & \multicolumn{4}{|l|}{$\square$} \\
\hline 2. & $\begin{array}{l}\text { Ik heb veel geleerd m.b.t. het houden van } \\
\text { col-gesprekken }\end{array}$ & \multicolumn{2}{|l|}{$\square$} & $\square$ & $\square$ \\
\hline 3. & $\begin{array}{l}\text { Ik vind het gebruik van eigen video-opnamen bij de } \\
\text { training zinvol }\end{array}$ & \multicolumn{2}{|l|}{$\square$} & $\square$ & $\square$ \\
\hline 4. & $\begin{array}{l}\text { Ik vind het gebruik van eigen video-opnamen bij de } \\
\text { training prettig }\end{array}$ & $\square$ & $\square$ & $\square$ & $\square$ \\
\hline 5. & Ik vind het aantal trainingsbijeenkomsten voldoende & $\square$ & $\square$ & $\square$ & $\square$ \\
\hline 6. & $\begin{array}{l}\text { Ik vind de begeleiding van de } \\
\text { trainingsbijeenkomsten goed }\end{array}$ & $\square$ & $\square$ & $\square$ & $\square$ \\
\hline 7. & $\begin{array}{l}\text { Ik vind de achtergrondinformatie (in de } \\
\text { trainingsmap) bruikbaar }\end{array}$ & $\square$ & $\square$ & $\square$ & $\square$ \\
\hline 8. & 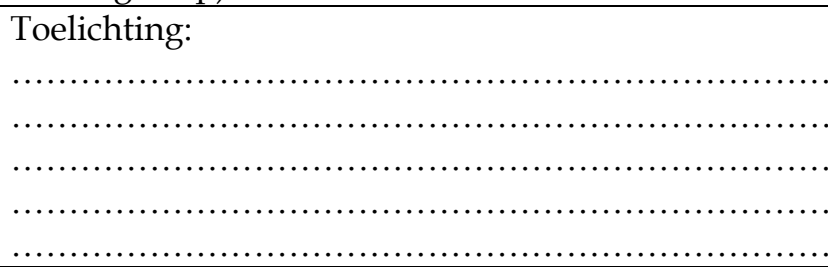 & & & & \\
\hline
\end{tabular}




\begin{tabular}{|c|c|c|c|c|c|}
\hline \multicolumn{6}{|c|}{$\begin{array}{l}\text { B. Intervisie over eigen lesfragmenten } \\
\text { Een deel van de gemeenschappelijke bijeenkomsten hebben we gebruikt voor het gezamenlijk (in de grote } \\
\text { groep van } 9 \text { collega's) bekijken en bespreken van (elkaars) lesfragmenten: }\end{array}$} \\
\hline 9. & Ik vind de werksfeer tijdens deze bijeenkomsten prettig & $\square$ & $\square$ & $\square$ & $\square$ \\
\hline 10. & $\begin{array}{l}\text { Ik heb veel geleerd van het tijdens deze bijeenkomst } \\
\text { bespreken van mijn eigen lesfragment }\end{array}$ & $\square$ & $\square$ & $\square$ & $\square$ \\
\hline 11. & $\begin{array}{l}\text { Ik heb veel geleerd van het tijdens deze bijeenkomst } \\
\text { bekijken en bespreken van de lesfragmenten van } \\
\text { anderen }\end{array}$ & $\square$ & $\square$ & $\square$ & $\square$ \\
\hline 12. & Ik vind het aantal bijeenkomsten hiervoor voldoende & $\square$ & $\square$ & $\square$ & $\square$ \\
\hline 13. & Ik vind de begeleiding van de bijeenkomsten goed & $\square$ & $\square$ & $\square$ & $\square$ \\
\hline 14. & $\begin{array}{l}\text { Ik wil meer achtergrond kennis over hoe je dingen kunt } \\
\text { aanpakken }\end{array}$ & $\square$ & $\square$ & $\square$ & $\square$ \\
\hline 15. & Toelichting: & & & & \\
\hline
\end{tabular}

C. Welke kwaliteiten vind je dat een begeleider van de bijeenkomsten moet hebben?

\begin{tabular}{|c|c|c|c|c|c|}
\hline 16. & Goed kunnen verwoorden, duidelijk kunnen uitleggen & $\square$ & $\square$ & $\square$ & $\square$ \\
\hline 17. & Zich kwetsbaar durven opstellen & $\square$ & $\square$ & $\square$ & $\square$ \\
\hline 18. & Durven in te grijpen bij discussies & $\square$ & $\square$ & $\square$ & $\square$ \\
\hline 19. & Open staan voor andere meningen/opvattingen & $\square$ & $\square$ & $\square$ & $\square$ \\
\hline 20. & Anderen kunnen motiveren & $\square$ & $\square$ & $\square$ & $\square$ \\
\hline 21. & Goed kunnen luisteren & $\square$ & $\square$ & $\square$ & $\square$ \\
\hline 22. & Goed kunnen samenvatten & $\square$ & $\square$ & $\square$ & $\square$ \\
\hline 23. & Ruime onderwijservaring hebben & $\square$ & $\square$ & $\square$ & $\square$ \\
\hline 24. & Een rijke theoretische achtergrond hebben & $\square$ & $\square$ & $\square$ & $\square$ \\
\hline 25. & Anders: & & & & \\
\hline
\end{tabular}




\section{Deel 2}

De vragen in deel 2 gaan over de besprekingen in je eigen col-groep

(col = collegiaal ondersteund leren).

In de col-groep zijn drie verschillende rollen:

a. De inbrenger van het lesfragment. Zijn/haar les wordt besproken

b. De gesprekspartner die het gesprek leidt en doorvraagt

c. De observant die het gesprek observeert en feedback geeft over de wijze waarop het gesprek is gehouden.

In de onderstaande vragen komen deze drie rollen na elkaar aan de orde.

\section{Vooraf:}

\begin{tabular}{|l|l}
\hline 26. & Hoeveel opgenomen lessen van jezelf heb je in je col-groep besproken:
\end{tabular}

\section{Inbrenger}

Je hebt tijdens de col-gesprekken video-opnamen van je eigen les bekeken en besproken. De onderstaande vragen gaan over je leerproces hierbij.

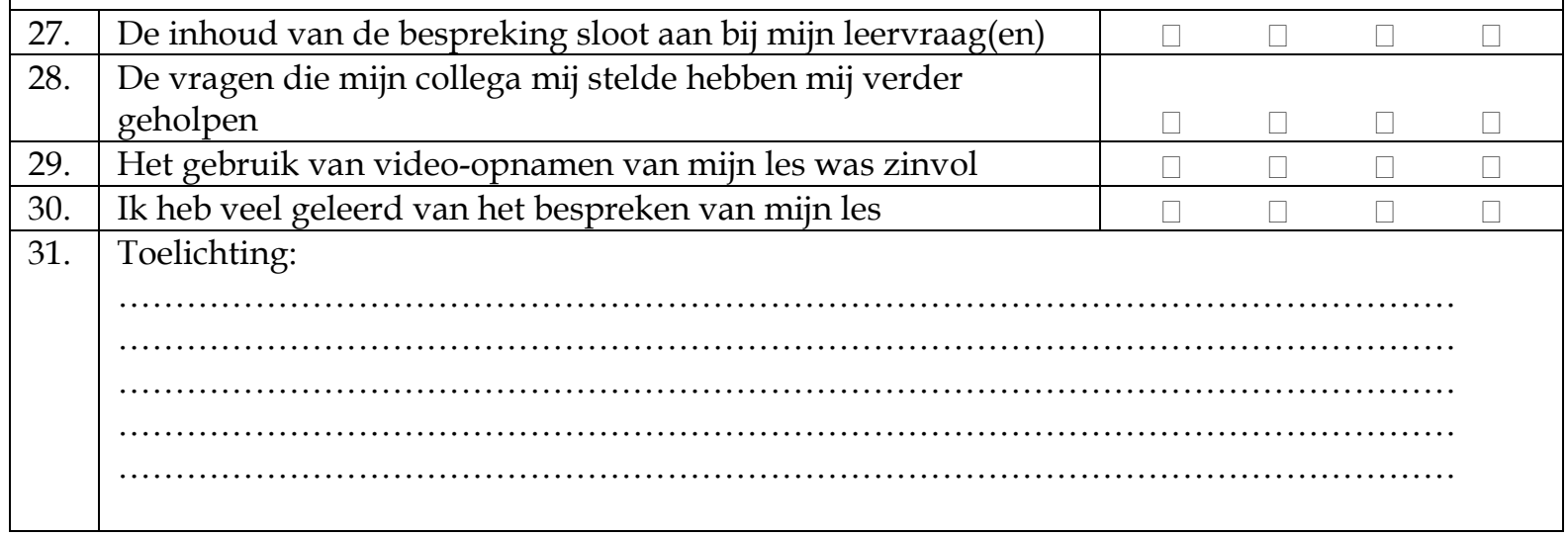

\section{E. Gesprekspartner}

Je hebt tijdens de col-gesprekken video-opnamen van de les van je collega bekeken en besproken. De onderstaande vragen gaan over je leerproces hierbij.

\begin{tabular}{|l|l|l}
\hline 32. & Ik kon het gesprek zelf goed leiden & $\square$ \\
\hline 33. & Ik vond het zien van een collega op video leerzaam & $\square$ \\
\hline 34. & $\begin{array}{l}\text { Ik vond het bespreken van de les van mijn collega zinvol voor } \\
\text { mijn eigen lesgeven }\end{array}$ \\
\hline 35. & $\begin{array}{l}\text { De feedback van de observator over het gesprek was voor mij } \\
\text { bruikbaar }\end{array}$ \\
\hline 36. & Toelichting: \\
& $\square$ \\
& $\square$ \\
\hline
\end{tabular}




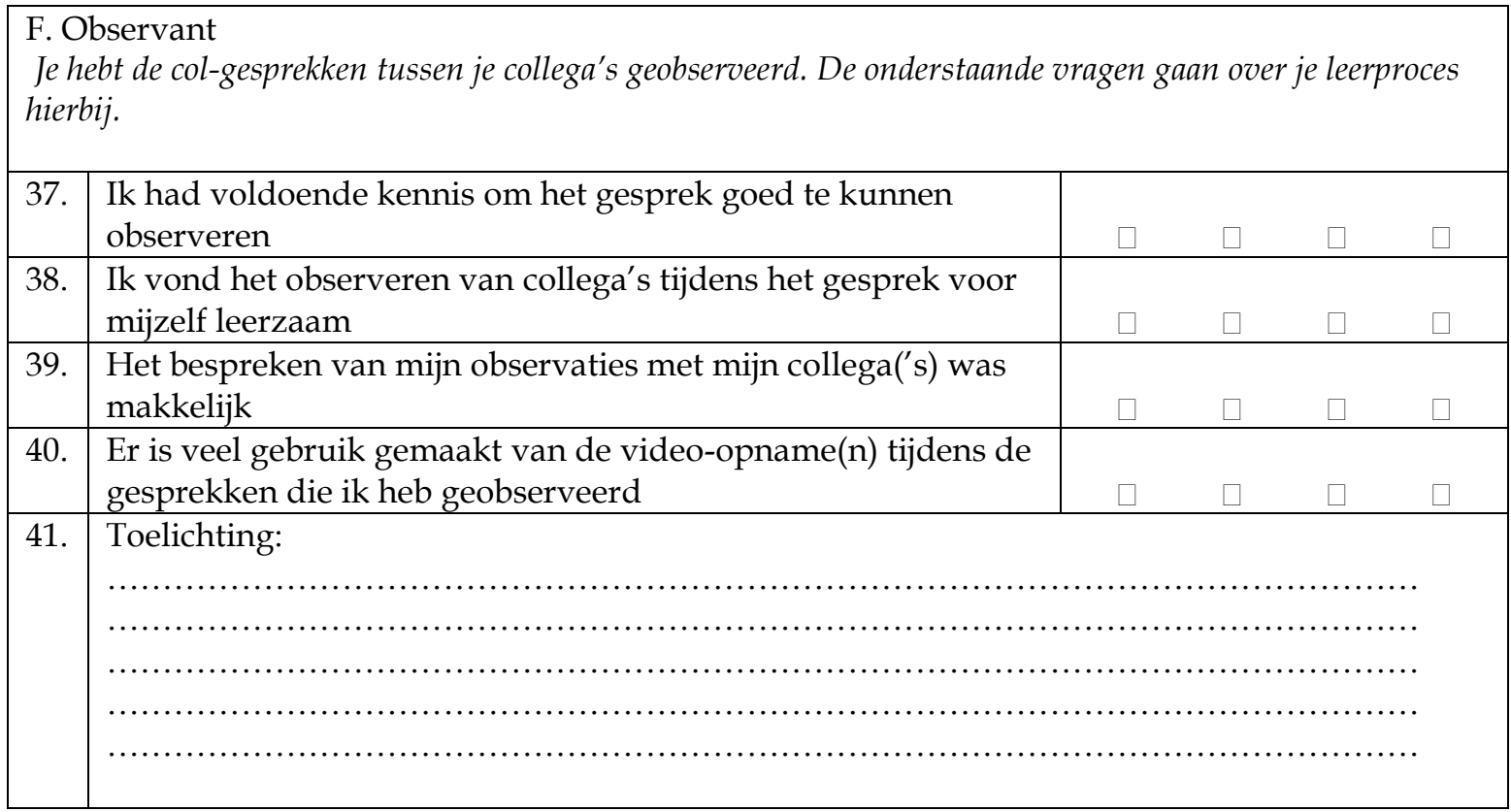

G. Opbrengsten van het intervisietraject

42. Ik heb bruikbare feedback gekregen over mijn handelen in de klas

43. Door de video van mijn eigen les te bekijken, zie ik nieuwe dingen

44. Door de video van mijn eigen les te bespreken met collega's, krijg ik nieuwe inzichten en/of ideeën

45. Ik leer te reflecteren door te verwoorden en verduidelijken van wat ik in mijn lesgeven doe en waarom

46. Ik leer helder te kunnen verwoorden wat mijn gedachten en mijn gevoelens zijn

47. Ik bezit meer theoretische kennis

48. Ik gebruik deze methode om te kijken hoe collega's werken en om daarvan te leren

49. Ik wissel kennis uit met collega's

50. Ik sta weer eens stil bij bepaalde onderdelen die er zijn ingeslopen en eigenlijk op automatisme gebeuren

51. Ik heb meer zelfvertrouwen gekregen als leraar

52. Ik sta meer open voor het samenwerken met collega's

53. Anders: 


\begin{tabular}{|c|c|c|c|c|c|}
\hline \multicolumn{6}{|c|}{ H. Noodzakelijke kwaliteiten } \\
\hline \multirow[t]{16}{*}{54.} & $\begin{array}{l}\text { Welke kwaliteiten moet een deelnemer bezitten in intervisie } \\
\text { trajecten (zoals het traject waar jij aan deelgenomen hebt)? }\end{array}$ & & & & \\
\hline & a. Gemotiveerd zijn om mee te werken & $\square$ & $\square$ & $\square$ & $\square$ \\
\hline & b. Consciëntieus zijn & $\square$ & $\square$ & $\square$ & $\square$ \\
\hline & c. Een aantal jaren onderwijservaring hebben & $\square$ & $\square$ & $\square$ & $\square$ \\
\hline & d. Goed kunnen verwoorden, duidelijk kunnen uitleggen & $\square$ & $\square$ & $\square$ & $\square$ \\
\hline & e. Een rijke theoretische achtergrond hebben & $\square$ & $\square$ & $\square$ & $\square$ \\
\hline & f. Zich kwetsbaar durven opstellen & $\square$ & $\square$ & $\square$ & $\square$ \\
\hline & g. Open staan voor andere meningen/opvattingen & $\square$ & $\square$ & $\square$ & $\square$ \\
\hline & h. Anderen kunnen motiveren & $\square$ & $\square$ & $\square$ & $\square$ \\
\hline & i. Goed kunnen luisteren & $\square$ & $\square$ & $\square$ & $\square$ \\
\hline & j. Goed kunnen samenvatten & $\square$ & $\square$ & $\square$ & $\square$ \\
\hline & k. Goed kunnen nadenken over eigen handelen & $\square$ & $\square$ & $\square$ & $\square$ \\
\hline & $\begin{array}{l}\text { 1. Een gemotiveerd iemand zijn die nog steeds bezig is } \\
\mathrm{m} \text {. met allerlei ontwikkelingen / vernieuwingen in } \\
\text { onderwijs }\end{array}$ & $\square$ & $\square$ & $\square$ & $\square$ \\
\hline & n. Iemand die voor veranderingen open staat & $\square$ & $\square$ & $\square$ & $\square$ \\
\hline & o. Iemand die mondig is & $\square$ & $\square$ & $\square$ & $\square$ \\
\hline & p. Anders: & & & & \\
\hline
\end{tabular}

\begin{tabular}{|c|c|c|c|c|c|}
\hline \multicolumn{6}{|c|}{ I. Algemene vragen } \\
\hline 55. & Ik vond de werksfeer tijdens de col-gesprekken goed & $\square$ & $\square$ & $\square$ & $\square$ \\
\hline 56. & Ik vind het aantal col-bijeenkomsten voldoende & $\square$ & $\square$ & $\square$ & $\square$ \\
\hline 57. & Ik vind het intervisietraject voor mij verrijkend & $\square$ & $\square$ & $\square$ & $\square$ \\
\hline 58. & Ik vind het intervisietraject voor mij zinvol & $\square$ & $\square$ & $\square$ & $\square$ \\
\hline 59. & Ik vind het deelnemen aan het intervisietraject leuk & $\square$ & $\square$ & $\square$ & $\square$ \\
\hline 60. & $\begin{array}{l}\text { Ik vind intervisie noodzakelijk voor mijn ontwikkeling als } \\
\text { leraar }\end{array}$ & $\square$ & $\square$ & $\square$ & $\square$ \\
\hline 61. & Ik wil betrokken blijven bij nieuwe intervisietrajecten & $\square$ & $\square$ & $\square$ & $\square$ \\
\hline
\end{tabular}

\begin{tabular}{|c|c|}
\hline \multicolumn{2}{|c|}{ J. Algemene gegevens } \\
\hline 62. & 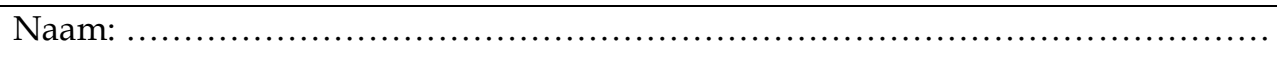 \\
\hline 63. & Aantal jaren werkzaam in het onderwijs: ............................................ \\
\hline 64. & 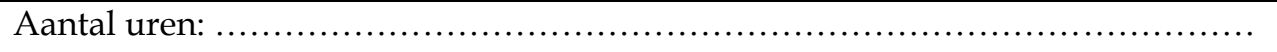 \\
\hline 65. &  \\
\hline 66. & Neventaken/functies: $\ldots \ldots \ldots \ldots \ldots \ldots \ldots \ldots \ldots \ldots \ldots \ldots \ldots \ldots \ldots \ldots \ldots \ldots$ \\
\hline
\end{tabular}




\section{APPENDIX 3 \\ Post-verification questionnaire (prototype PD program) (Chapter 4)}

Naam:

A. Opbrengsten van de methode van collegiaal ondersteund leren en videofeedback

$\begin{array}{llll}1 & 2 & 3 & 4 \\ \text { zeer } & \text { mee } & \text { mee } & \text { zeer } \\ \text { mee } & \text { eens } & \text { oneens } & \begin{array}{l}\text { mee } \\ \text { oneens }\end{array} \\ \text { eens } & & & \end{array}$

1. Ik denk meer systematisch over mijn gedrag na

2. Ik kan verwoorden en verduidelijken wat ik doe en wat ik daarmee wil bereiken

3. Ik zie de relatie tussen wat ik doe en hoe de leerling(en) hierop reageert.

4. Ik denk meer na over de relatie tussen het doel van het onderwijs, mijn functie als leraar en mijn concreet handelen

5. Ik sta stil bij bepaalde onderdelen die er in zijn geslopen en eigenlijk automatisch gebeuren

6. Ik wissel vaker ervaringen met collega's uit

7. Ik bezoek een les van een collega en/of nodig een collega uit om mijn les te bezoeken

8. Ik denk positiever over mijn handelen als leraar

9. Ik vond het zinvol om aan het traject mee te doen

10. Ik heb met collega's gesproken over het traject en het gebruik van video-opnamen

B. Het houden van coachingsgesprekken

In het intervisietraject is aandacht besteed aan het trainen in en het zelf voeren van 'col-gesprekken'.

11. Ik maak gebruik van gesprekstechnieken uit het traject 'collegiaal ondersteund leren' bij mijn:

a. gesprekken met collega's

b. gesprekken met leerlingen

c. gesprekken met ouders 
12. Het belangrijkste wat ik over het voeren van col-gesprekken geleerd heb, is voor mij:

13. De belangrijkste opbrengsten van het bekijken en bespreken van mijn eigen lessen is voor mij:

14. De belangrijkste opbrengsten van het bekijken en bespreken van lessen van anderen is voor mij: 


\section{APPENDIX 4 Questionnaire (PD program 'Learning to Notice') (Chapter 5)}

Questionnaire PD program

Reciprocal peer coaching with video feedback

This questionnaire concerns the professional development program in which you have participated at the [school name] in [school year]

In this questionnaire you are asked to describe your experiences with the method of reciprocal peer coaching with video feedback. It involves your experiences: with the six plenary meetings,

and also with the dialogues in your reciprocal peer coach group

With the help of your information we want to be able to make a statement about the yields of this professional development program.

We would appreciate it if you will answer this questionnaire. It is important for us and we hope you will give your support to it. 


\section{GOALS}

1. The goal of the program is to stimulate the professional development and learning of participants.

I believe this goal has been reached

certainly not $\square \square \square \square$ certainly

2. By means of this program:

2.1 I reflect more often on my actions/performances as teacher

2.2 I reflect more often on my own way of learning and the way I develop as a teacher

2.3 My competences as a teacher have increased

2.4 I gained more self-confidence as a teacher

certainly not $\square \square \square \square$ certainly

certainly not $\square \square \square \square$ certainly certainly not $\square \square \square \square$ certainly

certainly not $\square \square \square \square$ certainly

2.5 I reflect more often on certain aspects of my teaching that have become automatisms

2.6 I feel more supported by colleagues

2.7 I notice new things / better understand behavior in the classroom

2.8 I feel more open-minded towards cooperating with my colleagues within the program

2.9 I feel more open-minded towards cooperating with my colleagues outside the program

2.10 The communication with colleagues has improved, because I have a better understanding of what other people want or mean

2.11 I notice that my colleagues in the program have a better understanding of $\underline{m e}$

2.12 I gather shared knowledge with my colleagues

2.13 I have new ideas about ways to handle things

2.14 I have gained more knowledge of relevant theories

2.15 I see positive effects with my students

certainly not $\square \square \square \square$ certainly certainly not $\square \square \square \square$ certainly

certainly not $\square \square \square \square$ certainly

certainly not $\square \square \square \square$ certainly

certainly not $\square \square \square \square$ certainly

certainly not $\square \square \square \square$ certainly

certainly not $\square \square \square \square$ certainly certainly not $\square \square \square \square$ certainly

certainly not $\square \square \square \square$ certainly

certainly not $\square \square \square \square$ certainly

certainly not $\square \square \square \square$ certainly

2.16 Can you describe two positive effects you have observed in your students?

3. My personal learning goal was:

4. I feel I have attained this objective

certainly not $\square \square \square \square$ certainly 
5. To which factors would you ascribe your success (if any)?

5.1 My own efforts and commitment

5.2 Reflecting on and formulating my personal learning question/objective

5.3 The methodical approach and the performing of an inquiry

5.4 Seeing my own professional behavior on video

5.5 Seeing the behavior of my students on video

5.6 Discussing and analyzing the video of my own lessons with my colleagues

5.7 Viewing and discussing videos of lessons of colleagues

5.8 The support from colleagues in the program

6. How useful did you find the different parts of the program?

Please rate each part on a 10-point scale ( $10=$ very useful, $1=$ not useful at all)

6.1 Viewing and discussing videos of my own lessons

6.2 Viewing and discussing videos of lessons of colleagues

6.3 Acting as a coach for my colleagues

6.4 Observing and analyzing coaching dialogues in my triad

6.5 Observing and discussing coaching dialogues during the plenary meetings

6.6 Reflecting on and formulating my own personal learning objectives

6.7 Discussing each other's personal learning objectives with my peers

6.8 Working with an action plan and performing own inquiry

6.9 Discussing the action plans and inquiries of colleagues

6.10 The information in the binder concerning 'coaching dialogues

6.11 The information in the binder (and on the CD-ROM) concerning 'performing inquiries'

6.12 Further comments concerning question 6: 


\section{TIME INVESTED}

7. How many times have you shared coaching dialogues with your colleagues (as a learner, a coach or an observer) in the program?

7.1 In total, videos of my own lessons were discussed .... times

7.2 In total, as coach I have discussed .... videos of colleagues

7.3 In total, I have observed .... coaching dialogues in my subgroup

8. What was the average approximate duration of the coaching dialogues of the videos of your lessons? minutes

9. When did the coaching dialogues take place? (please mark all that apply)

9.1 on the day the video was recorded

9.2 within a week after the video was recorded

9.3 at a later time (more than a week after the video was recorded)

9.4 during a regular break

9.5 during a lesson interval (during a lesson hour in which you did not teach a class)

9.6 at the end of the (working) day

9.7 other, i.e.

10. Out of the total of six plenary meetings, I attended meetings

11. I feel I have invested a lot of time in the program

certainly not $\square \square \square \square$ certainly

12. This time investment was put to good use certainly not $\square \square \square \square$ certainly

13. According to you, what is the minimum amount of time spent required for a program like this?

14. Further comments concerning question $7 \mathrm{t} / \mathrm{m} 14$ (time investment): 


\section{COACHING}

15. How did you experience the coaching by your colleague?

15.1 Motivating

15.2 Assessing

15.3 Involved

15.4 Understanding

15.5 Pleasant

15.6 Relevant to my learning objectives

15.7 Strongly guided

15.8 Relaxed

15.9 Respectful

15.10 Enlightening/in-depth

16. During the coaching dialogue:

16.1 I was stimulated to stipulate myself what I wanted to change in my teacher behavior

16.2 I noticed new things in the video thanks to my colleague (other than the things I had already noticed myself)

16.3 By means of the coaching dialogue I gained more insight into the background of the behavior I observed in the video

16.4 By means of the coaching dialogue, I was stimulated to reflect on my role as a teacher and on my values as a teacher

16.5 By means of the coaching dialogue I gained new ideas about things I can do as a teacher

16.6 By means of the coaching dialogue I felt stimulated to try new things in classroom

certainly not $\square \square \square \square$ certainly certainly not $\square \square \square \square$ certainly certainly not $\square \square \square \square$ certainly certainly not $\square \square \square \square$ certainly certainly not $\square \square \square \square$ certainly certainly not $\square \square \square \square$ certainly certainly not $\square \square \square \square$ certainly certainly not $\square \square \square \square$ certainly certainly not $\square \square \square \square$ certainly certainly not $\square \square \square \square$ certainly

certainly not $\square \square \square \square$ certainly certainly not $\square \square \square \square$ certainly

certainly not $\square \square \square \square$ certainly certainly not $\square \square \square \square$ certainly certainly not $\square \square \square \square$ certainly certainly not $\square \square \square \square$ certainly

17. Coaching your colleague:

17.1 Coaching my colleague was easy to do

17.2 Coaching my colleague was enriching and informative for my own development

17.3 The feedback I received on my role as coach was meaningful

17.4 The training during the plenary meetings has taught me ways to coach my colleague

17.5 The most difficult part of coaching my colleague was:

certainly not $\square \square \square \square$ certainly certainly not $\square \square \square \square$ certainly certainly not $\square \square \square \square$ certainly certainly not $\square \square \square \square$ certainly

18. Do the changes brought about by the PD program have a positive influence on the following aspects?

18.1 Your contact with students

18.2 Classroom organization and maintaining order and discipline in your classroom

18.3 Your cooperation with other people such as your colleagues and/or parents

18.4 The ways you structure your lessons, your teaching strategies, the way you design tests, and so on (your pedagogical knowledge)

18.5 The way you gear your activities to individual differences between students not much $\square \square \square \square$ much

not much $\square \square \square \square$ much

not much $\square \square \square \square$ much

not much $\square \square \square \square$ much

not much $\square \square \square \square$ much 
18.6 The learning performances of your students

18.7 Your functioning as a person

18.8 Your insight in the way you function as a teacher and in your values as a teacher

18.9 Your insight in your own learning and development as a teacher

19. In the future, I will remain practicing the things I learned in the program

20. In the future, I will continue to video tape my own lessons on a regular basis

21. In the future, I want to remain involved in new programs where I can discuss and share with my colleagues not much $\square \square \square \square$ much

not much $\square \square \square \square$ much

not much $\square \square \square \square$ much

not much $\square \square \square \square$ much

certainly not $\square \square \square \square$ certainly

certainly not $\square \square \square \square$ certainly

certainly not $\square \square \square \square$ certainly

22. What are three of your most positive experiences with the program?

23. What are three of your most negative experiences with the program?

\section{BACKGROUND}

24. Name:

25. Age:

26. Subject taught:

27. Education:

28. Number of years employed in education:

29. Number of hours appointed:

30. Teaching the following groups:

31. Other functions or tasks at the school (besides teaching):

Thank you for completing this questionnaire! 


\section{APPENDIX 5 \\ Interview protocol of the semi-structured interviews \\ (PD program 'Learning to Notice') (Chapter 5)}

a. Introduction and checking of data of teacher's background

(age, years of experience, teaching subject, student groups, positions at the school)

b. Personal motives: expectations at the start of the program?

c. Listing teacher's roles in triads

(which triad, when did they meet, how often did they meet, how many video's did they discuss, which roles did the teacher perform in his triad: coachee, coach, observer)

d. Structuring the interview

The interviewer has 12 cards, each with one characteristic of the program. Each teacher is asked to select them in order of merits for their own learning process. The purpose of the cards is to have a structure to help the participant to tell his own story about his experiences in and evaluations of the program. The interview starts discussing the item the respondent selected as the most important, then the one chosen as second most important and so on. 
Cards:

1. Video feedback on your own professional performance

2. Video feedback on the performances and behavior of your students

3. Discussing the video tape of your own lesson in your triad

4. Observing and/or discussing the video tape of the lesson of your peer(s)

5 . Coaching your colleague in your triad

6. Functioning as an observer of coaching dialogues

7. Observing and/or analyzing the performance of the coach and the coaching dialogue

a. Observing the coaching dialogue of your peer in the triad

b. Discussing your own performance as a coach with your peer in the triad

c. Discussing video tapes of coaching dialogues during the plenary meetings

8. Professional development with the help of a self-formulated learning goal

9. Doing inquiry related to your learning goal

10. Presenting your inquiry and your learning process to your peers and discussing inquiries with colleagues

13. Other, namely ......

It is important to tell your own unique story

e. What was important for you with ... (selected card 1)

f. Can you describe to me important moments in the program with ... (selected card 1)?

- Which moments were important?

- Clarifying the different moments:

o recalling the context: what, when, where, with whom, etc.

○ what was important: what did you experience, thought, felt, wished, and what was important for this, etc.?

- results: what did you gain/learn, have you used these gains also in other situations, can you give examples, etc.?

- what was the role of your peer(s) in this?

- What is your evaluation of this characteristic of the program?

g. Next card:

What was important with... and can you describe to me important moments in the program with... ? (selected card 2) (repeating questions see 5 and 6). And so on until all cards are discussed.

h. Checking other characteristics of the program (when not already discussed before):

- Plenary meetings: quantity, quality, topics, binder, etc.

- The role of the trainers

- The way triads were composed: evaluations, security, influences on learning process and gains, etc.

- The role of management 
i. Could you name two characteristics of the program which must be built in new programs and two characteristics which should not be built in?

Do you have suggestions for improving the program?

\section{j. Closing of}

- How did you experience your participation in the program? How does the implemented program relate to your expectations beforehand?

- Does the program offer results for the school?

- Can you also implement similar programs in other contexts in the school? Determining factors for this?

- Would you want to participate next year in this or in a similar program? 


\section{APPENDIX 6}

Overview of individual teacher's learning goals and outcomes (Cohort A and B)

(PD program 'Learning to Notice') (Chapter 6) 


\begin{tabular}{|c|c|c|c|c|}
\hline $\begin{array}{l}\text { Co- } \\
\text { hort }\end{array}$ & Teacher & Inquiry & Learning goal / question for inquiry & Outcomes (presented at the last plenary meeting and/or in written report) \\
\hline A & Jane & $\begin{array}{l}\text { Report }+ \\
\text { Presentation }\end{array}$ & $\begin{array}{l}\text { How do I make my lesson more 'meaningful' for } \\
\text { my students? } \\
\text { How can students become more committed and } \\
\text { more actively involved with my subject? }\end{array}$ & $\begin{array}{l}\text { I made new teaching materials and tried them out in classroom. I } \\
\text { tested my students and from the test results I discovered that } \\
\text { students can learn very well when they have to discover things for } \\
\text { themselves. Making meaningful assignments for students is a lot of } \\
\text { work, but to create learning environment with a meaningful context } \\
\text { for learning of my subject appeared to activate and stimulate } \\
\text { students learning. } \\
\text { "I learned a lot [...], and I am pleased I have something very } \\
\text { concrete [developed teaching materials], which I can use next year". } \\
\text { (Jane, written report) }\end{array}$ \\
\hline
\end{tabular}

\begin{tabular}{|c|c|c|c|c|}
\hline $\mathrm{A}$ & Ellen & $\begin{array}{l}\text { Report }+ \\
\text { Presentation }\end{array}$ & $\begin{array}{l}\text { How do I increase the individual learning outputs } \\
\text { of my students in student group H4 [student group } \\
\text { in their fourth year of study in the Dutch Havo } \\
\text { school type]? }\end{array}$ & $\begin{array}{l}\text { I did various inquiries, such as: } \\
\text { - } \quad \text { analyzing all tests and test scores of students; } \\
\text { - I tested classroom interaction with an existing standardized test } \\
\quad \text { [VIL-test]; } \\
\text { - I studied video recordings; } \\
\text { - I gathered data with a student questionnaire. } \\
\text { Conclusion: students are not doing their homework enough. } \\
\text { "Students can work much harder, however, I have too much } \\
\text { sympathy with them and with every excuse they make. My own } \\
\text { empathy with students is counterproductive" [even in the eyes of } \\
\text { my students]. (Ellen, written report) }\end{array}$ \\
\hline $\mathrm{A}$ & Mary & $\begin{array}{l}\text { Report }+ \\
\text { Presentation }\end{array}$ & $\begin{array}{l}\text { How do I use collaborative learning strategies in my } \\
\text { classrooms? }\end{array}$ & $\begin{array}{l}\text { I experimented and learned a number of principles you have to use } \\
\text { to structure collaborative learning. The results are very positive, } \\
\text { because it gave me an opening at mastering my learning goal. I } \\
\text { want to continue to use forms of collaborative learning in the } \\
\text { classroom and next year I want to continue studying and mastering } \\
\text { the principles of collaborative learning. "This program made me } \\
\text { curious. I want to inquire more, learn more in the future." (Mary, } \\
\text { written report) }\end{array}$ \\
\hline
\end{tabular}




\begin{tabular}{llll}
\hline $\begin{array}{l}\text { Co- } \\
\text { hort }\end{array}$ & Teacher & Inquiry & Learning goal / question for inquiry \\
\hline A & Carol & $\begin{array}{l}\text { Report }+ \\
\text { Presentation }\end{array}$ & $\begin{array}{l}\text { How do I encounter and activate students in a more } \\
\text { positive manner (instead of mostly using warnings } \\
\text { or punishments)? }\end{array}$ \\
& & \\
\hline A & Lisa & $\begin{array}{l}\text { Report }+ \\
\text { Presentation }\end{array}$ & $\begin{array}{l}\text { Why do I feel frustrated as a teacher and why do I } \\
\text { feel helpless in the classroom sometimes? }\end{array}$
\end{tabular}

Outcomes (presented at the last plenary meeting and/or in written report)

During the start of my inquiry I observed video recordings, and I

realized that my non-verbal presentation could be more productive. For my inquiry:

- I studied video recordings of own classroom;

- I visited other classrooms;

- I interviewed students.

"My learning goal for next year will be: How can I change my own behavior so I am more satisfied with it?" (Carol, written report)

I made a plan with a number of concrete strategies to be used in classroom and experimented with them.

I learned: (a) not to solely focus on things that did not function as planned; (b) I have to work on my own time management at home and plan 'school-free weekends'.

"I am a little dissatisfied with the program. [...] I had hoped I would have learned more in it. I had a difficult learning goal, and I have learned about it, but I think there is still a lot that I have to work on." (Lisa, written report)

\begin{tabular}{lll}
\hline A & Paul1 & $\begin{array}{l}\text { Report }+ \\
\text { Presentation }\end{array}$
\end{tabular}$\quad$ How do I increase motivation in students?

I studied the video recordings; I interviewed my students; and I experimented with a new teaching method.

The tryout of the new teaching method was successful and students were motivated, but it is necessary to improve it on a number of specific points. Continuation of the inquiry is necessary, among others to study individual learning of various students. (Paul1, written report and presentation)

\begin{tabular}{|c|c|c|c|}
\hline $\mathrm{A}$ & Anne & $\begin{array}{l}\text { Report }+ \\
\text { Presentation }\end{array}$ &  \\
\hline
\end{tabular}

For my inquiry, among others:

- I studied the existing curriculum and the planning of school events (expected loss of lessons);

- I visit classrooms of colleagues teaching the same subject;

- I studied video recordings.

With the help of the gathered information I made a new planning for the curriculum. As a result I'm not taken by surprise when lessons are cancelled and have more time reserved for parts of the 


\begin{tabular}{|c|c|c|c|c|}
\hline $\begin{array}{l}\text { Co- } \\
\text { hort }\end{array}$ & Teacher & Inquiry & Learning goal / question for inquiry & Outcomes (presented at the last plenary meeting and/or in written report) \\
\hline & & & & $\begin{array}{l}\text { subject matter that proved to need more time to teach. } \\
\text { As a result of my inquiry I discovered a number of behavioral } \\
\text { interaction patterns between myself and my students in classroom } \\
\text { that hindered learning of students. To resolve this I made a number } \\
\text { of new rules for in the classroom to prevent these from occurring. } \\
\text { (Anne, written report and presentation) }\end{array}$ \\
\hline A & Kate & $\begin{array}{l}\text { Report }+ \\
\text { Presentation }\end{array}$ & 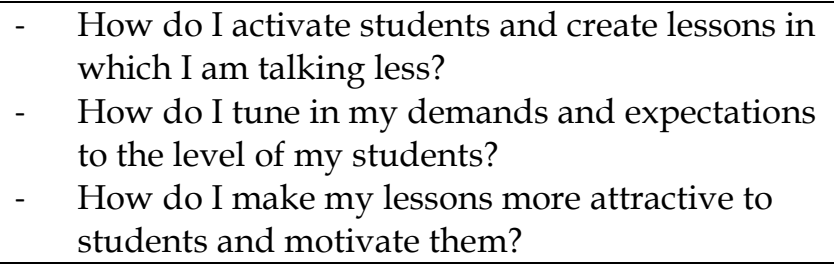 & $\begin{array}{l}\text { I performed three different inquiries. For each inquiry I studied } \\
\text { video recordings, I developed learning materials, I did tryouts in } \\
\text { classroom, and I checked outcomes with the help of student tests. } \\
\text { "The outcomes give me an incentive to go on with this kind of } \\
\text { experiments in classroom and to develop these further." (Kate, } \\
\text { written report) }\end{array}$ \\
\hline A & Brigid & $\begin{array}{l}\text { No report or } \\
\text { presentation } \\
\text { (leaving the } \\
\text { school) }\end{array}$ & Did participate in the other parts of the program & \\
\hline B & Frank & $\begin{array}{l}\text { Report }+ \\
\text { Presentation }\end{array}$ & $\begin{array}{l}\text { How can I give students more responsibility and } \\
\text { freedom for their own learning process without } \\
\text { losing control? }\end{array}$ & $\begin{array}{l}\text { I gathered new ideas from literature and on the internet about } \\
\text { different methods for teaching English grammar; I picked one } \\
\text { strategy and tested it out in classroom; I studied outcomes in } \\
\text { students on a standardized test we use in our school. I discovered } \\
\text { that most student groups benefited, however, weak learners } \\
\text { underachieved with the new method. } \\
\text { "Next step will be to search for strategies to offer different } \\
\text { approaches to student groups during grammar teaching". (Frank, } \\
\text { written report) }\end{array}$ \\
\hline B & Paul2 & $\begin{array}{l}\text { Report }+ \\
\text { Presentation }\end{array}$ & $\begin{array}{l}\text { Is it possible to coach individual students during } \\
\text { whole class teaching? }\end{array}$ & $\begin{array}{l}\text { I developed, tested in classroom, and evaluated a card system with } \\
\text { exercises and tasks for individual students. } \\
\text { The developed system is still lacking with regard to motivating } \\
\text { students to register their own progress. Therefore, a digital system } \\
\text { to register students' individual progress will be the next step. } \\
\text { (Paul2, written report) }\end{array}$ \\
\hline
\end{tabular}




\begin{tabular}{|c|c|c|c|c|}
\hline $\begin{array}{l}\text { Co- } \\
\text { hort }\end{array}$ & Teacher & Inquiry & Learning goal / question for inquiry & Outcomes (presented at the last plenary meeting and/or in written report) \\
\hline B & John & $\begin{array}{l}\text { Report }+ \\
\text { Presentation }\end{array}$ & How do I teach grammar in more interactive ways? & $\begin{array}{l}\text { I decided to investigate ways to change both the form and content } \\
\text { of the lessons in order to make them more interactive. } \\
\text { I used video recordings and the lesson observations of a team coach } \\
\text { for evidence to evaluate action. } \\
\text { "I have learned new skills for making lessons more interactive. I } \\
\text { have developed a range of activities that can appeal to learners } \\
\text { across the spectrum of learning styles. [...] The research also } \\
\text { increased my understanding of teaching strategies. [...] For any } \\
\text { future inquiry I am now aware of the need to plan from the onset a } \\
\text { detailed method of evaluating data." (John, written report) }\end{array}$ \\
\hline B & Sue & $\begin{array}{l}\text { Report }+ \\
\text { Presentation }\end{array}$ & $\begin{array}{l}\text { In which way can I use collaborative learning } \\
\text { strategies to differentiate in classroom? }\end{array}$ & $\begin{array}{l}\text { I started to study theories about collaborative learning strategies. } \\
\text { With the help of experiments, observations, and student } \\
\text { questionnaires I identified two chapters in the exercise books, one } \\
\text { difficult and one rather easy and decided to form mixed ability } \\
\text { student groups (difficult chapter) and single ability groups (easy } \\
\text { chapter). I tried out these strategies two times in a row and studied } \\
\text { the behavior of students. } \\
\text { I feel stimulated, I have mastered all kinds of aspects of } \\
\text { collaborative learning strategies, and I have identified what will be } \\
\text { the next thing to improve for the following year. } \\
\text { "Normally you don't do this kind of inquiry by yourself, though it } \\
\text { is very helpful for your professional development" (Sue, written } \\
\text { report) }\end{array}$ \\
\hline B & Harry & $\begin{array}{l}\text { Report }+ \\
\text { Presentation }\end{array}$ & $\begin{array}{l}\text { Studying video recording to investigate whether } \\
\text { there are things I can still improve in my lessons. }\end{array}$ & $\begin{array}{l}\text { I expected that my lessons were going well and this was confirmed. } \\
\text { Studying video feedback was interesting because you have much } \\
\text { more time to notice individual students and to check with yourself } \\
\text { whether you gave enough attention to every individual student, } \\
\text { especially the quiet ones. (Harry, presentation) } \\
\text { "I learned mostly from my peer coaching of a colleague, by helping } \\
\text { another by asking the right questions. It is hard to do, but you } \\
\text { discover it can be very helpful for your peer." (Harry, written } \\
\text { report) }\end{array}$ \\
\hline
\end{tabular}




\begin{tabular}{|c|c|c|c|c|}
\hline $\begin{array}{l}\text { Co- } \\
\text { hort }\end{array}$ & Teacher & Inquiry & Learning goal / question for inquiry & Outcomes (presented at the last plenary meeting and/or in written report) \\
\hline $\mathrm{B}$ & Kerstin & $\begin{array}{l}\text { Report }+ \\
\text { Presentation }\end{array}$ & $\begin{array}{l}\text { How do I motivate students to stay active learners } \\
\text { throughout the whole lesson? }\end{array}$ & $\begin{array}{l}\text { With the help of video feedback and peer coaching dialogues I } \\
\text { discovered that my research question was too extensive and I } \\
\text { primarily learned to scale down my learning goal. I have chosen to } \\
\text { focus only on the interaction in a specific student group and only on } \\
\text { the instruction at the start of the lesson. I have made some progress } \\
\text { with "keeping peace and quiet during instructions". "Staying } \\
\text { consistent towards students is something for me to work on." } \\
\text { (Kerstin, written report) }\end{array}$ \\
\hline B & Emily & $\begin{array}{l}\text { Report } \\
\text { (no presentation: } \\
\text { driving test) }\end{array}$ & $\begin{array}{l}\text { Using different teaching strategies in search of a } \\
\text { successful teaching method with a specific class. }\end{array}$ & $\begin{array}{l}\text { With the help of the peer coaching dialogues I developed ideas for } \\
\text { problem areas. I tested out different approaches in classroom and I } \\
\text { measured outcomes in classroom (concerning interactions) with the } \\
\text { help of an existing standardized test [VIL-test]. "We have all settled } \\
\text { down to some productive interaction. A great improvement in class } \\
\text { management and discipline." (Emily, written report) }\end{array}$ \\
\hline B & Sarah & $\begin{array}{l}\text { Report } \\
\text { (no presentation: } \\
\text { abroad for } \\
\text { school } \\
\text { excursion) }\end{array}$ & Development of new materials for the IB program. & $\begin{array}{l}\text { Development of new learning materials on World War I poetry and } \\
\text { experimenting with them in classroom. } \\
\text { "Another might think it wasn't a really productive year; however it } \\
\text { may be one of the most productive years of my career" (Sarah, } \\
\text { written report). }\end{array}$ \\
\hline B & Emma & $\begin{array}{l}\text { Presentation } \\
\text { (no report } \\
\text { because } \\
\text { inquiry was still } \\
\text { running) }\end{array}$ & $\begin{array}{l}\text { Every student is different and needs different } \\
\text { learning materials and instructions. Research goal: } \\
\text { Experimenting with more individual learning } \\
\text { approaches in classroom and developing own } \\
\text { teaching materials fitting in with more individual } \\
\text { learning approaches and to drop the existing } \\
\text { textbooks as soon as possible. }\end{array}$ & $\begin{array}{l}\text { I'm still in the phase of experimenting with a new approach and } \\
\text { materials, therefore it is too soon to evaluate. Tentative outcomes } \\
\text { based on own observations: } \\
\text { - Students cannot choose own moment to do the test (they just } \\
\text { postpone as much as possible). } \\
\text { - Elaborative feedback with many remarks and tips with } \\
\text { individual assignments is very effective (although very time- } \\
\text { consuming for the teacher). } \\
\text { - Individual learning and elaborative feedback helps the students } \\
\text { to feel 'being noticed'. However, lessons tend to become more } \\
\text { boring because the possibilities to stir things up in classroom } \\
\text { (e.g. telling an interesting story, doing a game) are diminished. } \\
\text { (Emma, presentation) }\end{array}$ \\
\hline
\end{tabular}




\begin{tabular}{|c|c|c|c|c|}
\hline $\begin{array}{l}\text { Co- } \\
\text { hort }\end{array}$ & Teacher & Inquiry & Learning goal / question for inquiry & Outcomes (presented at the last plenary meeting and/or in written report) \\
\hline B & Jill & Presentation & $\begin{array}{l}\text { Studying video recordings to investigate whether } \\
\text { there are still things I can improve in my lesson. }\end{array}$ & $\begin{array}{l}\text { I observed videotaped lessons and concluded I could change little } \\
\text { things with the laying out of instruction materials beforehand. (Jill, } \\
\text { presentation) }\end{array}$ \\
\hline B & Betty & Presentation & $\begin{array}{l}\text { Focused on the 'speaking/listening' part of the } \\
\text { curriculum of the subject English. Research } \\
\text { question: How can I find a balance between (a) my } \\
\text { wish to control the lesson and monitor students (but } \\
\text { not constantly dominating the conversation by } \\
\text { speaking myself), and (b) also using students' lesson } \\
\text { time for students to speak by themselves. }\end{array}$ & $\begin{array}{l}\text { Most instructive for this were the observations gathered from the } \\
\text { video recordings and the dialogues with my peer coach. Because of } \\
\text { my coach I was really activated to reflect on my own role as a } \\
\text { teacher. I discovered that I needed some control (it belongs to my } \\
\text { identity as a teacher), but also that too much structure is not always } \\
\text { good for my students. I experimented and found a strategy in my } \\
\text { lessons for balancing 'speaking/listening' and for restricting myself } \\
\text { and for reserving time for students practicing by themselves. } \\
\text { (Betty, presentation) }\end{array}$ \\
\hline B & Ruth & Presentation & $\begin{array}{l}\text { What is my role as a teacher when my students are } \\
\text { working in groups? }\end{array}$ & $\begin{array}{l}\text { I mostly teach at the front of the class explaining subject topics and } \\
\text { instructing students. I started to reflect on what it meant for my role as } \\
\text { a teacher when I wanted to change to more collaborative learning } \\
\text { strategies in classroom. However, most important to my inquiry were } \\
\text { not results connected to my learning goal, but results connected to the } \\
\text { process of peer coaching and inquiry. For the first time in my carrier I } \\
\text { started to look at myself and at my functioning as a teacher. In the past } \\
\text { I always focused at the results of my students, and because they were } \\
\text { OK, I never found cause to further investigate the way I teach and who } \\
\text { I am as a teacher. There was that little kingdom in classroom and now } \\
\text { for the first time it was opened up. At the end, I'm very pleased with } \\
\text { this process and outcomes. (Ruth, presentation) }\end{array}$ \\
\hline
\end{tabular}

\begin{tabular}{ll}
\hline B Julia & No report or Did participate fully with the other parts of the program \\
& presentation \\
& (emigrated \\
abroad) &
\end{tabular}




\begin{tabular}{|c|c|c|c|}
\hline $\begin{array}{l}\text { Co- } \\
\text { hort }\end{array}$ & Teacher & Inquiry & Outcomes (presented at the last plenary meeting and/or in written report) \\
\hline B & Ronald & $\begin{array}{l}\text { No report or } \\
\text { presentation } \\
\text { (no time due to } \\
\text { other duties in } \\
\text { school) }\end{array}$ & Did participate partially with the other parts of the program. \\
\hline B & Joe & $\begin{array}{l}\text { No report or } \\
\text { presentation } \\
\text { (no time: } \\
\text { became a father) }\end{array}$ & Did participate partially with the other parts of the program. \\
\hline B & George & $\begin{array}{l}\text { No report or } \\
\text { presentation } \\
\text { (no time: } \\
\text { Became a father) }\end{array}$ & Did participate partially with the other parts of the program. \\
\hline B & Eva & $\begin{array}{l}\text { No report or } \\
\text { presentation } \\
\text { (hospital visit) }\end{array}$ & Did participate partially with the other parts of the program \\
\hline
\end{tabular}




\section{CURRICULUM VITAE}

Rita Schildwacht was born on March 31, 1953 in Amsterdam. After her secondary schooling, she graduated as elementary school teacher in 1973. Next she studied Pedagogical and Educational Sciences at the Utrecht University and completed her Master degree in 1981. Between 1975 and 1984 she worked successively as research assistant, as lecturer and as researcher at Utrecht University and at VU University Amsterdam. Since 1985 she has worked at Fontys Secondary Teacher Training College Tilburg (FLOT) as a teacher educator, teacher trainer and researcher. She lectured both at the Bachelor and Master degree programs and coached students during their internships in schools of secondary education. In the course of her career she has specialised in post-graduate trainings on coaching for teacher educators and mentor teachers.

From 2004 till 2007 she has also been employed at the Ruud de Moor Centrum of the Open University in the Netherlands.

She was a member of the Research Group Learning Strategies [Kenniskring Lectoraat Leerstategieën] and since 2010 she joined the Research Group Teachers and Teacher Educators as Professionals [Kenniskring Professionaliteit van de beroepsgroep Leraren en Lerarenopleiders], both research groups at Fontys University of Applied Sciences.

Since 2005 she combined her work with a PhD-study. Rita Schildwacht has presented her research at both scientific conferences and vocational conferences.

Presentations and publications

Schildwacht, R., Bolhuis, S., \& Broeders, A. (2005). With a little help from a friend. Peer coaching in professional development. Paper presentation at PRAR 2005 (International Practitioners Research Conference \& Collaborative Action Research Network (CARN) Conference, Utrecht, the Netherlands. 
Also published in Proceedings PRAR 2005, and in Nicole Mockler (Ed). Local Research, Global Community: Action Research for a New Century, CARN Bulletin 11A, 2006.

Schildwacht, R. (2006). Wederzijdse peer-coaching met behulp van videofeedback. [Reciprocal peer coaching with videofeedback] Velon-conference [Teacher Educator Conference], Kerkrade, the Netherlands.

Schildwacht, R., \& Heunks, S. (2007). Ontwerprichtlijnen voor professionaliseringstrajecten van docenten. Paper presentation Fontys congres 'Onderzoeken en Ondervinden', Eindhoven, the Netherlands.

Schildwacht, R., Bolhuis, S., \& van den Akker, J.J.H. (2007). Stimulating teachers' professional development using video feedback with reciprocal peer coaching. Paper presentation 12th Biennial Conference for Research on Learning and Instruction (EARLI), Budapest, Hungary.

Schildwacht, R., Bolhuis, S., \& van den Akker, J.J.H. (2008). Ontwerprichtlijnen voor de professionele ontwikkeling van leraren met behulp van video feedback en wederzijdse peer coaching. [Design guidelines for teacher professional development with video feedback and reciprocal peer coaching]. Paper presentation Onderwijs Researchdagen (ORD) [Educational Research Days], Eindhoven, the Netherlands.

Schildwacht, R., Bolhuis, S., \& van den Akker, J.J.H. (2008). Does peer coaching with video feedback improve the quality of teachers' reflections on own professional behaviour? Paper presentation 4th EARLI SIG 14 Learning and Professional Development Conference, Jyväskylä, Finland.

Schildwacht, R. (2009). Reflecteren en coachen met videofeedback. Velov-Velon conference, Gent, Belgium.

Schildwacht, R., \& Heunks, S. (2009). Onderzoek van eigen onderwijspraktijk: leren zien en inzien, In: S. Bolhuis, P. Leenheer, \& G. van Luin (Eds.), Dat zoeken we zelf uit. Over onderzoek in de school door docenten, teamleiders en (midden)management. [We'll find out ourselves. On research in schools by teachers, teamleaders and (middle)management] MESO-focus, 73, Alphen aan de Rijn: Kluwer.

Schildwacht, R., \& Heunks, S. (2010). Bij nader inzien: Professionalisering door dialoog en videofeedback. Praktijkpublicaties 'Ons werk - werkt het?' [Publications for Practice 'Our work - does it work?] van het Lectoraat Leerstrategieën, Fontys Lerarenopleiding Tilburg. 


\section{ACKNOWLEDGEMENTS}

Working as a teacher educator is a privilege. This doctoral dissertation was inspired by the varied and interesting work in which I was involved as a teacher educator for over 30 years. Doing PhD research offered new perspectives and experiences. It turned out to be an intensive and interesting journey, providing me with all kinds of challenges - both personally and professionally. During this period, I was fortunate to be supported by many persons and my research would not have been possible without their help. To everybody who played a role in my research in the past years I would like to express my thanks. The following people I would like to thank specifically:

First of all, I want to thank my promotor Jan van den Akker and assistant promotor Sanneke Bolhuis, who each have provided invaluable guidance. The critical questions and discussions, in combination with the constructive suggestions and encouragements, inspired me to constantly strive for improvement and to keep reserving time to the project. Thank you so much for sharing your expertise and for your support and confidence.

I am grateful to the Management Board of Fontys and the director of my teacher education college (FLOT), Ans Buys, for the trust and support invested in me. The struggle to combine a PhD study with my work as a teacher educator hasn't always been easy. I would like to thank my team manager Simona Boersma and my colleagues at FLOT for their understanding and their kind questioning into my progress.

This design study is the result of a collaborative effort by the researcher and the practitioners in the school. Foremost, I would like to thank Saskia Heunks, who provided essential input for the design and the implementation of the program. Saskia, your pursuit of improvements and your continuous sharing of own expertise has been one of the pillars of this research project. I also want to express 
my thanks to the (former) members of the school management of the Stedelijk College Eindhoven, especially to Hans Teuwen, Mattie de Vugt and Rob van der Vorst, for their support to the program. And, last but not least, I would like to thank all teachers who participated in the program. Thank you for your collaboration and the frankness with which you shared your experiences and your evaluations of the program.

Parallel to this research I studied a similar program at Fontys, using reciprocal peer coaching with video feedback within a learning community of teacher educators, who in turn used their learning outcomes to coach student-teachers with video feedback. The outcomes of that study helped to better understand the functions of the various design principles. I would like to say thanks to my colleagues Anne Brand, Brigitte Weidema, Ton Denissen and Annie van Genugten for their contribution of time, energy, and expertise to that project.

Researchers need colleagues for a critical reflection on their research. Christa Teurlings, Ilona Mathijsen and Quinta Kools contributed during various stages of my study to the structuring and analysis of the data. I am grateful to Kara Vloet and Doreen Admiraal for our collective sharing of the ups and downs of a PhD study and for our constructive discussions.

I would like to thank Bram van IJperen for proofreading the English text and Sandra Schele for taking care of the lay-out.

I am proud to have Saskia Heunks and Anne Brand as my two paranymphs. This study would not have been the same without your contributions and support.

Throughout, my family and friends have encouraged me to carry on. All of you have contributed to my $\mathrm{PhD}$ research in your own way, for which I am grateful. Gert, you are my soul mate and have been my sparring partner throughout this $\mathrm{PhD}$ journey. Your unconditional support, understanding, and faith in me go far beyond my PhD research.

June 2012

Rita Schildwacht 